\title{
INVESTIGATING THE INTRAFOLLICULAR \\ FACTORS AFFECTING OOCYTE \\ DEVELOPMENTAL COMPETENCY
}

\section{ZARAMASINA LENA CLARK}

A thesis submitted to Victoria University of Wellington in fulfilment of the requirements for the degree of

Doctor of Philosophy

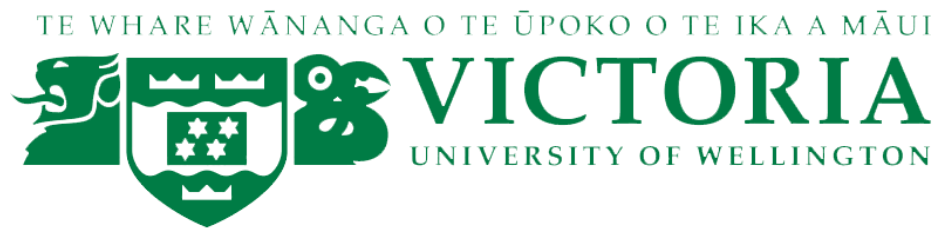

Victoria University of Wellington 





\section{ABSTRACT}

The number of cycles of assisted reproductive technologies (ART) performed increased by $\sim 9.5 \%$ globally between 2008 and 2010. In spite of this, the success rate in terms of delivery was only $\sim 19.0 \%$ (Dyer et al., 2016). This discrepancy between the demand for, and success of, these technologies necessitates the development of tools to improve ART efficiency. To facilitate this, a better understanding of how the microenvironment changes within the developing follicle to culminate in a mature, developmentally-competent oocyte is required. This study employed an in vivo and in vitro ovine model to investigate the relationship between the surrounding microenvironment and oocyte maturation, and in particular, the attainment of oocyte developmental competency and high-quality embryos.

The first objective of this $\mathrm{PhD}$ study was to comprehensively investigate the changing microenvironment of in vivo matured, presumptive preovulatory (PPOV) follicles from wildtype (++) and high ovulation rate $(\mathrm{OR} ; \mathrm{I+B+})$ ewes. The high $\mathrm{OR}$ ewes were heterozygous carriers of mutations in BMP15 (I+) and BMPRIB (B+). Functional differences in follicular somatic (granulosa and cumulus) cells between these genotypes, including differential gonadotropin responsiveness of granulosa cells, composition of follicular fluid and gene expression profiles in cumulus cells were evident. These differences emerged as part of a compensatory mechanism by which oocytes from smaller follicles, containing fewer granulosa cells, achieved developmental competency in I+B+ ewes.

The second objective of this PhD study was to develop new approaches for improving current in vitro maturation (IVM) strategies. The first approach utilised in this study focused on developing biomarkers that could be used to improve prediction of developmental competency in oocytes and in vitro produced embryos. This involved interrogating the hypothesis that a combination of molecular and morphokinetic biomarkers would better predict the developmental competency of oocytes and embryos compared to using these biomarkers alone. The second approach utilised in this $\mathrm{PhD}$ study tested the effects of modulating IVM conditions to better mimic the follicular microenvironment of a high, compared to a low, OR species on oocyte developmental competency and embryo quality. This involved supplementing IVM media with different ratios of two oocyte-secreted growth factors, i.e. GDF9:BMP15, that were representative of low or high OR species. These approaches demonstrated significant potential and warrant further investigation. 
The most significant finding of this study was that despite variances in the surrounding microenvironment during in vivo and in vitro oocyte maturation that culminated in differential gene expression patterns in cumulus cells, and divergent gonadotropinresponsiveness of granulosa cells, the gene expression signatures of developmentallycompetent oocytes and the morphokinetics of high-quality embryos were unaltered. This confirms the value of developing such biomarkers for oocyte development competency and embryo quality that remain unaltered despite a changing surrounding environment. Interestingly, simulating the ratio of GDF9:BMP15 that oocytes from high OR species are exposed to during maturation improved developmental competency in oocytes as demonstrated by increased blastocyst rates. Furthermore, this study has demonstrated that combinations of molecular (cumulus cell gene expression) and morphokinetic biomarkers improved the ability to predict developmental competency in oocytes and embryos. Overall, this study revealed novel information regarding the follicular microenvironment during final maturation and identified several novel approaches to improving the efficiency of ART. 


\section{ACKNOWLEDGEMENTS}

First and foremost, I would like to thank my supervisors. I am infinitely grateful to my primary supervisor, Dr Janet Pitman for the many opportunities I have had during this $\mathrm{PhD}$ project. I would like to thank Janet for her support and enthusiasm for this project, her patience and for encouraging me to do a $\mathrm{PhD}$ in the first place. I don't think I have ever regretted this decision and I am grateful to have done it in the Pitman lab. I would like to thank my secondary supervisor, Dr Dean Morbeck, for his support and invaluable input in the IVP aspects of this project.

I would also like to acknowledge the Royal Society of New Zealand Marsden Fund (13VUW-153) for funding this PhD project. Furthermore, I would like to thank the NZ Federation of Graduate Women Wellington Branch for the Research Award I received last year and acknowledge the support l've received from Victoria University of Wellington, in particular, the Victoria Doctoral Submission Scholarship. Research is only possible with funding and I thank these funding bodies for allowing me to work on and complete this project.

As part of my project I have been fortunate to learn from and work with many talented scientists I would like to thank Dr Jenny Juengel, Dr Derek Heath, Dr Janet Pitman and Prof Ken McNatty for all of their input and assistance with the Invermay trials. I would also like to thank Alexia Kauff and the Invermay farm staff for their assistance with the Invermay experiments. I am truly grateful for all the work that was put into these trials and for the ongoing support that I have received. I would also like to sincerely thank Dr Debbie Berg for allowing me to come to her lab and for teaching me IVP. Thank you for continuing to answer my questions and for your patience. I would also like to express my gratitude to Craig Doney for constructing both versions of the embryo box. Finally, I would like to thank Adam Nancekivell and Dr Elizabeth Hammond of Fertility Associates for their advice regarding the use of morphokinetics in this study.

To all of my lab mates, past and present, thank you for making this such an enjoyable experience, even when it was maybe not so enjoyable. I would like to thank Janet, La'tarsha, Sarah and Matire for giving up your time to denude with me. I'm also grateful to Catherine, Karmella, Adrian, Shalen, Peter, Brigitta and La'tarsha for keeping me sane during those long days and late nights at uni and for always being up for a coffee. 
Malo 'aupito Liz Richardson and Sonja Miller, being a member of the Āwhina whanau has been one of the highlights of my time here at VUW. Thank you both for your support and for the many things you have taught me.

Finally, I would like to thank my friends and family for their unfailing love and patience. To my friends, all of you, for reminding to do things that aren't in the lab and giving me the space to do what needed to be done. I'm also grateful to the Jamieson family, for their support and belief in my abilities. To the Clark and Faka'utoki families, thank you for instilling a sense of curiosity and a love of learning in me. I know that my grandparents, and in particular, my grandfathers, George and Paula, would have been thrilled by the idea that some of their grandchildren would become scientists and researchers. So, I dedicate this thesis to them. To my Mum, Dad, Aunties, Chris, Lini, Paula, Shay, Latu and George, thank you for being my biggest fans and for always pushing me even when I thought I had nothing left in the tank. Last but certainly not least, Dan, thank you for your love, for keeping me motivated and for your patience. You made all of the late nights and weekends at work more like adventures than work and I will be forever grateful to you for that. 


\section{TABLE OF CONTENTS}

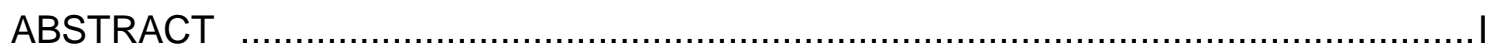

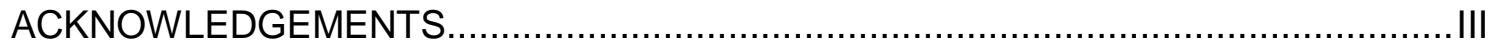

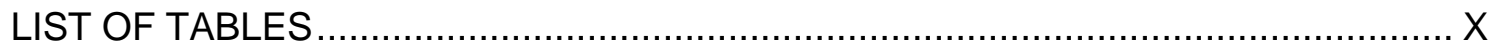

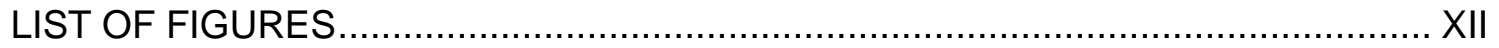

LIST OF COMMONLY USED ABBREVIATIONS ................................................. XIV

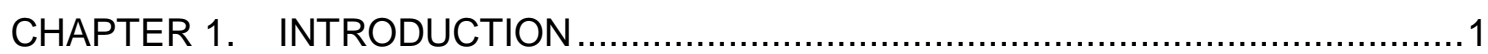

1.1. Oocyte Developmental Competence and Improving the Success Rates of Assisted Reproductive Technologies (ART) ...............................1

1.2. The Development of Competency in Mammalian Oocytes and

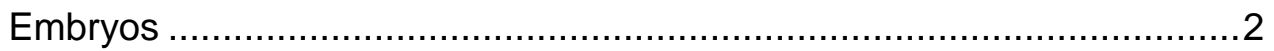

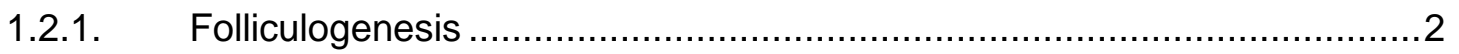

1.2.2. Final Maturation - Acquiring Developmental Competency .......................

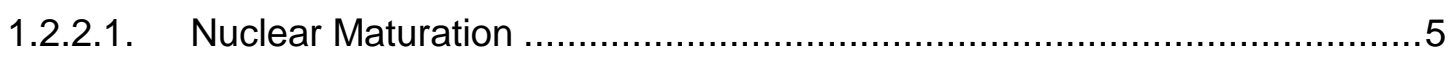

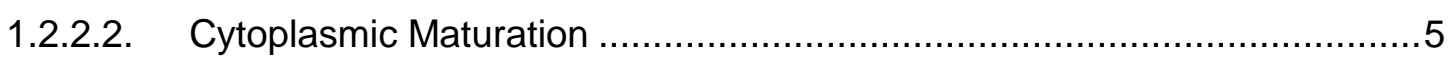

1.2.3. The COC - A Bidirectional Communication System...............................

1.2.3.1. The Granulosa and Cumulus Cells ..................................................

1.2.3.2. The Role of OSF in the Attainment of Developmental Competency .................................................................................

1.2.4. The Effects of Different Ratios of GDF9:BMP15 ….............................

1.3. The Importance of Animal Models........................................................11

1.4. In vitro Embryo Production (IVP) .....................................................12

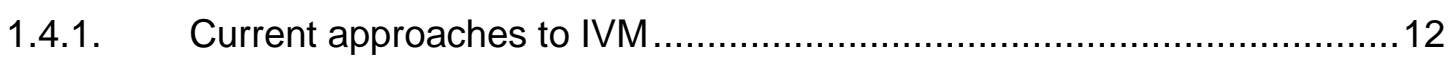

1.5. Predicting Developmental Competency in Oocytes and Early

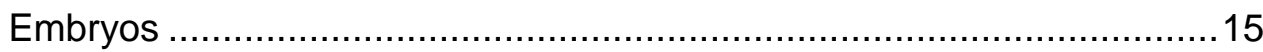

1.5.1. Morphological Grading of Developing Embryos ...................................16

1.5.2. Gene expression profiles as biomarkers of developmental

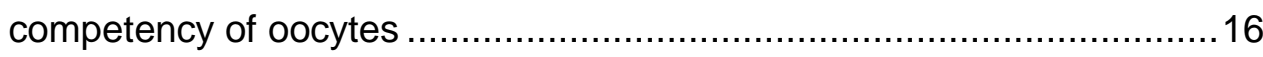

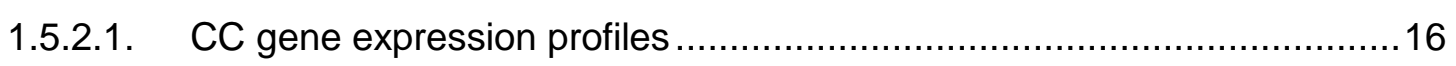

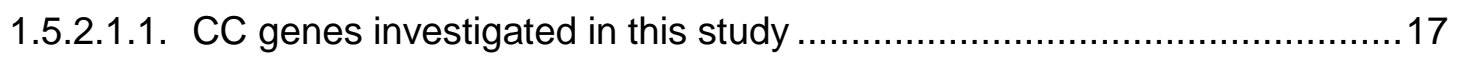

1.5.2.2. Oocyte gene expression profiles ..................................................... 18

1.5.2.2.1. Oocyte genes investigated in this study .......................................... 19

1.5.2.3. Gene expression profiles in the polar body .......................................20

1.5.3. Profiling of Culture Medium and Follicular Fluid ...................................21 
1.5.4. Morphokinetics in Early Embryos.................................................... 21

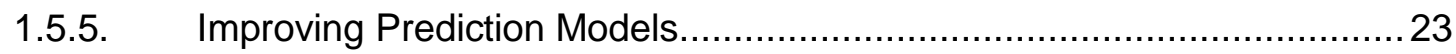

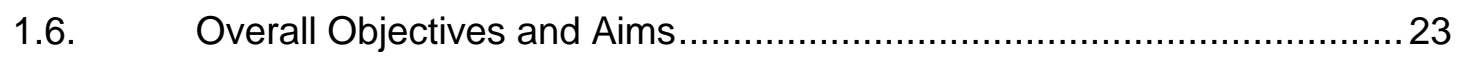

CHAPTER 2. GENERAL METHODOLOGY ................................................ 27

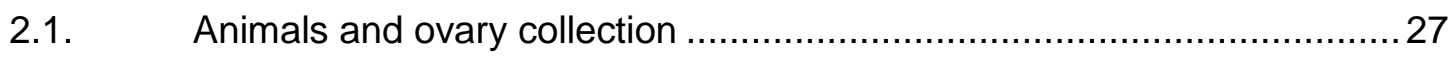

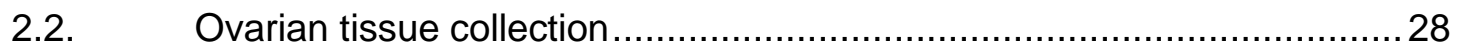

2.3. Gonadotropin-responsiveness cultures............................................29

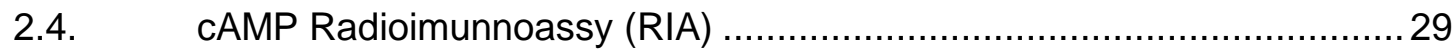

2.5. Follicular fluid and plasma component analysis ................................. 30

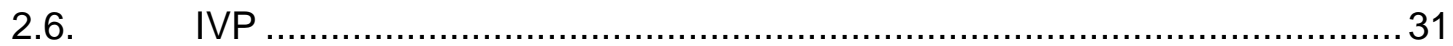

2.6.1. Specialised equipment: Modified culture plates and embryo box ............ 31

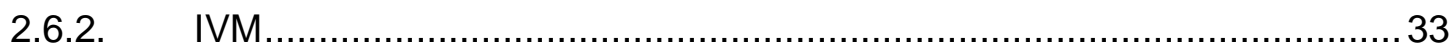

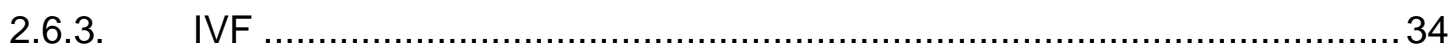

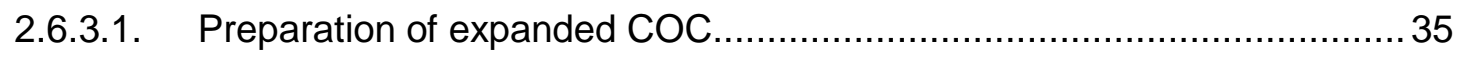

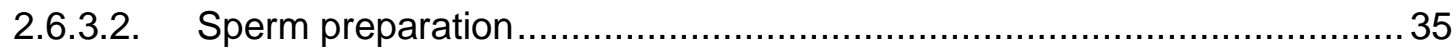

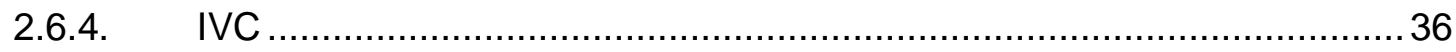

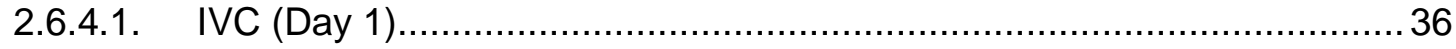

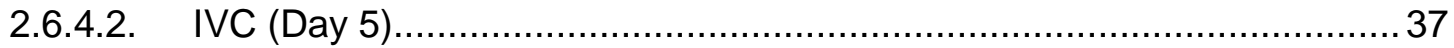

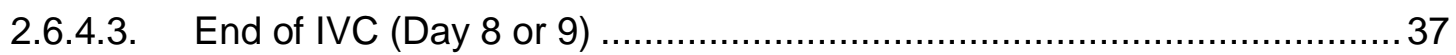

2.7. Quantitative Polymerase Chain Reaction (qPCR) ............................... 40

2.7.1. Total RNA extraction ..................................................................... 40

2.7.2. Complimentary DNA (cDNA) synthesis........................................... 41

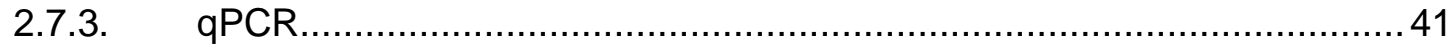

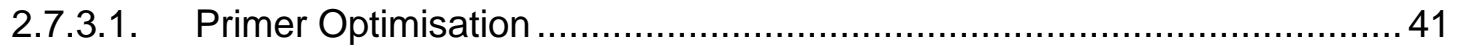

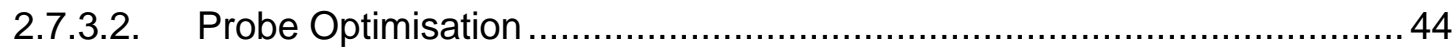

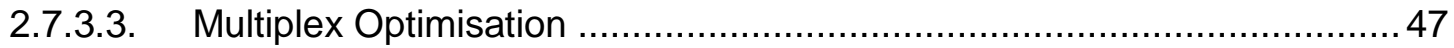

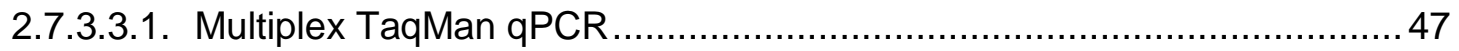

CHAPTER 3. THE MICROENVIRONMENT OF FOLLICLES UNDERGOING

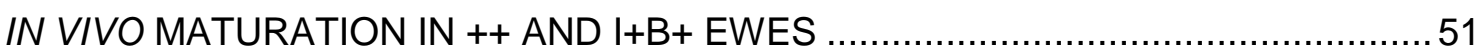

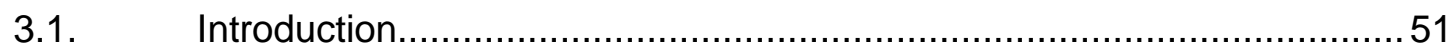

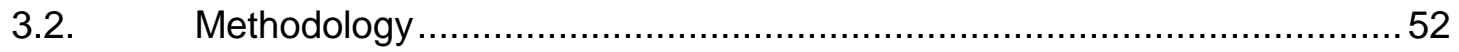

3.2.1. Ovarian tissue collection ................................................................. 52

3.2.2. Gonadotropin-responsiveness assays ........................................... 54 
3.2.3. Measurement of follicular fluid and plasma constituents .......................54

3.2.4. Gene expression measurement in CC and denuded oocytes..................55

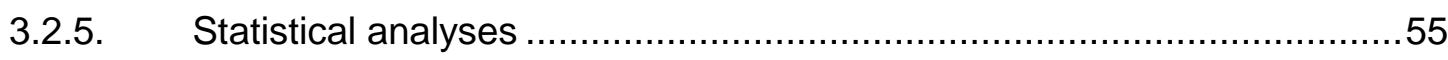

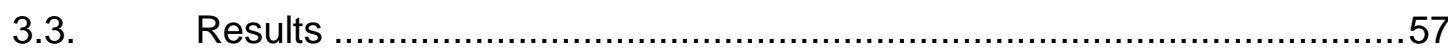

3.3.1. OR and follicular characteristics in ++ and $\mathrm{I}+\mathrm{B}+$ ewes ..........................57

3.3.2. Gonadotropin-responsive GC in ++ and I+B+ ewes............................57

3.3.3. Constituent concentrations in plasma of ++ and $\mathrm{I}+\mathrm{B}+$ ewes ...................60

3.3.3.1. Plasma amino acid concentrations of ++ and $I+B+$ ewes ........................60

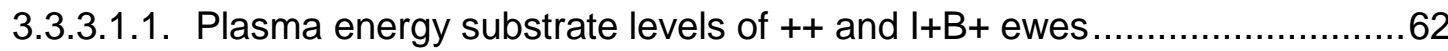

3.3.3.1.2. Plasma steroid concentrations of ++ and $\mathrm{I}+\mathrm{B}+$ ewes .............................62

3.3.3.2. Constituent concentrations in follicular fluid of ++ and $\mathrm{I}+\mathrm{B}+$ ewes ...........63

3.3.3.2.1. Amino acid concentrations in follicular fluid of ++ and $\mathrm{I}+\mathrm{B}+$ ewes ...........64

3.3.3.2.2. Energy substrate levels in follicular fluid of ++ and $\mathrm{I}+\mathrm{B}+$ ewes ................69

3.3.3.2.3. Steroid concentrations in follicular fluid of ++ and $\mathrm{I}+\mathrm{B}+$ ewes..................70

3.3.3.3. Relationship between follicular fluid and plasma amino acid

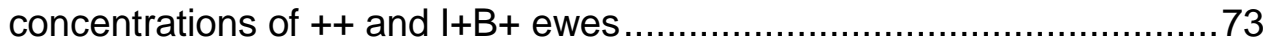

3.3.4. Gene expression levels in $\mathrm{COC}$ of ++ and $\mathrm{I}+\mathrm{B}+$ ewes ........................74

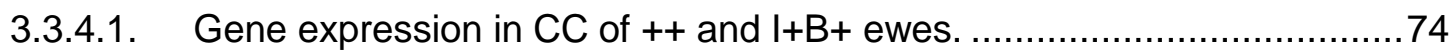

3.3.4.2. Gene expression in oocytes of ++ and $\mathrm{I}+\mathrm{B}+$ ewes. ...............................76

3.3.5. Summary of results ...................................................................... 78

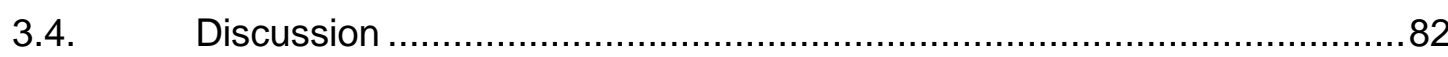

CHAPTER 4. MORPHOKINETIC AND MOLECULAR MARKERS OF DEVELOPMENTAL COMPETENCY IN IN VITRO PRODUCED

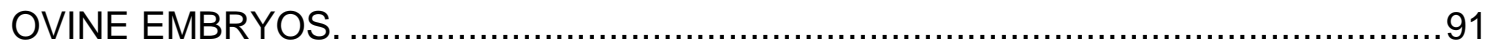

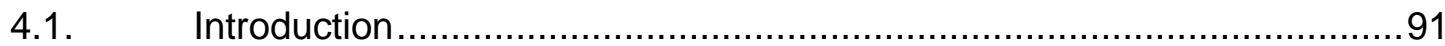

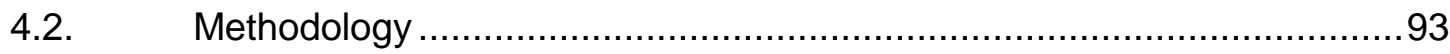

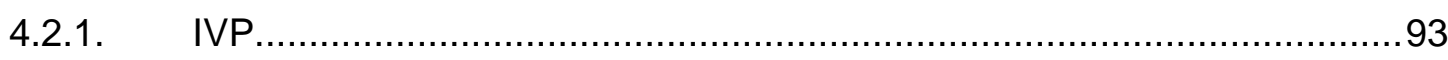

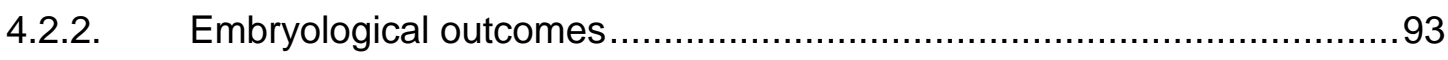

4.2.3. Morphokinetic measurements of embryos........................................... 94

4.2.4. Gene expression measurements of CC ...........................................94

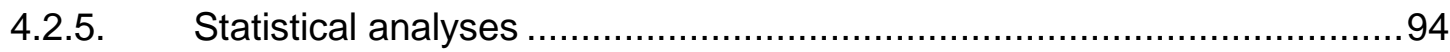

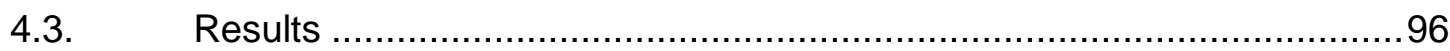

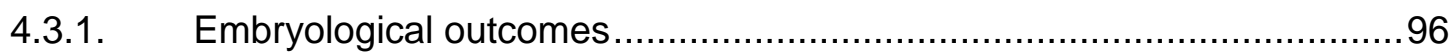

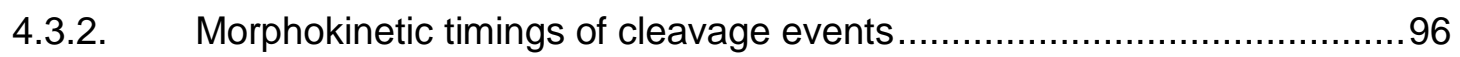


4.3.3. Identification of morphokinetic markers associated with embryological outcomes

4.3.4. Identification of molecular markers associated with embryological outcomes.

4.3.5. Correlating morphokinetic and molecular biomarkers for embryological outcomes

4.3.6. Predicting oocyte developmental competency using morphokinetic and molecular biomarkers

4.4. Discussion 104

CHAPTER 5. THE EFFECTS OF SPECIFIC RATIOS OF GDF9 AND BMP15 ON BIOMARKERS OF DEVELOPMENTAL COMPETENCY OF OVINE OOCYTES AND IVP EMBRYOS.

5.1. Introduction. 111

5.2. Methodology. 115

5.2.1. IVM conditions 115

5.2.2. IVP 116

5.2.3. Embryological outcomes........................................................ 118

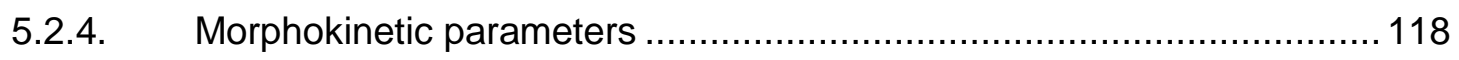

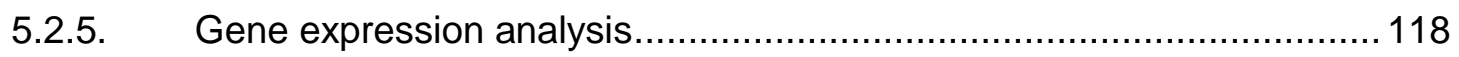

5.2.6. Statistical procedures .................................................................. 119

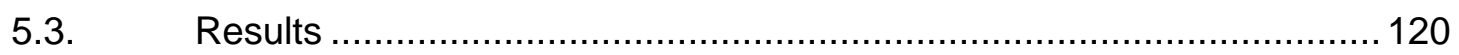

5.3.1. Overall embryological outcomes................................................... 120

5.4. Effects of IVM conditions on CC function.......................................... 120

5.4.1. Effects of IVM conditions on CC expansion ...................................... 120

5.4.1.1. Association between CC expansion and morphokinetic timings............ 121

5.4.1.2. Effects of IVM conditions on CC gene expression ............................. 122

5.4.1.3. Association between CC expansion and gene expression.................... 125

5.4.2. Effects of IVM conditions on early embryonic development .................. 126

5.4.2.1. Effects of IVM conditions on oocyte developmental competency ........... 126

5.4.2.2. Effects of IVM conditions on cleavage rate and embryological outcomes....

5.4.2.3. Associations between morphokinetic markers and embryological outcomes.

5.5. Discussion. 


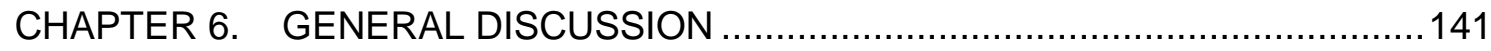

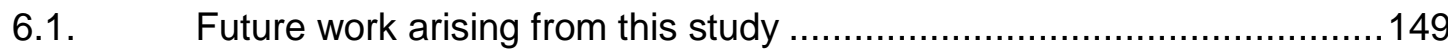

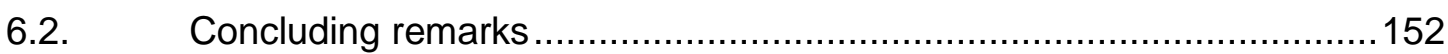

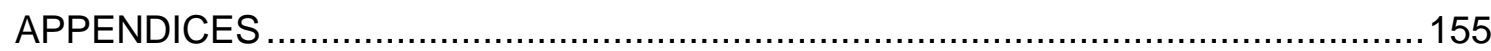

APPENDIX 1: Summary of information from each animal in the in vivo

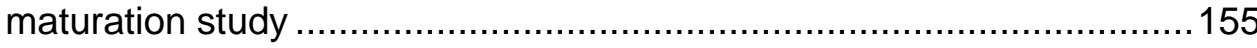

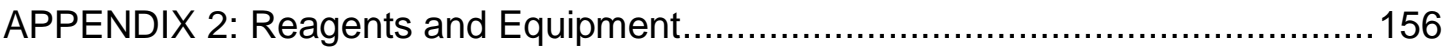

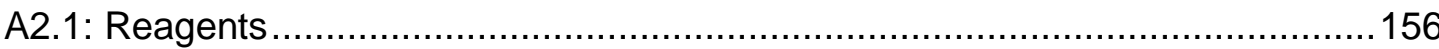

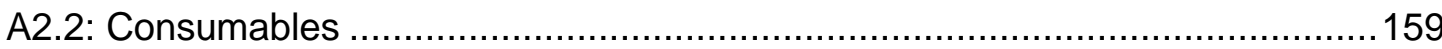

A2.3: Equipment and Software Programs ........................................................160

APPENDIX 3: Media Composition and Stock Solutions .......................................161

A3.1: General solutions and reagents ............................................................161

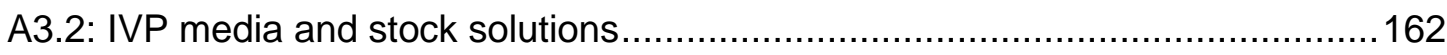

A3.3: RIA stock solutions and buffers ..............................................................165

APPENDIX 4: Summary of generalised linear mixed models ...................................167

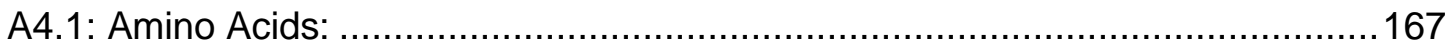

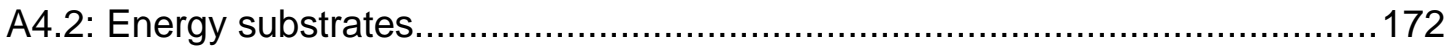

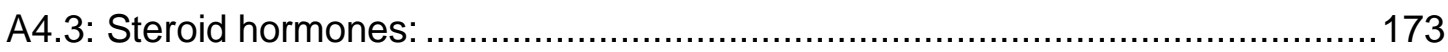

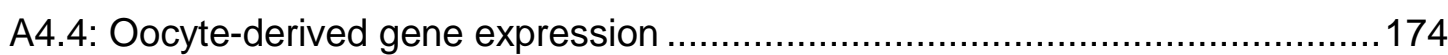

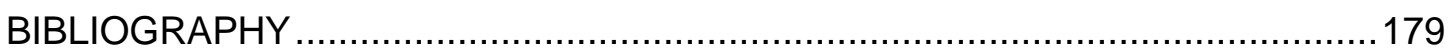




\section{LIST OF TABLES}

Table 1-1: Summary of ovulation rate in wild-type (++), Inverdale (I), Booroola (B) and $\mathrm{I}+\mathrm{B}+$ ewes.

Table 1-2: Function or significance of selected CC genes.

Table 1-3: Function or significance of the selected oocyte genes.

Table 1-4: Morphokinetic parameters associated with embryological outcomes in human studies.

Table 2-1: Ovine COC grading scale.

Table 2-2: Definition of morphokinetic events assessed in the time-lapse studies.

Table 2-3: NCBI accession numbers and forward $(F)$ and reverse $(R)$ primer sequences for the genes investigated in this study.

Table 2-4: The TaqMan probe sequences for the genes investigated in this study.

Table 2-5: The optimised probe, forward and reverse primer concentrations (nM) for the genes investigated in this study.

Table 2-6: PCR efficiency for each of the genes assessed in this study. 48

Table 3-1: Ratio of ovine follicular fluid to plasma concentration. .73

Table 3-2: Summary of follicular attributes in $\mathrm{I}+\mathrm{B}+$, compared to ++ , ewes. .78

Table 3-3: Summary of follicular attributes in preovulatory (PPOV; i.e. LHresponsive), compared to non-preovulatory (i.e. LH-unresponsive), follicles.

Table 4-1: Summary of the total numbers of embryos assessed in the IVP experiments (Chapter 4).

Table 4-2: Morphokinetic events in developmentally-competent ovine embryos.

Table 4-3: Timings of morphokinetic events in ovine embryos with different embryological outcomes.

Table 4-4: Summary of the Spearman's rank correlation coefficients $(\rho)$ between CC-derived gene expression and morphokinetic events.

Table 4-5: Summary of univariate binomial logistic regression analyses. 102

Table 4-6: Multivariate logistic regression predicting the likelihood of blastocyst formation as a measure of developmental competency 103

Table 4-7: Summary of morphokinetic events in ovine embryos 105

Table 5-1: Definition of CC expansion index (CEI) scores. 
Table 5-2: Summary of the total numbers of embryos assessed in the IVP experiments (Chapter 5 ).

Table 5-3: Timings of morphokinetic events in ovine embryos with different embryological outcomes following maturation under different IVM conditions

Table 6-1: Comparison of concentrations of IVM media components and the concentrations in ovine follicular fluid 


\section{LIST OF FIGURES}

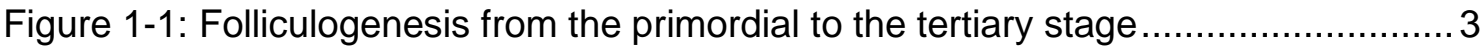

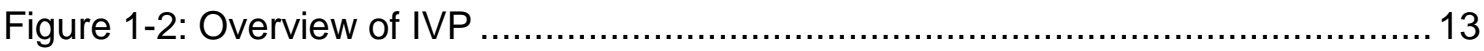

Figure 2-1: Synchronisation protocol for the Invermay experiments. .........................27

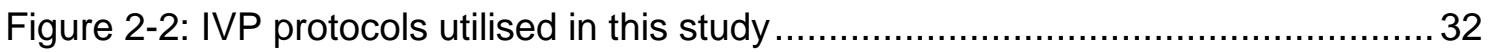

Figure 2-3: Specialised equipment utilised during IVP.......................................... 33

Figure 2-4: Formulae for adjusting the sperm to the appropriate concentration for IVF.

Figure 2-5: Representative images of the morphokinetic events described in an ovine blastocyst

Figure 2-6: Linear regression of $\log _{10} \mathrm{CC}$ number andC $\mathrm{C}_{\mathrm{T}}$ for the reference genes RPL19 and PPIA.

Figure 3-1: Diameter and number of GC in non-responsive, $\mathrm{FSH}$ responsive and $\mathrm{LH}$-responsive follicles in ++ and $\mathrm{I}+\mathrm{B}+$ ewes.

Figure 3-2: cAMP production of GC from non-responsive, FSH-responsive and $\mathrm{LH}$-responsive follicles from ++ and $\mathrm{I}+\mathrm{B}+$ ewes in the absence and presence of gonadotropins.

Figure 3-3: Total number of FSH-responsive and LH-responsive GC per sheep in ++ and $\mathrm{I}+\mathrm{B}+$ ewes.

Figure 3-4: Concentrations of L-forms of amino acids in plasma samples from ++ and $\mathrm{I}+\mathrm{B}+$ ewes.

Figure 3-5: Plasma concentrations of glucose, cholesterol, creatinine and triglycerides in ++ (white bars) and $\mathrm{I}+\mathrm{B}+$ ewes.

Figure 3-6: Plasma concentrations of cortisone, cortisol, corticosterone and $17 \beta$-oestradiol in ++ and $\mathrm{I}+\mathrm{B}+$ ewes.

Figure 3-7:Concentrations of the L-forms of amino acids in follicular fluid of growing and PPOV of ++ and $\mathrm{I}+\mathrm{B}+$ ewes.

Figure 3-8: Concentrations of the L-forms of amino acids in relation to follicle diameter in follicular fluid of growing and PPOV follicles of ++ and $\mathrm{I}+\mathrm{B}+$ ewes.

Figure 3-9: Concentrations of glucose and cholesterol in follicular fluid of growing and PPOV in ++ and $\mathrm{I}+\mathrm{B}+$ ewes.

Figure 3-10: Concentrations of glucose and cholesterol in relation to follicle diameter in follicular fluid of growing and PPOV in ++ and $\mathrm{I}+\mathrm{B}+$ ewes.

Figure 3-11: Concentrations of cortisol and 11-deoxycortisol in follicular fluid from ++ and $\mathrm{l}+\mathrm{B}+$ ewes. 
Figure 3-12: Concentrations of steroid hormones in follicular fluid of growing and PPOV from ++ and $\mathrm{I}+\mathrm{B}+$ ewes.

Figure 3-13: Relative mRNA expression levels of HAS2, HSP90B1, FSHR and GJA1 in single CC masses from growing and PPOV.

Figure 3-14: Relative mRNA expression levels of VCAN, PGR, EREG and $B M P R 2$ in CC masses from growing and PPOV follicles from ++ and $\mathrm{I}+\mathrm{B}+$ ewes.

Figure 3-15: Relative mRNA levels of PTTG1, HSF1, ZP3, PDE3A, PAPOLA, $A T R, B M P 15$ and $G D F 9$ in oocytes from follicles of ++ and $\mathrm{I}+\mathrm{B}+$ ewes.

Figure 4-1: Relative mRNA levels of HAS2, VCAN, HSP90B1, FSHR, PGR, GJA1, EREG and BMPR2 in post-IVM ovine CC based on embryological outcomes.

Figure 5-1: Key maturational processes influencing developmental competency in vivo and in vitro.

Figure 5-2: CC expansion index (CEI) score between COC that were incubated in different IVM conditions $(A)$ and between different embryological outcomes (B).

Figure 5-3: Total time taken to reach the 2-cell stage (t2C) in ovine embryos associated with different CC expansion index (CEI) scores following IVM.

Figure 5-4: Relative mRNA levels of HAS2, VCAN, HSP90B1, FSHR, PGR, GJA1, EREG and BMPR2 in ovine CC masses matured under different IVM conditions.

Figure 5-5: Relative mRNA levels of HAS2 and VCAN in post-IVM ovine CC masses with different degrees of $C C$ expansion.

Figure 5-6: Proportion of blastocysts (\%) following IVM under different conditions.

Figure 5-7: The proportion of presumptive zygotes that underwent cleavage to 2-cells $(\mathrm{A})$ and of cleaving embryos with different embryological outcomes (B) (\%) following maturation under different IVM conditions.

Figure 6-1: Distribution of HAS2, VCAN, HSP90B1, FSHR, PGR, GJA1, $E R E G$ and $B M P R 2$ in $\mathrm{CC}$ from in vivo and in vitro matured COC. 


\section{LIST OF COMMONLY USED ABBREVIATIONS}

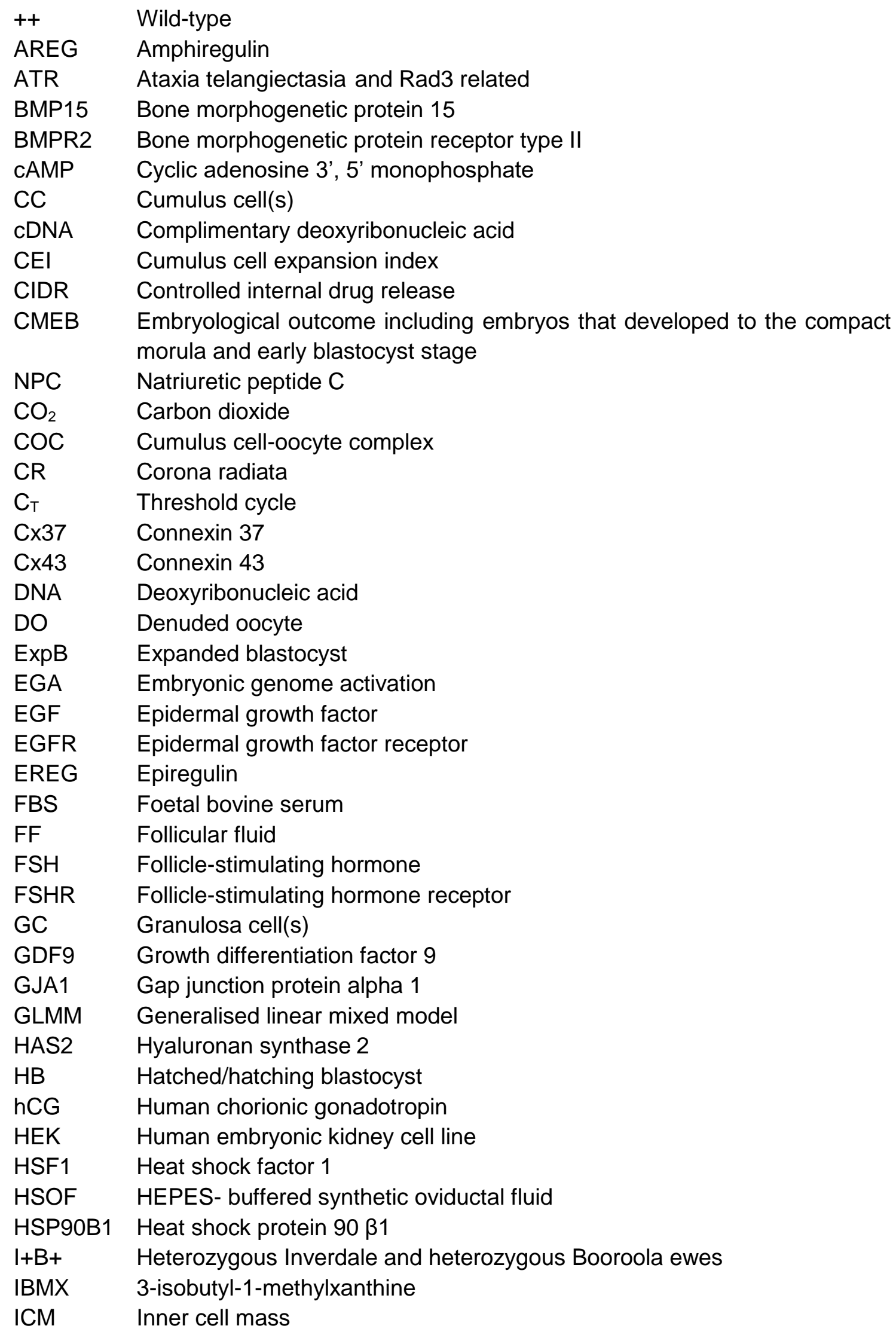




$\begin{array}{ll}\text { ICSI } & \text { Intra-cytoplasmic sperm injection } \\ \text { IVC } & \text { In vitro embryo culture } \\ \text { IVF } & \text { In vitro fertilisation } \\ \text { IVM } & \text { In vitro maturation } \\ \text { IVP } & \text { In vitro embryo production } \\ \text { LH } & \text { Luteinising hormone } \\ \text { LHR } & \text { Luteinising hormone receptor } \\ \text { mRNA } & \text { Messenger ribonucleic acid } \\ \text { N }_{2} & \text { Nitrogen } \\ \text { O }_{2} & \text { Oxygen } \\ \text { OR } & \text { Ovulation rate } \\ \text { OSF } & \text { Oocyte-secreted factor } \\ \text { PAPOLA } & \text { Poly (A) Polymerase Alpha } \\ \text { PBS } & \text { Phosphate-buffered saline } \\ \text { PDE3A } & \text { Phosphodiesterase 3A } \\ \text { PGF2 } \alpha & \text { Prostaglandin F2 } \alpha \\ \text { PGE2 } & \text { Prostaglandin E2 } \\ \text { PGR } & \text { Progesterone receptor } \\ \text { PPIA } & \text { Peptidylprolyl isomerase A } \\ \text { PTTG1 } & \text { Pituitary tumour-transforming gene 1 } \\ \text { qPCR } & \text { Quantitative polymerase chain reaction } \\ \text { rec } & \text { Recombinant } \\ \text { RIA } & \text { Radioimmunoassay } \\ \text { RPL19 } & \text { Ribosomal lipoprotein L19 } \\ \text { SOF } & \text { Synthetic oviductal fluid } \\ \text { VCAN } & \text { Versican } \\ \text { ZP3 } & \text { Zona pellucida glycoprotein 3 } \\ \end{array}$





\section{CHAPTER 1. INTRODUCTION}

\subsection{Oocyte Developmental Competence and Improving the Success Rates of Assisted Reproductive Technologies (ART)}

Despite the demand for, and widespread use of, assisted reproductive technologies (ART) in humans and domestic livestock species, the relatively low success rate and high expense associated with utilising these technologies indicates that these are far from optimal. In 2015 , only $22.8 \%$ of all human ART treatments resulted in a clinical pregnancy and $18.1 \%$ resulted in a live delivery in Australia and New Zealand (Fitzgerald et al., 2017). Likewise, globally in 2015, over 650,000 in vitro produced (IVP) bovine embryos, 1000 IVP ovine embryos and close to 600 equine IVP were reportedly transferred to recipients (Perry, 2016). Of the bovine IVP embryos, only $9 \%$ were produced from abattoir-derived oocytes, whilst none of the clinics surveyed reported the use of in vitro maturation (IVM) which refers to the collection of cumulus cell-oocyte complexes (COC) from antral follicles for the purposes of maturing the oocyte in vitro (De Vos et al., 2016).

The concept for IVM originated from seminal work by Pincus and Enzmann, (1935), where it was noted that COC removed from antral follicles underwent spontaneous nuclear maturation and suggested that it could be possible to mature oocytes in vitro provided that the in vivo environment could be replicated. Subsequently Robert Edwards (1965), demonstrated that mouse, sheep, cow, pig, rhesus monkey and human oocytes could be matured in vitro. Unfortunately, success rates using IVM are lower than traditional in vitro fertilisation (IVF; where oocytes are removed from mature follicles; in vivo maturation) both in clinical and domestic farm animal IVP scenarios. As a result, the use of IVM has largely been restricted in humans to patients susceptible to ovarian hyperstimulation syndrome and to research in domestic farm animals. Substantial evidence indicates that the collection of oocytes that are developmentally competent, that is, have the ability to form a viable embryo following fertilisation, is a major limiting factor in ART (Gilchrist et al., 2008; Li et al., 2008). The processes and factors that influence oocyte competency in vivo are still not fully understood. As such, identifying the key processes and factors that influence oocyte developmental competency may be used to improve IVM procedures and allow for the development of better methods of predicting oocyte competency. This study utilises an ovine (Ovis aries) model to study the factors affecting oocyte competency in mammals. This chapter will discuss what is currently understood about the attainment of 
developmental competency in mammals and the relevance of this knowledge to improving the success rates of assisted reproductive technologies.

\subsection{The Development of Competency in Mammalian Oocytes and Embryos}

\subsubsection{Folliculogenesis}

The primordial germ cells originate in the epiblast and migrate to the gonadal ridge during gastrulation (Chiquoine, 1954; Zamboni et al., 1979; Ginsburg et al., 1990; Lawson and Hage, 1994). At the site of the future gonad, the primordial germ cells differentiate into oogonia and undergo mitotic proliferation resulting in the production of the maximum number of oogonia, which in sheep occurs 75 days after mating (Smith et al., 1993). This is accompanied by the clustering of somatic cells, including primitive granulosa cells (GC), with the oogonia into specific regions which become enclosed by a basal lamina, forming the ovigerous cords (Zamboni et al., 1979; Sawyer et al., 2002). Subsequently, the oogonia either undergo apoptosis or enter meiosis and the latter will arrest at prophase I and are termed primary oocytes. These oocytes are said to be in a state of meiotic arrest. Primordial follicles are formed when primary oocytes, surrounded by a small number of pre-GC, are encapsulated in a basal lamina and detach from the base of the ovigerous cords (Juengel et al., 2002). Atresia occurs throughout folliculogenesis and by 90 days after mating, more than $75 \%$ of the maximum number of oocytes have undergone atresia (Sawyer et al., 2002).

In mammals, follicular growth progresses in a sequential manner in that the first primordial follicles that are formed at the base of the ovigerous cords are the first follicles which begin to develop (Henderson and Edwards, 1968; Polani and Crolla, 1991). The initiation of follicular growth occurs concomitantly with the formation of primordial follicles and continues, uninterrupted, throughout the life of the animal. Follicular growth continues until the oocytes are ovulated or undergo atresia (Edwards et al., 1970; Peters et al., 1975; Smith et al., 1993). This process occurs continuously throughout life or until the finite pool of follicles is exhausted, as occurs in menopause in women (Richardson et al., 1987).

The transition from primordial to primary follicles is characterised by a change in the morphology of the GC from squamous to cuboidal (Figure 1-1; Lintern-Moore and Moore, 1979). Thereafter, proliferation of the GC results in an increase in the number of layers surrounding the oocyte and these are now termed secondary follicles. Further proliferation 
of the GC is accompanied by the formation of small fluid-filled cavities within the follicle to ensure sufficient oxygenation of the intra-follicular compartment. These coalesce to form a single large fluid-filled cavity known as the antrum (Zamboni, 1974; Hirshfield, 1991; Rodgers and Irving-Rodgers, 2010).

Follicular fluid has long been considered to be composed of filtered components from the circulating plasma and secretions from the oocyte and GC (Edwards, 1974; Rodgers and Irving-Rodgers, 2010). In sheep, there are substantial differences in the reported concentrations of the majority of the amino acids, however this is likely to be due to differences in supplemental feeding procedures employed in these studies (Offer et al., 1975; Thelen et al., 2007; McNeil et al., 2016). By comparison, data concerning the concentration of amino acids in ovine follicular fluid is scarce (Gosden et al., 1990; Nandi et al., 2007). However, it has become clear that the composition of follicular fluid is known to vary as the follicle increases in size, the metabolic requirements of the cells of the follicle change and as different paracrine factors and signalling molecules are produced by the GC and cumulus cells (CC) and the oocyte (Gerard et al., 2002; Leroy et al., 2004; Orsi et al., 2005; Nandi et al., 2007; Hudson et al., 2014; Forde et al., 2016).

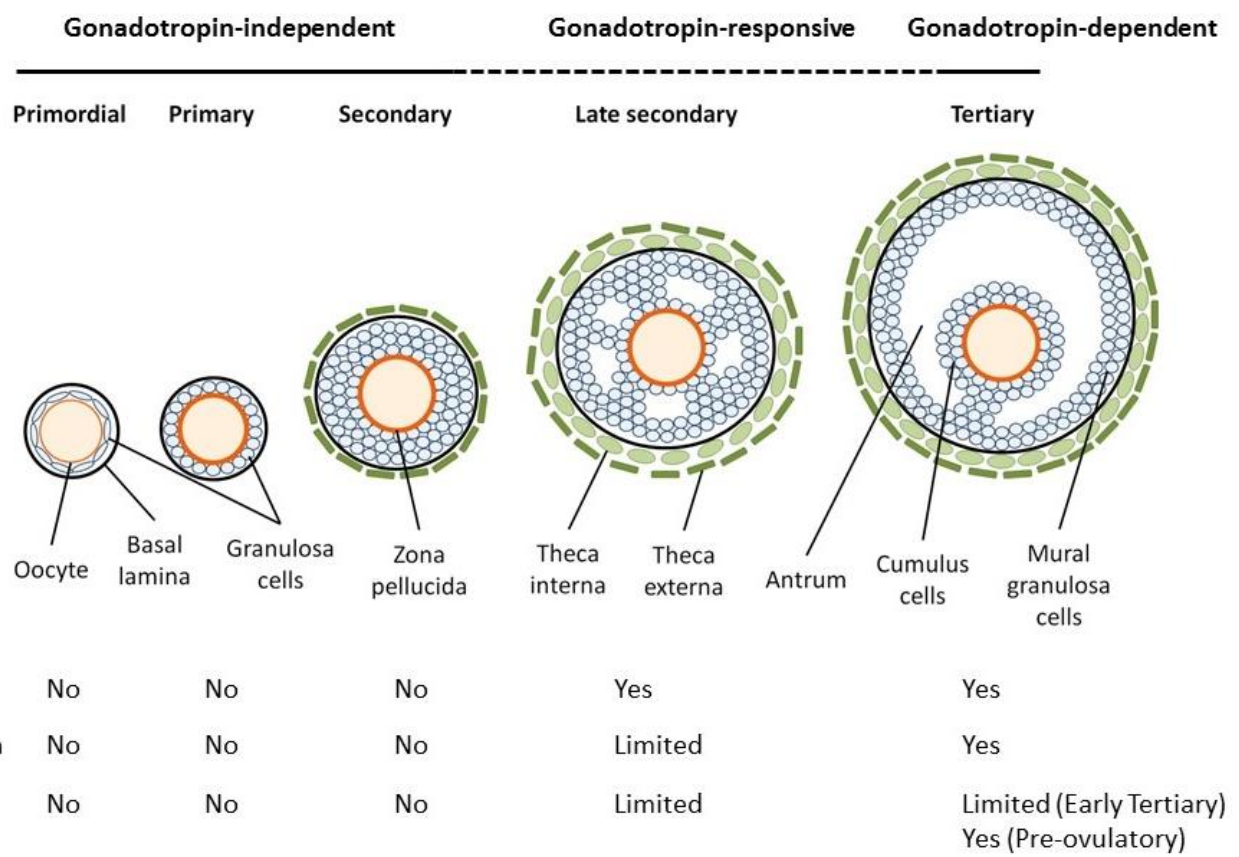

Figure 1-1: Folliculogenesis from the primordial to the tertiary stage. The gonadotropin-independent, gonadotropin-responsive and gonadotropin-dependent stages of development are indicated on the figure as well as the stages at which nuclear and cytoplasmic maturation are acquired. The developmental competency of oocytes from these follicles is also noted. Modified from a diagram supplied by Lisa Johnston (VUW BBMedSci Honours thesis, 2010). 
The development of the antrum demarcates the transition to an antral follicle and results in the differentiation of the GC into two distinct phenotypes. The mural GC located in the periphery of the follicle are mainly responsible for steroidogenesis, and the CC that are closely associated with the oocyte are involved in metabolically supporting the oocyte (Brower and Schultz, 1982; Armstrong et al., 1996; Carabatsos et al., 2000). During the antral phase, follicles transition from the gonadotropin-independent to the gonadotropin-responsive phase of folliculogenesis. This refers to the reliance of antral follicles on gonadotropins, specifically follicle stimulating hormone (FSH), to facilitate further development (Dufour et al., 1979). In the presence of FSH, the follicle continues to grow, due to an increase in the number of GC and the size of the antrum. In ewe, cow, sow and mare ovaries, the development of antral follicles occurs in multiple waves during a reproductive cycle and reflects the levels of FSH secretion (Sirois and Fortune, 1988; Souza et al., 1997; Ginther et al., 2003; Bracken et al., 2007; Baby and Bartlewski, 2011). The preovulatory follicle secretes large amounts of oestradiol and inhibin which provide negative feedback to the pituitary resulting in decreased circulating levels of $\mathrm{FSH}$ and causing atresia in the subordinate follicles (Baird et al., 1991; Mann et al., 1992; Sunderland et al., 1996; Bigelow and Fortune, 1998). Only a preovulatory follicle that expresses luteinising hormone (LH) receptors (LHR) on GC may maintain follicular growth in the presence of increasing LH levels, in spite of decreasing circulating FSH levels (Webb and England, 1982). The number of preovulatory follicles that develop at each reproductive cycle depends on the ovulation rate $(\mathrm{OR})$ phenotype and is species-specific. The preovulatory LH surge provides the required signal for the final maturational processes within the follicle and the oocyte, ultimately resulting in ovulation of a developmentally competent oocyte (Tsafriri et al., 1972; Eppig, 1980; Park et al., 2004). What is important to understand is that follicles initiate growth one at a time such that at any given moment within an ovary, every growing follicle is at a different developmental stage. Consequently every oocyte is exposed to a unique intra-follicular environment consisting of a milieu of growth factors and hormone signals (McNatty et al., 2014).

\subsubsection{Final Maturation - Acquiring Developmental Competency}

Although the ability to resume meiosis, that is, nuclear maturation, is acquired around the time of antrum formation, there are mechanisms that actively maintain oocytes in a state of meiotic arrest. Thus, complete oocyte developmental competency is only attained in the latter stages of follicular development, following the preovulatory LH surge. The LH surge initiates final maturational processes including the resumption of meiosis (Mehlmann, 
2005). Thus in vivo, nuclear and cytoplasmic maturation are co-ordinated via interplay between all follicular cell types. However during in vitro culture, oocytes are removed from the inhibitory environment present in antral follicles and as a consequence, spontaneously resume meiosis (Pincus and Enzmann, 1935). It is thought that the dysregulation of nuclear and cytoplasmic processes negatively impacts the developmental competency of oocytes that are collected for ART.

\subsubsection{Nuclear Maturation}

In the in vivo situation, oocytes are maintained in a state of meiotic arrest until the preovulatory LH surge (Mehlmann, 2005). The phenomenon of extracted oocytes undergoing spontaneous meiotic resumption indicates that nuclear maturation is regulated by meiosis-inhibiting compounds originating from other cellular compartment(s) of the follicle (Pincus and Enzmann, 1935; Edwards, 1965; Tsafriri et al., 1996). The central role of cyclic adenosine 3', 5' monophosphate (cAMP) in the maintenance of meiotic arrest was initially identified through the observation that supplementation of culture media with dibutyryl CAMP, a synthetic CAMP analogue, prolonged the duration of meiotic arrest in culture (Cho et al., 1974). Intra-oocyte cAMP levels are regulated through a combination of cAMP production, cAMP hydrolysis by phosphodiesterase enzymes and the modulation of both activities through mediators (for example, cyclic guanosine 3', 5' monophosphate; cGMP, and natriuretic peptide C; NPC). When high cAMP levels are maintained, either through exogenous supplementation of CAMP, stimulation of CAMP production, or inhibition of CAMP hydrolysis through the use of phosphodiesterase enzyme inhibitors, intraoocyte cAMP levels remain high and meiotic resumption is delayed (Homa, 1988; Tsafriri et al., 1996; Thomas et al., 2002).

\subsubsection{Cytoplasmic Maturation}

Cytoplasmic maturation refers to the gross structural changes, including the re-arrangement of cellular organelles, and the completion of metabolic processes that result in the accumulation of mRNA, (messenger ribonucleic acid) proteins and substrates (Hyttel et al., 1989; Assey et al., 1994; Brevini-Gandolfi and Gandolfi, 2001). These modifications support fertilisation and pre-implantation embryonic development prior to embryonic genome activation (EGA; Bao et al., 2000; Carabatsos et al., 2000; BreviniGandolfi and Gandolfi, 2001; Schier, 2007). In the in vitro situation, nuclear and cytoplasmic maturation is asynchronous, in that oocytes from antral follicles have the 
ability to undergo nuclear maturation but cytoplasmic maturation remains incomplete. During IVM, the processes required for the completion of cytoplasmic maturation are perturbed (Rizos et al., 2002). Moreover, the success rates of ART, including IVM, are significantly lower in prepubertal compared to adult ewes due, at least in part, to differences in cytoplasmic maturation in oocytes (O'Brien et al., 1997; Ptak et al., 2006; Reader et al., 2015a). Recent refinements to IVM systems incorporate pre-maturation phases with the aim of sustaining meiotic arrest through maintenance of elevated CAMP levels and this does result in improved rates of oocyte developmental competency (Albuz et al., 2010; Richani et al., 2014b; Zeng et al., 2014; Azari-Dolatabad et al., 2016). This pre-maturation step allows for additional time for the oocyte to complete maturational processes, prior to inducing meiotic resumption in vitro.

\subsubsection{The COC - A Bidirectional Communication System}

The development of a competent oocyte is reliant on bidirectional communication between the oocyte and surrounding somatic (granulosa and cumulus) cells. This communication system is characterised by the physical coupling of the oocyte to the GC and CC via gap junctions, and the production of paracrine factors, for example, the oocyte-secreted factors (OSF), growth differentiation factor 9 (GDF9) and bone morphogenetic protein 15 (BMP15). This enables the coordinated development and maturation of the oocyte and somatic cells, responses to metabolic requirements and external signals such as gonadotropins.

The granulosa and CC are physically coupled to each other and the oocyte through transzonal cytoplasmic projections known as gap junctions (Gilula et al., 1978). Gap junctions are comprised of proteins known as connexins (Cx). Within the follicle, gap junctions are comprised of connexin 43 (Cx43) and connexin 37 (Cx37) (Wiesen and Midgley, 1993; Simon et al., 1997). Gap junctions are permeable to ions and small molecules including amino acids, metabolites and signalling molecules $<1$ kilodalton (kDa) in size (Flagg-Newton et al., 1979; Bruzzone et al., 1996). Studies in gap junction protein alpha 1 (Gja1; encodes Cx43) and gap junction protein alpha 4 (Gja4; encodes Cx37) knockout mice have demonstrated that gap junctional communication is essential for follicular development past the secondary and late antral stages, respectively (Simon et al., 1997; Juneja et al., 1999; Carabatsos et al., 2000; Ackert et al., 2001). 
In antral follicles, the GC and CC are also responsive to components of the follicular fluid. As discussed in Section 1.2.1, the composition of follicular fluid is known to change dramatically as the follicle matures and in response to the changing energy and biosynthetic substrate demands of the cells of the follicle. The acquisition of the ability to respond to gonadotropins, glucose uptake is increased and there is an increasing requirement for metabolic substrates within the follicle (Boland et al., 1994; SuttonMcDowall et al., 2004; Harris et al., 2007). The formation of the antrum and follicular fluid provides a mechanism by which oxygen and nutritional supplies can be maintained in spite of increasing metabolic demand from proliferating GC (Redding et al., 2007). Despite this, there are very few studies documenting the composition of follicular fluid and the mechanisms by which the concentrations of components of the follicular fluid (for example, glucose and amino acids) are maintained and regulated. Such information is important when considering that composition of media in which $\mathrm{COC}$ are matured in vitro can have significant effects on developmental competency (Hong and Lee, 2007).

\subsubsection{The Granulosa and Cumulus Cells}

The somatic cells of the follicle are essential for the development of a competent oocyte as is illustrated by in vitro cultured denuded oocytes exhibiting impaired developmental competency (Luciano et al., 2005; Hussein et al., 2006). The GC and CC are involved in a number of key molecular support processes throughout folliculogenesis facilitated, in part, by the physical coupling of the somatic cells to each other and to the oocyte. Thus this coordination is maintained via gap junctions and by the ability of the somatic cells to respond to paracrine signals from the oocyte (Anderson and Albertini, 1976; Hayashi et al., 1999; Eppig et al., 2002). Following antrum formation, differentiation of the granulosa and CC results in a divergence in somatic cell function (Diaz et al., 2007).

In antral follicles, the major functions of the GC include steroidogenesis, transduction of external endocrine signals (for example, the preovulatory LH surge), and the production of paracrine factors including NPC, which act on the CC but result in downstream effects in the oocyte (Webb and England, 1982; Vanderhyden et al., 1993; Zhang et al., 2010b). Neither the CC, nor the oocyte, express the LH receptor. Thus, the GC play a key role in signal transduction of the preovulatory $\mathrm{LH}$ surge through the production of epidermal growth factor (EGF)-like proteins for which the oocyte and CC express receptors (Amsterdam et al., 1975; van Tol et al., 1996; Park et al., 2004). It is for this reason that EGF-like factors, specifically amphiregulin (AREG) and epiregulin (EREG) are more 
effective mediators of LH-signalling during IVM, than either LH or FSH (Procházka et al., 2011; Yamashita et al., 2011; Richani et al., 2013, 2014a).

Likewise, the CC also have a number of key roles that, due to their close association with the oocyte, are largely to do with metabolic support and transduction of external signals. The CC are essential for the attainment of developmental competency as performing IVM on denuded oocytes is grossly inefficient (Reichman et al., 2010). The metabolic support processes include amino acid transport (Colonna and Mangia, 1983; Eppig et al., 2005), glycolysis (Sutton et al., 2003; Sugiura et al., 2005; Caixeta et al., 2013), cholesterol synthesis, regulation of fatty acid levels and metabolism (Su et al., 2008; Aardema et al., 2013a; Paczkowski et al., 2014). Other key CC functions include steroidogenesis (Vitt et al., 2000; Shimada and Terada, 2002; Lucidi et al., 2003; Kawashima et al., 2008; Yamashita et al., 2011), regulation of nuclear maturation via cAMP/cGMP levels (Tsafriri et al., 1996; De La Fuente and Eppig, 2001; Park et al., 2004; Norris et al., 2009; Zhang et al., 2010b; Yamashita et al., 2011) and CC expansion (Eppig, 1980; Fülöp et al., 1997). In particular, current evidence suggests that the oocyte has a limited capacity for glucose uptake and glycolysis despite expressing a number of glucose transporters (Rieger and Loskutoff, 1994). The outer layers of CC facilitate glucose transport from the microenvironment during maturation and successively transfer glucose through the CC layers and then into the oocyte (Biggers et al., 1967; Sutton-McDowall et al., 2010). Furthermore, oocytes preferentially utilise pyruvate as an energy substrate but OSF have been shown to regulate the expression of key enzymes involved in glycolysis in CC (Sugiura et al., 2005, 2007).

\subsubsection{The Role of OSF in the Attainment of Developmental Competency}

It is now widely accepted that the oocyte is not merely a passive bystander in its own development but has an essential role in the attainment of developmental competency. Initial reports indicated that removal of an oocyte from the follicle, as opposed to puncturing the follicle without removing the oocyte, resulted in the luteinisation of the GC (El-Fouly et al., 1970). Since then, the capacity of the oocyte to regulate granulosa and CC function through the production of OSF has been intensively studied. Moreover, there is growing evidence that OSF play a key role in the attainment of developmental competency and coculture of COC with denuded oocytes increases developmental competency during IVM (Hussein et al., 2006; Dey et al., 2012). 
Two OSFs that have received considerable attention due to their regulation of follicular growth and maturation are members of the transforming growth factor- $\beta$ (TGF- $\beta$ ) superfamily; namely BMP15 and GDF9. Initial reports on the roles of these OSFs came from studies reporting the effects of natural mutations in these genes in sheep and the use of mouse knock-out models. In particular, BMP15 in sheep, and GDF9 in both sheep and mice, have been shown to be essential for folliculogenesis past the primary stage of development (Dong et al., 1996; Galloway et al., 2000; Hanrahan et al., 2004). Subsequently, GDF9 and BMP15 were found to modulate the proliferation rate and differentiation of GC and ultimately, OR in sheep (Dong et al., 1996; Eppig and O'Brien, 1996; Hayashi et al., 1999; Galloway et al., 2000; Hanrahan et al., 2004; Hussein et al., 2005). The complete absence of GDF9 protein in homozygous-knockout mice and in sheep with homozygous mutations, and the complete lack of BMP15 protein in sheep with homozygous mutations results in sterility (Dong et al., 1996; Hanrahan et al., 2004).

Overall, the somatic cells provide the oocyte with nutrients and metabolites required for oocyte growth, steroid hormones and other factors that influence oocyte maturation (Armstrong et al., 1996; Carabatsos et al., 2000). In turn, the oocyte directs somatic cell proliferation and differentiation through the production of OSF, thus indirectly influencing oocyte competence (Hayashi et al., 1999; Eppig et al., 2002). This bidirectional communication system allows for the synchronised growth and maturation of both the oocyte and the associated somatic cells.

\subsubsection{The Effects of Different Ratios of GDF9:BMP15}

The role of OSF in controlling ovulation rate has been studied extensively in sheep. Naturally-occurring mutations in either the GDF9 and BMP15 genes or the specific Type 1 receptor for BMP15 have been identified and characterised in several prolific breeds of sheep. Ewes that carry a heterozygous mutation in either GDF9 or BMP15 have an increased ovulation rate and are highly prolific (Galloway et al., 2000; Hanrahan et al., 2004). Ewes that carry a heterozygous mutation in the Type 1 BMP15 receptor (BMPR1B gene) are also known to have an increased ovulation rate Interestingly, OR is further increased in double-copy BMPRIB sheep genotypes whilst in double-copy GDF9 or BMP15 genotypes, ewes are sterile (Davis et al., 1982; Mulsant et al., 2001). Two such breeds are the Inverdale (mutation in BMP15 gene) and Booroola (mutation in BMPR1B gene) and ewes carrying only one functional copy of the aforementioned genes $(\mathrm{I}+\mathrm{B}+)$ 
have a predictably higher ovulation rate compared to wild-type ewes (Table 1-1; Davis et al., 1999).

Table 1-1: Summary of ovulation rate in wild-type (++), Inverdale (I), Booroola (B) and $\mathrm{I}+\mathrm{B}+$ ewes.

\begin{tabular}{lcccc}
\hline & $\begin{array}{c}\text { Wild- } \\
\text { type (++) }\end{array}$ & Inverdale (I+) & Booroola (B+) & I+B+ \\
\hline Mutation & & $\begin{array}{c}\text { Missense } \\
\text { mutation in } \\
\text { BMP15 (Galloway } \\
\text { et al., 2000) }\end{array}$ & $\begin{array}{c}\text { Point mutation in } \\
\text { BMPR1B/ALK6 } \\
\text { (Mulsant et al., 2001) }\end{array}$ & \\
$\begin{array}{l}\text { Ovulation rate in } \\
\text { heterozygous } \\
\text { ewes (Davis et al., } \\
\text { 1999) }\end{array}$ & $1.7 \pm 0.1$ & $2.4 \pm 0.1$ & $3.0 \pm 0.1$ & $4.4 \pm 0.1$ \\
\hline
\end{tabular}

Through a comparative study of mammalian species that differ in ovulation rate phenotypes and thus litter size, species-specific expression patterns of GDF9 and BMP15 were identified. The ratios of GDF9:BMP15 mRNA were identical in oocytes within species, regardless of stage of follicular development, but differed between species (Crawford and McNatty, 2012). Interestingly, the ratios of the mono-ovulatory species studied (i.e., sheep, cow and red deer) revealed a higher expression of BMP15, than GDF9, mRNA and vice versa was observed in the poly-ovulatory species (i.e., mouse and rat). The pig was an exception with higher expression of BMP15, than GDF9 mRNA despite being a poly-ovulatory species (Crawford and McNatty, 2012). Intriguingly evidence from the Pitman laboratory reveals that granulosa cells in pigs, and no other species tested, also expressed GDF9 mRNA(Christoforou, 2017). This implies that porcine granulosa cells are exposed to a higher ratio of GDF9:BMP15 mRNA than what is suggestive from oocyte-derived expression levels. These results indicate that GDF9 and BMP15 are involved in the mechanism by which ovulation rate is regulated in different species. Furthermore, although the reasons for this are unclear, it is important to note that the ratio, rather than the absolute expression levels appear to be characteristic of different ovulation rate phenotypes.

There is compelling evidence that increasing native and exogenous GDF9 and BMP15 levels during IVM improves developmental competency. Initial reports involved studies in which COC were cultured with denuded oocytes during IVM, improving developmental competency in terms of blastocyst rate (Hussein et al., 2006; Dey et al., 2012; Gomez et al., 2012). This was attributed to OSF and subsequently GDF9, BMP15 and fibroblast 
growth factor 8 (FGF-8) have been shown to improve developmental competency (Yeo et al., 2008; Hussein et al., 2011; Mottershead et al., 2012; Sudiman et al., 2014a, 2014b; Machado et al., 2015). Furthermore, supplementation of IVM culture medium with recombinant forms of GDF9 and BMP15 either alone or in combination also improved blastocyst rate (Hussein et al., 2006, 2011; Sudiman et al., 2014b; Machado et al., 2015).

Many studies have used conditioned media containing recombinant forms of GDF9 and BMP15. These studies have demonstrated that while the mature forms of GDF9 and BMP15 are accepted as being the biologically active form, particularly in terms of granulosa cell proliferation, the mature forms do not improve developmental competency. In contrast, it is in fact the pro-mature forms that improve developmental competency (Mottershead et al., 2012; Sudiman et al., 2014a, 2014b). Pro-cumulin, a heterodimer of pro-mature GDF9 and BMP15, improved developmental competency to a greater extent than either pro-GDF9 or pro-BMP15 alone, thus exploiting the synergistic actions of these proteins (Mottershead et al., 2015). In humans, higher levels of mature GDF9 protein were associated with unaltered BMP15 levels in follicular fluid and are associated with higher embryo quality (Gode et al., 2011). Therefore, it is possible that divergent GDF9:BMP15 protein ratios are associated with differential developmental competency, however this has yet to be rigorously examined. Collectively, this evidence would suggest that GDF9 and BMP15 modulate developmental competency in vitro.

\subsection{The Importance of Animal Models}

The study of maturational events in mono-ovulatory species such as humans, cows and sheep is problematic because in general, only one follicle will complete folliculogenesis to the preovulatory stage. Whilst in theory, superovulation procedures afford a solution to this issue, the fact remains that these procedures do not overcome the inherent hierarchy of follicles within the ovary (McNatty et al., 2010). Thus, the study of such follicles is likely to be confounded by the inclusion of atretic and developmentally-compromised follicles. Alternatively, the high OR genotypes discussed herein provide a simple solution although these models have yet to be fully characterised. The causative mutations responsible for the high OR phenotype in these sheep has been identified (Mulsant et al., 2001; Hanrahan et al., 2004). If there are similar maturational processes in wild-type and high OR ewes, these are likely to be key processes contributing to developmental competency. Furthermore, these may be processes that are important in a range of mammalian species 
with differing OR phenotypes. In contrast, differences in follicle maturation between wildtype and $\mathrm{I}+\mathrm{B}+$ ewes may indicate potential therapeutic approaches for ART.

Research aimed at improving ART in humans is governed by logistical and ethical concerns. As such, it is important to identify and characterise relevant animal models in which to undertake this research. Although, mouse models are useful, the disadvantages of such a model are that there a number of key differences, in terms of the regulation of meiotic arrest and early embryonic development compared to humans. In mice, there is some evidence that the intraoocyte cAMP production is sufficient to maintain meiotic arrest (DiLuigi et al., 2008). In contrast, stimulation of intraoocyte cAMP production only transiently maintained meiotic arrest in bovine oocytes and it has since become clear that in bovine oocytes, the majority of cAMP in the oocytes originated from the CC compartment (Homa, 1988; Thomas et al., 2002). Another key difference, is the timing of EGA, a key developmental milestone in early embryonic development which occurs at approximately the $4-8$ cell stage in human embryos (Braude et al., 1988). In mice, it is thought to occur around the $2-4$ cell stage however in ovine and bovine embryos, this does not occur until the $8-16$ cell stage (Crosby et al., 1988; Telford et al., 1990; Shirazi et al., 2016). Moreover, mouse, sheep, cow and human embryos are susceptible to developmental arrest at the time of EGA indicating that impaired embryonic development may be due to deficiencies in oocyte maturation (Camous et al., 1984; Gandolfi and Moor, 1987; Crosby et al., 1988; Telford et al., 1990).

\subsection{In vitro Embryo Production (IVP)}

The term IVP refers to the assortment of ART procedures that are used to produce an embryo (Figure 1-2). There are three major components to these procedures that include oocyte maturation, fertilisation and in vitro embryo culture (IVC). Globally, the success rates of ART in humans does not appear to be improving and the delivery rate in 2008 , 2009 and 2010 were $19.1 \%, 18.7 \%$ and $19.1 \%$, respectively (Dyer et al., 2016). To improve the success rates of ART, it is likely that a more comprehensive understanding of the processes that influence developmental competency in vivo is required.

\subsubsection{Current approaches to IVM}

Herein, IVM refers to the use of immature oocytes from unstimulated ovaries, i.e. without gonadotropin priming, although in the clinical setting a number of variations exist that are 
also referred to by the same name (Edwards, 1965; De Vos et al., 2016). In theory, IVM has distinct advantages including a larger starting pool of oocytes available for ART (basically any antral follicle) and patients are not required to undergo controlled ovarian hyper-stimulation treatments (Trounson et al., 1994; Thompson and Gilchrist, 2013; Walls et al., 2015a). However, efficiency of IVM in clinical practice is low and thus, is not widely used. For example, there were no reported cases of IVM in Australia and New Zealand in 2014 or 2015 (Harris et al., 2016; Fitzgerald et al., 2017). Thus, it is important to develop better hormonal stimulation regimens or IVM procedures to improve the efficiency of ART.

\section{In vitro Embryo Production(IVP) Overview}

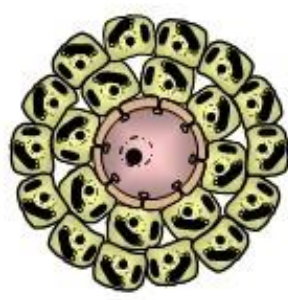

- Encompasses procedures which result in in vivo maturation such as superovulation or controlled ovarian hyperstimulation. COC are recovered by ovum pick-up (OPU).

- For IVM, generally, $\mathrm{COC}$ are aspirated from abattoir ovaries or alternatively obtained by OPU and matured in vitro in media supplemented with gonadotropins.

\section{Fertilisation}

$\mathrm{COC}$ are fertilised by either:

- in vitro fertilisation (IVF) - sperm are prepared and added to media containing the matured oocyte and incubated for a given amount of time to allow for fertilisation

- Intracytoplasmic sperm injection (ICSI) - a single sperm is selected and injected directly into the cytoplasm of the oocyte

\section{In vitro embryo culture (IVC)}

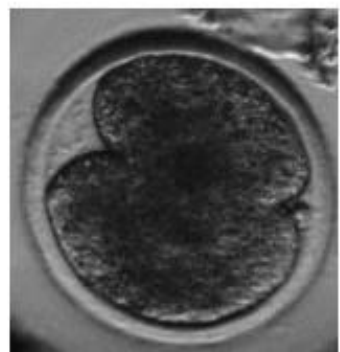

Presumptive zygotes are generally cultured for up to 8 days. At the end of IVC, embryos can be cryopreserved, transferred or collected for research.

Figure 1-2: Overview of IVP. The three major components of IVP include oocyte maturation (in vitro or in vivo), fertilisation (IVF or ICSI) and embryo culture. 
Follicular development occurs in a sequential manner, thus the microenvironment within each follicle is unique, and at any given time each oocyte within the ovary will have differential developmental competency (Edwards et al., 1970). Hormonal stimulation procedures used to collect oocytes for IVP increase the number of follicles that develop to a large size in the hopes of collecting greater numbers of developmental competent oocytes, by providing lengthy administration of gonadotropins and removing negative feedback from the developing follicles. However, significant variations in the exact size of these follicles and granulosa cell responsiveness to FSH and LH remain (McNatty et al., 2010). Considering the roles of FSH and LH during folliculogenesis, it is likely that the each of these follicles continues to maintain a unique follicular microenvironment relative to other follicles. Thus, the developmental hierarchy of follicles and the inherent developmental competency of the associated oocytes remains unchanged. As a result, oocytes removed from gonadotropin-stimulated ovaries are of varying developmental competency resulting in varied embryological outcomes following ART and potentially accounting the inefficiency of these technologies. In addition, hormonal stimulation procedures have been linked to altered development (for example, shorter stature) in children when compared to naturally-conceived children (Savage et al., 2012). There is also evidence that the gene expression profile in CC is altered in response to different hormonal stimulation protocols (Assou et al., 2013).

Advances in current understanding of follicular maturation in vivo have been used to develop new IVM strategies. These strategies involve IVM protocols incorporating pre-maturation steps aimed at maintaining elevated cAMP and thus, meiotic arrest, and employing EGF-like factors, rather than LH, to induce meiotic resumption (Albuz et al., 2010; Yamashita et al., 2011; Richani et al., 2013). However, artificially modulating cAMP levels using phosphodiesterase inhibitors, in particular, 3-isobutyl-1-methylxanthine (IBMX), or using forskolin to stimulate cAMP production in oocytes, have been associated with chromosomal abnormalities in embryos and increased membrane permeability and oocyte swelling, respectively (Yool et al., 1996; Spits et al., 2015). As such, it seems that more physiologically relevant interventions, for example the use of NPC to prolong meiotic arrest, may be safer for clinical use (Campen et al., 2016). The induction of high levels of CAMP in the COC improved EGF receptor (EGFR) signalling within the COC as well as the developmental competency of the oocyte (Conti et al., 2006; Richani et al., 2014b). Likewise, GDF9 and BMP15 are known to upregulate EGFR expression in CC during IVM and this is thought to contribute to the positive effects of GDF9 and BMP15 on developmental competency (Su et al., 2010; Ritter et al., 2015). There is also evidence 
that supplementing IVM media with a combination of AREG and BMP15 improved the rates of blastocyst formation and prolonged gap junction communication (Sugimura et al., 2014). Interestingly, it appears that native OSF from small and mid-sized porcine antral follicles differentially induced EGF-responsiveness in $\mathrm{CC}$ from $\mathrm{COC}$ with low developmental competency (Ritter et al., 2015). The reasons for this were unclear but it is evident that the mechanisms by which OSF, including GDF9 and BMP15, modulate developmental competency require further investigation.

\subsection{Predicting Developmental Competency in Oocytes and Early Embryos}

In the clinical and research setting, determination of embryo quality utilises a grading system that comprises of morphological assessments of cleavage stage, degree of fragmentation, number and morphology of blastomeres, inner cell mass (ICM) and trophectoderm number and morphology, with respect to the number of days in culture. While subjective, there is evidence that embryologists are able to make consistent and comparable observations and assessments of embryo quality using morphological assessment alone (Arce et al., 2006; Paternot et al., 2011). Notwithstanding, the use of morphological embryo grading systems have failed to improve the success rates of ART past $20 \%$ (Dyer et al., 2016; Harris et al., 2016; Fitzgerald et al., 2017). With low live birth rates and increasing use of elective single embryo transfer (eSET), methods that assess developmental competency in cultured oocytes have become highly desirable.

There has been considerable interest in the development of informative biomarkers from materials that are routinely discarded during ART. This includes the granulosa and CC which are removed from the oocyte prior to fertilisation, the polar bodies that may be removed by biopsy and analysed, as well as spent culture media and follicular fluid that can undergo component or metabolite analysis. There is accumulating evidence that the timing of events (including cleavage and fragmentation) in early embryonic development is informative of subsequent developmental potential. With improvements in the technology available, it is now possible to monitor early cleavage events in developing embryos that may then be used to better identify embryos with the greatest potential for development (Wong et al., 2010; Cruz et al., 2012). Increasingly, clinical embryology programmes are interested in and have been incorporating new technologies such as time-lapse monitoring of embryos with the goal of improving the success rates of ART. 


\subsubsection{Morphological Grading of Developing Embryos}

Traditionally, decisions regarding the quality and the competency of developing embryos have relied on the morphology of the developing embryo. Decisions regarding the quality of the embryo are made during routine checks. For example, industry standard ruminant protocols have development checks on Day 1 of IVC (approximately 24 hours after the addition of sperm), following a media change on Day 5 and then on the final day of the experiment (Day 7 or 8 ). On Day 5, the number of non-cleaving embryos is recorded and the stage of development of the remaining embryos is assessed. By Day 5, developing blastocysts in high-quality embryos would be expected. There are several blastocyst grading systems, but the majority involve the assessment of the ICM, the trophectoderm and the size of the blastocoel.

Countries including Spain and the United Kingdom, have implemented standardised embryo grading systems and various organisations and meetings have produced guidelines for grading embryos including the SART guidelines, the Istanbul consensus workshop standards (Racowsky et al., 2009). In implementing these guidelines, there have been improvements in reducing the variability due to different observers performing the morphological assessments and retrospective analyses indicate overall improvements in live birth rate (Racowsky et al., 2009; Vernon et al., 2009; Assin et al., 2011). Thus, morphological embryo assessments remain an integral method for selecting which embryos to use following ART.

\subsubsection{Gene expression profiles as biomarkers of developmental competency of oocytes}

\subsubsection{1. $\quad \mathrm{CC}$ gene expression profiles}

The development of the oocyte and the GC and CC are inextricably linked. As such, gene expression profiles in the somatic cells have been investigated as biomarkers of oocyte competency. Although sharing the same developmental origins, granulosa and CC in antral follicles have different gene expression patterns, reflecting their different functions. As such, analysis of pooled samples is not appropriate and it is likely that gene expression profiles from these samples are confounded by the functional differences between these two cell types. The CC are thought to be an ideal source for biomarker candidates due to their close association to the oocyte during the final maturational stages. Furthermore, the $\mathrm{CC}$ are routinely removed and discarded during ART. Moreover, CC gene expression is 
perturbed in in vitro matured $\mathrm{COC}$ and this has been correlated to decreased developmental competency (Dieleman et al., 2002; Tesfaye et al., 2009; Virant-Klun et al., 2013).

Several human studies have attempted to identify a gene expression profile in CC which could be used to predict the developmental competency of the associated oocyte (McKenzie et al., 2004; Anderson et al., 2009; lager et al., 2013). In one such study, ranking each follicle within each patient based on the gene expression levels of four key CC-derived gene markers, resulted in the selection of one developmentally competent oocyte from a pool of oocytes with $52 \%$ (c.f. $23 \%$ at random) efficiency. Moreover, if three oocytes are selected using this ranking system, the efficiency of including at least one competent oocyte in this pool increased from $52 \%$ (using random selection) to $80 \%$ (Ekart et al., 2013). The challenge remains to further improve the predictability of oocyte competency by increasing the number of marker genes used in the screen or by utilising expression profiles of alternative genes.

\subsection{CC genes investigated in this study}

In this $\mathrm{PhD}$ study, ten genes (including two reference gene) were investigated in the CC. These genes are summarised in Table 1-2. Genes were selected for inclusion based on evidence that they were associated with developmental competency or involved in key developmental processes such as cumulus cell expansion (HAS2 and VCAM), protein processing (HSP90B1), gonadotropin, steroid hormone and OSF signalling ( $F S H R, P G R$, EREG and BMPR2) and gap junction communication (GJA1). Briefly, the HAS2 and VCAN genes encode proteins involved in CC expansion (LeBaron et al., 1992; Fülöp et al., 1997; Dragovic et al., 2005). The HSP90B1 gene encodes an anti-apoptotic chaperone protein (reviewed in: Yang and $\mathrm{Li}, 2005$ ). The FSHR gene encodes the FSH receptor (reviewed in: Simoni et al., 1997). The PGR gene encodes the progesterone receptor which has an important role in ovulation (Lydon et al., 1995; Robker et al., 2000). The GJA1 gene encodes the connexin 43 protein, a component of the gap junctions (reviewed in: (GrazulBilska et al., 1997). The EREG gene encodes epiregulin, an EGF-like peptide important for propagating the downstream effects of the preovulatory $\mathrm{LH}$ surge, including $\mathrm{CC}$ expansion (Park et al., 2004). The BMPR2 gene encodes the BMPR2 protein, a serinethreonine kinase type II receptor involved in OSF signalling (Vitt et al., 2000; Moore et al., 2003). 
Table 1-2: Function or significance of selected CC genes.

\begin{tabular}{|c|c|}
\hline Gene & Function/Significance \\
\hline $\begin{array}{l}\boldsymbol{R P L 1 9}^{\star} \\
\text { (Ribosomal lipoprotein L19) }\end{array}$ & $\begin{array}{l}\text { - Validated for use in human and rat CC (Campen, 2013; Ekart et } \\
\text { al., 2013). }\end{array}$ \\
\hline \multirow{2}{*}{$\begin{array}{l}\text { PPIA* }^{\star} \\
\text { (Peptidylprolyl Isomerase A) } \\
\text { HAS2 } \\
\text { (Hyaluronan Synthase 2) }\end{array}$} & - Validated for use in bovine CC (Macabelli et al., 2014). \\
\hline & $\begin{array}{l}\text { - Regulates the production of hyaluronic acid, an extracellular matrix } \\
\text { component involved in CC expansion (Fülöp et al., 1997). } \\
\text { - Expression has been correlated to increased developmental } \\
\text { competency in human studies (Cillo et al., 2007; Ekart et al., 2013) }\end{array}$ \\
\hline $\begin{array}{l}\text { VCAN } \\
\text { (Versican) }\end{array}$ & $\begin{array}{l}\text { - Versican binds to and stabilizes hyaluronan in the extracellular } \\
\text { matrix during cumulus cell expansion (LeBaron et al., 1992) } \\
\text { - Correlated to increased developmental competency in human } \\
\text { studies (Gebhardt et al., 2011; Ekart et al., 2013) } \\
\text { - Expression altered following IVM (Dunning et al., 2007) }\end{array}$ \\
\hline $\begin{array}{l}\text { HSP90B1 } \\
\text { (Heat shock protein } 90 \beta 1 \text {, } \\
\text { Grp94, Endoplasmin) }\end{array}$ & $\begin{array}{l}\text { - Anti-apoptotic chaperone protein, (Yang and Li, 2005) } \\
\text { - Linked to oocyte competency in animal studies (You et al., 2012; } \\
\text { Assidi et al., 2013; Takeo et al., 2013) }\end{array}$ \\
\hline $\begin{array}{l}\text { FSHR } \\
\text { (FSH receptor) }\end{array}$ & $\begin{array}{l}\text { - G-protein coupled receptor for FSH (Simoni et al., 1997) } \\
\text { - Associated with developmental competency (Ekart et al., 2013; } \\
\text { Dhali et al., 2017) } \\
\text { - Divergent expression in IVM c.f. IVF (Salhab et al., 2013) }\end{array}$ \\
\hline $\begin{array}{l}\boldsymbol{P G R} \\
\text { (Progesterone receptor) }\end{array}$ & $\begin{array}{l}\text {-Expressed in the dominant follicle and has a key role in ovulation } \\
\text { (Lydon et al., 1995; Robker et al., 2000) } \\
\text { - Correlated to increased developmental competence in several } \\
\text { studies (Hasegawa et al., 2005; Ekart et al., 2013) }\end{array}$ \\
\hline $\begin{array}{l}\text { GJA1 } \\
\text { (Connexin 43) }\end{array}$ & $\begin{array}{l}\text { - Component of gap junctions within the follicle (Wiesen and Midgley, } \\
\text { 1993) } \\
\text { - Correlated to developmental competency (Hasegawa et al., 2005; } \\
\text { Assidi et al., 2011) }\end{array}$ \\
\hline $\begin{array}{l}\text { EREG } \\
\text { (Epiregulin) }\end{array}$ & $\begin{array}{l}\text { - EGF-like factor involved in potentiating the effects of LH in the } \\
\text { follicle (Park et al., 2004) } \\
\text { - Co-culture with EREG during IVM improved developmental } \\
\text { competency (Procházka et al., 2011) } \\
\text { - Expression in CC was associated with developmental } \\
\text { competency (Huang et al., 2015) }\end{array}$ \\
\hline $\begin{array}{l}\text { BMPR2 } \\
\text { (Bone morphogenetic protein } \\
\text { receptor type II) }\end{array}$ & $\begin{array}{l}\text { - Serine-threonine kinase receptor involved in OSF signalling in the } \\
\text { follicle (Vitt et al., 2002; Moore et al., 2003) }\end{array}$ \\
\hline
\end{tabular}

\subsubsection{Oocyte gene expression profiles}

There are also notable differences in oocyte gene expression profiles between in vivo and in vitro matured oocytes, the latter of which are known to have reduced developmental competency (Lonergan et al., 2003). As discussed previously, maternal mRNAs and proteins have an indispensable role during early embryonic development and thus the expression levels of key genes in the oocyte have been proposed as biomarkers of 
developmental competency (Mourot et al., 2006; Fair et al., 2007; Virant-Klun et al., 2013). To generate oocyte gene expression profiles, the oocyte must be sacrificed. However, a more comprehensive understanding of the gene expression profile associated with developmental competency has applications in the research setting where it could be used to assess developmental competency of oocytes.

\subsection{Oocyte genes investigated in this study}

In this $\mathrm{PhD}$ study, ten genes (including two reference genes) were investigated in the oocyte. These genes are summarised in Table 1-3. Genes were selected for inclusion based on evidence that they were associated with developmental competency or involved in key developmental processes such regulation of the cell cycle (PTTG1 and ATR), nuclear maturation (PDE3A, HSF1), fertilisation (ZP3), storage of mRNA (PAPOLA), and GC and CC function and OR (BMP15 and GDF9). Specifically, the PTTG1 gene encodes a protein involved in cell cycle regulation (Chu et al., 2012). The HSF1 gene encodes a transcription factor which regulates stress inducible genes and is important for early embryonic development (Christians et al., 2000; Bierkamp et al., 2010). The ZP3 gene encodes zona pellucida protein 3 which has a role in fertilisation and germinal vesicle breakdown (Gao et al., 2017). The PDE3A gene encodes phosphodiesterase 3A, the

predominant oocyte cAMP-hydrolysing phosphodiesterase (Richard et al., 2001). The PAPOLA gene encodes the enzyme that adds the 3'-polyA tail to pre-mRNAs (Dutta et al., 2016). The ATR gene encodes Ataxia telangiectasia and Rad3 related protein which detects DNA damage and replication errors during meiosis (reviewed in: Carroll and Marangos, 2013). The BMP15 and GDF9 genes encodes BMP15 and GDF9 which are known to influence granulosa and CC proliferation and function. 
Table 1-3: Function or significance of the selected oocyte genes.

\begin{tabular}{|c|c|}
\hline Gene & Function/Significance \\
\hline $\begin{array}{l}\boldsymbol{R P L 1 9}^{\star} \\
\text { (Ribosomal lipoprotein L19) }\end{array}$ & $\begin{array}{l}\text { - Validated for use in human and rat oocytes (Campen, 2013; } \\
\text { Ekart et al., 2013) }\end{array}$ \\
\hline $\begin{array}{l}\boldsymbol{P P I A}^{*} \\
\text { (Peptidylprolyl Isomerase A) }\end{array}$ & - Validated for use in bovine oocytes (Macabelli et al., 2014) \\
\hline $\begin{array}{l}\text { PTTG1 } \\
\text { (Pituitary Tumour- } \\
\text { Transforming Gene } 1 \text { aka } \\
\text { Securin) }\end{array}$ & $\begin{array}{l}\text { - Involved in cell cycle regulation; DNA damage responses and } \\
\text { possibly EGA and has been associated with developmental } \\
\text { competency (Mourot et al., 2006). } \\
\text { - Expression is modulated by different hormonal stimulation } \\
\text { protocols (Chu et al., 2012) }\end{array}$ \\
\hline $\begin{array}{l}\text { HSF1 } \\
\text { (Heat shock factor } 1)\end{array}$ & $\begin{array}{l}\text { - A major transactivator of stress inducible genes and known } \\
\text { maternal effect gene, essential for the progression of meiosis } \\
\text { (Christians et al., 2000; Bierkamp et al., 2010) }\end{array}$ \\
\hline $\begin{array}{l}\text { ZP3 } \\
\text { (Zona pellucida glycoprotein } \\
\text { 3) }\end{array}$ & $\begin{array}{l}\text { - Important role in meiotic resumption and fertilization (Gao et } \\
\text { al., 2017) } \\
\text { - Expression in polar bodies decreases with maternal age (Jiao } \\
\text { et al., 2012) }\end{array}$ \\
\hline $\begin{array}{l}\text { PDE3A } \\
\text { (Phosphodiesterase 3A) }\end{array}$ & $\begin{array}{l}\text { - Predominant cAMP hydrolysing phosphodiesterase in } \\
\text { mammalian oocytes (Richard et al., 2001) } \\
\text { - Involved in reducing cAMP levels to allow for meiotic } \\
\text { resumption (Tsafriri et al., 1996; Shen et al., 2010) }\end{array}$ \\
\hline $\begin{array}{l}\text { PAPOLA } \\
\text { (Poly (A) Polymerase Alpha) }\end{array}$ & $\begin{array}{l}\text { - Enzyme involved in poly-adenylation of mRNAs that are } \\
\text { stored during cytoplasmic maturation (Dutta et al., 2016) } \\
\text {-Expression is modified by different hormonal stimulation } \\
\text { protocols (Chu et al., 2012) }\end{array}$ \\
\hline $\begin{array}{l}\text { ATR } \\
\text { (Ataxia telangiectasia and } \\
\text { Rad3 related) }\end{array}$ & $\begin{array}{l}\text { - Detects DNA damage and replication errors during meiosis } \\
\text { (Brown et al., 2014) } \\
\text { - Expression is increased in embryos that cleaved faster } \\
\text { (Orozco-Lucero et al., 2014) }\end{array}$ \\
\hline $\begin{array}{l}\text { BMP15 } \\
\text { (Bone morphogenetic protein } \\
\text { 15) }\end{array}$ & $\begin{array}{l}\text { - Mutations in BMP15 in sheep alter ovulation rate (Galloway et } \\
\text { al., 2000) }\end{array}$ \\
\hline $\begin{array}{l}\text { GDF9 } \\
\text { (Growth differentiation factor } \\
\text { 9) }\end{array}$ & $\begin{array}{l}\text { - Mutations in GDF9 in sheep alter ovulation rate (Hanrahan et } \\
\text { al., 2004) }\end{array}$ \\
\hline
\end{tabular}

${ }^{*}$ Reference gene

\subsubsection{Gene expression profiles in the polar body}

The first polar body is extruded from oocyte following meiotic resumption and can be aspirated and subjected to gene expression analyses. This procedure is minimally invasive as it requires the zona pellucida to be punctured but the oocyte remains unaffected (Klatsky et al., 2010). Additionally, gene expression in the polar body has been shown to accurately reflect gene expression in the associated oocyte indicating that this approach could be used to develop biomarkers of developmental competency (Reich et al., 2011; Jiao et al., 2012; Jiao and Woodruff, 2013). 


\subsubsection{Profiling of Culture Medium and Follicular Fluid}

Metabolic processes are perturbed in $\mathrm{COC}$ and embryos that are matured in vitro compared to those that are matured in vivo (Khurana and Niemann, 2000; Katz-Jaffe et al., 2005; Dunning et al., 2007). It has been hypothesised that the composition or concentrations of components of follicular fluid may be useful biomarkers of developmental competency. This includes the concentrations of amino acid, paracrine factors (including GDF9, BMP15 and NPC for example), fatty acids and steroid hormones that are known to fluctuate throughout the oestrus cycle and in response to metabolic stress, and are associated with differential developmental competency (Tsafriri and Channing, 1975; Botero-Ruiz et al., 1984; Gerard et al., 2002; Leroy et al., 2004; Orsi et al., 2005; Sinclair et al., 2008; Gode et al., 2011; Aardema et al., 2013b; Hudson et al., 2014; Forde et al., 2016; Moore et al., 2017). Furthermore, there is also evidence that protein expression profiles differ in embryos with different embryological outcomes (Katz-Jaffe et al., 2006). These studies have demonstrated that it may be possible to develop biomarkers based on protein expression profiles. Subsequently, protein expression profiles in spent culture media from blastocysts that implanted were shown to be different from those that did not implant (Domínguez et al., 2008). The major weakness of these approaches are the limited sample volumes available for protein profiling and the complexity of these techniques. However, with continuing improvements to these technologies, it is possible that proteomic approaches to identifying developmentally competent oocytes and embryos may be feasible.

\subsubsection{Morphokinetics in Early Embryos}

Payne et al. (1997), utilised time-lapse photography to document the kinetic events after fertilisation using intra-cytoplasmic sperm injection (ICSI) in humans and provided indications that this technology was safe and did not alter fertilisation rate or subsequent embryonic development. Further interest in these techniques followed a landmark paper which illustrated that three parameters could be used to identify embryos that would develop to the blastocyst stage with $\geq 93 \%$ specificity and sensitivity. The three morphokinetic parameters predictive of oocyte competency were 1) duration of the first cytokinesis (known as P1), 2) time taken from the end of the first cleavage (to two cells,) to the beginning of the second cleavage (t2C) and 3) time taken between the second and third cleavages (cc2; Wong et al., 2010). 
Recently, several different studies have investigated embryo selection models for humans based on retrospectively correlating outcomes like blastocyst formation, aneuploidy risk, implantation and patient pregnancy (Chavez et al., 2012; Meseguer et al., 2012; Campbell et al., 2013). Of the parameters identified thus far, various morphokinetic parameters have been confirmed in several different human studies as being correlated to embryo development and implantation potential and these are summarised in Table 1-4.

Table 1-4: Morphokinetic parameters associated with embryological outcomes including embryo quality, blastocyst formation, blastocyst expansion, implantation potential and embryo ploidy

\begin{tabular}{|c|c|}
\hline Morphokinetic parameter & Outcome assessed \\
\hline $\begin{array}{l}\text { t2C - time to completely divide } \\
\text { into } 2 \text { blastomeres }\end{array}$ & $\begin{array}{l}\text { Blastocyst formation (Wong et al., 2010; Conaghan et al., } \\
\text { 2013; Burruel et al., 2014; Desai et al., 2014) } \\
\text { Blastocyst expansion (Dal Canto et al., 2012) } \\
\text { Implantation potential (Desai et al., 2014; Rubio et al., } \\
\text { 2014) } \\
\text { Embryo ploidy (Chavez et al., 2012) }\end{array}$ \\
\hline $\begin{array}{l}\text { t3C - time to completely divide } \\
\text { into } 3 \text { blastomeres }\end{array}$ & $\begin{array}{l}\text { Blastocyst formation (Cruz et al., 2012; Conaghan et al., } \\
\text { 2013) } \\
\text { Blastocyst expansion (Dal Canto et al., 2012) } \\
\text { Implantation potential (Desai et al., 2014) } \\
\text { Embryo ploidy (Chavez et al., 2012) }\end{array}$ \\
\hline $\begin{array}{l}\text { t4C - time to completely divide } \\
\text { into blastomeres }\end{array}$ & $\begin{array}{l}\text { Embryo quality (Hammond et al., 2015) } \\
\text { Blastocyst formation (Desai et al., 2014) }\end{array}$ \\
\hline $\begin{array}{l}\text { t5C }- \text { time to completely divide } \\
\text { into } 5 \text { blastomeres }\end{array}$ & $\begin{array}{l}\text { Blastocyst formation (Cruz et al., 2012; Herrero et al., } \\
\text { 2013) } \\
\text { Blastocyst expansion (Dal Canto et al., 2012) } \\
\text { Implantation potential (Meseguer et al., 2011, 2012; Desai } \\
\text { et al., 2014; Rubio et al., 2014) }\end{array}$ \\
\hline $\begin{array}{l}\text { t8C - time to completely divide } \\
\text { into } 8 \text { blastomeres }\end{array}$ & $\begin{array}{l}\text { Blastocyst formation (Herrero et al., 2013; Desai et al., } \\
\text { 2014) } \\
\text { Implantation potential (Herrero et al., 2013; Desai et al., } \\
\text { 2014) }\end{array}$ \\
\hline $\begin{array}{l}\text { cc2 - duration of the second cell } \\
\text { cycle }\end{array}$ & $\begin{array}{l}\text { Blastocyst formation (Wong et al., 2010) } \\
\text { Implantation potential (Meseguer et al., 2011, 2012; Rubio } \\
\text { et al., 2014; Dominguez et al., 2015) }\end{array}$ \\
\hline $\begin{array}{l}\text { s2 - interval between the } \\
\text { cleavage from } 3 \text { to } 4 \text { cells }\end{array}$ & $\begin{array}{l}\text { Blastocyst formation (Wong et al., 2010; Cruz et al., 2012; } \\
\text { Herrero et al., 2013) } \\
\text { Blastocyst quality (Hashimoto et al., 2012) } \\
\text { Implantation potential (Meseguer et al., 2011, 2012; } \\
\text { Herrero et al., 2013; Rubio et al., 2014) } \\
\text { Embryo ploidy (Chavez et al., 2012) }\end{array}$ \\
\hline Interval between $\mathrm{t} 8 \mathrm{C}$ and $\mathrm{t} 5 \mathrm{C}$ & $\begin{array}{l}\text { Blastocyst quality (Hashimoto et al., 2012) } \\
\text { Blastocyst expansion (Dal Canto et al., 2012) }\end{array}$ \\
\hline
\end{tabular}


These findings suggest that successful embryo development was at least in some way dependent or influenced by maternal factors, as all of these events occur prior to EGA in both humans and ovine embryos. A number of studies have published findings in agreement with these and in fact, many fertility clinics now offer this type of screening as a method for choosing the embryo with the most potential for development to the blastocyst stage and subsequently undergo implantation (Herrero et al., 2013; VerMilyea et al., 2014).

\subsubsection{Improving Prediction Models}

Although the approaches discussed above have shown promise, it is clear that to improve the predictive ability of these technologies, new approaches need to be investigated. In the case of morphokinetic markers, there is new evidence suggesting that the predictive potential of morphokinetic data is limited and that improvements to current success rates may not be feasible (Milewski et al., 2017). Therefore, an alternative approach is to use a combination of different types of biomarkers. Combinations of morphokinetic biomarkers and either CC gene expression or proteomic analyses of spent embryo culture media have demonstrated that these approaches are feasible and may improve predictive ability, but will require further investigation (Dominguez et al., 2015; Hammond et al., 2015).

\subsection{Overall Objectives and Aims}

The overall objectives of this study were to identify the intra-follicular factors that regulate oocyte competency and identify biomarkers that will enable the prediction of competent oocytes using a non-invasive approach. By characterising the intra-follicular microenvironment in ovine follicles and the kinetics of early embryonic development in ovine embryos, this project also aims to provide evidence that this is a relevant model for studying oocyte developmental competency in humans. These objectives were.

To identify the key factors involved in determining oocyte competency, the morphological and molecular characteristics of growing and presumptive preovulatory follicles (PPOV) were investigated in wild-type $(++)$ as well as high $\mathrm{OR}(\mathrm{I}+\mathrm{B}+)$ ewes. Similarities in developmental processes were hypothesised to indicate key maturational processes that are likely to be relevant in a range of mammalian species with different OR phenotypes. Likewise, differences in developmental processes were hypothesised to indicate processes that may be involved in the mechanism by which OR is regulated in $\mathrm{I}+\mathrm{B}+$ ewes. 
Secondly, it was hypothesised that by employing a combination of molecular (gene expression) and morphokinetic biomarkers, the accuracy of predicting developmental competency in oocytes and embryos could be improved. To this end, an ovine IVM/IVF system was established and the timing of morphokinetic events in embryos were characterised. Thereafter, the efficacy of a model consisting of both molecular and morphokinetic biomarkers was assessed.

Thirdly, the effects of different ratios of recombinant porcine GDF9 and BMP15 on developmental competency in ovine embryos were investigated. The molecular and morphokinetic tools that were characterised in the previous chapter were employed to elucidate the mechanism by which these ratios affect the COC and embryo. 


\section{CHAPTER 2. GENERAL METHODOLOGY}

The details of the reagents and equipment used in this study, including the suppliers and relevant product codes, are listed in Appendix 1. The recipes for all stock solutions and media recipes are listed in Appendix 2.

\subsection{Animals and ovary collection}

All animal experiments presented herein (see CHAPTER 3) were performed with the approval (application numbers: 13228 and 13489) of the AgResearch Invermay Animal Ethics Committee in accordance with the Animal Welfare Act of New Zealand. The ewes included in this study were $3-4$ years of age and had access to pasture and water ad libitum. The genotype of heterozygous Inverdale $\left(\mathrm{FecX}^{1 /+}\right)$ - Booroola $\left(\mathrm{FecX}^{\mathrm{B} /+}\right)$ cross $\left(F_{e c X^{1 / B}}\right)$ and wild-type $\left(\mathrm{FecX}^{+/+}\right)$ewes were confirmed by genotyping (GenomNZ, Mosgiel, New Zealand). Oestrus synchronisation was undertaken as illustrated in Figure 2-1. Briefly, progesterone controlled internal drug release (CIDR-G) devices were inserted intra-vaginally in ewes for 10 days. Twenty-four hours before CIDR removal, $175 \mu \mathrm{g}$ dose (equivalent to $0.7 \mathrm{~mL}$ ) of prostaglandin F2 $\alpha$ (PGF2 $\alpha$ ) analogue, Estrumate, was administered intramuscularly. Following the detection of the onset of oestrus, as determined from crayon marks from a teaser ram, the ewes were euthanised by captive bolt which was followed by exsanguination and thereafter, the ovaries were collected.

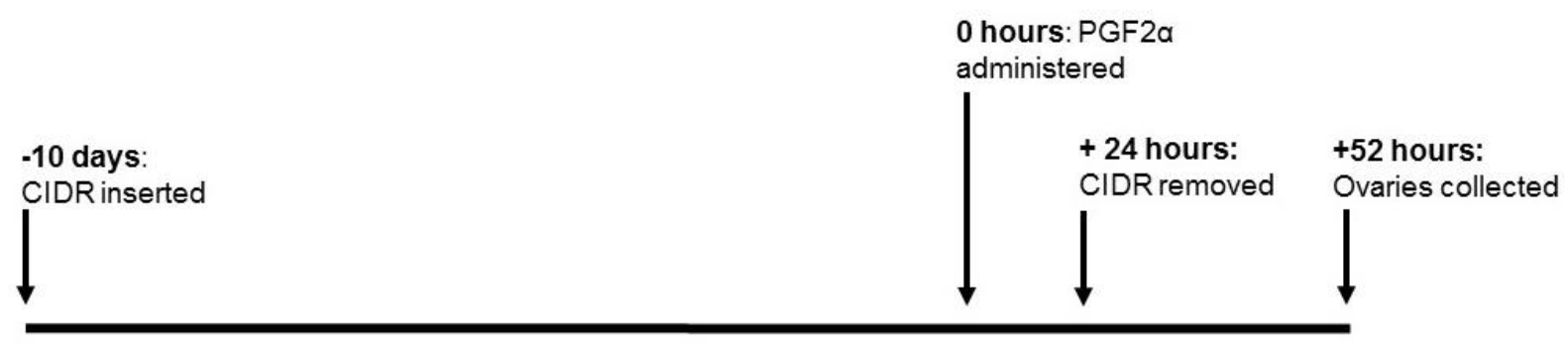

Figure 2-1: Synchronisation protocol for the Invermay experiments.

The IVP experiments detailed in Section 2.6 and described in CHAPTER 4 and CHAPTER 5 involved the use of abattoir-derived ovaries (Taylor Preston Meatworks, Ngauranga, Wellington) and commercially available ram semen (Genetic Gains Ltd, Invercargill, New Zealand). As such, specific ethical approval was not required for these studies. 


\subsection{Ovarian tissue collection}

All ovaries were immediately collected into pre-warmed $\left(37^{\circ} \mathrm{C}\right) 0.9 \%(\mathrm{w} / \mathrm{v})$ saline for transport to the laboratory. In the laboratory, excess fat was removed and the ovaries were rinsed in saline to remove any blood. To eliminate bacteria contamination, ovaries were briefly rinsed in pre-warmed $\left(37^{\circ} \mathrm{C}\right) 70 \%(\mathrm{v} / \mathrm{v})$ ethanol before being washed three times in fresh pre-warmed saline. Individual ovaries were transferred to a dry petri dish.

For in vivo maturation experiments (CHAPTER 3 ), all follicles $\geq 1 \mathrm{~mm}$ in diameter were individually dissected out and each transferred to a new, dry $35 \mathrm{~mm}$ petri dish. The size of the follicle was estimated using a calibrated micrometer and the presence of follicular wall vascularisation was recorded. Following puncture of the follicular wall, follicular fluid was assessed for the presence of cellular debris and the volume of which was recorded, before being transferred into a $1.5 \mathrm{~mL}$ microcentrifuge tube containing $100 \mu \mathrm{L}$ of phosphate buffered saline (PBS) and stored at $-20^{\circ} \mathrm{C}$ until further analysis. The COC was transferred into dissection media (Appendix 2) until the next step. The COC was then transferred through two wash wells of a 96-well plate containing $50 \mu \mathrm{L}$ of PBS and finally into $10 \mu \mathrm{L}$ of PBS where the CC were removed by repeated pipetting. The resultant denuded oocyte was further washed in PBS. Both the denuded oocyte and the CC mass were transferred separately into $0.65 \mathrm{~mL}$ tube (in the smallest volume of PBS possible) and stored at $-80^{\circ} \mathrm{C}$. The remaining follicle wall was transferred to a petri dish containing dissection media and scraped with a nichrome loop to collect the GC. The GC were counted using a haemocytometer and centrifuged at $300 \mathrm{~g}$, before being re-counted and re-suspended in $1 \mathrm{~mL}$ of dissection media in preparation for the gonadotropin-responsiveness experiments (Section 2.3).

For IVM experiments (CHAPTER 4 and CHAPTER 5), the ovaries were cut in half and transferred to a dish containing aspiration media (Appendix 3). Each follicle between 1 $5 \mathrm{~mm}$ in diameter was punctured with a 20-gauge needle attached to a $1 \mathrm{~mL}$ syringe. Once punctured, the follicle was flushed with a small amount of aspiration media to liberate the COC. The COC were then collected and transferred into a dish containing $\mathrm{H} 199+10 \%$ $(\mathrm{w} / \mathrm{v})$ foetal bovine serum (FBS) until IVP experiments (Section 2.6). 


\subsection{Gonadotropin-responsiveness cultures}

Where sufficient GC were recovered, the cells were then added at a final concentration of 60,000 cells/well in a 48-well plate. Cells were incubated with either GC culture media alone (control) or GC culture media containing purified ovine FSH (100 ng/mL; OVA2, Moore et al., 1997), or human chorionic gonadotropin (hCG;1000 ng/mL; CR121; 13,450 IU/mg; NICHD, Bethesda, MD, USA) for 45 minutes in a $37^{\circ} \mathrm{C}$ waterbath. The 48 -well plates containing the samples were heated to $80{ }^{\circ} \mathrm{C}$ for 15 minutes and cooled on ice before being transferred to $1.5 \mathrm{~mL}$ tubes and stored at $-20{ }^{\circ} \mathrm{C}$. For each follicle, $\mathrm{GC}$ samples were incubated in media or treatment in triplicate, except when an insufficient number of cells had been collected. The minimum requirement for inclusion of a follicle was $\geq 1 \times 10^{6}$ cells allowing for at least one control replicate and one hCG replicate.

\section{4. cAMP Radioimunnoassy (RIA)}

The concentrations of cAMP in control and treated (FSH and hCG) GC samples were measured using an established RIA methodology (Jolly et al., 1997; McNatty et al., 2009). Briefly, $100 \mu \mathrm{L}$ of thawed sample or standard $(1-1000 \mathrm{fmol} / 100 \mu \mathrm{L}$ ) were added to polypropylene assay tubes in duplicate or triplicate, respectively. The samples were acetylated by adding $5 \mu \mathrm{L}$ of $1: 2(\mathrm{v} / \mathrm{v})$ acetic anhydride: triethylamine and immediately vortexed for 5 seconds. A $100 \mu \mathrm{L}$ aliquot of cAMP tracer ( 10 000 counts per minute; adenosine 3', 5'-cyclic phosphoric acid, 2'-O-succinyl [ $\left.{ }^{125} \mathrm{I}\right]$-iodotyrosine methyl ester) in tracer buffer was added to all tubes. The total counts tubes were capped to ensure they received no further reagents thereafter. All tubes, except the non-specific binding tubes, received $100 \mu \mathrm{L}$ of rabbit-raised anti-0, 2-monosuccinyl-adenosine-3',5'- cAMP IgG (1: 15,000 in antibody buffer; produced and gifted by Dr Jenny Juengel, AgResearch Invermay). Samples were then mixed thoroughly and incubated at $4{ }^{\circ} \mathrm{C}$ overnight. The next day, $50 \mu \mathrm{L}$ of sheep-raised anti-rabbit $\lg \mathrm{G}$ (1:50 in antibody buffer supplemented with $30 \%$ ( $v / v)$ hypophysectomised sheep serum; produced and gifted by $\mathrm{Dr}$ Jenny Juengel, AgResearch Invermay) was added to all tubes and incubated at room temperature for 60 minutes. Finally, $1 \mathrm{~mL}$ of the cold separation buffer was added to all samples and the samples were centrifuged at $2000 \mathrm{~g}$ for 25 minutes at $10^{\circ} \mathrm{C}$. For each tube, excluding the total counts tubes, the supernatant was decanted and the radioactivity of the pellet was measured using a gamma counter (Wallac Wizard² Automatic Gamma Counter). The cross-reactivity with cGMP was $0.5 \%$. The intra-assay coefficients of variation for the low, medium and high controls were $8.1 \%, 5.9 \%$ and $9.3 \%$ respectively. The inter-assay 
coefficients of variation for the low, medium and high controls were $15.4 \%, 6.1 \%$ and $10.5 \%$.

\subsection{Follicular fluid and plasma component analysis}

Of the follicular fluid samples that were collected, only those with corresponding gonadotropin responsiveness and gene expression data were selected for analysis. The volume of follicular fluid samples were made up to a minimum total volume of $150 \mu \mathrm{L}$ in PBS. Plasma samples were collected from ewes prior to euthanasia and were included for analysis. All samples were stored at $-20^{\circ} \mathrm{C}$ until measurements were conducted.

Analyses of plasma and follicular fluid for measurements of glucose, cholesterol, amino acids and steroid hormone concentrations were conducted by Mr Eric Thorstensen at the Liggins Institute, University of Auckland using methods that have been described elsewhere (Bloomfield et al., 2002; Green et al., 2011; Thorstensen et al., 2012). Briefly, the concentrations of glucose and cholesterol present in plasma and follicular fluid were measured using enzymatic colorimetric assays, the reagents for which were supplied by Roche (Mannheim, Germany), on a Hitachi 902 autoanalyser (Hitachi High Technologies Corporation, Tokyo, Japan). The limit of quantitation for both glucose and cholesterol was $0.11 \mathrm{mM}$. Due to low plasma concentrations of $17 \beta$-oestradiol and progesterone, these were also measured using the autoanalyser. Plasma and follicular fluid concentrations of cortisone, cortisol, corticosterone, 11-deoxycortisol and testosterone, and follicular fluid concentrations of $17 \beta$-oestradiol and progesterone were measured using a highperformance liquid chromatography mass spectrometer system consisting of a Waters Alliance 2690 Separations module (Waters Corporation, Milford, MA, USA) followed by an Ion Max APCI source on a Finnigan TSQ Quantum Ultra AM triple quadrupole mass spectrometer, controlled by Finnigan Xcalibur software (Thermo Electron Corporation, San Jose, CA, USA). The limits of quantitation for cortisone, cortisol, corticosterone, 11-deoxycortisol, testosterone, 17ß-oestradiol and progesterone were $0.025 \mathrm{ng} / \mathrm{mL}$, $0.050 \mathrm{ng} / \mathrm{mL}, 0.025 \mathrm{ng} / \mathrm{mL}, 0.025 \mathrm{ng} / \mathrm{mL}, 0.010 \mathrm{ng} / \mathrm{mL}, 0.020 \mathrm{ng} / \mathrm{mL}$ and $0.100 \mathrm{ng} / \mathrm{mL}$, respectively. The $\mathrm{L}-$ forms of alanine, arginine, asparagine, aspartic acid, citrulline, glutamic acid, glutamine, glycine, histidine, hydroxyproline, isoleucine, leucine, methionine, ornithine, phenylalanine, proline, serine, taurine, threonine, tyrosine and valine were also measured in the plasma and follicular fluid samples using a modified fluorescence-tagged high-performance liquid chromatography method, described previously in Bloomfield et al., (2002) and Thorstensen et al., (2012). The limit of quantitation for aspartic acid and 
hydroxyproline was $1 \mu \mathrm{M}$, glycine was $10 \mu \mathrm{M}$ while the remainder of the amino acids had a limit of quantitation of $2 \mu \mathrm{M}$.

\subsection{IVP}

The IVP protocols described herein were based on protocols described by (Reader et al., 2015a, 2015b), but have been modified to allow for the tracking of individual COC through IVF. This enables embryonic outcomes to be correlated with CC gene expression profiles. The protocols used for IVP in the current study are summarised in Figure 2-2.

\subsubsection{Specialised equipment: Modified culture plates and embryo box}

Modifications to the culture plates were made using a $1.5 \mathrm{~mm}$ drill bit attached to the opposite end of a teasing needle as shown in Figure 2-3. The drill bit was rotated in the same position while applying minimal pressure, to create a well in which the COC or oocyte was placed during in vitro culture. Any excess plastic created when making the wells was removed using the teasing needle. The wells were washed with $70 \%$ ethanol for sterilisation purposes. Prior to use, the wells were rinsed 3 times with the appropriate culture media and then overlaid with a drop of fresh culture media. The IVM plates contained 10 wells/drop, while the IVF plates contained 5 wells/drop.

Due to the requirement for low oxygen conditions during embryo culture, IVP experiments require the use of modular incubation chambers which are fitted inside a carbon dioxide $\left(\mathrm{CO}_{2}\right)$ incubator. This allows for gas and temperature conditions to be customised appropriately. Two embryo box prototypes were constructed to fit three Primo Vision ${ }^{\mathrm{TM}}$ microscopes each. The first prototype was a sealed poly(methyl methacrylate) (perspex) box (500 mm x $255 \mathrm{~mm} \times 260 \mathrm{~mm}$; Figure 2-3C). However due to strength concerns, the second prototype was a sealed stainless-steel box of similar size. Both boxes had a shelf on which, the Primo Vision ${ }^{\mathrm{TM}}$ cameras were placed. Under the shelf was a tray of water for humidification purposes. Both boxes contained a sealed port(s) through which the camera cables connected and an inlet and outlet port through which a low oxygen $\left(\mathrm{O}_{2}\right)$ gas mixture $\left(5 \% \mathrm{CO}_{2}, 7 \% \mathrm{O}_{2}\right.$ and $88 \%$ nitrogen; $\mathrm{N}_{2}$ ) could be introduced to fill the chamber. After the culture plates were placed under the cameras, the low $\mathrm{O}_{2}$ gas mixture was turned on to allow the gas to flow through the box for at least 5 minutes before being closed again and the inlet and outlet ports were sealed, thus creating a low oxygen culture environment within the incubator. 


\section{In vitro embryo production (IVP)}

\section{Day -1 : In vitro maturation (IVM)}

- COC are extracted from abattoir-derived ovaries

- Grade I and II COC (Table 2-2) selected for IVM

- Cultured for 25 hours under either:

\section{Group Culture Conditions}

Modified culture dish:

-10 microwells/drop

$-10 \mathrm{COC} / \mathrm{drop}$

$-50 \mu \mathrm{L}$ drops

- No media supplements
OR Single culture Conditions

Unmodified culture dish

$-1 \mathrm{COC} / \mathrm{drop}$

- $50 \mu \mathrm{L}$ drops

- With or without media

supplements (i.e. rec

pGDF9 and BMP15)

\section{Day 0 : In vitro fertilisation(IVF) \\ - Cumulus cells loosened and collected for qPCR Modified culture dish: \\ - 5 partially-denuded COC/drop \\ - Add sperm preparation \\ - $50 \mu \mathrm{L}$ drops $\left(1.5 \times 10^{6} \mathrm{sperm} / \mathrm{mL}\right)$ \\ - 18 - 20 hour incubation}

- Partially-denuded COC were transferred into:
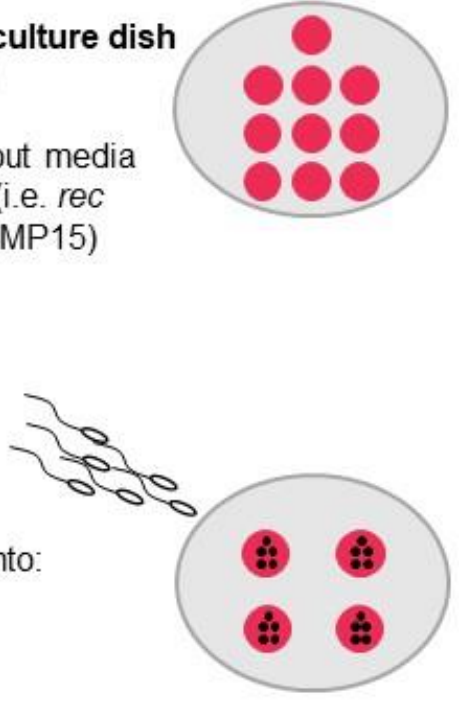

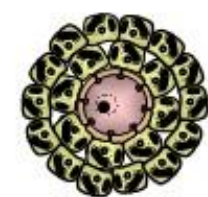




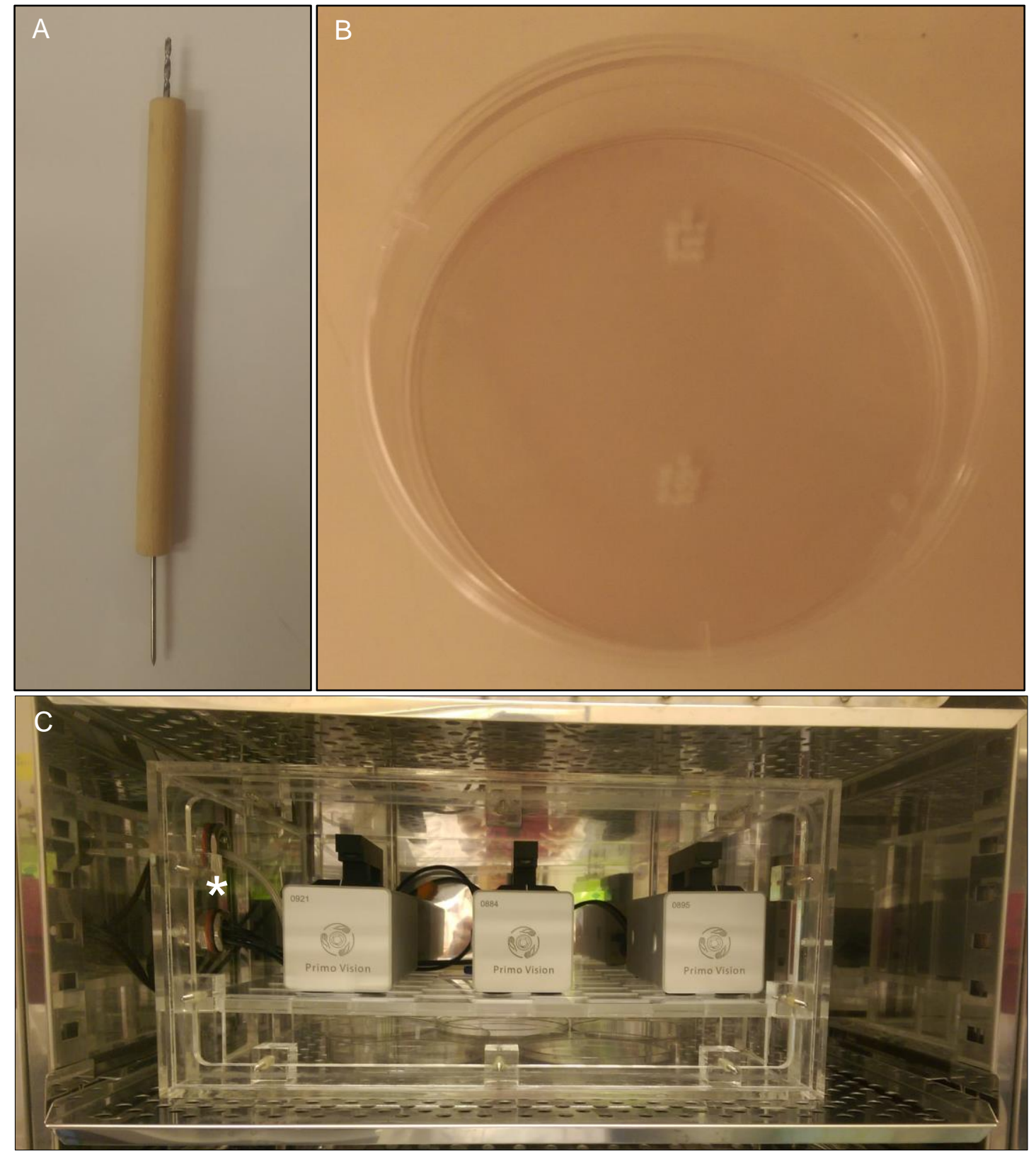

Figure 2-3: Specialised equipment utilised during IVP. Tool (A) used to modify IVM (B) and IVF culture plates, and the first embryo box prototype (C) inside the $\mathrm{CO}_{2}$ incubator with three cameras installed, below the cameras are petri dishes filled with water which were used as humidifying pans. Above the * symbol, is a fitting containing the gas inlet and outlet ports and below * symbol is the fitting containing the camera cables.

\subsubsection{IVM}

On the morning of each experiment, the ovaries were collected from the abattoir and transported to the laboratory in pre-warmed saline. Meanwhile, the IVM media was prepared by thawing an aliquot of IVM media and cysteamine was added to a final concentration of $0.1 \mathrm{mM}$. For the experiments described in CHAPTER 5, the appropriate 
treatments (e.g. recombinant pig GDF9 or BMP15; produced in-house; (Alhussini, 2016; Swinerd, 2016)) were also added to the IVM media. Then $40 \mu \mathrm{L}$ drops of IVM media were added on the surface of sterile $60 \mathrm{~mm}$ petri dishes and overlaid with $9 \mathrm{~mL}$ of mineral oil. The IVM plates were placed into the $\mathrm{CO}_{2}$ incubator to equilibrate to the conditions of $38.5^{\circ} \mathrm{C}, 5 \% \mathrm{CO}_{2}$ and $96 \%$ humidity for at least two hours.

Where possible, all dissection and handling of plates during IVP experiments were performed on a heated stage set to $38.5^{\circ} \mathrm{C}$. Every effort was made to minimise the time that $\mathrm{COC}$ and embryos spent outside of the incubator. Following the extraction of COC from ovaries, all COC were transferred to a second dish containing $\mathrm{H} 199+10 \%(\mathrm{w} / \mathrm{v})$ FBS for selection. Only COC of Grade 1 or 2 (see Table 2-1) were selected for IVM. The selected COC were washed in a $35 \mathrm{~mm}$ petri dish containing B199 + $10 \%$ (w/v) FBS before being transferred to the equilibrated IVM drops. The resultant volume of each IVM drop (regardless of single or group culture) was $50 \mu \mathrm{L}$. The IVM plates containing the selected COC were returned to the incubator for 25 - 27 hours.

\section{Table 2-1: Ovine COC grading scale.}

\begin{tabular}{ll}
\hline Grade & Appearance \\
\hline 1 & Many layers of tight CC \\
2 & CC layers are less compact and fewer \\
3 & Corona radiata (CR) only, zona pellucida may be exposed \\
4 & No CC but cytoplasm appears normal \\
5 & Expanded/mature oocyte \\
6 & $\begin{array}{l}\text { Degenerate. Oocyte cytoplasm is } \\
\text { degenerate/absent/lysed. This grade also includes } \\
\end{array}$ \\
\hline
\end{tabular}

\subsubsection{IVF}

Culture plates containing the IVF media require a minimum of 2 hours of equilibration prior to use. Thus, on the morning of the Day 0, IVF plates containing complete IVF media were prepared. These consisted of the appropriate number of $30 \mu \mathrm{L}$ drops on a $60 \mathrm{~mm}$ petri dish overlaid with $9 \mathrm{~mL}$ of mineral oil. The plates were placed in the embryo box and the box was sealed for equilibration. 


\subsubsection{Preparation of expanded COC}

Prior to the beginning of sperm preparation, a 96-well plate was set-up containing $50 \mu \mathrm{L}$ of pre-warmed HEPES-buffered synthetic oviductal fluid (HSOF) in the first two rows of the plate. The $\mathrm{COC}$ were removed from the embryo box and transferred through two washes of HSOF and into $10 \mu \mathrm{L}$ of HSOF where most of the CC were removed by repeated manual pipetting. The partially-denuded $\mathrm{COC}$ was then transferred into the next well containing $50 \mu \mathrm{L}$ of pre-warmed HSOF. The CC were collected into a $0.65 \mathrm{~mL}$ tube and stored at $-80^{\circ} \mathrm{C}$ prior to the gene expression studies. The COC were washed in a final well containing $50 \mu \mathrm{L}$ of equilibrated complete IVF media before being transferred into $30 \mu \mathrm{L}$ drops of equilibrated IVF media and returned to the embryo box.

\subsubsection{Sperm preparation}

All IVF experiments described herein were conducted using semen from the same ram identified as Waihora 40 . The Waihora 40 semen used in this study was chosen following a series of IVF experiments that assessed the ability of semen from three different rams at four different concentrations to fertilise oocytes. The Waihora 40 semen resulted in the highest fertilisation rate (95\% c.f. $45-78 \%$ ) of all of those assessed.

A Percoll gradient was prepared by pipetting $1 \mathrm{~mL}$ of a $90 \%$ Percoll solution into a $15 \mathrm{~mL}$ tube and overlaying this with $1 \mathrm{~mL}$ of a $45 \%$ Percoll solution. One semen straw was removed from liquid nitrogen and placed in a $30-35{ }^{\circ} \mathrm{C}$ water bath for 30 seconds. The straw was then dried with a tissue and then a tissue sprayed with $70 \%$ ethanol was used to sterilise both ends of the straw. In aseptic conditions, the ends of the straw were cut and the semen collected into a $35 \mathrm{~mm}$ petri dish. An aliquot of semen ( 200 $\mu \mathrm{L})$ was carefully applied to the Percoll gradient using a sterile glass pasteur pipette attached to the end of a syringe. The tube containing the Percoll gradient and semen was then centrifuged at $700 \mathrm{~g}$ for 25 minutes at room temperature. In the meantime, the remaining semen was transferred to a warmed glass slide and a coverslip placed on top prior to microscopic evaluation to determine the post-thaw sperm motility rate. The minimum postthaw motility rate was $50 \%$. Following centrifugation, the sperm pellet was removed using a glass pasteur pipette and transferred to a new $15 \mathrm{~mL}$ tube and carefully re-suspended in $1 \mathrm{~mL}$ of HSOF at room temperature before being centrifuged at $200 \mathrm{~g}$ for 5 minutes. The HSOF was then removed and $200 \mu \mathrm{L}$ of equilibrated complete IVF media was carefully added whilst gently mixing to re-suspend the sperm pellet. 
A $10 \mu \mathrm{L}$ aliquot of a 1:20 aqueous dilution of the sperm preparation, was added to each side of a haemocytometer and the number of sperm present was counted. The volume of the remaining sperm preparation was measured and stored in a warm, dark environment. The sperm concentration was adjusted to $7.5 \times 10^{6} \mathrm{sperm} / \mathrm{mL}$ with equilibrated IVF media using the formula in Figure 2-4.

$$
\begin{aligned}
& \text { i. Final vol.of sperm }(\mu L)=\frac{\text { Average sperm count } \times \text { Vol.of sperm measured }}{37.5} \\
& \text { ii.Vol. of media to add }(\mu L)=\text { Final vol.of sperm }- \text { Vol. of sperm measured }
\end{aligned}
$$

Figure 2-4: Formulae for adjusting the sperm to the appropriate concentration for IVF. In formula $i$., the final volume of sperm refers to the volume after adjustment, the average sperm count refers the total number of sperm counted and the volume of sperm measured refers to the volume measured after resuspension in equilibrated complete IVF media, following the removal of the aliquot for counting. In formula ii., the volume of media to add is the volume of media that must be added to the sperm preparation so that when added to the prepared IVF plates, it results in a final concentration of $1.5 \times 10^{6} \mathrm{sperm} / \mathrm{mL}$.

To complete the IVF step, $10 \mu \mathrm{L}$ of the adjusted sperm preparation ( 75 000 sperm) was added to media drops containing the partially-denuded COC in the IVF plates resulting in a final concentration of $1.5 \times 10^{6} \mathrm{sperm} / \mathrm{mL}$ in each of the $50 \mu \mathrm{L}$ IVF drops. The IVF plates containing the oocyte and the sperm were returned to the embryo box. The embryo box was then flushed with the low $\mathrm{O}_{2}$ gas mixture for at least 5 minutes and sealed.

\subsubsection{IVC}

\subsubsection{IVC (Day 1)}

On the morning of Day 1 , at least $5 \mathrm{~mL}$ each of HSOF and synthetic oviductal fluid (SOF) media were aliquoted into $15 \mathrm{~mL}$ tubes. Depending on the experiment, Primo Vision ${ }^{\mathrm{TM}}$ 9or 16-well plates were prepared by wetting the wells with $<10 \mu \mathrm{L}$ of SOF and then tapping the plates vigorously on the bench to remove air pockets from the bottom of the wells. The media and any resulting air bubbles were aspirated off and replaced with $20-32 \mu \mathrm{L}$ of SOF media. A wash drop of the same volume of SOF media was also added to the side of the culture drop. Prior to being placed in the Primo Vision TM plate wells, embryos were placed in the wash drop to remove the remaining traces of the IVF media. Both drops were overlaid with $2.5 \mathrm{~mL}$ mineral oil and were placed, with the remaining SOF, in the embryo box. Again, the embryo box was flushed with low $\mathrm{O}_{2}$ gas mixture for at least 5 minutes to allow the plates and extra media to equilibrate. 
At 18 hours after the addition of sperm (post-IVF), oocytes were transferred to a 96-well plate containing $50 \mu \mathrm{L}$ of pre-warmed HSOF. The fertilised oocytes (zygotes - 2 cell embryos) were then transferred to a second wash well containing $50 \mu \mathrm{L}$ of the equilibrated SOF media, and transferred the appropriate well in an equilibrated Primo Vision ${ }^{\mathrm{TM}}$ plate in the smallest volume of SOF media possible.

Prior to beginning an IVP experiment, the Primo Vision ${ }^{\mathrm{TM}}$ microscopes were wiped down with $70 \%$ ethanol before being placed in an embryo box to allow for equilibration.

The Primo Vision ${ }^{\mathrm{TM}}$ plates, in which the embryos now reside, were placed on the microscopes. Microscope adjustments via the associated software were made that included image focusing, recording duration and image capture frequency before the program was started. These settings are described in detail in the relevant chapters (CHAPTER 4 and CHAPTER 5). The Primo Vision ${ }^{\mathrm{TM}}$ plates would remain undisturbed in the embryo box for a further 7-8 days (Day 8-9), except for a media change on Day 5.

\subsubsection{IVC (Day 5)}

On the morning of Day 5, $1.5 \mathrm{~mL}$ of SOF media was aliquoted into a $15 \mathrm{~mL}$ tube and placed in the embryo box. The box was flushed with the low $\mathrm{O}_{2}$ gas mixture and resealed as described previously. On the afternoon of Day 5, the Primo Vision ${ }^{\mathrm{TM}}$ software was paused, the plates were removed from the embryo box and the media in which the embryos resided, was replaced. This was achieved by the careful aspiration of spent media and addition of fresh equilibrated SOF media, all performed under the mineral oil. This step was repeated three more time to incorporate three wash steps prior to final media refreshment. The plates were then placed back on the microscopes, the embryo box again filled with the low $\mathrm{O}_{2}$ gas mixture and re-sealed, and the Primo Vision ${ }^{\mathrm{TM}}$ software restarted.

\subsubsection{End of IVC (Day 8 or 9)}

At the end of each experiment, the Primo Vision ${ }^{\mathrm{TM}}$ capture software would automatically stop acquiring images as per the programming details and the plates were removed from the microscopes and the embryos discarded.

The total number of embryos that cleaved normally and reached blastocyst stage or arrested in development was recorded. Of the remaining embryos, a distinction was made 
between embryos that remained at the 1-cell (zygotes) stage (i.e. failed to cleave) and those that cleaved abnormally (i.e. zygotes that immediately formed $>3$ cell embryos or disordered cleavages). Aside from comparing the proportions to embryos that cleaved normally, the uncleaved and abnormally-cleaved embryos were not included in the data analyses. The embryos that cleaved normally were grouped according to the stage of development reached at time of arrest or experiment end. As such, there were four groupings based on embryonic outcome, i) arrested at or before the 8-cell stage ( $\leq 8$-cell), ii) arrested after the 8-cell stage but before the morula stage (>8-cell), iii) arrested as compacted morulae or early blastocysts (CMEB), and iv) blastocysts (where the blastocoel increased in size such that the diameter of the embryo increased by $10 \%$ ). The total number of blastocysts were recorded to determine the blastocyst rate. Embryos that reached the blastocyst stage were graded according to the blastocyst grading system developed by Gardner and Schoolcraft (1999). However, further investigation regarding differences in embryo quality (grade) were not undertaken due to the limited numbers of blastocysts available for analysis.

The time-lapse videos were annotated using the Primo Vision ${ }^{\mathrm{TM}}$ Analyzer software program. The time-lapse parameters investigated in this thesis were based on terminology used human morphokinetic studies rather than domestic animal embryology. The timelapse videos for each embryo were observed separately and the timings for each morphokinetic event (see Table 2-2 and Figure 2-5) were annotated at the first instance at which each event was observed. Where necessary, the videos were replayed and the images viewed frame by frame to accurately determine when these events occurred. The images in Table 2-2 are presented as direct representations of the images that are available for analysis using this time-lapse system. Notably, ovine the blastomeres in ovine embryos are darker than human embryos. The timings were converted to decimal time for analyses. The exact timing of fertilisation was unknown as oocytes were left undisturbed with sperm for 18 hours during the IVF step. Therefore, the morphokinetic events for each embryo were corrected to time to divide to the 2-cell stage (t2C), rather than the timing of zygote formation (i.e. observation of two pronuclei). 


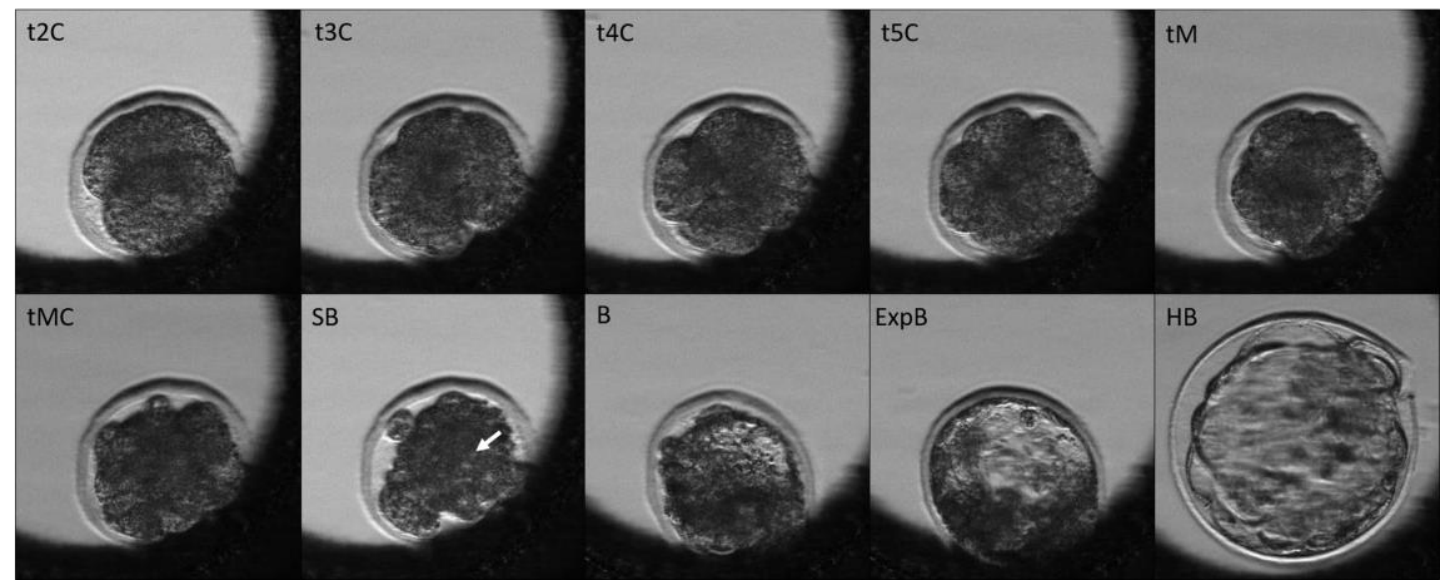

Figure 2-5: Representative images of the morphokinetic events described in Table 2-2 in an ovine embryo. $\mathrm{t} 2 \mathrm{C}, \mathrm{t} 3 \mathrm{C}, \mathrm{t} 4 \mathrm{C}$ and $\mathrm{t} 5 \mathrm{C}$ refer to the total time to cleave to $2,3,4$ and 5 blastomeres, respectively. $\mathrm{tM}$ and $\mathrm{tMC}$ refer to the total time to form a morula and undergo compaction. The white arrow in the SB panel indicates the location of the developing blastocoel. $\mathrm{B}$ indicates a blastocyst (i.e. the growing blastocoel results in a $10 \%$ increase in the diameter of the embryo), while ExpB refers to expanded blastocysts and HB to hatched/hatching blastocysts. The images in Table 2-2 are presented as direct representations of the images that are available for analysis using this time-lapse system. Notably, ovine the blastomeres in ovine embryos are darker than human embryos.

Table 2-2: Definition of morphokinetic events assessed in the time-lapse studies.

\begin{tabular}{|c|c|}
\hline $\begin{array}{c}\text { Morphokinetic } \\
\text { Event }\end{array}$ & Definition \\
\hline t2C & Time to divide* into 2 blastomeres. \\
\hline b3c & Beginning ${ }^{\star *}$ of cleavage to 3 blastomeres. \\
\hline t3C & Time to divide* into 3 blastomeres. \\
\hline t4C & Time to divide* into 4 blastomeres. \\
\hline b5C & Beginning ${ }^{* *}$ of cleavage to 5 blastomeres. \\
\hline t5C & Time to divide* into 5 blastomeres. \\
\hline tM & $\begin{array}{l}\text { Time to morula formation i.e. the time at which individual blastomere } \\
\text { shape is not visible. }\end{array}$ \\
\hline tMC & Time to full morula compaction. \\
\hline SB & Time at which the blastocoel is first visualised \\
\hline B & Blastocyst - Time at which the blastocyst increases $10 \%$ in size. \\
\hline ExpB & $\begin{array}{l}\text { Expanded blastocyst - Time at which the blastocyst increases } 30 \% \text { in } \\
\text { size. The blastocyst is also expanding and contracting with the zona } \\
\text { pellucida thinning. }\end{array}$ \\
\hline HB & $\begin{array}{l}\text { Hatching/hatched blastocyst - Time to herniation of the blastocyst from the } \\
\text { zona pellucida. }\end{array}$ \\
\hline cc2 & Duration of the second cell cycle (b3C - t2C) \\
\hline cc3 & Duration of the third cell cycle (b5C - t3C) \\
\hline cc3a & Duration of the interval between the 4 -and 5 -cell stage ( $\mathrm{t} 5 \mathrm{C}-\mathrm{t} 4 \mathrm{C}$ ) \\
\hline s2 & Synchronicity of the second cell cycle ( $\mathrm{t} 4 \mathrm{C}-\mathrm{b} 3 \mathrm{C})$ \\
\hline
\end{tabular}




\subsection{Quantitative Polymerase Chain Reaction (qPCR)}

\subsubsection{Total RNA extraction}

Using aspetic technique, total RNA was extracted from samples using the ArrayPure ${ }^{\mathrm{TM}}$ Nano-scale RNA Purification Kit. While these experiments were being conducted, the Nano-scale RNA Purification Kit was discontinued by the manufacturer. The MasterPure ${ }^{\mathrm{TM}}$ RNA Purification Kit contains the same buffers (with different names) and Proteinase $\mathrm{K}$ at a higher concentration of $50 \mu \mathrm{g} / \mathrm{mL}$ (compared to $5 \mu \mathrm{g} / \mathrm{mL}$ in the original kit). Thus, the adaptation for the MasterPure ${ }^{\mathrm{TM}}$ RNA Purification kit involved a larger dilution $(1: 300 \mathrm{v} / \mathrm{v})$ of Proteinase $\mathrm{K}$ in the buffer than the Nano-scale RNA Purification Kit (1:30 v/v). Apart from this modification, RNA extractions were performed as per the manufacturer's instructions and are described herein. Where the names of the buffers were changed, these are included in () following the names of the buffers from the Nano-scale RNA purification kit.

When using the Nano-scale Kit, the Proteinase $\mathrm{K}$ was diluted at a ratio of $1: 30(\mathrm{v} / \mathrm{v})$ in Nano-scale Lysis Solution. Alternatively, when using the MasterPure Kit, the Proteinase K was diluted at a ratio of 1:300 (v/v) in Tissue and Cell Lysis Solution. Regardless, $30 \mu \mathrm{L}$ of diluted Proteinase $\mathrm{K}$ solution was added to each of the samples and vortexed briefly. Following a centrifugation step to collect contents at the bottom of the tube, samples were incubated at $67^{\circ} \mathrm{C}$ for 15 minutes. The samples were cooled on ice for 4 minutes before $18 \mu \mathrm{L}$ of MPC Protein Precipitation Reagent was added to each sample and vortexed. The samples were centrifuged at $12,000 \mathrm{~g}$ for 7 minutes at $4{ }^{\circ} \mathrm{C}$ and the resultant supernatant was transferred to a new $0.65 \mathrm{~mL}$ tube. An aliquot of $50 \mu \mathrm{L}$ of RNase-free isopropanol was added to each sample, vortexed briefly and centrifuged for 5 minutes at $12,000 \mathrm{~g}$ at $4{ }^{\circ} \mathrm{C}$. Isopropanol was removed with a pipette and the nucleic acid pellet was air-dried for 5 minutes. The pellet was re-suspended in $20 \mu \mathrm{L}$ of a DNase mixture (1:40 DNase I: DNase buffer solution) and incubated at $37^{\circ} \mathrm{C}$ for 30 minutes. At the end of the incubation period, $20 \mu \mathrm{L}$ of $2 \times$ Nano-scale solution ( $2 \times$ Tissue and Cell Lysis solution) was added to each sample, vortexed for 5 seconds and briefly centrifuged. A further $20 \mu \mathrm{L}$ of MPC Protein Precipitation Reagent was added to each sample and vortexed before being placed on ice for 4 minutes. The samples were centrifuged at $12,000 \mathrm{~g}$ for 5 minutes at $4{ }^{\circ} \mathrm{C}$. The resultant supernatant was transferred to a new $0.65 \mathrm{~mL}$ tube where $50 \mu \mathrm{L}$ of RNase-free isopropanol was added. Each sample was thoroughly vortexed and centrifuged at $12,000 \mathrm{~g}$ for 5 minutes at $4{ }^{\circ} \mathrm{C}$. The isopropanol was removed and the pellet 
was washed with $50 \mu \mathrm{L}$ of $70 \%(\mathrm{v} / \mathrm{v})$ aqueous RNase-free ethanol and centrifuged for a further 3 minutes at $7,500 \mathrm{~g}$ at $4{ }^{\circ} \mathrm{C}$. The ethanol was removed and the purified RNA pellet was air-dried for 5 minutes before being re-suspended in $10 \mu \mathrm{L}$ of $\mathrm{U} / \mathrm{P} \mathrm{dH}_{2} \mathrm{O}$. Total RNA was re-suspended by vigorous vortexing for 2 minutes, incubation at $55^{\circ} \mathrm{C}$ for 2 minutes and a final vortex step for a further 30 seconds before being briefly centrifuged and stored at $-80^{\circ} \mathrm{C}$

\subsubsection{Complimentary DNA (cDNA) synthesis}

Reagents from the SuperScript ${ }^{\circledR}$ VILO ${ }^{\text {TM }}$ CDNA Synthesis Kit were used to synthesise cDNA from the total RNA samples according to the manufacturer's instructions. Briefly, a master mix, sufficient for 10 samples, was prepared on ice that contained $40 \mu \mathrm{L}$ of $5 \times$ VILO $^{\text {TM }}$ Reaction Mix, $40 \mu \mathrm{L}$ of U/P dH $\mathrm{dH}_{2} \mathrm{O}$ and $20 \mu \mathrm{L}$ of SuperScript ${ }^{\circledR}$ III Enzyme Blend. The RNA samples were retrieved, thawed and the total RNA sample ( $10 \mu \mathrm{L})$ was transferred into ultra-thin walled $0.2 \mathrm{~mL}$ PCR tubes. Then $10 \mu \mathrm{L}$ of the master mix was added to each of the tubes before being briefly vortexed to allow for sufficient mixing. The tubes containing the reaction components were placed in the Rotor-Gene ${ }^{\mathrm{TM}} 6000$ Rotary Analyzer and incubated at $25{ }^{\circ} \mathrm{C}$ for 10 minutes and then $42{ }^{\circ} \mathrm{C}$ for 120 minutes. The reaction was completed by a final incubation at $85^{\circ} \mathrm{C}$ for 5 minutes. The cDNA samples were then stored at $-20^{\circ} \mathrm{C}$ until further processing.

\subsection{3. qPCR}

The forward and reverse oligonucleotide primers, and TaqMan probes used in this study were designed using the Beacon Designer software package. The primer pairs designed to measure relative gene expression levels in single oocytes and single CC masses are listed in Table 2-3, while the associated probe sequences are listed in Table 2-4.

\subsubsection{Primer Optimisation}

To determine the optimal concentrations for each of the primer pairs, total cDNA was synthesised from a pool of 20 ovine COC. In the case of some CC-derived genes (e.g. HAS2, PGR \& EREG), expression levels were insufficient and hence, CC masses from in vitro matured, expanded $\mathrm{COC}$, were collected as described in Section 2.6.2. 
Table 2-3: NCBI accession numbers and forward (F) and reverse (R) primer sequences for the genes investigated in this study.

\begin{tabular}{|c|c|c|}
\hline Gene & $\begin{array}{l}\text { NCBI Accession } \\
\text { No. }\end{array}$ & Primers \\
\hline RPL19* & XM_004012836 & $\begin{array}{l}\text { F - TAAGCGAAAGGGTACTGCCAATG } \\
\text { R - TTCTTAGATTCACGGTATCGTCTGAG }\end{array}$ \\
\hline$P P I A^{*}$ & NM_001308578 & $\begin{array}{l}\text { F - TTACTTAACCACCAGACCAT } \\
\text { R - CGAGAGCACAAAGATTATAGG }\end{array}$ \\
\hline PTTG1 & XM_004009036 & $\begin{array}{l}\text { F - GTTGGCAAAATGTTTGATG } \\
\text { R - GTCCATCCGTCTTAACTG }\end{array}$ \\
\hline HSF1 & XM_004011897 & $\begin{array}{l}\text { F - GTCGTCAACAAGCTCATC } \\
\text { R - GTGCTCCAGAGAGTACTG }\end{array}$ \\
\hline$Z P 3$ & XM_004020981 & $\begin{array}{l}\text { F - CTGTCGATGCTGTAGCAA } \\
\text { R - TTCCCCAGGAAGATCAAC }\end{array}$ \\
\hline PDE3A & XM_004007550 & $\begin{array}{l}\text { F - CCCGGTGTTTAAGAGGAG } \\
\text { R - GTGGTCCCATTCTGAATG }\end{array}$ \\
\hline PAPOLA & XM_012099023 & $\begin{array}{l}\text { F - CTGGTGAGCATGTTTTATG } \\
\text { R - GGGGAAAAGACTAGACTC }\end{array}$ \\
\hline ATR & XM_012102124 & $\begin{array}{l}\mathrm{F} \text { - GACCAGATCATTCACTATCA } \\
\text { R - AGACCTGTTAGCATGTAC }\end{array}$ \\
\hline BMP15 & NM_001114767 & $\begin{array}{l}\text { F - AGCTCTGGAATCACAAGG } \\
\text { R - GTCCAATGATGAAGTGCC }\end{array}$ \\
\hline GDF9 & NM_001142888 & $\begin{array}{l}F-G A C T C C T C A G T G C C A A G A \\
R-A A G C G A T T G A G C C A T C A G\end{array}$ \\
\hline HAS2 & XM_00401166 & $\begin{array}{l}\mathrm{F} \text { - CAGACACAGAAAACCTTAG } \\
\mathrm{R} \text { - GCAGAATTAAAATAAACCCATA }\end{array}$ \\
\hline VCAN & XM_004009069 & $\begin{array}{l}\text { F - CAACCTACCTTGTCATTTC } \\
\text { R - CGTCTTGTCCAATTCAATC }\end{array}$ \\
\hline HSP90B1 & XM_004006679 & $\begin{array}{l}\mathrm{F} \text { - CACAGTTCATAAACTTTCCTA } \\
\mathrm{R} \text { - GCTTCATCATCAGATTCTTC }\end{array}$ \\
\hline FSHR & NM_001009289 & $\begin{array}{l}\mathrm{F} \text { - CAACCTGCTATACATCGA } \\
\mathrm{R} \text { - GTGCTTAATACCTGTGTTG }\end{array}$ \\
\hline$P G R$ & XM_015100878 & $\begin{array}{l}\mathrm{F} \text { - CTTCCTAGAAGGACAGTTAC } \\
\text { R - GACTCAAAGCTGTACTGTG }\end{array}$ \\
\hline GJA1 & XM_004011159 & $\begin{array}{l}\text { F - TCTTCAAGTCTGTCTTCGAGGTG } \\
\text { R - CTGATGCGGGCAGGGATC }\end{array}$ \\
\hline EREG & XM_012135539 & $\begin{array}{l}\mathrm{F} \text { - GAGCAAAGAATATGTGGC } \\
\text { R - CTGAGGTCACTCTTTCATA }\end{array}$ \\
\hline BMPR2 & NM_001306123 & $\begin{array}{l}\mathrm{F} \text { - TGCCTTATGCTTTGGATA } \\
\mathrm{R} \text { - CAGCAGTTTCAGATTATCTAG }\end{array}$ \\
\hline
\end{tabular}

\footnotetext{
${ }^{*}$ Reference gene
} 
Table 2-4: The TaqMan probe sequences for the genes investigated in this study.

\begin{tabular}{|c|c|}
\hline Gene & TaqMan Probe (5' - 3') \\
\hline RPL19 & [CY5]TTCTCATCCTCCTCATCCACGTTACCTTCTCGG[BHQ3] \\
\hline PPIA & [6FAM]TCTGTAGCCCAGGAGAGCACCC[BHQ1] \\
\hline PTTG1 & [6FAM]TGTTGACAGTTCCCAAAGCCTTTCT[BHQ1] \\
\hline HSF1 & [ROX]AGTTCCTCATCTCGCTGGTGCAGT[BHQ2] \\
\hline$Z P 3$ & [HEX]CGTCTGCTTCCTCCGTCACTTGC[BHQ1] \\
\hline PDE3A & [6FAM]CGGACATCTCGGCGGACACC[BHQ1] \\
\hline PAPOLA & [ROX]ATCCTCCATTGTGCTCCATTCTGTC[BHQ1] \\
\hline ATR & [HEX]ACAGTAGACAGTTGACCAAGACCTAACA[BHQ1] \\
\hline BMP15 & [ROX]ACCAGAACTCAAGAACCTCACTACCT[BHQ2] \\
\hline GDF9 & [HEX]CATCCTGTGTACCTGCCAAGTATAGC[BHQ1] \\
\hline HAS2 & [6FAM]AGCAGCAGCGATATGTCTCCTT[BHQ1] \\
\hline VCAN & [ROX]ACCATGCCTACCTTACCACCTAGT[BHQ2] \\
\hline HSP9OB1 & [HEX]CTTCTTCTTCGGCAGGTTCCTCAA[BHQ1] \\
\hline FSHR & [6FAM]CCTGATGCCTTCCAGAACCTTCC[BHQ1] \\
\hline$P G R$ & [ROX]TCTGAATCGGGCCATCTCCTCT[BHQ2] \\
\hline GJA1 & [HEX]CGGCACTCAAGCTGAATCCATAGATGTACCACT[BHQ1] \\
\hline EREG & [6FAM]TCTTGTTCCTTGTCATAGTTGCTGGTTC[BHQ1] \\
\hline BMPR2 & [HEX]CGCTGCTGCCTCCATCATATTCATA[BHQ1] \\
\hline
\end{tabular}

* Reference gene

Primer optimisation was conducted using the reagents and protocols from the Brilliant II SYBR $\AA$ Green QPCR Master Mix kit. The SYBR® Green I fluorescent dye binds nonspecifically to double-stranded DNA. In the denaturation step of the PCR cycle, only singlestranded DNA is present and thus, there is very little fluorescence. During the annealing/extension step, the synthesis of dsDNA allows for the binding of the dye. The fluorescence is measured at the end of the annealing/extension step in each cycle. The threshold cycle $\left(\mathrm{C}_{\mathrm{T}}\right)$ is defined as the cycle at which the intensity of the fluorescent signal is higher than background fluorescence levels. The $\mathrm{C}_{T}$ is dependent on the initial concentration of the template in the sample. To ensure that a single product is produced, a melt step was included in the protocol.

For each gene, the forward and reverse primers were titrated from $50-500 \mathrm{nM}$ and the most dilute combination that yielded the lowest $\mathrm{C}_{T}$ was chosen as the optimal primer concentration (Table 2-5). For each sample, a duplicate reaction mix of $26 \mu \mathrm{L}$ of $2 \times$ SYBR 
Green Master Mix, the appropriate forward and reverse primer concentrations and between 1.04 to $2.08 \mu \mathrm{L}$ of cDNA template was prepared and the volume was corrected

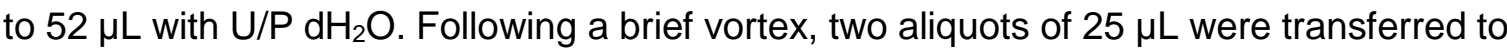
$0.1 \mu \mathrm{L}$ strip tubes. The cDNA samples were amplified in a Rotor-Gene ${ }^{\mathrm{TM}} 6000$ Rotary 56 Analyzer under the following conditions: one cycle at $95{ }^{\circ} \mathrm{C}$ for 10 minutes, 40 cycles at $95^{\circ} \mathrm{C}$ for 15 seconds and $60^{\circ} \mathrm{C}$ for 60 second. The melt step involved heating samples incrementally by $0.5^{\circ} \mathrm{C}$ for 5 seconds, from $60^{\circ} \mathrm{C}$ to $95^{\circ} \mathrm{C}$.

\subsubsection{Probe Optimisation}

This study involved a number of multiplex qPCR reactions which are listed in Table 2-6 and included two reference genes, 60S ribosomal protein L19 (RPL 19) and peptidylprolyl isomerase A (PPIA) (Crawford and McNatty, 2012; Macabelli et al., 2014). The multiplex reactions utilised TaqMan chemistry, which is characterised by specific combinations of fluorophores and quenchers that are listed in Table 2-4. When the quencher and fluorophore are in close proximity, i.e. the probe has not yet hybridised and so is intact, there is no measurable fluorescence. Release of the fluorescence is generated during the annealing-extension step in which the Taq polymerase separates the quencher from the fluorophore.

Although both RPL19 and PPIA have previously been used as references genes, neither have been validated for use in ovarian cells from sheep. For this purpose, ovine COC were collected as described in Section 2.2 and washed in $100 \mu \mathrm{L}$ of PBS before being denuded in a further $100 \mu \mathrm{L}$ of PBS. The oocytes were removed and the $\mathrm{CC}$ suspension was collected into a $0.65 \mathrm{~mL}$ tube. A $50 \mu \mathrm{L}$ aliquot of the CC suspension was removed and $5 \mu \mathrm{L}$ of Trypan blue stain added. The total number and viability (\%) of the CC was determined using a haemocytometer under an inverted microscope at $400 \times$ magnification. The samples were then serially diluted in PBS and stored at $-80{ }^{\circ} \mathrm{C}$ until RNA extraction and CDNA synthesis were performed. The relationship between $C C$ number and the expression levels of RPL19 and PPIA mRNA are depicted in Figure 2-6A and B respectively. There was a strong linear relationship between both RPL19 and PPIA mRNA expression levels and CC number. This validates both genes as appropriate reference genes. 
Table 2-5: The optimised probe, forward and reverse primer concentrations (nM) for the genes investigated in this study.

\begin{tabular}{|c|c|c|}
\hline Gene & Probe concentration (nM) & Primer concentration (nM) \\
\hline \multirow[t]{2}{*}{$R P L 19^{*}$} & 50 & $F-200$ \\
\hline & & $R-200$ \\
\hline \multirow[t]{2}{*}{$P P I A^{*}$} & 50 & $F-300$ \\
\hline & & $R-300$ \\
\hline \multirow[t]{2}{*}{ PTTG1 } & 50 & $F-300$ \\
\hline & & $R-200$ \\
\hline \multirow[t]{2}{*}{ HSF1 } & 100 & $F-300$ \\
\hline & & $R-200$ \\
\hline \multirow[t]{2}{*}{ ZP3 } & 100 & $F-500$ \\
\hline & & $R-400$ \\
\hline \multirow[t]{2}{*}{ PDE3A } & 100 & $F-100$ \\
\hline & & $R-200$ \\
\hline \multirow[t]{2}{*}{ PAPOLA } & 100 & $F-500$ \\
\hline & & $R-500$ \\
\hline \multirow[t]{2}{*}{ ATR } & 200 & $F-500$ \\
\hline & & $R-500$ \\
\hline \multirow[t]{2}{*}{ BMP15 } & 50 & $F-400$ \\
\hline & & $R-300$ \\
\hline \multirow[t]{2}{*}{ GDF9 } & 100 & $F-200$ \\
\hline & & $R-300$ \\
\hline \multirow[t]{2}{*}{ HAS2 } & 50 & $F-300$ \\
\hline & & $R-500$ \\
\hline \multirow[t]{2}{*}{ VCAN } & 100 & $F-500$ \\
\hline & & $R-500$ \\
\hline \multirow[t]{2}{*}{ HSP90B1 } & 100 & $F-300$ \\
\hline & & $R-500$ \\
\hline \multirow[t]{2}{*}{ FSHR } & 50 & $F-300$ \\
\hline & & $R-200$ \\
\hline \multirow[t]{2}{*}{$P G R$} & 50 & $F-400$ \\
\hline & & $R-500$ \\
\hline \multirow[t]{2}{*}{ GJA1 } & 50 & $F-200$ \\
\hline & & $R-50$ \\
\hline \multirow[t]{2}{*}{$E R E G$} & 100 & $F-400$ \\
\hline & & $R-200$ \\
\hline \multirow[t]{2}{*}{ BMPR2 } & 100 & $F-200$ \\
\hline & & $R-200$ \\
\hline
\end{tabular}

${ }^{*}$ Reference gene 

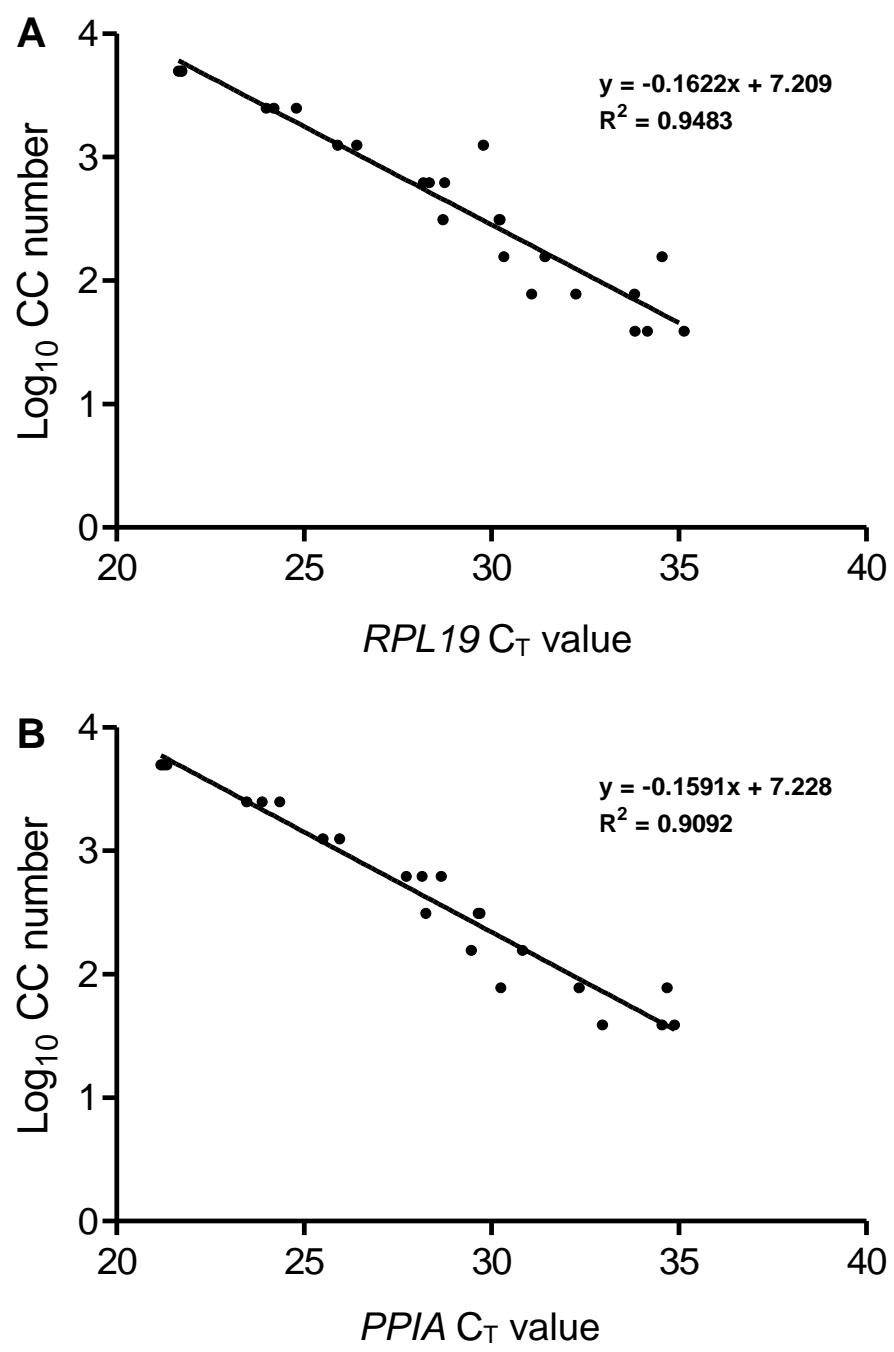

Figure 2-6: Linear regression of $\log _{10} C C$ number and $C_{T}$ for the reference genes RPL19 (A) and PPIA (B).

The optimal probe concentrations were determined by titrating the appropriate probe from $50-300 \mathrm{nM}$. The optimal probe concentration was determined to be the lowest concentration that resulted in the lowest $\mathrm{C}_{\mathrm{T}}$ without affecting endpoint fluorescence. The reagents and protocols from the Brilliant Multiplex QPCR Master Mix kit were used to determine the optimal probe concentrations and to measure the relative gene expression levels of genes in single denuded oocytes, single CC masses. For each sample, a reaction mix containing $26 \mu \mathrm{L}$ of $2 \times$ Brilliant Multiplex QPCR Master Mix, the appropriate probe concentration, the optimised forward and reverse primers concentrations, $1.04-2.08 \mu \mathrm{L}$ of cDNA template was prepared to a final volume of $52 \mu \mathrm{L}$ using U/P $\mathrm{dH}_{2} \mathrm{O}$. When assessing a large number of samples, a master mix excluding the cDNA was prepared 
and then aliquoted into $0.2 \mathrm{~mL}$ PCR tubes prior to the cDNA was added. Once the reaction mixture, including the cDNA, had been prepared and thoroughly mixed, duplicate $25 \mu \mathrm{L}$ aliquots were transferred to $0.1 \mathrm{~mL}$ strip tubes. The strip tubes were capped and run on the Rotor-Gene ${ }^{\mathrm{TM}} 6000$ Rotary 56 Analyzer under the following conditions: one cycle at $95^{\circ} \mathrm{C}$ for 10 minutes, 40 cycles at $95^{\circ} \mathrm{C}$ for 15 seconds and $60^{\circ} \mathrm{C}$ for 60 seconds.

\subsubsection{Multiplex Optimisation}

To ensure that the multiplex reactions were optimised, the reaction efficiencies for each of the multiplexes was determined (Table 2-6). In each case, a serial dilution (1:1 to $1: 128$ ) of 20 ovine COC cDNA in U/P dH $\mathrm{H}_{2} \mathrm{O}$ were prepared. Because each dilution resulted in the halving of the cDNA template, theoretically, each of the reactions containing successive dilutions should differ by one $\mathrm{C}_{\mathrm{T}}$. This allows for the reaction efficiency to be determined and an assessment of the goodness of fit $\left(R^{2}\right)$ of the data.

\subsection{Multiplex TaqMan qPCR}

The following protocols were used to assess the relative expression levels of genes of interest in experimental samples. A master mix containing $26 \mu \mathrm{L}$ of $2 \times$ Multiplex QPCR master mix, the optimised probe, forward and reverse primer concentrations for each gene, $1.04-2.08 \mu \mathrm{L}$ of undiluted template cDNA that was prepared to a final volume of $52 \mu \mathrm{L}$ with $\mathrm{U} / \mathrm{P} \mathrm{dH}_{2} \mathrm{O}$. Duplicate $25 \mu \mathrm{L}$ aliquots were added to $0.1 \mathrm{~mL}$ strip tubes for each of the samples. Due to the number of samples that were assessed in this study, multiple reaction runs were performed and a calibrator sample was included the beginning and end of each run. Two genes (RPL19 and PPIA) were chosen as reference genes. The gene RPL19 was included in each multiplex set for normalisation purposes. The gene $P P I A$ was included in only one multiplex set as validation for the normalisation reference gene (RPL19). The samples were also corrected to the $\mathrm{C}_{\mathrm{T}}$ value (for each gene) of the calibrator sample. Thus, the $2^{-\Delta \Delta C T}$ method was used to determine the relative expression levels of the candidate genes (Livak and Schmittgen, 2001).

Gene expression in single oocytes were corrected only to the calibrator sample and thus the $2^{-\Delta C T}$ method was used to determine the total relative expression level of the candidate genes per oocyte (Livak and Schmittgen, 2001). The expression levels of RPL19 and PPIA were also measured and compared in these samples to ensure that the total RNA extraction and cDNA synthesis steps had been successful. 
Table 2-6: PCR efficiency for each gene assessed in this study.

\begin{tabular}{|c|c|c|}
\hline & Gene & $\begin{array}{c}\text { Efficiency } \\
(\%)\end{array}$ \\
\hline \multicolumn{3}{|l|}{ Oocyte: } \\
\hline \multirow[t]{4}{*}{ Multiplex 1} & PTTG1 & 95 \\
\hline & HSF1 & 96 \\
\hline & $Z P 3$ & 90 \\
\hline & $R P L 19$ & 100 \\
\hline \multirow[t]{4}{*}{ Multiplex 2} & PDE3A & 95 \\
\hline & PAPOLA & 100 \\
\hline & $A T R$ & 96 \\
\hline & RPL19 & 93 \\
\hline \multirow[t]{4}{*}{ Multiplex 3} & PPIA & 86 \\
\hline & BMP15 & 85 \\
\hline & GDF9 & 85 \\
\hline & RPL 19 & 92 \\
\hline \multicolumn{3}{|l|}{ CC: } \\
\hline \multirow{4}{*}{ Multiplex 1} & HAS2 & 103 \\
\hline & VCAN & 99 \\
\hline & HSP90B1 & 99 \\
\hline & RPL19 & 100 \\
\hline \multirow[t]{4}{*}{ Multiplex 2} & FSHR & 93 \\
\hline & $P G R$ & 92 \\
\hline & GJA1 & 99 \\
\hline & RPL19 & 94 \\
\hline \multirow[t]{3}{*}{ Multiplex 3} & $E R E G$ & 81 \\
\hline & BMPR2 & 85 \\
\hline & $R P L 19$ & 83 \\
\hline \multirow{2}{*}{ Multiplex 4} & PPIA & 88 \\
\hline & RPL19 & 87 \\
\hline
\end{tabular}




\section{CHAPTER 3. THE MICROENVIRONMENT OF FOLLICLES UNDERGOING IN VIVO MATURATION IN ++ AND I+B+ EWES}

\subsection{Introduction}

Full developmental competency of the oocyte is defined as the ability to develop into a viable embryo following fertilisation. It is acquired gradually during follicular growth and completed by the preovulatory LH surge. The processes involved in the final maturation of mammalian oocytes are not fully understood. As such, in vitro maturation systems are currently unable to replicate the efficacy of in vivo maturation as evidenced by the associated success rates of these in vitro ART.

In high OR species, for example pigs, up to twenty developmentally-competent oocytes can be produced each reproductive cycle. In comparison, low OR species (such as cows, sheep and humans) will produce one or two developmentally-competent oocytes per reproductive cycle. Consequently, studying the events that occur during these final maturational stages is a considerable logistical issue in low OR species due simply, to low numbers of fully-matured oocytes. Superovulation procedures increase the number of follicles that grow to a large size by providing lengthy administration of gonadotropins whilst removing negative feedback from the developing follicles. However, this does not overcome the developmental hierarchy of follicles within an ovary and may be an important reason for the inefficiency of these technologies (McNatty et al., 2010). Thus, studying the precise events that occur during final maturation of oocytes following hormonal stimulation procedures poses the risk of including matured, but substandard oocytes that would not be ovulated in an unstimulated cycle. Therefore, better models are required to study the final maturational events in low OR species.

Naturally-occurring high OR sheep genotypes provide a unique model in which final maturational events can be studied. In particular, ewes carrying a single copy of a mutation in BMP15 $(\mathrm{I}+)$ and in BMPRIB $(\mathrm{B}+$; collectively $\mathrm{I}+\mathrm{B}+)$ are known to have an increased $\mathrm{OR}$ compared to wild-type (++) ewes (Davis et al., 1999). While the effects of these genes on OR, preovulatory follicle diameter, total GC number and gene expression in whole follicles have been reported previously, the molecular and biochemical characteristics of follicles relating to the attainment of oocyte developmental competence in these ewes, or in sheep in general, has not been thoroughly investigated (Davis et al., 1999; McNatty et al., 2016; Juengel et al., 2017). 
The overall aim of this study was to investigate the key maturational events in a typically low OR species, Ovis aries. These experiments investigated the microenvironment in growing and presumptive preovulatory follicles in sheep with low (++) and high ( $(+\mathrm{B}+) \mathrm{OR}$, thus taking advantage of ewes in which a higher number of in vivo matured oocytes are produced each reproductive cycle. The rationale for comparing these genotypes was that similarities in follicular maturation events and pathways between the two genotypes would identify key maturational processes or events that are likely involved in the attainment of oocyte developmental competency in a range of mammalian species. Conversely differences would provide further insight into the mechanisms by which OR is increased in $\mathrm{I}+\mathrm{B}+$ ewes without compromising the developmental competency of the oocyte.

The specific aims of this study were to compare: (i) OR; (ii) follicular morphology, including size and GC number; (iii) intra-follicular biochemical microenvironment, including amino acid, steroid hormone and metabolite concentrations; (iv) GC responsiveness to gonadotropins and (iv) key CC-derived and oocyte-derived molecular markers of developmental competency in growing and presumptive pre-ovulatory (PPOV) follicles in $\mathrm{I}+\mathrm{B}+$ and ++ ewes.

\subsection{Methodology}

For information on the reagents and equipment used in this study, including the suppliers and relevant product codes, refer to Appendix 2. Likewise, for information on the recipes for all stock solutions and media refer to Appendix 3.

\subsubsection{Ovarian tissue collection}

The experiments described herein were performed with the approval of the AgResearch Invermay Animal Ethics Committee in accordance with the Animal Welfare Act of New Zealand. A total of 20 ewes were included in this study ( $N=11++$ ewes and $9 \mathrm{I}+\mathrm{B}+$ ewes). Oestrous cycles were synchronised as described in Section 2.1 and illustrated in Figure 2-1. A blood sample was collected at the time of euthanasia by jugular venepuncture and ovarian tissue was collected as described in Section 2.2. In contrast to previous studies, the ovaries were collected at a later time point (52 hours after PGF2 $\alpha$ administration and 28 hours after CIDR removal). This was done to ensure that tissues were collected after the preovulatory LH surge but prior to ovulation, allowing for the collection of expanded COC. Once recovered, the ovaries were trimmed of extraneous tissue, weighed and the 
number of corpora albicans were recorded as a measurement of the number of ovulations in the previous cycle. Individual follicles $\geq 1 \mathrm{~mm}$ in diameter were individually dissected out and each was transferred to a clean, dry $35 \mathrm{~mm}$ petri dish. From these experiments, data were collected from a total of 668 individual follicles. Criteria for inclusion of a sample in each experiment is described briefly at the beginning of each section. Further information on the number of samples collected for each analysis is included in Appendix 1.

Prior to follicular puncture, the diameter of the follicle was measured using a calibrated scale and the degree of vascularisation was noted. The follicular wall was punctured using a 20-gauge needle. Any follicular fluid present was visualised for debris and then collected into $100 \mu \mathrm{L}$ of PBS and stored at $-20^{\circ} \mathrm{C}$. The COC was transferred into a 6-well plate containing dissection media. The follicular wall was also transferred into a new petri dish containing a known volume ( $1 \mathrm{~mL}$ or $2 \mathrm{~mL}$ depending on follicular size) of dissection media and the GC were scraped from the follicle into the media using a nichrome loop. The total number of $\mathrm{GC}$ in each follicle were counted using a haemocytometer and the cells were pelleted by centrifugation at $300 \mathrm{~g}$ for 10 minutes. The GC pellet was gently re-suspended in $1 \mathrm{~mL}$ dissection media and re-counted in preparation for a gonadotropin-responsiveness assay. Where a sufficient number of GC were recovered to enable at least one replicate of each treatment and control, 60,000 GC were added to each well of a 48-well plate. The plated GC were incubated in triplicate (where possible) in a $600 \mu \mathrm{L}$ final volume with or without purified ovine FSH $(100 \mathrm{ng} / \mathrm{mL})$ or $\mathrm{hCG}(1000 \mathrm{ng} / \mathrm{mL})$ for 45 minutes in a $37^{\circ} \mathrm{C}$ waterbath. The samples were then placed in an $80^{\circ} \mathrm{C}$ waterbath for 15 minutes and cooled on ice before the contents of each well was transferred to $1.5 \mathrm{~mL}$ tubes and stored at $-20{ }^{\circ} \mathrm{C}$ until further processing.

Simultaneously, the morphology of the COC (i.e. compact or expanded) from each follicle was recorded before being transferred into a well of a 96-well plate. The COC was transferred through two wash wells containing $100 \mu \mathrm{L}$ of PBS and then into a third well containing $10 \mu \mathrm{L}$ of PBS where the CC were dissociated from the oocyte by repeated pipetting. The denuded oocyte was transferred into a final wash well containing $100 \mu \mathrm{L}$ of PBS. The CC and the denuded oocyte were then transferred into separate microcentrifuge tubes and stored at $-80{ }^{\circ} \mathrm{C}$ until further processing.

During the dissection process, the health of the follicles was assessed based on a number of parameters. A healthy follicle was defined as that which had visible blood capillaries in the theca interna, exhibited no debris in the follicular fluid, encompassed a healthy-looking 
oocyte (symmetrical with a robust zona pellucida) surrounded by either expanded or compact CC that displayed no evidence of apoptosis and, contained a number of GC that was $\geq 25 \%$ of the maximum number of GC for a given follicle size, regardless of genotype. Atretic follicles were defined as follicles that failed one or more of the aforementioned criteria. In this study, the maximum number of GC recorded in 1, 2, 3, 4, 5, 6, 7 and $8 \mathrm{~mm}$ diameter follicles was $1.46 \times 10^{6}, 2.3 \times 10^{6}, 2.4 \times 10^{6}, 1.7 \times 10^{6}, 7.7 \times 10^{6}, 5.3 \times 10^{6}$, $10.5 \times 10^{6}$ and $7.9 \times 10^{6}$, in ++ ewes. In $\mathrm{I}+\mathrm{B}+$ ewes, the maximum number of $\mathrm{GC}$ recorded in $1,2,3,4$ and $5 \mathrm{~mm}$ diameter follicles was $1.0 \times 10^{6}, 1.3 \times 10^{6}, 1.8 \times 10^{6}, 1.6 \times 10^{6}$ and $1.6 \times 10^{6}$, respectively. The validity of the aforementioned criteria for assessing of ovine follicles in,$++ \mathrm{B}+$ and BB ewes has been established previously and was also applied to the I+B+ ewes in the current study (McNatty et al., 1986). Gonadotropin-responsiveness, follicular fluid constituent and gene expression data were only measured in healthy follicles from which a COC and sufficient numbers (at least $1.2 \times 10^{5}$ ) of GC were retrieved.

\subsubsection{Gonadotropin-responsiveness assays}

The responsiveness of GC to gonadotropin stimulation was assessed by measuring CAMP production using a radioimmunoassay protocol described in Section 2.4. Follicles were termed FSH- or LH-responsive if standardised cAMP production was $\geq 5 \mathrm{pmol} / 10^{6} \mathrm{GC}$ following treatment with either $100 \mathrm{ng} / \mathrm{mL}$ of $\mathrm{FSH}$ or $1000 \mathrm{ng} / \mathrm{mL}$ of hCG, respectively. Likewise, non-responsive follicles were those that produced $<5 \mathrm{pmol} / 10^{6} \mathrm{GC}$ after gonadotropin treatment. The threshold of $\geq 5 \mathrm{pmol} / 10^{6} \mathrm{GC}$ was also employed in previous studies which have included,$++ \mathrm{I}+$ and $\mathrm{I}+\mathrm{B}+$ animals and was determined to be a high response to the doses of FSH and hCG that were used (McNatty et al., 2009, 2016). Even though the ovaries were recovered at a later stage than the previous studies, these thresholds were determined to be appropriate. With the exception of three individual follicles, all follicles containing an expanded follicle had GC which produced $\geq 5 \mathrm{pmol} / 10^{6}$ cAMP. Data from this sheep was excluded from the gonadotropin responsiveness studies.

\subsubsection{Measurement of follicular fluid and plasma constituents}

The measurements of glucose, cholesterol, triglycerides, amino acids, steroids, and creatinine in plasma and/or follicular fluid samples were performed by Mr Eric Thorstensen at the Liggins Institute, University of Auckland as described in Section 2.5. Due to the small number of non- LH-responsive follicles that contained an appreciable volume of follicular fluid, results from these were combined (i.e. follicles that were non-responsive to both $\mathrm{LH}$ 
and $\mathrm{FSH}$ and follicles that were responsive to $\mathrm{FSH}$, but not $\mathrm{LH}$ ) for further analyses and termed growing follicles. Likewise, LH-responsive follicles containing expanded COC were known as presumptive preovulatory follicles, i.e. PPOV. All samples from PPOV were included in these analyses. Where possible, the next largest growing follicle and a follicle representing the median diameter of the growing follicles from each ewe were also included.

The amino acids measured in this study were the L-forms of alanine, arginine, asparagine, aspartic acid, citrulline, glutamic acid, glutamine, glycine, histidine, hydroxyproline, isoleucine, leucine, lysine, methionine, ornithine, phenylalanine, proline, serine, taurine, threonine, tyrosine and valine. Likewise, the steroid hormones included in this study were cortisone, cortisol, corticosterone, 11-deoxycortisol and testosterone, 17 $\beta$-oestradiol (oestradiol) and progesterone. The concentrations of glucose and cholesterol were also measured in the follicular fluid and plasma samples while creatinine and triglycerides were measured in the plasma only.

\subsubsection{Gene expression measurement in $\mathrm{CC}$ and denuded oocytes}

The methodologies performed to extract total RNA, synthesise cDNA and measure gene expression by qPCR in single CC masses and single oocytes is described in Section 2.7. Gene expression was only investigated in samples whereby both the CC mass and its associated denuded oocyte were successfully collected. The only exception were nine samples whereby the oocyte ruptured during denudation but was assumed to be from a healthy PPOV follicle as the CC were expanded. Due to the limited number of samples from PPOV follicles, if the oocyte ruptured or appeared to be close to rupturing, the oocyte was immediately removed from majority of $\mathrm{CC}$ mass and placed in another well containing PBS. Once the oocyte ruptured, as much of the associated contents as possible were removed from the remaining $\mathrm{CC}$ and the $\mathrm{CC}$ samples were transferred into a separate well containing PBS prior to being transferred into $0.65 \mathrm{~mL}$ microcentrifuge tubes for storage at $-80^{\circ} \mathrm{C}$.

\subsubsection{Statistical analyses}

To test for differences in OR, numbers of follicles with gonadotropin-responsive GC, GC number, and plasma concentrations of specific amino acids, glucose, cholesterol, creatinine, triglyceride and steroid hormones between the ++ and $\mathrm{I}+\mathrm{B}+$ ewes, a t-test was 
employed and Welch's correction was applied where there was an unequal sample size or variance.

Where data were not normally distributed and one main effect was to be investigated (for example, genotype) Mann-Whitney $U$ tests were used. When the effect of both genotype and follicular stage (i.e. growing or PPOV) were to be investigated, a generalised linear mixed model (GLMM) was used. Once an appropriate distribution was identified, the model was fitted including main effects of genotype and follicular stage, as well as a random effect of sheep. Due to the small and unbalanced nature of the samples in this study, the post-estimation settings were altered. Namely, the varied degrees of freedom (Satterthwaite Approximation) option was selected as the method for determining the degrees of freedom for significance tests. Where the assumptions of the model were violated, the robust estimates option was selected for the method for testing fixed effects and coefficients. The results of the main effects and any interactions are reported in the appropriate sections of this chapter but further information regarding the GLMMs is included in Appendix 4. The proportion of variation that could be attributed to sheep-to-sheep variation for each model was also calculated using the following formula and reported in the appropriate sections of this chapter:

$\%$ variation due to sheep-to-sheep differences $=$ (sheep-to-sheep variation $\div($ sheep-to-sheep variation + residual variaion $)) \times 100$

Differences in CC-derived gene expression could not be assessed using GLMMs as appropriate distributions for the data could not be identified. Therefore, CC-derived gene expression data were analysed using Mann-Whitney $U$ tests. For these data, genotype differences were investigated first. If no genotype difference was detected, data was combined and differences between follicular stage (growing and PPOV) were assessed using the combined data. Where significant genotype differences were identified, differences between follicular stages were investigated separately for each genotype. Additionally, genotypic differences within the growing and PPOV follicles were also investigated.

The figures in this chapter were created using GraphPad Prism (v5.0) whilst all statistical analyses were undertaken using SPSS Statistics (v23). Throughout this thesis, normally distributed data were presented as mean \pm SEM. To present the central tendency of nonnormally distributed data informatively, geometric mean and $95 \%$ confidence limits were used (Manikandan, 2011). The alpha level for these analyses was 0.05 . 


\subsection{Results}

A summary of the of the data (samples) collected from each animal in this study is included in Appendix 1.

\subsubsection{OR and follicular characteristics in ++ and $\mathrm{I}+\mathrm{B}+$ ewes}

The OR and morphological characteristics of follicles that were differentially responsive to gonadotropins were investigated in ++ and $\mathrm{I}+\mathrm{B}+$ ewes. Two ++ ewes did not exhibit a follicle containing a morphologically expanded COC (i.e. a PPOV) and therefore were excluded from the OR analysis. The mean \pm SEM OR was $1.7 \pm 0.2$ and $4.4 \pm 0.7$ in ++ (low OR) and $\mathrm{I}+\mathrm{B}+$ (high OR) ewes, respectively. A t-test with Welch's correction indicated that mean $\mathrm{OR}$ in $\mathrm{I}+\mathrm{B}+$ ewes was significantly higher $(\mathrm{P}=0.0059, \mathrm{~N}=9$ in each group) than in ++ ewes.

The diameter of, and total number of GC in, follicles differed between genotypes in each of the categories. Namely, in follicles that were unresponsive to either FSH or LH (nonresponsive), responsive to $\mathrm{FSH}$ but not $\mathrm{LH}$ (FSH-responsive) or responsive to $\mathrm{LH}$ (LHresponsive) were larger in diameter $(P<0.0005, P<0.0005$ and $P=0.001$, respectively) and contained more $\mathrm{GC}(\mathrm{P}<0.0005, \mathrm{P}<0.0005$ and $\mathrm{P}<0.0005$, respectively $)$ in ++ , compared to $\mathrm{I}+\mathrm{B}+$, ewes (Figure 3-1).

\subsubsection{Gonadotropin-responsive $\mathrm{GC}$ in ++ and $\mathrm{I}+\mathrm{B}+$ ewes.}

The ability of GC of follicles from ++ and I+B+ ewes to respond to FSH or hCG was investigated and follicles were classified as either non-responsive, FSH-responsive or LHresponsive as described in Section 3.2.2. The concentration of cAMP synthesised by GC of individual follicles incubated with media alone (control), FSH or hCG was measured and the results are presented as both cAMP amount produced per $10^{6} \mathrm{GC}$ and per follicle, as depicted in Figure 3-2. 

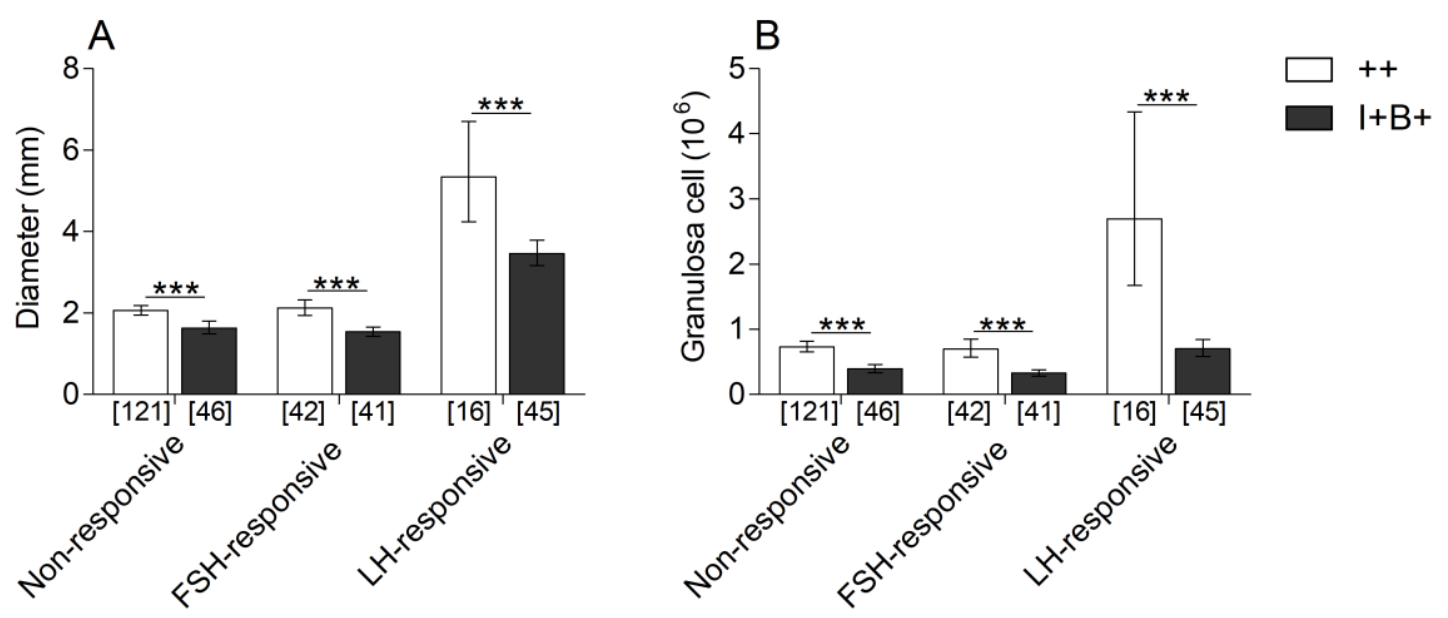

Gonadotropin Responsiveness

Figure 3-1: Diameter (A) and number of GC (B) in non-responsive, FSH responsive and LH-responsive follicles in ++ (white bars) and I+B+ (grey bars) ewes. The values represent the geometric mean and $95 \%$ confidence limit. Genotypic differences were analysed using Mann-Whitney $U$ tests. The number of observations for each group are included in [ ] below the appropriate group at the bottom of the figure. Statistically significant differences are denoted by asterisk $\left({ }^{*} P<0.05\right.$, $\left.{ }^{* *} P<0.01,{ }^{* *} P<0.001\right)$.

Overall, the basal rate of cAMP production standardised to per $10^{6} \mathrm{GC}$ of non-responsive follicles was higher $(\mathrm{P}=0.042)$ in $\mathrm{I}+\mathrm{B}+$, compared to ++ , ewes (Figure $3-2 \mathrm{~A}$ and $\mathrm{C}$, respectively). Moreover, FSH-stimulated cAMP production rate was higher $(\mathrm{P}=0.005)$ per $10^{6} \mathrm{GC}$ of FSH-responsive follicles of $\mathrm{I}+\mathrm{B}+$, compared to ++ , ewes (Figure 3-2B). In contrast, hCG-stimulated cAMP production rate per $10^{6} \mathrm{GC}$ of FSH- and $\mathrm{LH}$-responsive follicles were similar between $\mathrm{I}+\mathrm{B}+$ and ++ ewes. With the exception of the hCG-treated GC from non-responsive follicles, cAMP production per follicle was higher $(P<0.0005)$ in follicles of ++ , compared to $\mathrm{I}+\mathrm{B}+$, ewes regardless of stage or treatment (Figure 3-2D-F). This conspicuous observation is due to the larger numbers of GC in the follicles of ++ ewes as depicted in Figure 3-1. 

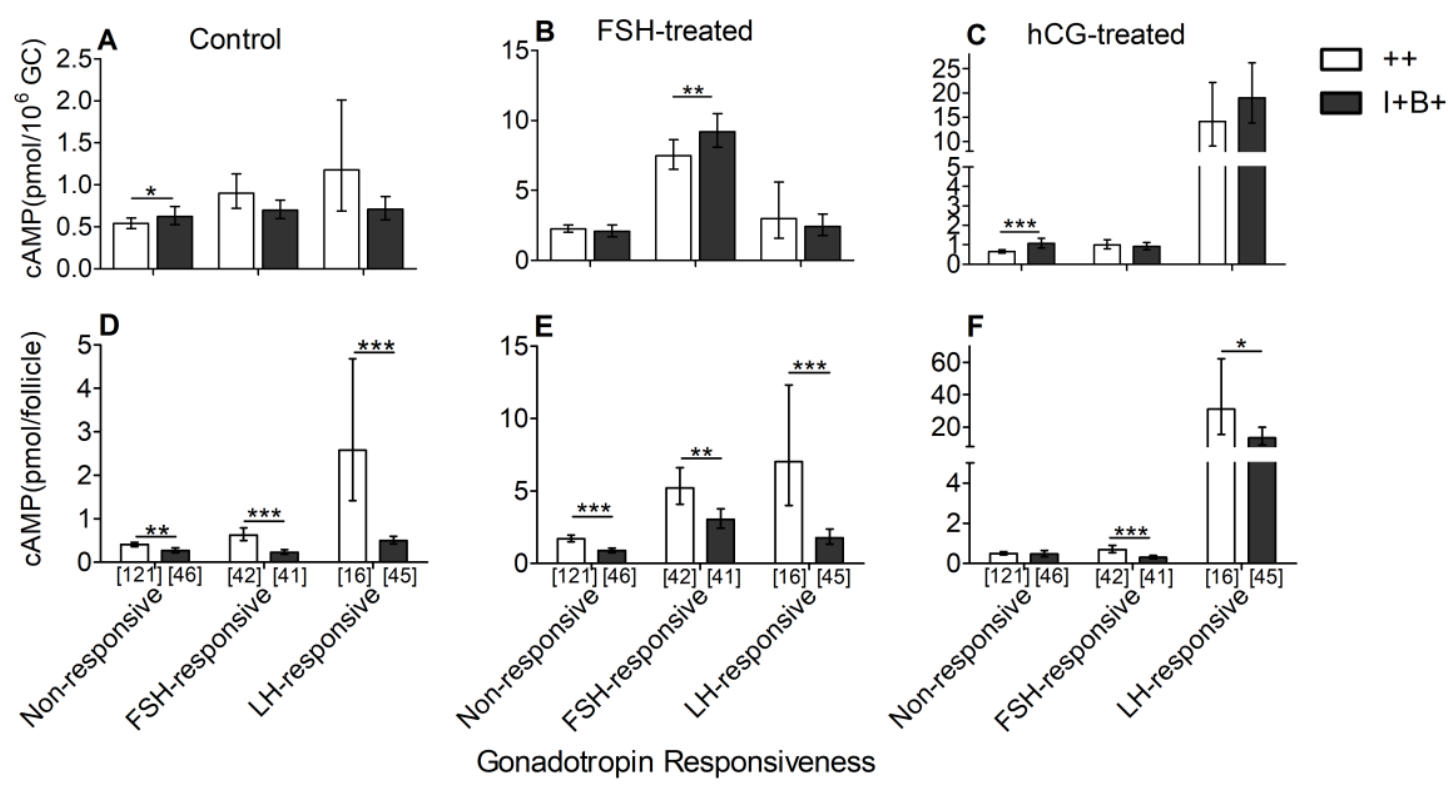

Figure 3-2: cAMP production of GC from non-responsive, FSH-responsive and LHresponsive follicles from ++ (white bars) and I+B+ (grey bars) ewes in the absence and presence of gonadotropins. Data is represented as standardised cAMP production (pmol/106 GC; A - C) and as cAMP production per follicle (pmol/follicle; D - F) following incubation with media alone (control; $A \& D), F S H(B \& E)$, or hCG (C \& F). Values represent geometric mean and $95 \%$ confidence limit. The number of observations for each group are included in [ ] below the appropriate group at the bottom of the figure. Differences between genotypes were analysed using Mann-Whitney $U$ tests and statistically significant differences are denoted by asterisk $\left({ }^{*} \mathrm{P}<0.05,{ }^{* *} \mathrm{P}<0.01,{ }^{* \star *} \mathrm{P}<0.001\right)$.

To gain further insight into the effect of differential gonadotropin-responsiveness in low and high OR the ewes, the total number of FSH- and LH-responsive GC per sheep were compared between genotypes (Figure 3-3). Whilst there was no genotype difference in the number of FSH-responsive GC, there was a tendency for more $(P=0.0599) \mathrm{LH}$-responsive $\mathrm{GC}$ in ++, compared to $\mathrm{I}+\mathrm{B}+$, ewes. 

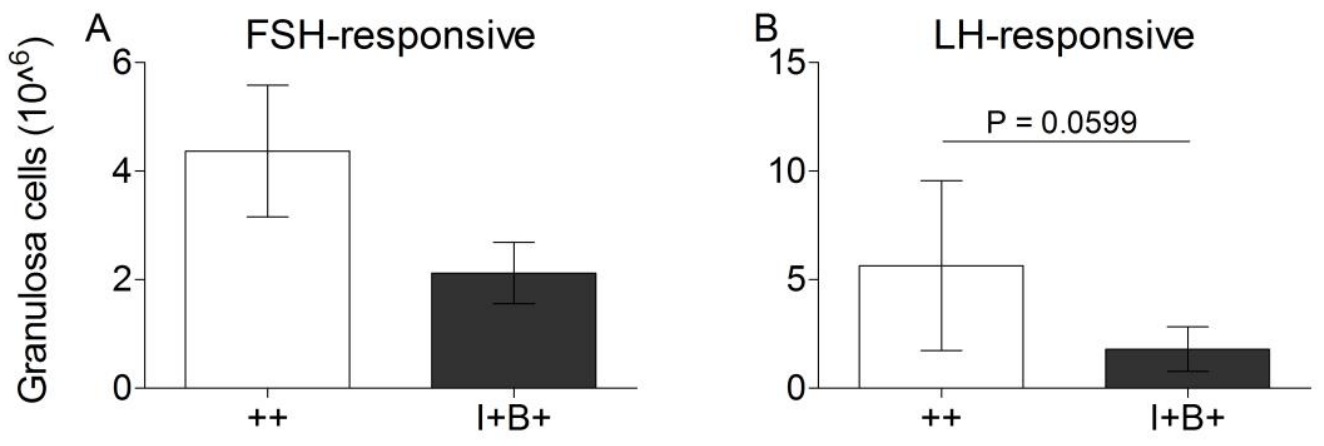

Genotype

Figure 3-3: Total number of FSH-responsive and LH-responsive GC per sheep in ++ (white bars) and I+B+ (grey bars) ewes. Data represents the mean (and $95 \%$ confidence limit) number of GC that are: A) responsive to $\mathrm{FSH}$, i.e. total number of $\mathrm{GC}$ from $\mathrm{FSH}$ responsive follicles, B) responsive to $\mathrm{LH}$, i.e. total number of $\mathrm{GC}$ from $\mathrm{LH}$ responsive follicles in ++ and $\mathrm{I}+\mathrm{B}+$ ewes. Data is from $18(\mathrm{~N}=9++$ and $\mathrm{N}=9 \mathrm{I}+\mathrm{B}+)$ ewes. T-tests with Welch's correction were performed and where there was a trend towards significance, the P-value has been reported on the appropriate graph.

\subsubsection{Constituent concentrations in plasma of ++ and $I+B+$ ewes}

Plasma concentrations of amino acids, glucose, cholesterol, creatinine, triglycerides and steroids were measured so that comparisons could be made to corresponding concentrations in growing and PPOV follicles. A large variation between plasma and follicular fluid concentrations may indirectly indicate the metabolic status of the follicular cells and, in particular, the metabolic demands of the oocyte.

\subsubsection{Plasma amino acid concentrations of ++ and $\mathrm{I}+\mathrm{B}+$ ewes}

The concentrations of the L-forms of alanine, arginine, asparagine, aspartic acid, citrulline, glutamic acid, glutamine, glycine, histidine, hydroxyproline, isoleucine, leucine, lysine, methionine, ornithine, phenylalanine, proline, serine, taurine, threonine, tyrosine and valine were measured in plasma samples from nine ++ and nine $\mathrm{I}+\mathrm{B}+$ ewes. Only ewes which exhibited a morphologically expanded COC (i.e. a PPOV) were included in these analyses. The results from these measurements are depicted in Figure 3-4. 

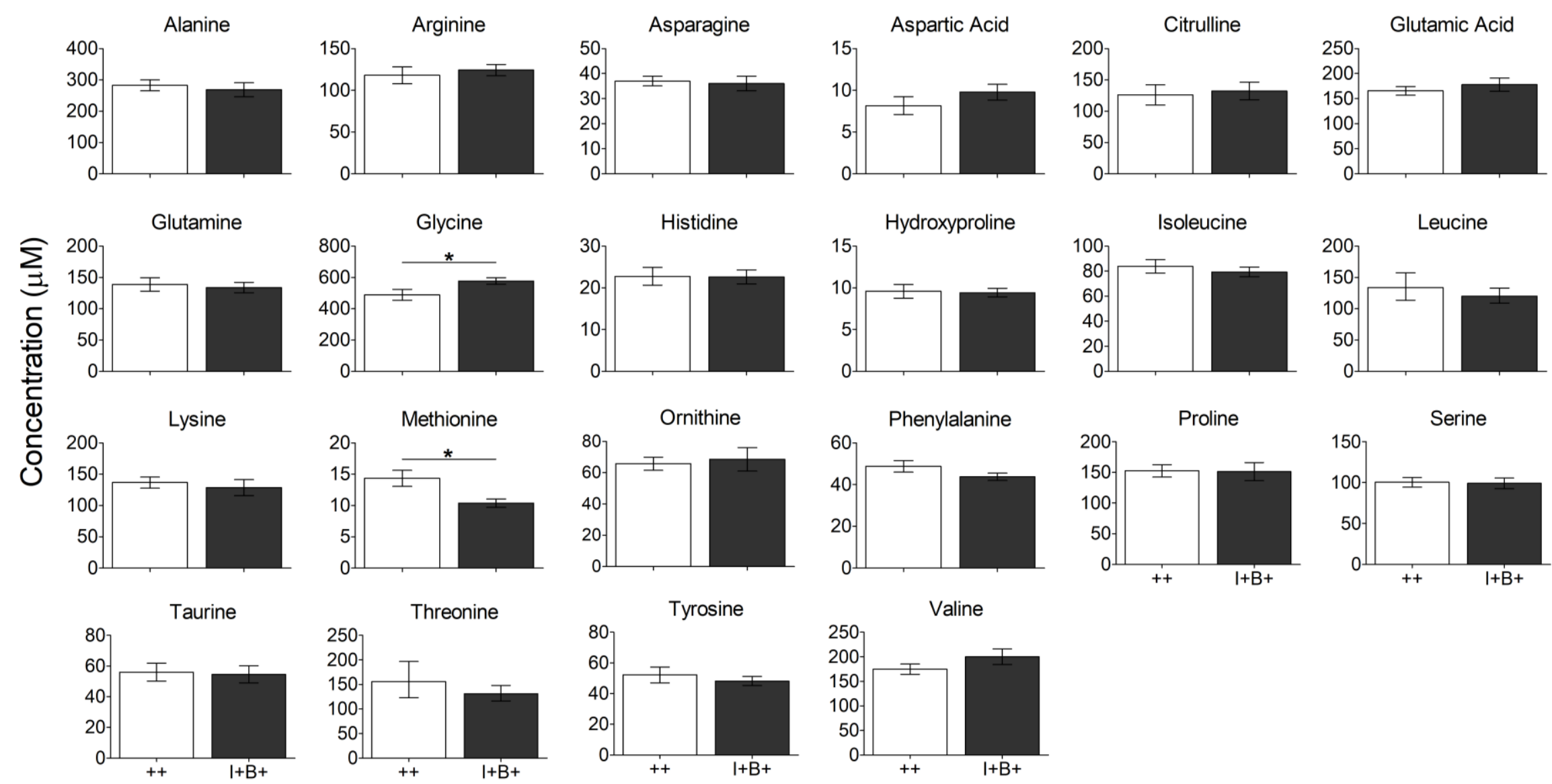

Genotype

Figure 3-4: Concentrations of L-forms of amino acids in plasma samples from ++ (white bars) and I+B+ (grey bars) ewes. Data represents samples from $18(\mathrm{~N}=9++$ and $\mathrm{N}=9 \mathrm{I}+\mathrm{B}+)$ ewes and are presented as mean \pm SEM or geometric mean (95\% confidence limits) where data were non-normally distributed (leucine and threonine). Non-normal data was natural log-transformed and all data were analysed using t-tests. Significant differences are denoted by asterisk ( $\left.{ }^{*} P<0.05\right)$. 
There were no differences between ++ and $\mathrm{I}+\mathrm{B}+$ ewes in the concentrations of alanine, arginine, asparagine, aspartic acid, citrulline, glutamic acid, glutamine, histidine, hydroxyproline, isoleucine, leucine, lysine, ornithine, phenylalanine, proline, serine, taurine, threonine, tyrosine or valine. In contrast, genotypic differences were observed in plasma concentrations of glycine and methionine with concentrations being increased $(P=0.047)$ and decreased $(P=0.014)$, respectively in $\mathrm{I}+\mathrm{B}+$ ewes.

\subsection{Plasma energy substrate levels of ++ and $\mathrm{I}+\mathrm{B}+$ ewes}

Plasma concentrations of glucose, cholesterol, creatinine and triglycerides were not different between ++ and $\mathrm{I}+\mathrm{B}+$ ewes (Figure 3-5).

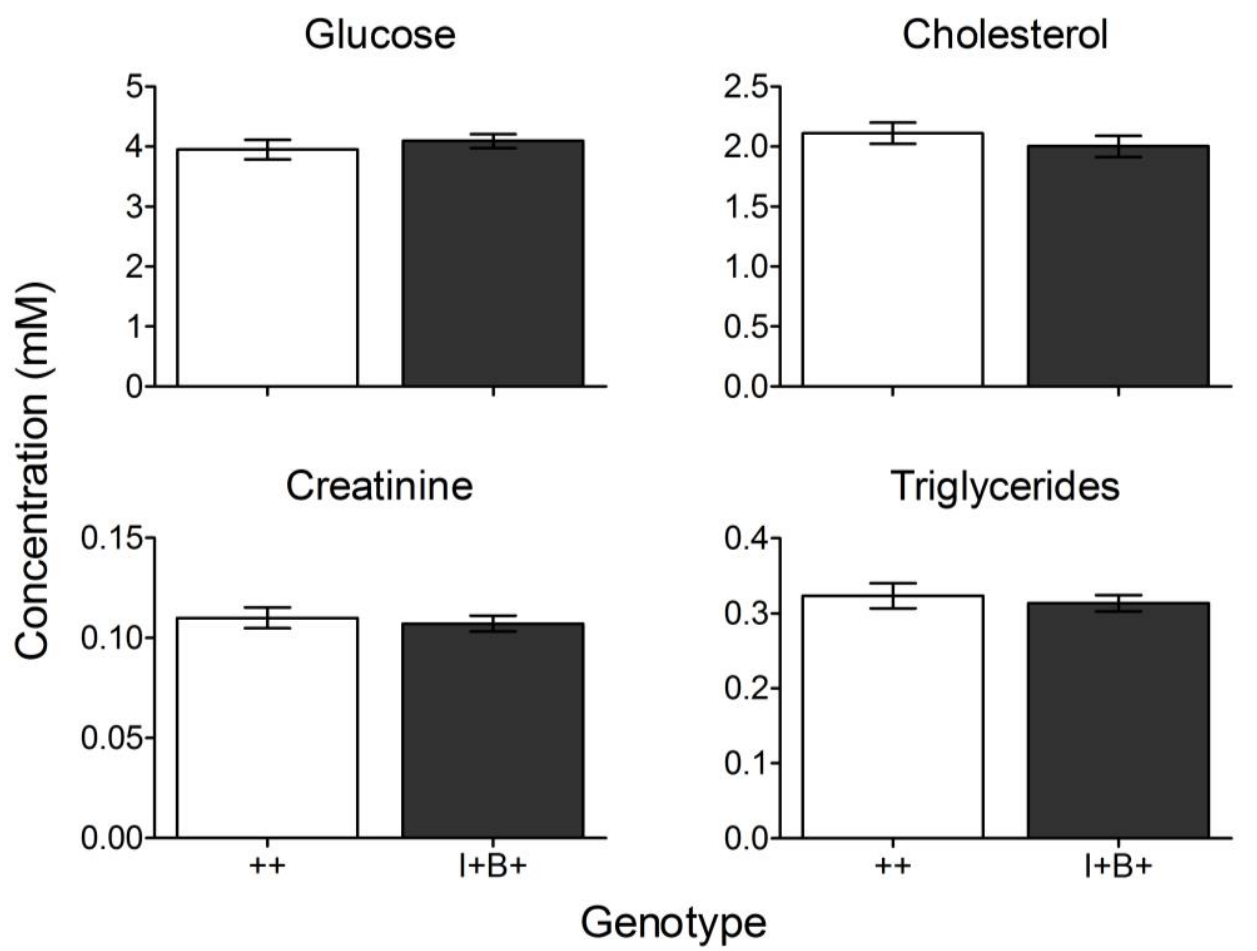

Figure 3-5: Plasma concentrations of glucose, cholesterol, creatinine and triglycerides in ++ (white bars) and I+B+ (grey bars) ewes. Data represents samples from $18(\mathrm{~N}=9++; \mathrm{N}=9 \mathrm{I}+\mathrm{B}+)$ ewes and are presented as mean \pm SEM. All data were analysed using t-tests.

\subsection{Plasma steroid concentrations of ++ and $\mathrm{I}+\mathrm{B}+$ ewes}

Plasma concentrations of cortisone, cortisol, corticosterone, 11-deoxycortisol, androstenedione, testosterone, $17 \beta$-oestradiol, and progesterone were analysed in ++ and $\mathrm{I}+\mathrm{B}+$ ewes. Testosterone and progesterone concentrations were below the assay 
detection limit (10 and $50 \mathrm{pg} / \mathrm{mL}$, respectively). Concentrations of 11-deoxycortisol and androstenedione were only detected in plasma of one ewe.

Plasma concentrations of cortisone, cortisol, corticosterone and 17 $\beta$-oestradiol are depicted in Figure 3-6. There were no genotype differences in cortisone, corticosterone or $17 \beta$-oestradiol concentrations. However, there was a tendency $(P=0.072)$ for plasma cortisol concentrations to be higher in ++ , compared to $\mathrm{I}+\mathrm{B}+$, ewes.

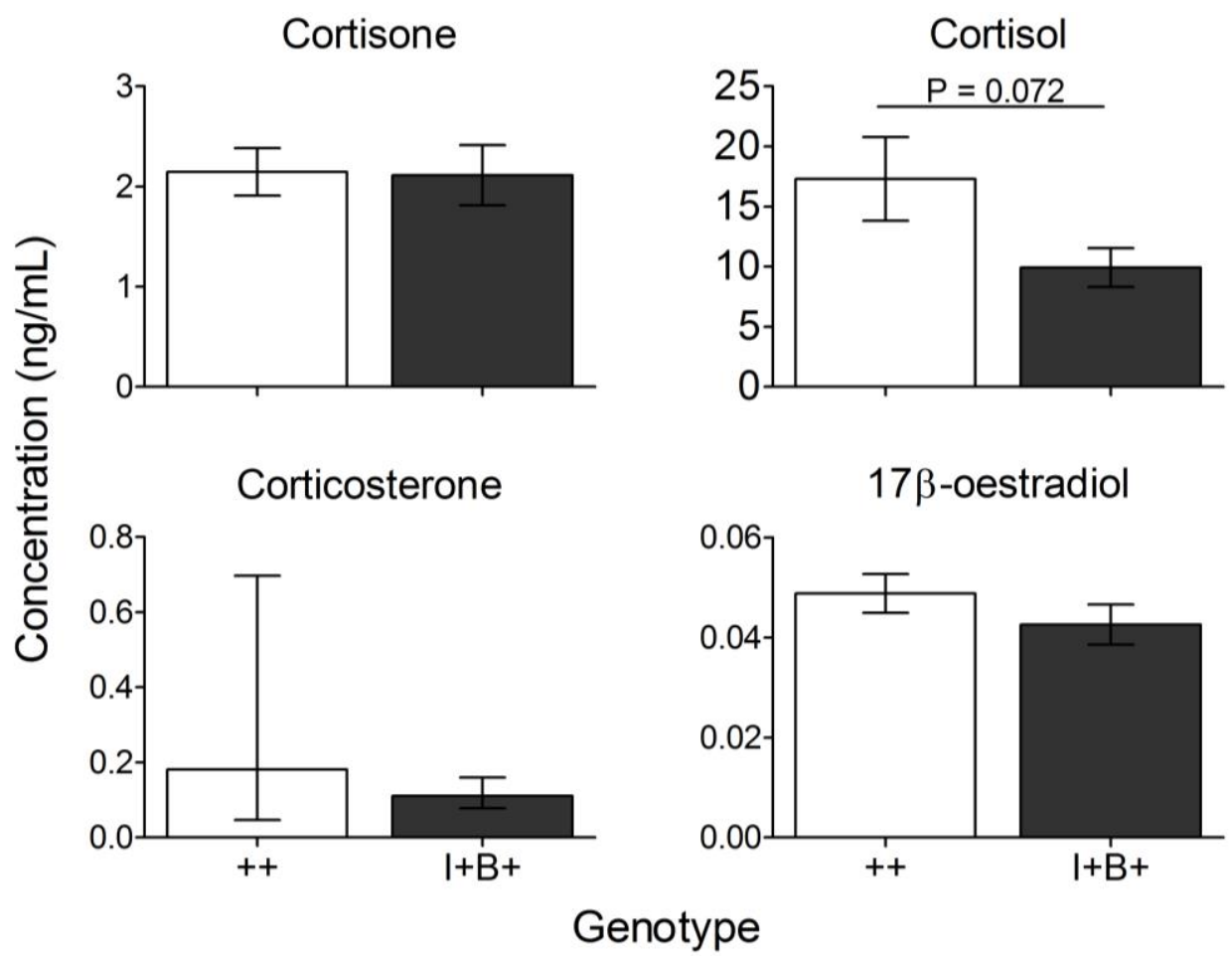

Figure 3-6: Plasma concentrations of cortisone, cortisol, corticosterone and $17 \beta$-oestradiol in ++ (white bars) and I+B+ (grey bars) ewes. Data represents samples from $18(\mathrm{~N}=9++, \mathrm{N}=9 \mathrm{I}+\mathrm{B}+)$ ewes and are presented as mean \pm SEM where data were normally distributed (cortisone, cortisol and 17 $\beta$-oestradiol), or as geometric mean and $95 \%$ confidence limits where data were non-normally distributed (cortisol). Non-normal data was natural log-transformed and the data analysed using t-tests and where there was a trend towards significance, the P-value has been reported on the appropriate graph.

\subsubsection{Constituent concentrations in follicular fluid of ++ and $\mathrm{I}+\mathrm{B}+$} ewes

Herein, the data from non-responsive and FSH-responsive follicles were combined (termed growing follicles), and compared to that of PPOV follicles. The mean ( \pm SEM)

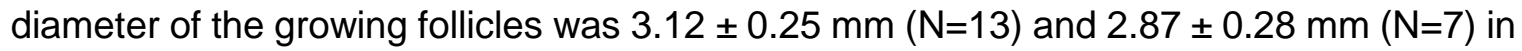
++ and $\mathrm{I}+\mathrm{B}+$ ewes, respectively. Likewise, in PPOV follicles, the mean diameter was 
$6.93 \pm 0.28 \mathrm{~mm}(\mathrm{~N}=11)$ and $4.07 \pm 0.08 \mathrm{~mm}(\mathrm{~N}=26)$ in ++ and $\mathrm{I}+\mathrm{B}+$ ewes, respectively. The results in this section describe the composition of follicular fluid in growing and PPOV follicles, compared to that of plasma, in ++ and $\mathrm{I}+\mathrm{B}+$ ewes.

\subsection{Amino acid concentrations in follicular fluid of ++ and $\mathrm{I}+\mathrm{B}+$ ewes}

The concentrations of the L-forms of alanine, arginine, asparagine, aspartic acid, citrulline, glutamic acid, glutamine, glycine, histidine, hydroxyproline, isoleucine, leucine, lysine, methionine, ornithine, phenylalanine, proline, serine, taurine, threonine, tyrosine and valine were measured in follicular fluid samples from growing and PPOV follicles of ++ and $\mathrm{I}+\mathrm{B}+$ ewes. Ornithine concentrations were measurable in fewer than half of the samples, and in only one growing follicle from each genotype. The geometric means (95\% confidence limit) of ornithine concentrations in PPOV were $0.021(0.014,0.034) \mathrm{mM}$ and $0.027(0.015,0.050) \mathrm{mM}$ in ++ and $\mathrm{I}+\mathrm{B}+$ ewes, respectively. The concentrations of the remaining amino acids are depicted in Figure 3-7.

Threonine was the only amino acid where there was no effect of follicular stage, genotype or follicular stage $\times$ genotype interaction on concentrations in the follicular fluid. According to the model, $24.3 \%$ of the unexplained variation in threonine could be attributed to between-sheep variation.

Aspartic acid and glutamic acid exhibited no main effects of follicular stage or genotype but did exhibit a follicular stage $\times$ genotype interaction $(P=0.026$ and 0.043 , respectively). It appeared that whilst concentrations of these amino acids are similar between genotypes in growing follicles, concentrations are higher in PPOV follicles of $\mathrm{I}+\mathrm{B}+$, compared to ++, ewes. A 19.2 and $<0.1 \%$ proportion of the unexplained variation for aspartic acid and glutamic acid could be attributed to between-sheep variation, respectively.

Alanine, histidine and proline exhibited a main effect of follicular stage with no effect of genotype or interaction. The concentration of alanine was higher in PPOV $(P=0.010)$ compared to growing follicles. In contrast, the concentrations of histidine and proline were lower $(P<0.0005)$ in PPOV compared to growing follicles. $A$ 20.2, 0.1 and $10.1 \%$ proportion of the unexplained variation for alanine, histidine and proline could be attributed to between-sheep variation, respectively. 
Tyrosine and valine exhibited a main effect of genotype with no effect of follicular stage or interaction. The concentrations of tyrosine and valine were lower $(P=0.041$ and $P=0.002$, respectively) in growing and PPOV follicles of ++ , compared $\mathrm{I}_{+} \mathrm{B}+$, ewes. Less than $0.1 \%$ proportion of the unexplained variation for both tyrosine and valine could be attributed to between-sheep variation, respectively.

Arginine, citrulline, glutamine, isoleucine, leucine, lysine, methionine and taurine exhibited main effects of both follicular stage and genotype, but no interaction. The relationships were similar between amino acids whereby overall concentrations of arginine, citrulline, glutamine, isoleucine, leucine, lysine, methionine and taurine were lower $(P=0.026,0.004$, $0.001,<0.0005,0.004,<0.0005,<0.0005$ and 0.032 , respectively) in follicular fluid of ++ , compared to $\mathrm{I}+\mathrm{B}+$, ewes, and were lower $(\mathrm{P}=0.004,<0.0005,<0.0005,<0.0005,<0.0005$, $<0.0005,<0.0005$ and $<0.0005$, respectively) in PPOV, compared to growing, follicles. The proportion of variation due to sheep was $22.9 \%$ for arginine, $21.4 \%$ for citrulline, $11.0 \%$ for glutamine, $7.6 \%$ for isoleucine, $24.2 \%$ for leucine, $2.5 \%$ for lysine, $<0.1 \%$ for methionine and $3.5 \%$ for taurine.

Asparagine, glycine, hydroxyproline and serine exhibited a main effect of follicular stage, as well as a follicular stage $\times$ genotype interaction $(P=0.021,0.010,0.019$ and 0.022 , respectively). Overall, asparagine, glycine, hydroxyproline and serine concentrations were lower ( $\mathrm{P}=0.003,<0.0005,<0.0005$ and $<0.0005$, respectively) in PPOV, compared to growing, follicles. Additionally, the concentrations of asparagine, glycine, hydroxyproline and serine did not appear to be different between genotypes in growing follicles but were higher in PPOV of $\mathrm{I}+\mathrm{B}+$, compared to ++ , ewes. Variation due to sheep was determined to be $19.9 \%$ for asparagine, $12.7 \%$ for glycine, $<0.1 \%$ for hydroxyproline and $8.7 \%$ for serine. 

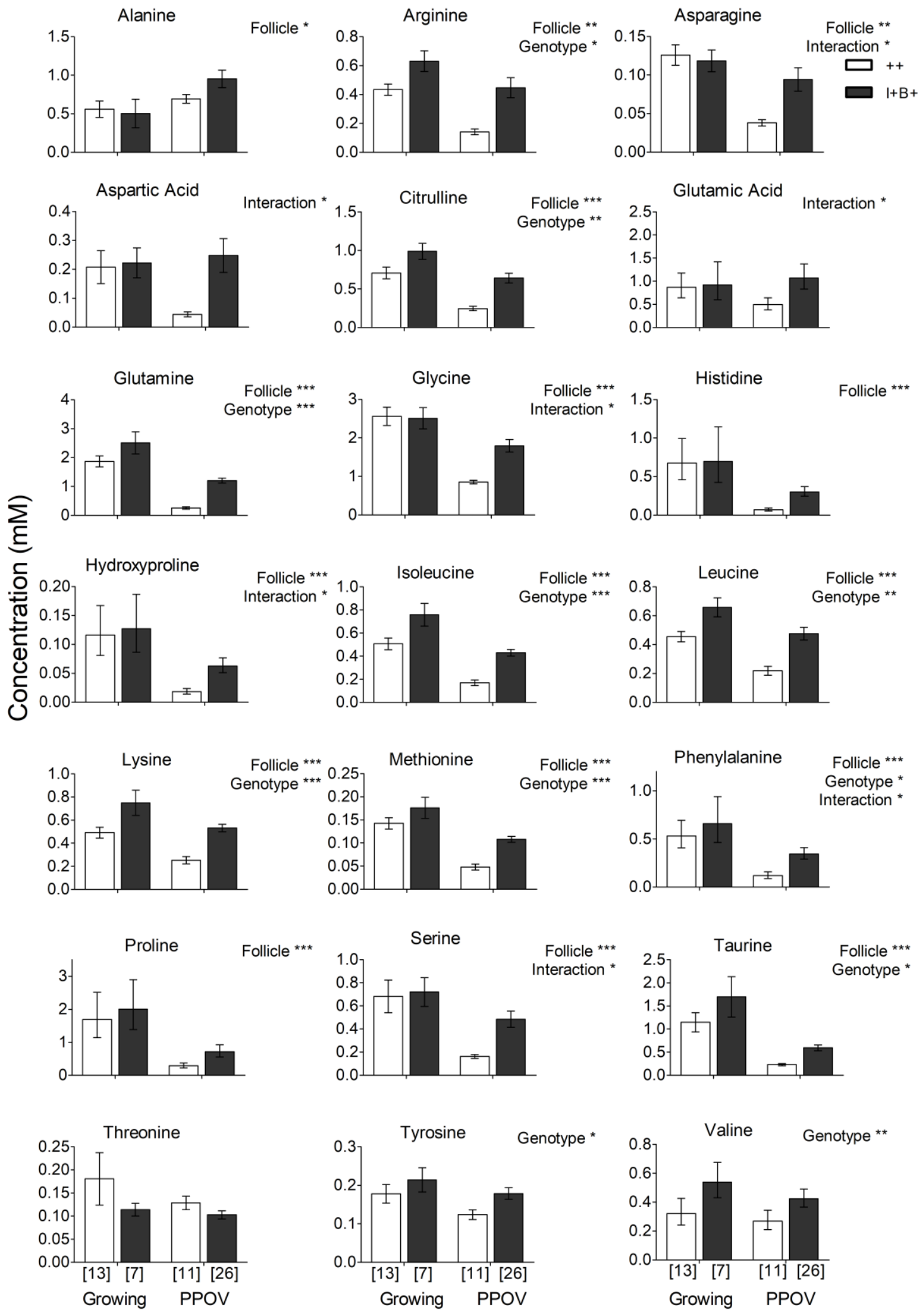
Figure 3-7: Concentrations of the L-forms of amino acids in follicular fluid of growing and presumptive preovulatory follicles (PPOV) of ++ (white bars) and I+B+ (grey bars) ewes. Data are presented as mean \pm SEM where data were normally distributed (alanine, arginine, asparagine, aspartic acid, citrulline, glutamine, glycine, isoleucine, leucine, lysine, methionine, serine, taurine, threonine and tyrosine) and as geometric mean and $95 \%$ confidence limits where data were non-normally distributed (glutamic acid, histidine, hydroxyproline, phenylalanine, proline, and valine). The number of observations for each group were the same for all the amino acids and are included in [ ] below the appropriate group at the bottom of the figure. All data were analysed using generalised linear mixed models and significant main effects of follicular stage (follicle), genotype and/or an interaction effect where present, are depicted beside the appropriate amino acid and are denoted by asterisk ( $\left.{ }^{*} \mathrm{P}<0.05,{ }^{* *} \mathrm{P}<0.01,{ }^{* * *} \mathrm{P}<0.001\right)$.

Phenylalanine exhibited main effects of follicular stage, genotype and a significant follicular stage $\times$ genotype interaction. Overall concentrations were lower $(\mathrm{P}<0.0005)$ in PPOV, compared to growing, follicles and higher $(P=0.012)$ in follicles of $\mathrm{I}+\mathrm{B}+$, compared to ++ , ewes. Moreover, the genotype difference in concentrations was larger in the PPOV, compared to the growing, follicles which contributed to a significant interaction ( $P=0.023)$. The proportion of variation due to between sheep variation was $<0.1 \%$.

Although the diameter of the growing follicles was comparable between genotypes, the diameter of PPOV from ++ ewes was greater that for $\mathrm{I}+\mathrm{B}+$ ewes. As such, the results presented in Figure 3-7, indicated that there may be a relationship between follicle diameter and amino acid concentration in follicular fluid.

As depicted in Figure 3-8, there did not appear to be a relationship between follicle diameter and the concentrations of alanine and threonine. However, the graphs depict a negative relationship between follicle diameter and the concentration of arginine, asparagine, aspartic acid, citrulline, glutamic acid, glutamine, glycine, histidine, hydroxyproline, isoleucine, leucine, lysine, methionine, phenylalanine, proline, serine, taurine, tyrosine and valine. 

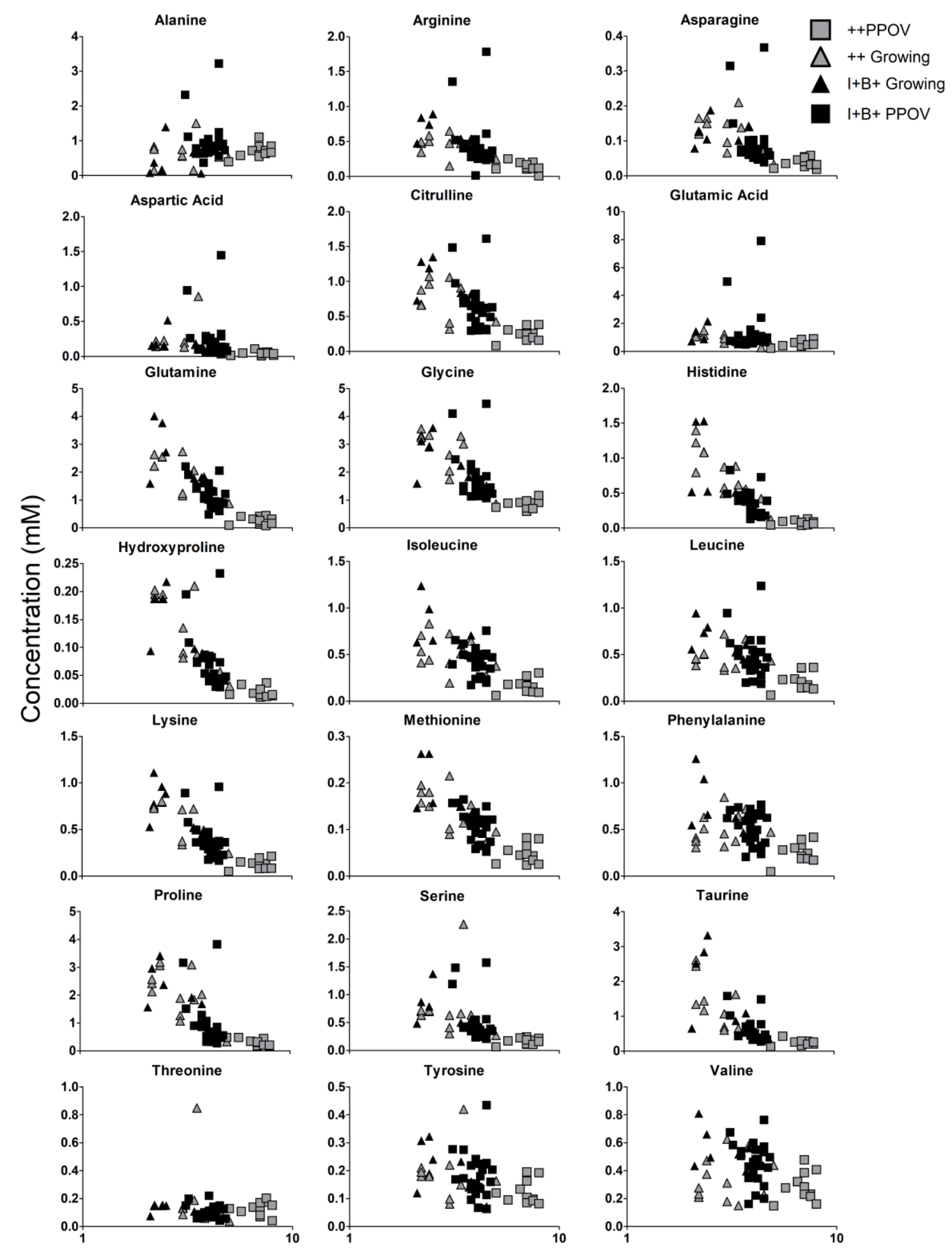

Log follicle diameter

Figure 3-8: Concentrations of the L-forms of amino acids in relation to follicle diameter in follicular fluid of growing (triangle) and presumptive preovulatory follicles (PPOV; square) follicles of ++ (grey) and I+B+ (black) ewes. Each point represents data from a single follicle 


\subsection{Energy substrate levels in follicular fluid of ++ and $I+B+$ ewes}

Concentrations of glucose and cholesterol in the follicular fluid of growing and PPOV follicles from ++ and $\mathrm{I}+\mathrm{B}+$ ewes are depicted in Figure 3-9. There was a main effect of follicular stage, as well as a follicular stage $\times$ genotype interaction for both constituents. Overall, both glucose and cholesterol concentrations were lower $(P<0.0005$ and $<0.0005$, respectively) in PPOV, compared to growing, follicles. The genotype effect was more pronounced in PPOV, compared to growing, follicles, which contributed to the interaction ( $P=0.041$ for glucose and $P=0.026$ for cholesterol). The variation between sheep accounted for $19.0 \%$ and $1.9 \%$ of the unexplained variation for glucose and cholesterol, respectively.

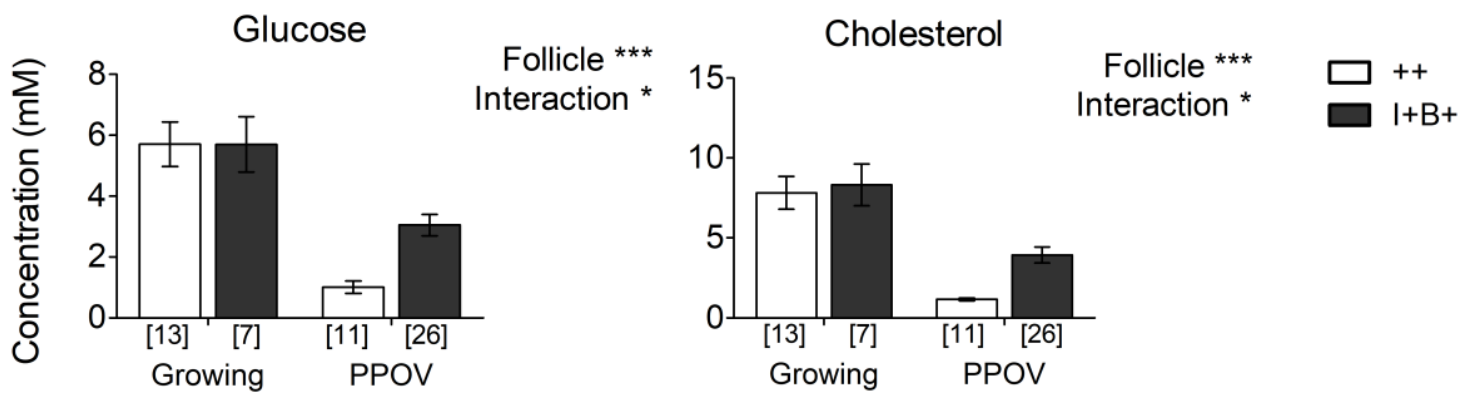

Follicular Stage

Figure 3-9: Concentrations of glucose and cholesterol in follicular fluid of growing and presumptive preovulatory follicles (PPOV) in ++ (white bars) and I+B+ (grey bars) ewes. Data for glucose is presented as mean \pm SEM while data for cholesterol is presented as geometric mean and $95 \%$ confidence limit. The number of observations for each group are included in [ ] below the appropriate group. Data was analysed using generalised linear mixed models and where significant main effects of follicular stage (follicle), genotype and/or an interaction effect were identified, these are noted beside the relevant graph and are denoted by asterisk $\left({ }^{*} \mathrm{P}<0.05\right.$, $\left.{ }^{* *} \mathrm{P}<0.01,{ }^{* * *} \mathrm{P}<0.001\right)$. 
The relationship between follicle diameter and the concentrations of glucose and cholesterol in follicular fluid was also investigated. As depicted in Figure 3-10, there did appear to be a negative relationship between follicle diameter and the concentration of glucose and cholesterol.

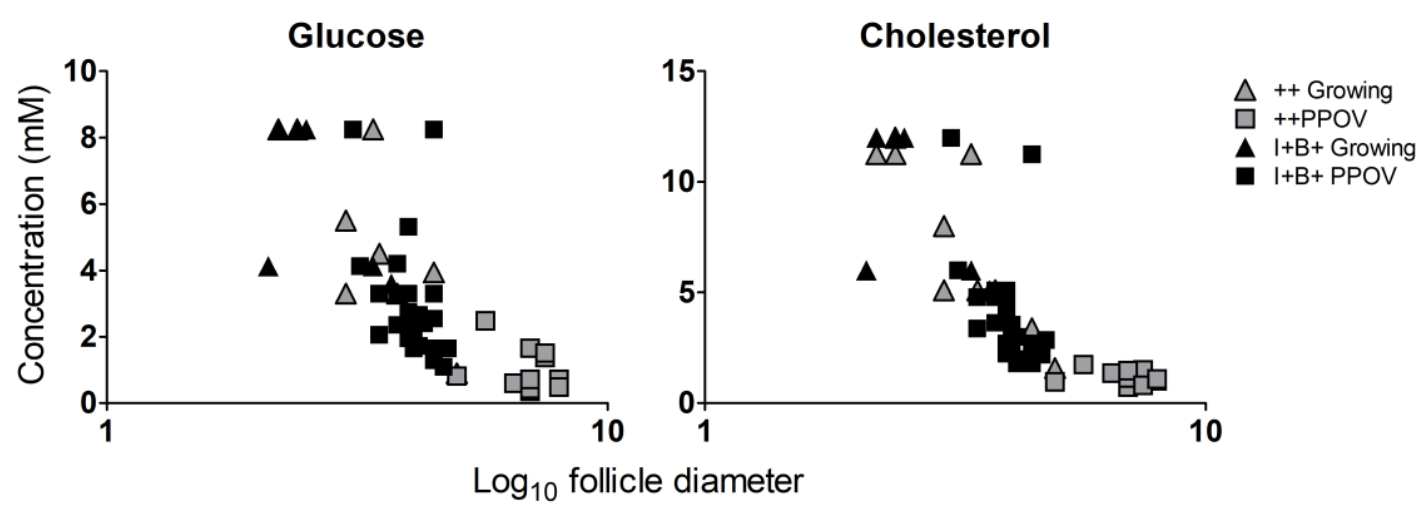

Figure 3-10: Concentrations of glucose and cholesterol in relation to follicle diameter in follicular fluid of growing (triangles) and presumptive preovulatory follicles (PPOV; squares) in ++ (grey) and I+B+ (black) ewes. Each point represents data from a single follicle.

\subsection{Steroid concentrations in follicular fluid of ++ and $\mathrm{I}+\mathrm{B}+$ ewes}

Corticosterone concentrations could only be measured in seven out of 57 follicular fluid samples and was subsequently excluded from further analyses. The mean \pm SEM concentration of corticosterone was $1.53 \pm 0.96 \mathrm{ng} / \mathrm{mL}(\mathrm{N}=3)$ in ++ ewes and $0.84 \pm$ $0.48 \mathrm{ng} / \mathrm{mL}(\mathrm{N}=4)$ in $\mathrm{I}+\mathrm{B}+$ ewes. Likewise, cortisol and 11-deoxycortisol were measurable in only 14 and 26 samples, respectively. Due to the reduced number of samples available for analyses, only genotype differences were investigated for these steroid hormones. There were no genotype differences in cortisol or 11-deoxycortisol concentrations (Figure 3-11). 

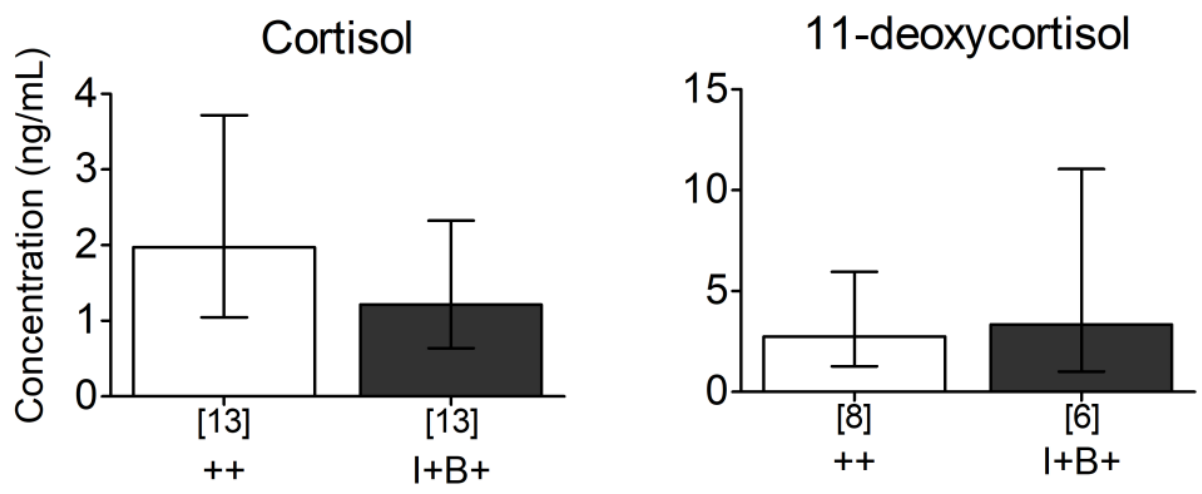

Genotype

Figure 3-11: Concentrations of cortisol and 11-deoxycortisol in follicular fluid from ++ (white bars) and $\mathrm{I}+\mathrm{B}+$ (grey bars) ewes. The number of observations for each group are included in [ ] below the appropriate group and are presented as geometric mean and $95 \%$ confidence limits. Data was analysed using Mann-Whitney U tests.

The follicular fluid concentrations of cortisone, androstenedione, testosterone, 17 $\beta$-oestradiol and progesterone are depicted in Figure 3-12.

There was no effect of genotype or follicular stage on follicular fluid concentrations of cortisone. Sheep-to-sheep variation accounted for $33.0 \%$ of unexplained variation in this model. 


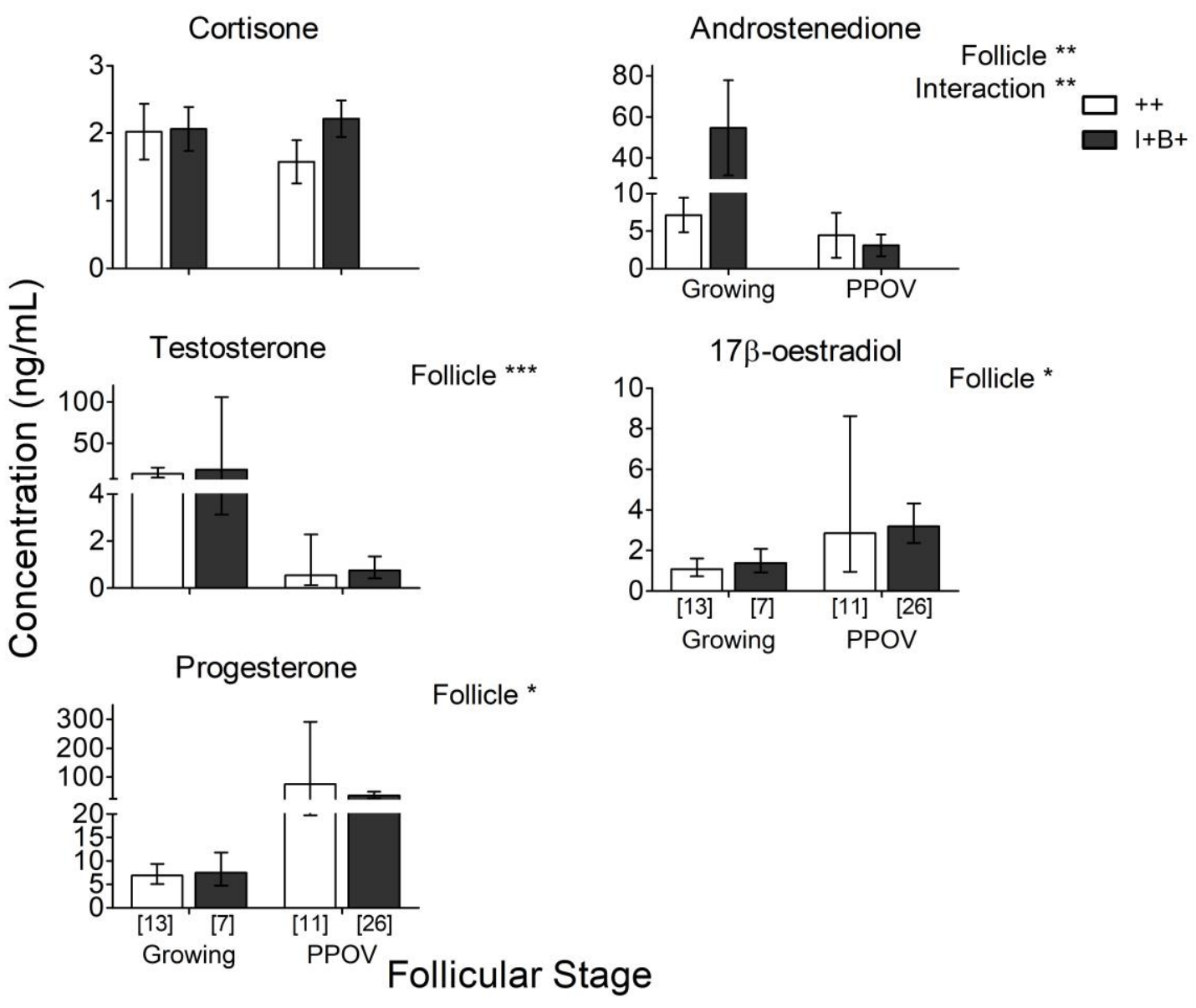

Figure 3-12: Concentrations of steroid hormones in follicular fluid of growing and presumptive preovulatory follicles (PPOV) from ++ (white bars) and I+B+ (grey bars) ewes. Data are presented as mean \pm SEM (cortisone and oestradiol) or as geometric mean and $95 \%$ confidence limits where data were non-normally distributed (androstenedione, testosterone and progesterone). The number of observations for each group are included in [ ] below the appropriate group. The data was analysed using GLMM and main effects of follicular stage (follicle), genotype and/or an interaction effect where present, are depicted beside the relevant graphs and are denoted by asterisk ( ${ }^{*} P<0.05$, $\left.{ }^{* *} \mathrm{P}<0.01,{ }^{* * *} \mathrm{P}<0.001\right)$.

There was a significant effect of follicular stage, but not genotype, on testosterone, $17 \beta$ oestradiol and progesterone concentrations. Concentrations of testosterone were lower $(P<0.0005)$ and $17 \beta$-oestradiol and progesterone were higher $(P=0.032$ and 0.017 , respectively) in PPOV, compared to growing, follicles. Variation due sheep-to-sheep variation was $1.4 \%$ for testosterone, $<0.1 \%$ for $17 \beta$-oestradiol and $0.1 \%$ for progesterone.

There were significant effects of follicular stage and follicular stage $\times$ genotype interactions on androstenedione concentrations in follicular fluid. Mean androstenedione concentrations were lower $(\mathrm{P}=0.002)$ in PPOV, compared to growing follicles in both genotypes. Concentrations of androstenedione were not different between genotypes in 
PPOV but were lower $(\mathrm{P}=0.003)$ in growing follicles of ++ compared to $\mathrm{I}+\mathrm{B}+$ ewes leading to an interaction. The variation in the model due to sheep-to-sheep variation was $0.8 \%$.

\subsubsection{Relationship between follicular fluid and plasma amino acid concentrations of ++ and $\mathrm{I}+\mathrm{B}+$ ewes}

The relationship between follicular fluid- and plasma-derived amino acid concentrations of ++ and $\mathrm{I}+\mathrm{B}+$ ewes are presented in Table 3-1. Interestingly, the concentration of all of the amino acids, except for threonine, was higher in follicular fluid compared to plasma regardless of genotype and follicular stage. The ratios also reflected the results of the follicular fluid, amino acid concentration analyses in that there appeared to be an effect of follicular size, that is, higher ratios were observed in smaller follicles.

Table 3-1: Ratio of ovine follicular fluid to plasma concentration.

\begin{tabular}{ccccc}
\hline & \multicolumn{4}{c}{ Ratio (Follicular fluid: plasma) } \\
\cline { 2 - 5 } Amino acid & \multicolumn{3}{c}{ Growing } & \multicolumn{2}{c}{ PPOV } \\
\cline { 2 - 5 } & $\mathrm{I}+\mathrm{B}+$ & ++ & $\mathrm{I}+\mathrm{B}+$ & ++ \\
\hline Alanine & $2.0 \pm 0.7$ & $3.0 \pm 0.4$ & $3.4 \pm 0.4$ & $2.7 \pm 0.2$ \\
Arginine & $4.9 \pm 0.5$ & $3.7 \pm 0.3$ & $3.6 \pm 0.6$ & $1.3 \pm 0.2$ \\
Asparagine & $3.2 \pm 0.4$ & $3.5 \pm 0.3$ & $2.5 \pm 0.4$ & $1.0 \pm 0.1$ \\
Aspartic acid & $27.5 \pm 7.8$ & $29.9 \pm 6.9$ & $28.9 \pm 8.0$ & $5.6 \pm 0.9$ \\
Citrulline & $7.1 \pm 0.9$ & $6.2 \pm 0.6$ & $2.1 \pm 0.3$ & $4.6 \pm 0.5$ \\
Glutamic acid & $5.4 \pm 0.9$ & $5.7 \pm 0.6$ & $7.3 \pm 1.4$ & $3.4 \pm 1.4$ \\
Glutamine & $18.5 \pm 2.6$ & $14.4 \pm 2.2$ & $8.6 \pm 0.7$ & $1.9 \pm 0.3$ \\
Glycine & $4.2 \pm 0.5$ & $5.2 \pm 0.6$ & $3.1 \pm 0.3$ & $1.9 \pm 0.1$ \\
Histidine & $35.9 \pm 8.9$ & $40.6 \pm 7.2$ & $14.0 \pm 1.5$ & $3.3 \pm 0.3$ \\
Hydroxyproline & $15.3 \pm 2.6$ & $12.9 \pm 1.7$ & $7.6 \pm 0.8$ & $2.3 \pm 0.3$ \\
Isoleucine & $9.5 \pm 1.3$ & $6.1 \pm 0.6$ & $5.2 \pm 0.4$ & $2.1 \pm 0.3$ \\
Leucine & $5.3 \pm 0.5$ & $3.5 \pm 0.3$ & $3.8 \pm 0.4$ & $1.7 \pm 0.2$ \\
Lysine & $6.0 \pm 0.7$ & $3.6 \pm 0.3$ & $4.1 \pm 0.4$ & $1.9 \pm 0.3$ \\
Methionine & $17.2 \pm 1.8$ & $10.4 \pm 1.1$ & $10.1 \pm 0.8$ & $3.6 \pm 0.5$ \\
Phenylalanine & $15.3 \pm 2.2$ & $11.8 \pm 1.2$ & $8.3 \pm 0.8$ & $2.7 \pm 0.3$ \\
Proline & $14.12 \pm 2.6$ & $13.4 \pm 1.6$ & $5.7 \pm 1.0$ & $2.3 \pm 0.3$ \\
Serine & $6.9 \pm 1.2$ & $6.9 \pm 1.4$ & $5.0 \pm 0.8$ & $1.6 \pm 0.2$ \\
Taurine & $36.8 \pm 11.0$ & $19.4 \pm 3.3$ & $11.1 \pm 1.1$ & $4.2 \pm 0.5$ \\
Threonine & $0.8 \pm 0.1$ & $1.3 \pm 0.5$ & $0.7 \pm 0.1$ & $0.8 \pm 0.1$ \\
Tyrosine & $4.2 . \pm 0.7$ & $3.7 \pm 0.6$ & $3.6 \pm 0.3$ & $2.6 \pm 0.7$ \\
Valine & $3.1 \pm 0.3$ & $1.8 \pm 0.2$ & $2.5 \pm 0.2$ & $1.5 \pm 0.2$ \\
\hline
\end{tabular}




\subsubsection{Gene expression levels in $\mathrm{COC}$ of ++ and $\mathrm{I}+\mathrm{B}+$ ewes}

The expression levels of key CC- and oocyte-derived genes involved in candidate pathways for the attainment of oocyte maturation were measured to identify potential key maturational processes in follicles of $\mathrm{I}+\mathrm{B}+$ and ++ ewes. Information on these genes are in Table 1-2 and Section 1.5.2.1.1. Likewise, information on the oocyte genes can be found in Table 1-3 and Section 1.5.2.2.1..

\subsubsection{Gene expression in $\mathrm{CC}$ of ++ and $\mathrm{I}+\mathrm{B}+$ ewes.}

Preliminary analyses indicated no genotype differences in the expression levels of HAS2, HSP90B1, FSHR and GJA1 mRNA however, differences due to follicular stage were evident. For these analyses, data from both genotypes were pooled. Specifically, HAS2 mRNA expression levels were higher $(\mathrm{P}<0.0005)$ in PPOV, compared to growing, follicles. In contrast, expression levels of HSP90B1, FSHR and GJA1 were lower ( $P=0.005$, $<0.0005$ and $<0.0005$, respectively) in PPOV, compared to growing, follicles (

Figure 3-13).

Genotype differences were evident for VCAN, PGR, BMPR2 and EREG genes $(\mathrm{P}<0.0005$, $\mathrm{P}=0.006, \mathrm{P}=0.001$ and $\mathrm{P}=0.035$ respectively) and data were treated separately (Figure 3-14). Expression levels were also investigated for differences due to follicular stage. 

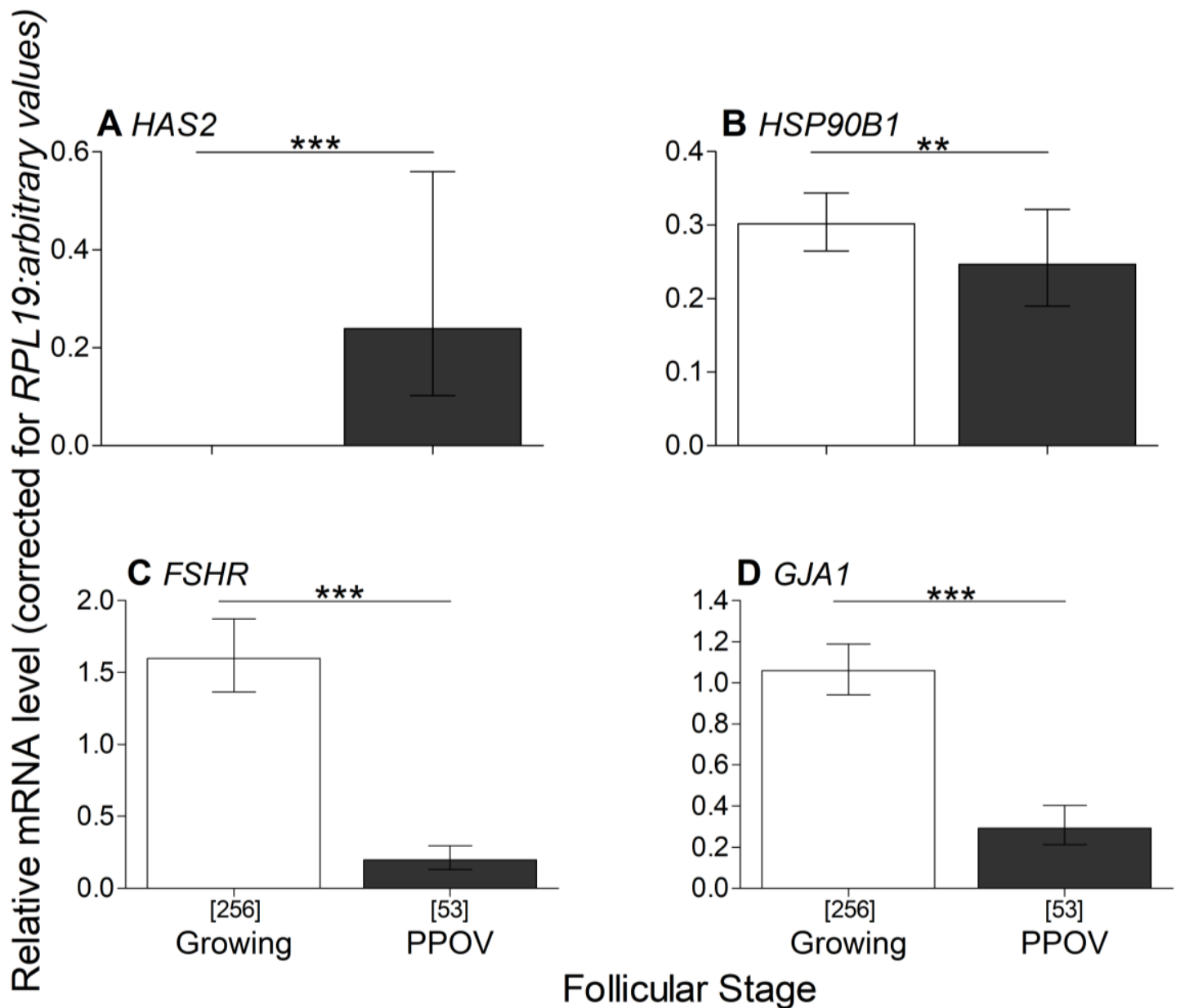

Follicular Stage

Figure 3-13: Relative mRNA expression levels of HAS2, HSP90B1, FSHR and GJA1 in single CC masses from growing (white bars) and presumptive preovulatory follicles (PPOV; grey bars). Data represents the geometric mean and $95 \%$ confidence limit of the linearised $\mathrm{C}_{\mathrm{T}}$ values. The number of observations for each group are included in [ ] below the appropriate group. Data was analysed using Mann-Whitney $U$ tests and statistical differences are denoted by asterisk $\left({ }^{*} P<0.05\right.$, $\left.{ }^{* *} P<0.01,{ }^{* * *} P<0.001\right)$.

For genes with genotype differences, the effect of follicular stage is depicted in Figure 3-14. In both ++ and I+B+ ewes, mRNA levels of VCAN, PGR, EREG and BMPR2 were higher ( $\mathrm{P}<0.0005$ for all genes) in PPOV, compared to growing, follicles. There was no difference in $P G R$ expression in growing follicles between the genotypes. In contrast, expression of $\operatorname{VCAN}(\mathrm{P}=0.021)$ and BMPR2 $(\mathrm{P}=0.046)$ was higher in growing follicles of $\mathrm{I}+\mathrm{B}+$ ewes, while EREG expression was higher in growing follicles of ++ ewes $(\mathrm{P}=0.001)$.

In PPOV follicles, the expression levels of VCAN, PGR and BMPR2 did not differ between genotypes while EREG expression was higher in ++ compared to $\mathrm{I}+\mathrm{B}+$ ewes $(\mathrm{P}<0.0005)$. 

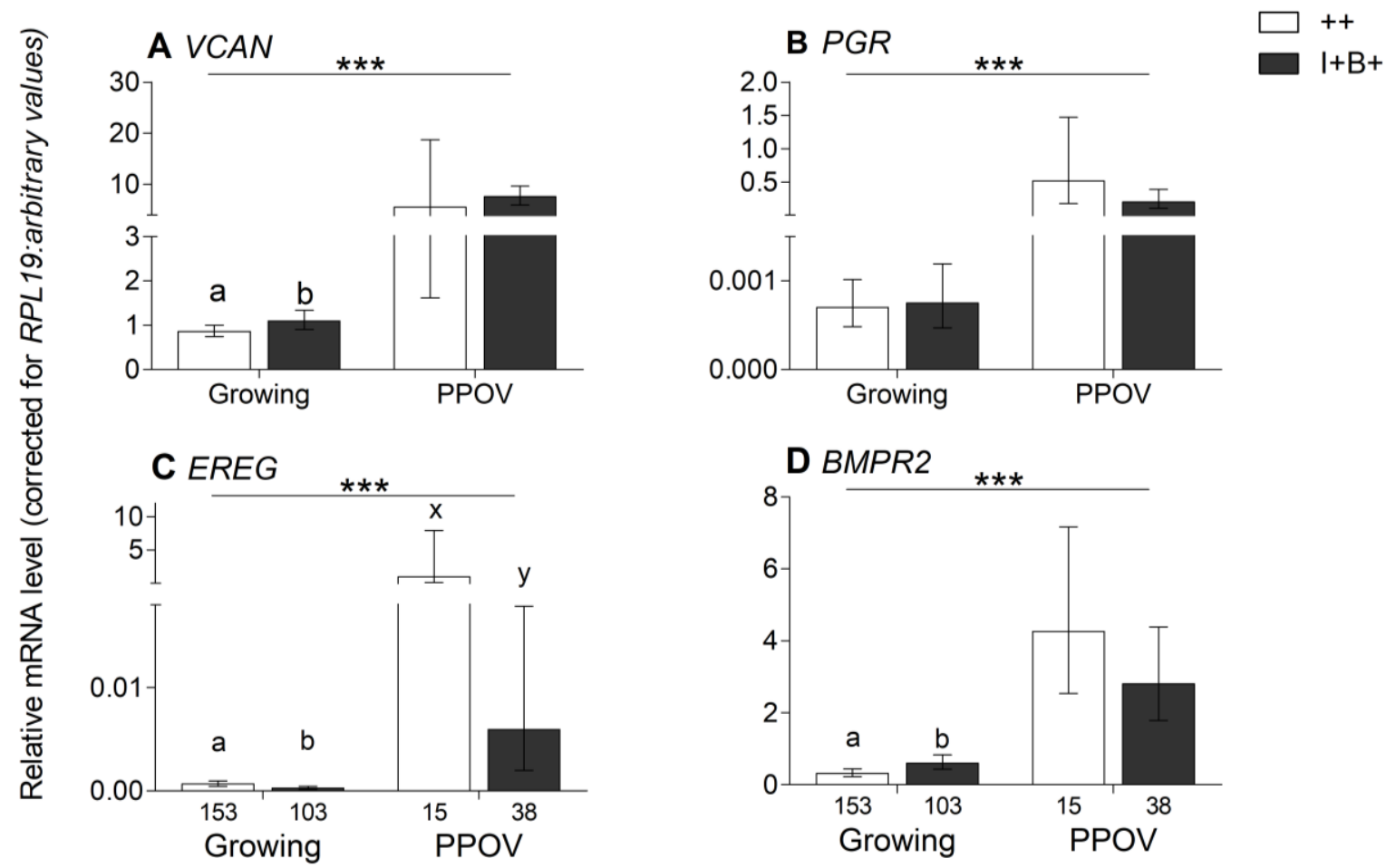

Follicular Stage

Figure 3-14: Relative mRNA expression levels of VCAN, PGR, EREG and BMPR2 in CC masses from growing and presumptive preovulatory (PPOV) follicles from ++ (white bars) and I+B+ (grey bars) ewes. Data represents the geometric mean and $95 \%$ confidence limit of the linearised $\mathrm{C}_{\mathrm{T}}$ values of individual $\mathrm{CC}$ masses. The number of observations for each group are included in [ ] below the appropriate group. Data was analysed using Mann-Whitney U tests. Statistical differences between follicular stage are denoted by asterisks * $\left({ }^{*} \mathrm{P}<0.05\right.$, $\left.{ }^{* *} \mathrm{P}<0.01,{ }^{* * *} \mathrm{P}<0.001\right)$ while groups not sharing a common letter indicate a genotype difference $(P<0.05)$.

\subsubsection{Gene expression in oocytes of ++ and $I+B+$ ewes.}

The mRNA levels of PTTG1, HSF1, ZP3, PDE3A, PAPOLA, ATR, BMP15 and GDF9 as measured in single oocytes from follicles of ++ and $\mathrm{I}+\mathrm{B}+$ ewes are depicted in Figure 3-15. There were no effects of genotype or follicular stage, or any interaction, on any of these genes measured. However, there was a trend towards lower $(P=0.051) B M P 15$ expression levels in oocytes from I+B+, compared to ++ , ewes (Figure 3-15). For each of the models, a substantial proportion of the observed variation was due to between-sheep variation. This proportion was $67.2 \%$ for PTTG1, $83.1 \%$ for HSF1, $81.6 \%$ for ZP3, $98.7 \%$ for PDE3A, $65.5 \%$ for PAPOLA, $82.7 \%$ for ATR, $75.7 \%$ for BMP15 and $98.7 \%$ for GDF9. 

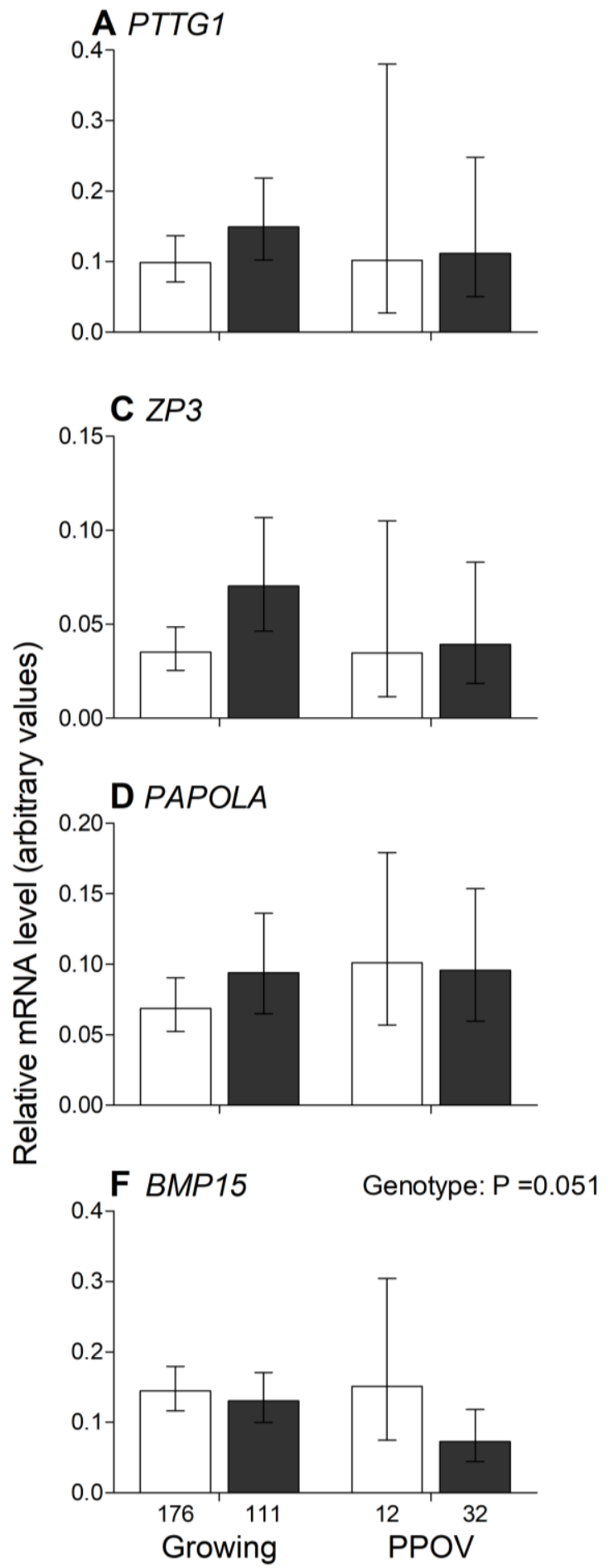
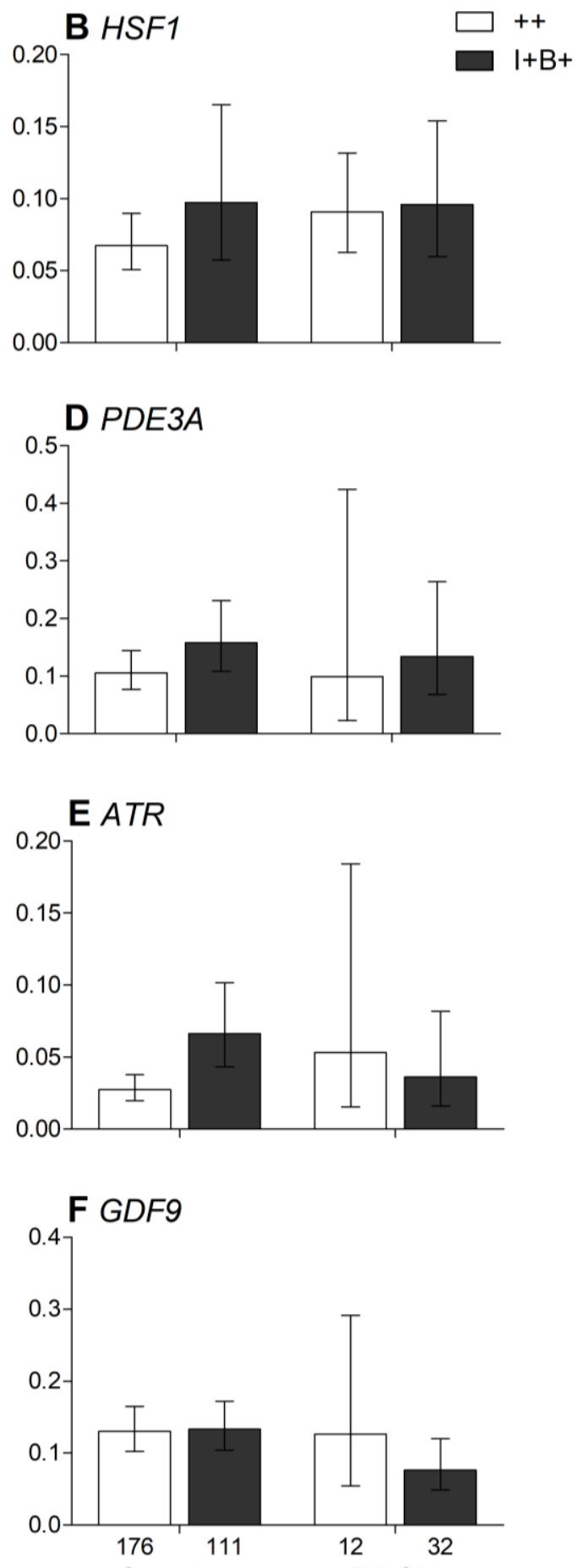

Growing

Follicular Stage

Figure 3-15: Relative mRNA levels of PTTG1, HSF1, ZP3, PDE3A, PAPOLA, ATR, $B M P 15$ and GDF9 in oocytes from follicles of ++ (white bars) and $1+B+$ (grey bars) ewes. Data are presented as mean \pm SEM $(H S F 1$ and $P D E 3 A)$ or as geometric mean and $95 \%$ confidence limits where data were non-normally distributed (PTTG1, ZP3, PAPOLA, $A T R, B M P 15$ and GDF9). The number of observations for each group are included in [ ] below the appropriate group. The data was analysed using GLMM and where there was a trend towards significance for the main effects of follicular stage (follicle), genotype and/or an interaction, the P-value has been reported beside the appropriate graph. 


\subsubsection{Summary of results}

The following tables summarise the key findings of all of the experiments described within CHAPTER 3. The summary tables are compiled to compare differences due to genotype (i.e. I+B+ c.f. ++; Table 3-2) or follicular stage (i.e. i.e. PPOV c.f. growing follicles; Table 3-3). Those attributes in which a genotype $x$ follicular stage interaction is observed are noted in both tables by $\xi$.

Table 3-2: Summary of follicular attributes in I+B+, compared to ++, ewes.

\begin{tabular}{|c|c|c|}
\hline Attributes & \multicolumn{2}{|c|}{ I+B+ (c.f. ++) } \\
\hline Ovulation rate & \multicolumn{2}{|c|}{ 个个 } \\
\hline Follicle diameter & \multicolumn{2}{|c|}{$\downarrow \downarrow$} \\
\hline Number of GC / follicle & \multicolumn{2}{|c|}{$\downarrow \downarrow$} \\
\hline cAMP synthesis & Per $10^{6} \mathrm{GC}$ & Per follicle \\
\hline Non-responsive & 个个 & $\downarrow \downarrow$ \\
\hline FSH-responsive & $\uparrow \uparrow$ & $\downarrow \downarrow$ \\
\hline LH-responsive & $=$ & $\downarrow \downarrow$ \\
\hline Amino acid concentrations & Plasma & Follicular fluid \\
\hline Alanine & $=$ & $=$ \\
\hline Arginine & $=$ & $\uparrow$ \\
\hline${ }^{\xi}$ Asparagine & $=$ & $=$ \\
\hline${ }^{\xi}$ Aspartic Acid & $=$ & $=$ \\
\hline Citrulline & $=$ & 个个 \\
\hline$\xi_{\text {Glutamic Acid }}$ & $=$ & $=$ \\
\hline Glutamine & $=$ & 个个 \\
\hline छGlycine & $\uparrow$ & $=$ \\
\hline Histidine & $=$ & $=$ \\
\hline ६Hydroxyproline & $=$ & $=$ \\
\hline Isoleucine & $=$ & 个个 \\
\hline Leucine & $=$ & 个个 \\
\hline Lysine & $=$ & 个个 \\
\hline Methionine & $\downarrow$ & 个个 \\
\hline Ornithine & $=$ & ND \\
\hline §Phenylalanine & $=$ & $\uparrow$ \\
\hline Proline & $=$ & $=$ \\
\hline ¿Serine & $=$ & $=$ \\
\hline Taurine & $=$ & $\uparrow$ \\
\hline Threonine & $=$ & $=$ \\
\hline Tyrosine & $=$ & $\uparrow$ \\
\hline Valine & $=$ & 个个 \\
\hline \multicolumn{3}{|l|}{ Metabolites } \\
\hline${ }^{\xi}$ Glucose & $=$ & $=$ \\
\hline${ }^{\xi}$ Cholesterol & $=$ & $=$ \\
\hline Creatinine & $=$ & NM \\
\hline Triglycerides & $=$ & NM \\
\hline
\end{tabular}




\section{Steroid Hormones}

Corticosterone

Cortisol

Corticosterone

$17 \beta$-oestradiol

11-deoxycortisol

§Androstenedione

Testosterone

Progesterone

$\begin{array}{cc}= & = \\ = & = \\ = & N D \\ = & = \\ \text { ND } & = \\ \text { ND } & = \\ \text { ND } & = \\ \text { ND } & =\end{array}$

CC-derived gene expression

HAS2

VCAN

HSP90B1

FSHR

PGR

GJA1

EREG

BMPR2

Oocyte-derived gene expression

PTTG1

HSF1

ZP3

$P D E 3 A$

PAPOLA

ATR

$=$

个个

$=$

$=$

个个

$=$

$\downarrow$

个个

${ }^{\xi}$ BMP15

GDF9

$=$

$=$

$=$

$=$

$=$

$=$

$=(\downarrow)$

Arrows indicates significant differences $(\uparrow$ or $\downarrow-P<0.05$, $\uparrow \uparrow$ or $\downarrow \downarrow P<0.01)$; = indicates no difference; $\xi$ indicates a genotype $\times$ follicle interaction for follicular fluid data; $=(\downarrow)$ indicates a trend towards significance. $\mathrm{ND}=$ not detectable; $\mathrm{NM}=$ not measured. 
Table 3-3: Summary of follicular attributes in preovulatory (PPOV; i.e. LHresponsive), compared to non-preovulatory (i.e. LH-unresponsive), follicles. Those attributes in which a genotype $x$ follicular stage interaction is observed are noted in both tables by $\xi$

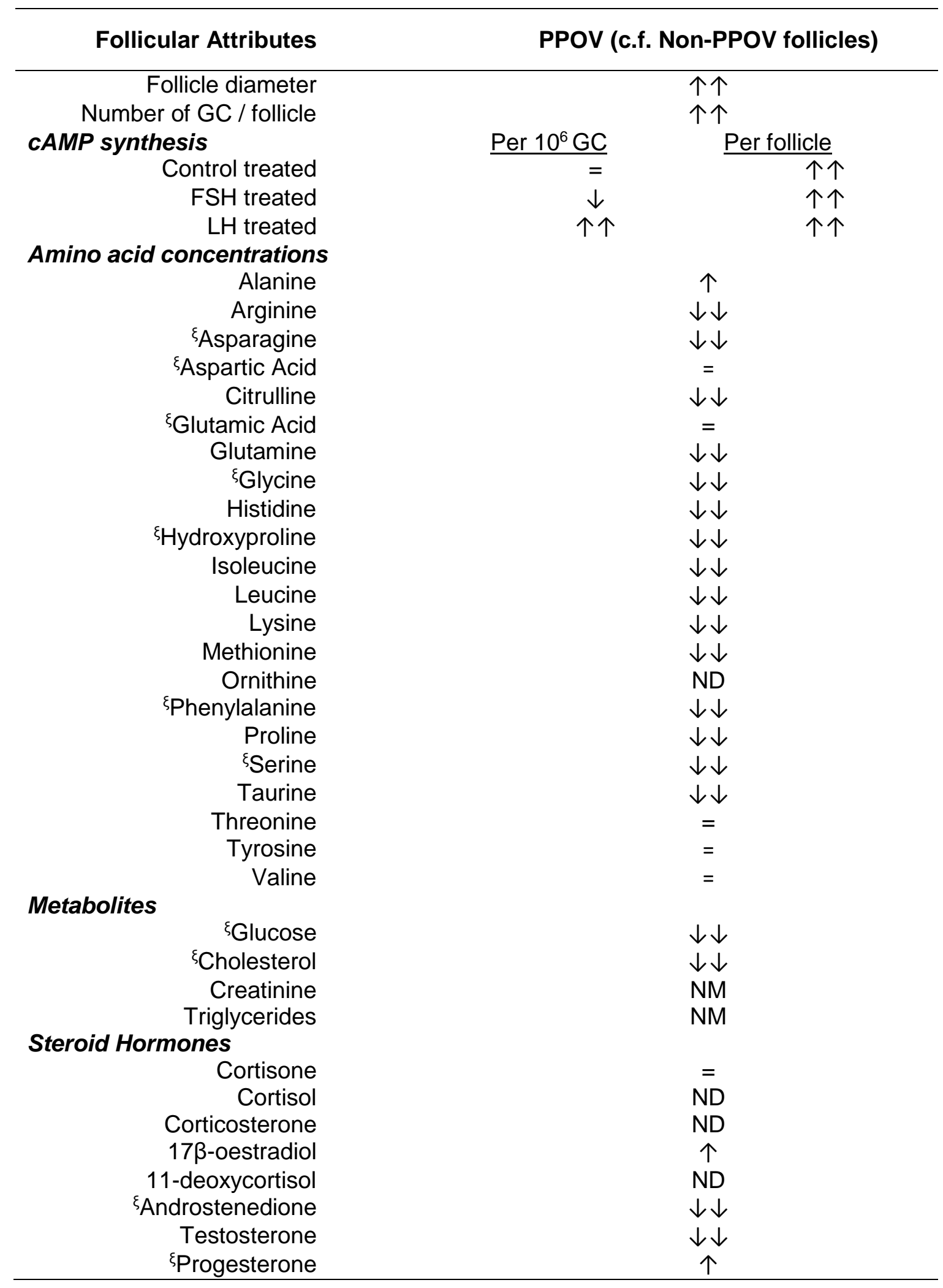




\begin{aligned} & \hline CC-derived gene expression \\ & HAS2 $\uparrow \uparrow \\ &$ VCAN $\uparrow \uparrow \\ &$ HSP9OB1 $\downarrow \downarrow \\ &$ FSHR $\downarrow \downarrow \\ &$ PGR $\uparrow \uparrow \\ &$ GJA1 $\downarrow \downarrow \\ &$ EREG $\uparrow \uparrow \\ &$ BMPR2 $\uparrow \uparrow \\ &$ Oocyte-derived gene expression \\ & PTTG1 $= \\ &$ HSF1 $= \\ &$ ZP3 $= \\ &$ PDE3A $= \\ &$ PAPOLA $= \\ & A T R= \\ &$ BMP15 $= \\ &$ GDF9 $= \\ & \\ &$\hline\end{aligned}

Arrows indicates significant differences $(\uparrow$ or $\downarrow-P<0.05$, $\uparrow \uparrow$ or $\downarrow \downarrow P<0.01)$; = indicates no differences; ${ }^{\xi}$ indicates a genotype $x$ follicle interaction. $N D=$ not detectable; $N M=$ not measured. 


\subsection{Discussion}

The results reported herein provide novel findings on the changing microenvironment of maturing follicles in sheep. By comparing growing and PPOV follicles of two sheep genotypes that exhibit a low $(++; \mathrm{OR}=1.7 \pm 0.2)$ and high $(1+\mathrm{B}+$; $\mathrm{OR}=4.4 \pm 0.7) \mathrm{OR}$, key mechanisms critical to follicular maturation and the attainment of oocyte developmental competency have been identified. A very important finding from this study was that despite the large morphological, biochemical and molecular differences identified between the follicles of ++ and $\mathrm{I}+\mathrm{B}+$ ewes, global gene expression levels in oocytes were similar between genotypes, except for one of the naturally-mutated genes (BMP15) in the $1+\mathrm{B}+$ ewes. This suggests that whilst the follicular somatic cells may function at a different level in I+B+ ewes to compensate for fewer GC per follicle, the key maturational processes that result in a developmentally competent oocyte are not compromised.

In agreement with a previous report, the LH-responsive follicles of $\mathrm{I}+\mathrm{B}+$, in comparison to ++ , ewes, were smaller in size and contained fewer GC (McNatty et al., 2016). The capacity of GC from a follicle to respond to $\mathrm{LH}$ (or the similar molecule $\mathrm{hCG}$ ) is unique to a preovulatory follicle (Webb and England, 1982). Regardless of differences in the timing of ovarian tissue collection, the acquisition of $\mathrm{LH}$ receptors on the GC of comparatively smaller follicles of $\mathrm{I}+\mathrm{B}+$ ewes was observed. This phenomenon has been observed in other high OR ewes including heterozygous and homozygous carriers of the Booroola mutation ( $\mathrm{B}+$ or $\mathrm{BB}$, respectively; a mutation in $B M P R I B)$ and in heterozygous carriers of the Inverdale mutation (I+; a mutation in BMP15) (McNatty et al., 1986, 2009, 2016; Henderson et al., 1987; Shackell et al., 1993; Crawford et al., 2011).

Precocious attainment of $\mathrm{LH}$ receptors on $\mathrm{GC}$ of follicles in $\mathrm{I}+\mathrm{B}+$ ewes has significant morphological implications but this study also identified associated molecular differences in CC. Specifically, VCAN, PGR, EREG and BMPR2 genes were upregulated as the follicle matured. The three former genes are not surprising considering they are regulated by $\mathrm{LH}$ (Park and Mayo, 1991; Russell et al., 2003; Park et al., 2004; Cotterill et al., 2012). Likewise, BMPR2 expression has been positively associated with follicle size and thus follicular stage, as was observed in PPOV follicles of both genotypes (Feary et al., 2007; Chen et al., 2009; Paradis et al., 2009).

Interestingly, the $V C A N$ and $E R E G$ genes also exhibit genotype differences whereby expression is higher and lower, respectively in $\mathrm{I}+\mathrm{B}+$, compared to ++ , ewes. These genes 
have been identified as potential biomarkers of oocyte developmental competency, whereby lower expression levels are associated with decreased developmental competency and poor embryological outcomes in IVM systems (Dunning et al., 2007; Adriaenssens et al., 2010; Ekart et al., 2013; Richani et al., 2013). In this respect, the increased expression levels of $V C A N$ in $C C$ of $\mathrm{I}+\mathrm{B}+$ ewes would imply that developmental competency in the associated oocyte is improved in these follicles or that the follicles, as a whole, are compensating for fewer cells. The genotype differences in VCAN expression were evident in growing follicles but were not maintained at the PPOV stage. This would suggest that premature LH-responsiveness, initiates other key maturational process in the smaller growing follicles of $\mathrm{I}+\mathrm{B}+$ ewes, perhaps allowing for sufficient time to achieve full developmental competency. Despite being upregulated in PPOV in response to $\mathrm{LH}$, overall EREG expression was decreased in $\mathrm{CC}$ of $\mathrm{I}+\mathrm{B}+$ ewes, in both growing and PPOV follicles. While, EGF-like factors including EREG, facilitate LH-signalling in the CC, EREG expression is also modulated by BMP15 in CC in mice (Yoshino et al., 2006). Therefore, it is plausible that decreased $E R E G$ expression in $\mathrm{CC}$ from $\mathrm{I}+\mathrm{B}+$ ewes occurred as a result of the decreased BMP15 protein levels or signalling through its receptors, namely BMPR2 and BMPRIB (Moore et al., 2003).

Although BMPR2 mRNA expression levels were increased in $\mathrm{I}+\mathrm{B}+$ ewes, there is currently no evidence reported that $B M P R 2$ expression is directly modulated by $\mathrm{LH}$. In fact, hCG and $\mathrm{LH}$ have been shown to downregulate BMPR2 expression in GC under both in vivo and in vitro conditions (Jayawardana et al., 2006; Brannian et al., 2010; Nio-Kobayashi et al., 2015). Alternatively, BMPR2 expression in GC in vitro, was upregulated in the presence of oestradiol (Jayawardana et al., 2006). Furthermore, follicle diameter was consistently smaller in non-, FSH- and LH-responsive follicles from $\mathrm{I}+\mathrm{B}+$ ewes, making it unlikely that genotype differences in BMPR2 expression, particularly in growing follicles can be attributed to differences in follicular size. Premature LH-responsiveness results in increased androstenedione concentrations in growing follicles from $\mathrm{I}+\mathrm{B}+$ ewes compared to ++ ewes and LH has previously been shown to induce androstenedione production in theca cells from small antral follicles (McNatty et al., 1979, 1984). Likewise, follicles from Booroola ewes $(\mathrm{B}+$ and $\mathrm{BB})$ produced higher concentrations of oestradiol compared to size matched follicles from ++ ewes (McNatty et al., 1986). In CC from patients with polycystic ovary syndrome (PCOS), there was also a positive correlation between follicular fluid testosterone and androstenedione concentrations and BMPR2 expression in preovulatory follicles (Resende et al., 2012). Although, it hasn't been shown in the current study, it is possible that increased BMPR2 expression in $\mathrm{CC}$ from $\mathrm{I}+\mathrm{B}+$ ewes occurred as 
a result of altered steroid hormone synthesis which is thought to occur as a result of precocious LH responsiveness.

The LH and FSH receptors are G protein receptors coupled to adenylyl cyclase. Activation of these receptors through ligand binding results in the synthesis of cAMP. In this, and other (McNatty et al., 1986, 2009, 2016; Henderson et al., 1987; Jolly et al., 1997; Crawford et al., 2011) studies, quantification of cAMP production by GC in response to either FSH or hCG treatment has been used to classify follicles into developmental stages. Based on their ability to respond to gonadotropins, the PPOV follicles (i.e. LH-responsive) may be identified leading to investigations of potential differences in gonadotropin-responsiveness of follicles in sheep with differing OR. Interestingly, follicles that were unresponsive to gonadotropins from $\mathrm{I}+\mathrm{B}+$ ewes appeared to have a higher basal cAMP production rate than the equivalent follicles from ++ ewes. This phenomenon appeared to be even more noticeable in the FSH-responsive follicles following FSH treatment. However, when cAMP levels are calculated on a per follicle basis, regardless of gonadotropin-responsive status or treatment, all follicles produced more cAMP in ++, compared to equivalents in I+B+, ewes due to increased numbers of GC. This was confirmed by follow-up analyses using GLMM that indicated that when total GC number was included as a factor, there were no differences due to genotype in cAMP synthesised per follicle.

The GC from I+ ewes were initially reported to have increased FSH-induced cAMP synthesis compared to GC from similar-sized follicles in ++ ewes (Shackell et al., 1993). The subsequent studies in I+ ewes (and other studies in BB ewes) using a highly purified FSH preparation could not corroborate these findings and determined that the differences reported in the initial study were due to the use of high concentrations of an LHcontaminated FSH preparation (McNatty et al., 2009; Crawford et al., 2011). The current study also used a highly purified ovine FSH preparation (OVA2), but the timing of ovary recovery differed and follicles were classified based on gonadotropin-responsiveness rather than follicle diameter. Whilst, it is of interest that GC in FSH-responsive follicles of $\mathrm{I}+\mathrm{B}+$ ewes had a higher cAMP synthesis rate compared to that in ++ ewes, comparisons between the current and previous studies are made with caution. Direct immunofluorescent measurement of surface receptor density in GC preparations from Booroola ewes (BB) showed increased FSHR, LHR and BMPRIB levels compared to wildtype ewes (Regan et al., 2015). This suggests that GC from I+B+ewes in this study, which carry a single copy of the Booroola mutation, may have a higher density of FSHR. This would account for the increased FSH-dependent CAMP synthesis observed and some of 
the associated gene expression differences in $\mathrm{I}_{+} \mathrm{B}+$ ewes. However, FSHR gene expression levels in $\mathrm{CC}$, in the current study, and in whole follicles, in a previous study, were not found to be higher in I+B+ewes (Juengel et al., 2017). Elucidating the role of FSHR in the phenotypic and molecular differences presented herein would be worthwhile and will require further investigation of protein levels and cell surface receptor density in $\mathrm{I}+\mathrm{B}+$ ewes.

The total number of FSH- and LH-responsive GC was determined for each ewe as a combination of those present on the two ovaries. Despite significant differences between genotypes at the level of individual follicles, there were no differences in the numbers of FSH- or LH-responsive GC between the genotypes. Furthermore, no genotype differences were identified in plasma steroid hormones. This has previously been demonstrated for $\mathrm{I}+, \mathrm{BB} \mathrm{B}+$ animals where the total number of $\mathrm{GC}$ from ovulatory follicles, that is $\mathrm{LH}$ responsive GC, and oestradiol and inhibin were not different from wild-type ewes, despite increased OR in I+, B+ and BB animals (Niswender et al., 1990; Shackell et al., 1993; McNatty et al., 1995). Collectively, this implies a similar overall endocrine output from the GC, as evidenced by plasma oestradiol concentrations, despite major morphological and molecular differences in the ovaries of the $\mathrm{I}+\mathrm{B}+$ and ++ ewes in this study (Niswender et al., 1990; Juengel et al., 2004, 2013; Fabre et al., 2006).

The plasma concentrations of glucose, cholesterol, creatinine, triglycerides and amino acids, excluding methionine and glycine, were similar between the two genotypes. Methionine, under the activation of ATP, is converted to S-adenosylmethionine, a critical donor of the methyl group involved in protein methylation (Bottiglieri, 2002). Methionine deficiency results in a methyl donor shortage and subsequently, DNA repair mechanisms are impaired (Mattson and Shea, 2003). Plasma concentrations of methionine are reportedly reduced in cows with poor genetic merit for fertility (Moore et al., 2017). Furthermore, given its role in protein methylation, methionine is obviously important during periods of high metabolic demand in cows such as periods of rapid growth for meat production or during lactation (Richardson and Hatfield, 1978; Schwab et al., 1992). Glycine is a conditionally essential amino acid and has a wide range of roles in metabolism, anti-oxidant reactions and neurological function and as a substrate for nucleotide, protein, glutathione, heme, creatinine and uric acid biosynthesis (Wang et al., 2013). Plasma glycine concentrations are decreased in obese humans and ewes and obesity is known to be associated with metabolic dysfunction and negatively impacts fertility and oocyte developmental competency (Felig et al., 1969; Satterfield et al., 2012; Grindler and Moley, 
2013). The $\mathrm{I}+\mathrm{B}+$ animals used in these experiments had higher body condition scores and more fatty tissue in the abdominal area, than the ++ animals. Together with data indicating that heterozygous Inverdale $\left(\mathrm{I}_{+}\right)$ewes are more responsive (in terms of $\mathrm{OR}$ ) to nutritional intervention than wild-type ewes, it is plausible that decreased BMP15 signalling alters metabolism in $\mathrm{I}+\mathrm{B}+$ animals and could contribute to the mechanism(s) by which OR is increased (Demmers et al., 2011).

Similarly, is possible that the altered amino acid concentrations in follicular fluid are attributable to genotypic differences associated with altered fertility as has been documented in bovine models (Forde et al., 2016; Moore et al., 2017). In the current study, tyrosine and valine concentrations differed based on genotype but were unaffected by follicular stage. The implications of these differences in terms of effects on oocyte developmental competency are unclear and remain to be determined. However, altering amino acid concentrations in IVM media modulates developmental competency, suggesting that differences in follicular fluid composition may have significant impacts on final maturation in oocytes (Lee and Fukui, 1996; Hong and Lee, 2007). It appears that the increase in OR in the $\mathrm{I}+\mathrm{B}+$ animals may be due, at least in part, to improved follicular fluid composition. Although, the role of BMP15 signalling in modulating amino acid concentrations within the follicle is still uncertain, OSF are known to modulate glycolysis, cholesterol synthesis and the expression of amino acid transporters in the cumulus cells (Eppig et al., 2005; Sugiura et al., 2005; Su et al., 2008).

Alternatively, the differences in the concentrations of glucose, cholesterol, and amino acids, excluding aspartic acid, glutamic acid, threonine, tyrosine and valine, in growing and PPOV follicles may reflect the increasing metabolic requirements of the follicle in response to gonadotropin signalling (Mills and Feit, 1976; Boland et al., 1994; Gerard et al., 2002; Sutton-McDowall et al., 2004; Orsi et al., 2005; Harris et al., 2007; Chand and Legge, 2011). Increased utilisation of amino acids by oocytes during IVM has been associated with decreased developmental competency (Hemmings et al., 2012). Thus, it is unlikely that these differences can be attributed to metabolic changes in the oocyte alone. A relationship between follicular size and follicular fluid concentrations of glucose, cholesterol and amino acids exists in a number of other species including cows, pigs and humans (Plonowski et al., 1999; Orsi et al., 2005; Hong and Lee, 2007; Forde et al., 2016). Glycolytic activity within follicles is largely restricted to the GC and CC whilst the inverse relationship between cholesterol concentrations and steroid hormone synthesis (particularly oestradiol and progesterone concentrations) indirectly indicates that 
differences in GC number may explain the differences in follicular fluid composition (Boland et al., 1994; Harris et al., 2007; Sutton-McDowall et al., 2010). Compared to growing follicles in $\mathrm{I}+\mathrm{B}+$, which contained the fewest $\mathrm{GC}$, growing ++ and $\mathrm{I}+\mathrm{B}+\mathrm{PPOV}$ follicles contained 1-2-fold more GC while ++PPOV follicles contained 11-12-fold more GC. Thus glucose, cholesterol and the arginine, asparagine, aspartic acid, citrulline, glutamic acid, glutamine, glycine, hydroxyproline, isoleucine, leucine, lysine, phenylalanine, serine and taurine are expected to be important for supporting GC proliferation and function.

In general, overall amino acid concentrations were higher in follicular fluid than plasma resulting in high follicular fluid: plasma ratios and suggesting an active transfer of these factors into the follicle. Although they have not been fully characterised, a number of cationic amino acid transporters and sodium-couple neutral amino acid transporters have been identified within the follicle (Colonna and Mangia, 1983; Meier et al., 2002; Bermúdez et al., 2004; Eppig et al., 2005). The concentrations of the amino acids in follicular fluid from preovulatory follicles tended to be higher in ovine follicles compared to mouse, bovine and human follicles (Harris et al., 2005; Orsi et al., 2005; Jóźwik et al., 2017). Consequently, it appears that there may be species differences in the requirements or accumulation of amino acid in the follicle.

As expected, a significant effect of follicular stage was identified for steroid hormone concentrations in follicular fluid. Androstenedione and testosterone, concentrations decreased with maturity while the reverse was true of oestradiol and progesterone. These results are verified by data on expression of steroidogenic enzymes in ovine follicles (Moor et al., 1975; McNatty et al., 1979, 1984; Logan et al., 2002). Thus, increasing oestradiol synthesis in LH-responsive GC and increasing granulosa and theca cell numbers during follicular development result in an increased rate of utilisation of androstenedione and testosterone for the production of oestradiol (McNatty et al., 1984). The concentrations of androstenedione were higher in growing follicles from $\mathrm{I}+\mathrm{B}+$ ewes but not in the PPOV follicles presumably due to precocious LH-responsiveness in growing follicles from I+B+ ewes. In support of this theory, cultured theca cells from small antral follicles from Booroola ewes (BB) produced increased androstenedione in response to low doses of $\mathrm{LH}$ and have an increased basal rate of androstenedione production compared to follicles from ++ ewes (Campbell et al., 2006). Furthermore, LH-dependent androstenedione production was detected in small antral follicles $(<5 \mathrm{~mm})$ in a bovine model and occurs prior to measurable oestradiol synthesis (McNatty et al., 1984). Furthermore, if GC from I+B+are indeed more 
responsive to FSH signalling, CYP19A1 expression and activity may be increased, as has been shown in bovine GC and in small $(1-3 \mathrm{~mm})$ and medium $(3-<4.5 \mathrm{~mm})$ sized follicles in I+B+ ewes (Silva et al., 2006; Juengel et al., 2017). In combination, the increased androstenedione concentrations would allow for increased synthesis of testosterone and increased cytochrome P450 aromatase activity and may explain why despite having fewer $\mathrm{GC}$, similar concentrations of oestradiol were measured in PPOV follicles from I+B+and ++ ewes.

In spite of all the morphological, biochemical and molecular differences discussed to this point, it is worth noting that in this study that several CC-derived genes and all of the oocyte-derived genes (aside from the naturally mutated gene in the $\mathrm{I}+\mathrm{B}+$ ewes) did not differ between the genotypes. This is in agreement with data showing that BMP15 but not GDF9 expression was decreased in oocytes from Booroola (BB) ewes (Crawford et al., 2011). Of the CC-derived genes, there were no genotype differences in genes that played a role in $\mathrm{CC}$ expansion (HAS2), regulation of protein processing and endoplasmic reticulum stress (HSP90B1), gap junction communication (GJA1) and CC proliferation and survival (FSHR). Likewise, genes investigated in the oocyte have roles in cell cycle regulation and DNA damage responses (PTTG1 and ATR), polyadenylation of mRNA (PAPOLA), facilitating fertilisation (ZP3), regulation of intraoocyte cAMP concentrations (PDE3A) and the regulation of stress responses involving heat shock proteins (HSF1). In agreement with our hypothesis, these genes may represent key pathways during follicular maturation. Furthermore, data from embryo transfer studies using oocytes from I+B+ ewes indicated that in addition to high OR, the ovulated oocytes are developmentally competent, as evidenced by the high proportion of embryos that were recovered (McNatty et al., 2016).

In contrast to the genes investigated in the oocyte, the expression levels of CC-derived genes differed significantly between growing and PPOV follicles. This was not unexpected and HAS2 mRNA expression was largely confined to PPOV follicles, due to its involvement in CC expansion (Sugiura et al., 2009). In contrast, FSHR and GJA1 expression in this study was decreased in follicles of increasing maturity. This was also expected as FSHresponsiveness diminishes in GC that acquire LH receptors, and gap junctions within the COC close following the preovulatory LH surge, as has been reported previously in bovine and human CC (Calder et al., 2003; Jeppesen et al., 2012; Li et al., 2015b). The role of the HSP90B1 gene in CC is not fully understood but in other tissues it has an integral role in the regulation of protein folding and secretion. Perhaps more interestingly, the expression levels of $H S P 90 B 1$ was increased in response to a wide-range of situations 
that leads to endoplasmic reticulum stress (as reviewed by Yang and Li, 2005). The higher levels present in growing, compared to PPOV, follicles may reflect increased protein synthesis and processing that occurs prior to transcriptional silencing following final maturation. This is supported by increased methionine levels observed in growing follicles. The lack of genotype differences reflects the associated requirement for chaperone and regulatory proteins like HSP90B1 during follicular maturation. These results indicate that regardless of the large number of morphological and biochemical differences in follicles of ++ and I+B+ ewes, there are many key maturational processes that are not altered and could be thought to be relevant to a range of mammalian species with different OR. Moreover, despite alterations in the follicular microenvironment resulting from genotype differences and/or maturational stage, it appears that processes in the oocyte are not altered.

Overall, the data presented in this chapter has provided novel insight into key maturational processes occurring in vivo during the final maturational processes in the follicle. Furthermore, the inclusion of a high OR genotype in this study has allowed a larger number of PPOV follicles to be investigated without the requirement for superovulation, as well as providing intriguing evidence of the concomitant premature acquisition of LH-responsiveness in GC and initiation of final maturational processes. During this time the microenvironment of follicles, and in particular, follicular fluid composition, is altered in $\mathrm{I}+\mathrm{B}+$ ewes. The combination of these factors appears to favour the attainment of developmental competency in oocytes from multiple follicles, characteristic of high OR species. These results in combination with the key maturational processes that were identified in the gene expression studies should be used to investigate whether manipulation of IVM systems, including altering media composition, could improve the success rates of IVM. 


\section{CHAPTER 4. MORPHOKINETIC AND MOLECULAR MARKERS OF DEVELOPMENTAL COMPETENCY IN IN VITRO PRODUCED OVINE EMBRYOS.}

\subsection{Introduction}

The ability to accurately and non-invasively predict oocyte and embryo developmental competency would greatly improve the success rates of ART. To date, there are no accurate methods for identifying developmentally competent oocytes and embryos. This chapter is focussed on identifying biomarkers and more desirably, combinations of biomarkers that can be used to better predict the developmental competency of IVP ovine embryos as a model for human embryos.

In recent years, a substantial amount of research has been published on the use of morphokinetic parameters to predict outcomes in human embryos produced from ART (Table 1-4; Wong et al., 2010; Meseguer et al., 2011, 2012, Cruz et al., 2012, 2013; Dal Canto et al., 2012; Bellver et al., 2013; Fréour et al., 2013; Muñoz et al., 2013; Desai et al., 2014; Rubio et al., 2014; Hammond et al., 2015). Depending on the study, these outcomes have included prediction of successful implantation, aneuploidy of the embryo, and developmental competency of the oocyte. Utilising time-lapse monitoring systems reduces the need for disruption of embryo culture and allows for assessment of development while having no known negative impacts on embryo and blastocyst development, implantation or clinical pregnancy rates (Cruz et al., 2011; Kirkegaard et al., 2012). Many morphokinetic markers have been identified as potential biomarkers of developmental competency of the oocyte and several prediction models have been developed (Meseguer et al., 2011; Campbell et al., 2013; Conaghan et al., 2013; VerMilyea et al., 2014). However, external validation of these models has been limited and where assessed, validation studies have failed to replicate the initial results (Kirkegaard et al., 2014; Fréour et al., 2015; Kieslinger et al., 2015). A recent report has indicated that most of the information from morphokinetic data has already been extracted and this would suggest that only limited improvements can be made to prediction models based solely on morphokinetic biomarkers (Milewski et al., 2017). To date, there are no published morphokinetic studies from Ovis aries.

An alternative approach to predicting developmental competency has been to utilise components that are closely associated with the oocyte or developing embryo but are 
discarded during ART. As discussed in Section 1.5, these components include spent culture media, follicular fluid, polar bodies extruded from the oocyte, or the granulosa or $\mathrm{CC}$. The CC have an indispensable role in the attainment of developmental competency in the oocyte. As a result, gene expression profiles of CC have been investigated as biomarkers of developmental competency in the associated oocyte.

Despite the potential of these approaches, development of reliable and effective biomarkers from these technologies has proven difficult. By utilising a combination of CCderived mRNA levels of candidate genes and morphokinetic markers, it may be possible to better predict embryonic outcomes, however this has yet to be rigorously examined (Wong et al., 2010; Hammond et al., 2015). The overall aim of this chapter was to investigate the efficacy of utilising a combination of these types of biomarkers to predict embryological outcome in ovine embryos following IVP. The specific aims of this chapter were to: 1) characterise the timing of specific morphokinetic markers; 2) determine the correlation between morphokinetic markers and embryonic outcome; 3 ) identify key CCderived genes (molecular markers) that predict embryological outcome; and 4) combine the morphokinetic and molecular biomarkers to assess potential improvements in their ability to predict developmental competency. 


\subsection{Methodology}

\subsubsection{IVP}

The IVP methodology used herein has been fully described in Section 2.6. Of the seven replicate experiments performed to determine the precise timings of key morphokinetic events in ovine embryos, CC samples were collected in four of these experiments for gene expression analyses. In each replicate experiment, culture plates were modified for IVM such that 10 wells could be immersed under a single media drop (Figure 2-2 and Figure 2-3). Single COC were placed in each of the wells, thus for each drop, 10 COC in total were transferred in $10 \mu \mathrm{L}$ of B199 $+10 \%$ FBS. For IVF, culture plates were modified such that 5 wells could be immersed under a single media drop. Following IVM, the COC was transferred into two wash wells containing HSOF in a 96-well plate. Most of the CC mass were gently removed by repeated manual pipetting in $10 \mu \mathrm{L}$ of HSOF. The CC were collected into a $0.65 \mathrm{~mL}$ tube and stored at $-80^{\circ} \mathrm{C}$ until further processing. The partiallydenuded COC was then transferred in $2 \mu \mathrm{L}$ of equilibrated complete IVF media to the appropriate well of a prepared IVF plate. The volume of the IVF drops once all of the COC had been transferred was $40 \mu \mathrm{L}$. The location of the well into which each oocyte was placed was recorded and the tube containing the associated CC was labelled accordingly. Subsequently, when the embryo was transferred to the Primo Vision ${ }^{\mathrm{TM}}$ culture plate, the well in which each embryo was placed was recorded. This allowed each individual COC to be tracked so that embryonic outcome, morphokinetic timing and CC-derived mRNA expression could be correlated for each COC.

\subsubsection{Embryological outcomes}

Four embryological outcomes were selected for analyses in this study. These include: 1) failure to progress past the 8-cell stage (arrest $\leq 8$-cell stage), represents the interval prior to EGA; 2) developmental arrest of embryos after the 8-cell stage but prior to the formation of a morula (arrest $>8$-cell stage) represents the transition from maternal to embryonic genome control; 3 ) the formation of a compact morula or early blastocyst stage (CMEB), represents the timing of the first cell fate decision when the morula compacts and the polarised blastomeres undergo asymmetric cell divisions that result in ICM cells and trophectoderm cells and; 4) formation of a blastocyst (these were blastocysts in which the growing blastocoel resulted in a $10 \%$ increase in diameter of the embryo), which represents the final pre-implantation stage of embryonic development. It should be noted that embryos included in the CMEB group are likely to be arrested rather than showing 
delayed developmental kinetics as in addition to developmental arrest, these embryos displayed morphological signs of necrosis in blastomeres (swelling of the cell to the point of rupture) by the final day of IVC.

\subsubsection{Morphokinetic measurements of embryos}

The methodology used herein to measure morphokinetic timings has been fully described in Section 2.6.4.3. The morphokinetic parameters that were investigated are described in Table 2-2. On occasion, an embryo had already cleaved to the 2-cell stage prior to the commencement of the time-lapse project. For these embryos, the time taken to reach the 2-cell stage was recorded as the time of the first image that was acquired, i.e. the beginning of the time-lapse recording.

\subsubsection{Gene expression measurements of $\mathrm{CC}$}

The methodology used herein to measure the mRNA expression levels of candidate CCderived genes has been fully described in Section 2.7. Only the CC mass samples that corresponded to embryos that cleaved were included.

\subsubsection{Statistical analyses}

Due to differences in the timing of fertilisation, i.e. formation of a zygote, the timing of each cleavage event was normalised to the timing of formation of the 2-cell embryo. To identify biomarkers of oocyte and embryo quality, mRNA expression levels of individual CC masses, and morphokinetic timings of early embryos, were each individually analysed regarding embryonic outcomes using a one-way ANOVA. If the data was not normally distributed, it was transformed such that it displayed a normal distribution. Where transformation failed to result in a normal distribution, the data was analysed using a nonparametric Kruskal-Wallis $\mathrm{H}$ test. Correlations between the morphokinetic parameters and gene expression levels of all genes were assessed using Spearman's rank correlation. Finally, to assess the accuracies of using a combination of morphokinetic and molecular biomarkers to predict developmental competency (i.e. blastocyst formation), binomial logistic regression was performed. For these analyses, there were only two embryological outcomes, the formation of a blastocyst or a developmentally arrested embryo. The arrest group was the combination of the embryos that arrested $\leq 8$-cell, $>8$-cell and at the compact morula or early blastocyst stage. Due to the large number of potential biomarkers included 
in this study, each parameter was subjected to univariate binomial logistic regression to select those parameters that would be included in the final multivariable model. Statistical analyses were conducted using $R$ software program (version 3.3.1), except for the logistic regression analyses, which were conducted using SPSS Statistics (version 23). The figure in this chapter (Figure 4-1) was created using GraphPad Prism (version 5.0). The alpha level for these analyses was 0.05 . 


\subsection{Results}

\subsubsection{Embryological outcomes}

The embryological outcomes for all seven replicate experiments are listed in Table 4-1. The overall cleavage rate was $65.7 \%$, whilst the rate of uncleaved and abnormally-cleaved embryos were $21.2 \%$ and $13.1 \%$, respectively. Of the embryos that cleaved, $23.3 \%$ arrested at or before the 8-cell stage, $37.8 \%$ arrested after the 8-cell stage, $22.2 \%$ reached the compact morula or early blastocyst stage and $16.7 \%$ were classified as blastocysts. The overall blastocyst rate for these experiments was $30.0 \%$.

Table 4-1: Summary of the total numbers of embryos assessed in the IVP experiments. The proportion (\%) of embryos in each of the categories is noted and the ratios of the number of embryos to the total number of embryos are listed in brackets.

\begin{tabular}{|c|c|}
\hline Summary of experiments & Rate (\#) \\
\hline \multicolumn{2}{|l|}{ Cleavage } \\
\hline Cleaved & $67.5 \%(90 / 137)$ \\
\hline Uncleaved & $21.2 \%(29 / 137)$ \\
\hline Abnormal & $13.1 \%(18 / 137)$ \\
\hline \multicolumn{2}{|l|}{ Embryonic Development } \\
\hline$\leq 8$-cell & $23.3 \%(21 / 90)$ \\
\hline$>8$-cell & $37.8 \%(34 / 90)$ \\
\hline CMEB & $22.2 \%(20 / 90)$ \\
\hline Blastocysts & $16.7 \%(15 / 90)$ \\
\hline Overall blastocyst rate & $30.0 \%(27 / 90)$ \\
\hline
\end{tabular}

\subsubsection{Morphokinetic timings of cleavage events}

The timings of morphokinetic events in developmentally-competent ovine embryos, i.e. blastocysts with good morphology, are described in Table 4-2. For the purposes of this experiment, developmentally competent embryos were defined as those in which the blastocoel took up more than half the embryo by Day 7 in culture. It is important to note that this definition differs from that for the blastocyst group used subsequently. The timings that represent $\mathrm{t} 2 \mathrm{C}, \mathrm{t} 3 \mathrm{C}, \mathrm{t} 4 \mathrm{C}$ and $\mathrm{t} 5 \mathrm{C}$ occur over a shorter period ( $<24$ hours) compared to later morphokinetic events. 
Table 4-2: Morphokinetic events in developmentally-competent ovine embryos. The median and interquartile range is reported in hours post-IVF for each morphokinetic event and the median and interquartile range (decimal hours) of the interval between each morphokinetic event and preceding morphokinetic event are reported. The number of blastocysts included at each morphokinetic event are included in [ ]. Two embryos developed to the hatching/hatched blastocyst stage and both timings are included.

\begin{tabular}{ccc}
\hline $\begin{array}{c}\text { Morphokinetic } \\
\text { Event }\end{array}$ & $\begin{array}{c}\text { Timing } \\
\text { (decimal hours post-fertilisation) }\end{array}$ & $\begin{array}{c}\text { Interval } \\
\text { (decimal hours) }\end{array}$ \\
\hline $\mathbf{t 2 C}$ & 23.48 & \\
{$[\mathrm{n}=17]$} & $(21.05-24.98)$ & \\
$\mathbf{t 3 C}$ & 31.17 & +9.33 \\
{$[\mathrm{n}=17]$} & $(28.20-33.78)$ & $(4.167-9.917)$ \\
$\mathbf{t 4 C}$ & 32.32 & +0.837 \\
{$[\mathrm{n}=17]$} & $(30.88-35.04)$ & $(8.25-11.17)$ \\
$\mathbf{t 5 C}$ & 40.45 & +9.16 \\
{$[\mathrm{n}=17]$} & $(36.18-45.87)$ & $(11.94-22.78)$ \\
$\mathbf{t M}$ & 78.85 & +35.99 \\
{$[\mathrm{n}=17]$} & $(72.60-90.23)$ & $(50.46-64.89)$ \\
$\mathbf{t M C}$ & 105.40 & +26.51 \\
{$[\mathrm{n}=17]$} & $(94.87-139.40)$ & $(70.77-114.20)$ \\
$\mathbf{S B}$ & 139.40 & +34.17 \\
{$[\mathrm{n}=17]$} & $(130.70-152.50)$ & $(107.90-128.00)$ \\
$\mathbf{B}$ & 160.80 & +21.30 \\
{$[\mathrm{n}=17]$} & $(150.30-169.00)$ & $(128.50-146.30)$ \\
ExpB & 180.30 & +21.80 \\
{$[\mathrm{n}=11]$} & $(164.60-185.00)$ & $(140.40-163.10)$ \\
HB & $179.50,183.83$ & $-0.82,+2.35$ \\
{$[\mathrm{n}=2]$} & &
\end{tabular}

\subsubsection{Identification of morphokinetic markers associated with embryological outcomes}

The timings of key cleavage events (morphokinetic markers) in embryos with four different embryological outcomes (i.e. arrest $\leq 8$-cell stage, arrest $>8$-cell stage, CMEB and blastocyst) are depicted in Table 4-3. There were no statistical differences between embryological outcome and the total time taken to develop into 2-cell (t2C), 3-cell (t3C), 4-cell (t4C), 5-cell ( $t 5 C$ ) stage, morula (tM), compact morula (tMC), development of a blastocoel (SB), the duration of the third (cc3) cell cycle and the interval between the cleavage from 4- to 5-cells (cc3a; $5 \mathrm{C}-\mathrm{t} 4 \mathrm{C}$ ). However, the synchronicity of the second cell cycle (s2; i.e. the time taken from first visualisation of the cleavage furrow in the 2-cell embryo (b3C) to the completion of division into four blastomeres (t4C)) was significantly different between embryological outcomes $(\mathrm{P}=0.018)$. In embryos that arrested at or before the 8-cell stage, the duration of $\mathrm{s} 2$ was longer than in embryos that arrested after 
the 8-cell stage $(P=0.005)$, embryos that arrested at the compact morula or early blastocyst state (CMEB; $P=0.006)$ and embryos that developed to the blastocyst stage $(P=0.002)$.

Table 4-3: Timings of morphokinetic events in ovine embryos with different embryological outcomes. The t $2 \mathrm{C}$ values are presented in decimal hours post-IVF while the remaining morphokinetic parameters are normalised to t2C (hours). Values represent the geometric mean (95\% confidence limits) with the number of observations noted in [ ]. The values representing tM were transformed (square root $y$ ) and analysed, like the t5C values by one-way ANOVA. The values representing $\mathrm{tMC}$ and SB were analysed by t-test and $\mathrm{t} 2 \mathrm{C}, \mathrm{t} 3 \mathrm{C}, \mathrm{t} 4 \mathrm{C}, \mathrm{cc} 3$ and $\mathrm{s} 2$ values were analysed using Kruskal-Wallis $\mathrm{H}$ tests. Where statistical differences were identified, (denoted by * $P<0.05$ ), Dunn's multiple comparison test was performed. Groups not sharing a common letter are significantly different, NS denotes the within row values are not significantly different to each other.

\begin{tabular}{|c|c|c|c|c|c|}
\hline \multicolumn{6}{|c|}{ Embryological Outcome } \\
\hline & $\begin{array}{c}\text { Arrest } \leq 8 \text {-cell } \\
\text { stage }\end{array}$ & $\begin{array}{c}\text { Arrest }>8 \text {-cell } \\
\text { stage }\end{array}$ & CMEB & Blastocysts & $\begin{array}{c}\mathrm{P}- \\
\text { value }\end{array}$ \\
\hline t2C & $\begin{array}{c}24.81 \\
(22.67,27.15) \\
{[n=21]}\end{array}$ & $\begin{array}{c}22.39 \\
(21.46,23.36) \\
{[n=33]}\end{array}$ & $\begin{array}{c}23.49 \\
(22.11,24.96) \\
{[n=21]}\end{array}$ & $\begin{array}{c}23.17 \\
(21.95,24.44) \\
{[n=15]}\end{array}$ & NS \\
\hline t3c & $\begin{array}{c}6.64 \\
(4.93,8.94) \\
{[n=16]}\end{array}$ & $\begin{array}{c}3.17 \\
(2.01,4.99) \\
{[n=33]}\end{array}$ & $\begin{array}{c}4.98 \\
(3.22,7.70) \\
{[n=21]}\end{array}$ & $\begin{array}{c}6.24 \\
(4.24,9.18) \\
{[n=15]}\end{array}$ & NS \\
\hline t4C & $\begin{array}{c}11.57 \\
(7.82,17.11) \\
{[n=14]}\end{array}$ & $\begin{array}{c}4.83 \\
(3.23,7.22) \\
{[n=33]}\end{array}$ & $\begin{array}{c}6.90 \\
(5.08,9.37) \\
{[n=21]}\end{array}$ & $\begin{array}{c}8.68 \\
(6.70,11.23) \\
{[n=15]}\end{array}$ & NS \\
\hline t5C & $\begin{array}{c}18.04 \\
(15.01,21.70) \\
{[n=11]}\end{array}$ & $\begin{array}{c}13.10 \\
(10.41,16.47) \\
{[n=33]}\end{array}$ & $\begin{array}{c}13.29 \\
(9.68,18.25) \\
{[n=21]}\end{array}$ & $\begin{array}{c}18.16 \\
(15.59,21.14) \\
{[n=15]}\end{array}$ & NS \\
\hline tM & - & $\begin{array}{c}44.07 \\
(35.63,54.52) \\
{[n=27]}\end{array}$ & $\begin{array}{c}52.87 \\
(44.01,63.50) \\
{[n=21]}\end{array}$ & $\begin{array}{c}53.30 \\
(47.90,66.18) \\
{[n=15]}\end{array}$ & NS \\
\hline tMC & - & - & $\begin{array}{c}95.93 \\
(86.48,106.41) \\
{[n=21]}\end{array}$ & $\begin{array}{c}85.60 \\
(75.40,97.19) \\
{[n=15]}\end{array}$ & NS \\
\hline SB & - & - & $\begin{array}{c}118.39 \\
(107.82,130.00) \\
{[n=11]}\end{array}$ & $\begin{array}{c}115.94 \\
(109.14,123.15) \\
{[n=15]}\end{array}$ & NS \\
\hline $\operatorname{cc3}$ & $\begin{array}{c}9.30 \\
(5.63,15.38) \\
{[n=11]}\end{array}$ & $\begin{array}{c}7.69 \\
(6.01,9.84) \\
{[n=33]}\end{array}$ & $\begin{array}{c}4.54 \\
(2.37,8.69) \\
{[n=21]}\end{array}$ & $\begin{array}{c}9.21 \\
(6.37,13.33) \\
{[n=15]}\end{array}$ & NS \\
\hline cc3a & $\begin{array}{c}5.195 \\
(2.64,10.22) \\
{[11]}\end{array}$ & $\begin{array}{c}6.030 \\
(4.50,8.09) \\
{[32]}\end{array}$ & $\begin{array}{c}4.81 \\
(2.84,8.16) \\
{[21]}\end{array}$ & $\begin{array}{c}8.74 \\
(6.76,11.29) \\
{[15]}\end{array}$ & NS \\
\hline s2 & $\begin{array}{c}3.97^{\mathrm{a}} \\
(1.89,8.34) \\
{[\mathrm{n}=13]}\end{array}$ & $\begin{array}{c}1.67^{\mathrm{b}} \\
(1.15,2.44) \\
{[\mathrm{n}=33]}\end{array}$ & $\begin{array}{c}1.50^{\mathrm{b}} \\
(0.96,2.36) \\
{[\mathrm{n}=21]}\end{array}$ & $\begin{array}{c}1.45^{\mathrm{b}} \\
(0.85,2.46) \\
{[\mathrm{n}=15]}\end{array}$ & * \\
\hline
\end{tabular}


The distribution of the duration of the second (cc2) was bimodal. As such, it was not subjected to analysis using Kruskal Wallis tests. The geometric mean (95\% Cl) duration of cc2 was $5.11(3.24,8.04) \mathrm{h}, 1.95(1.03,3.67) \mathrm{h}, 3.05(1.51,6.15) \mathrm{h}$ and 5.31 (3.20, $8.83) \mathrm{h}$ in embryos that arrested at or before the 8-cell stage ( $\leq 8$-cell stage), arrested after the 8-cell stage (>8-cell stage), compact morula and early blastocyst stage (CMEB), and developed to the blastocyst stage, respectively.

\subsubsection{Identification of molecular markers associated with embryological outcomes}

The mean relative expression levels of HAS2, VCAN, HSP90B1, FSHR, PGR, GJA1, $E R E G$ and $B M P R 2$ mRNA in CC associated with different embryological outcomes are depicted in Figure 4-1. There were no statistical differences in the mRNA expression levels of HAS2, VCAN, HSP90B1, FSHR, PGR and GJA1 between embryological outcomes. In contrast, expression levels of BMPR2 mRNA differed between embryological outcomes $(P=0.0452)$. The relative expression levels of BMPR2 mRNA in those embryos that developed into blastocysts were higher than in the group that arrested after the 8-cell stage $(P=0.0396)$.

\subsubsection{Correlating morphokinetic and molecular biomarkers for embryological outcomes}

The correlations between morphokinetic and molecular (CC-derived gene expression) biomarkers were also investigated and are presented in Table 4-4. The relative mRNA levels of GJA1 and BMPR2 were positively correlated with the time taken to develop into a 2-cell embryo (t2C; $\mathrm{P}=0.0012$ and $\mathrm{P}=0.0306$, respectively). The relative levels of $P G R$ mRNA were negatively correlated with both the total time taken to morula ( $\mathrm{M}$; $\mathrm{P}=0.0264$ ) and blastocoel formation (SB; $\mathrm{P}=0.0001$ ). 


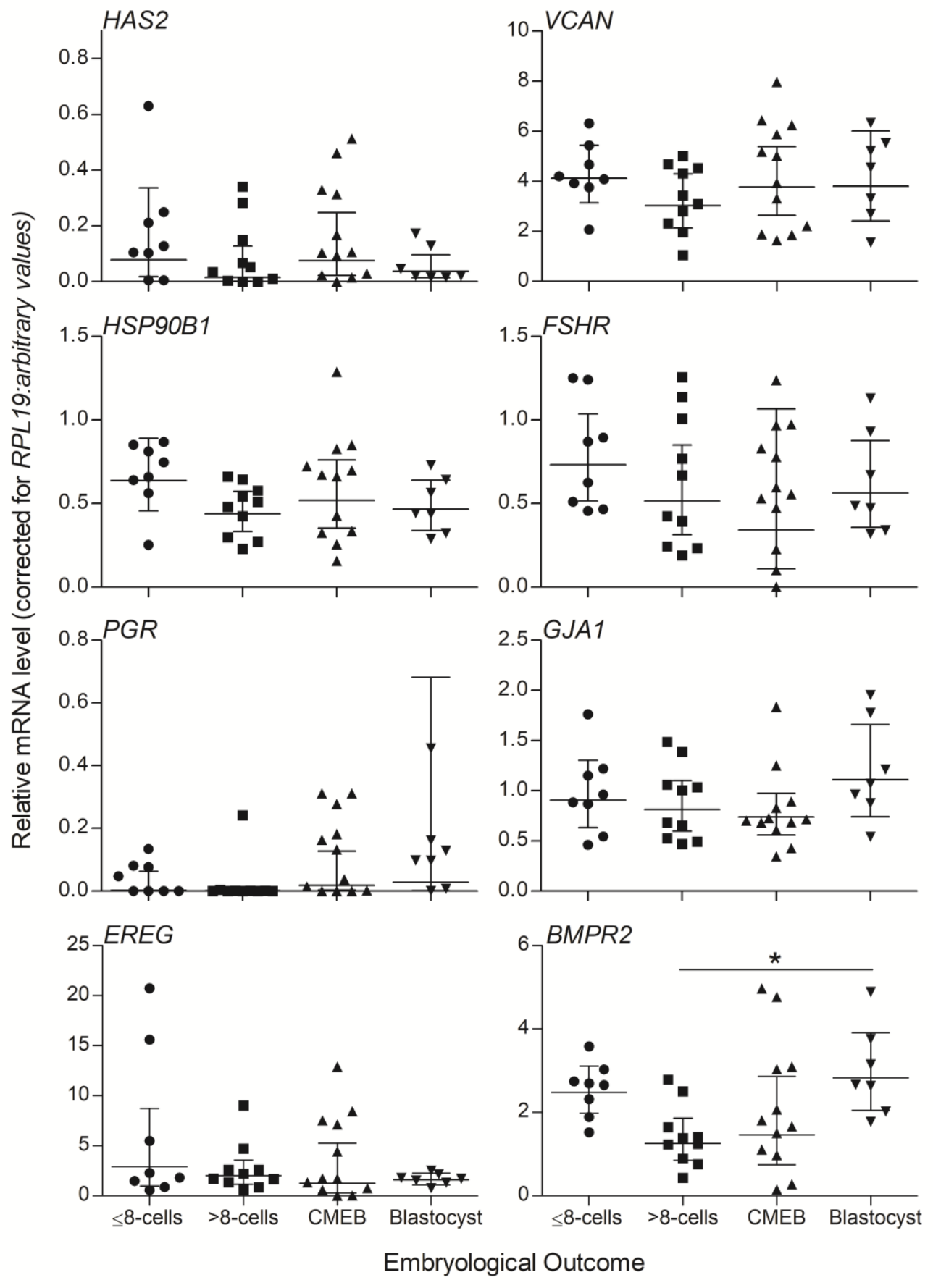

Figure 4-1: Relative mRNA levels of HAS2, VCAN, HSP90B1, FSHR, PGR, GJA1, EREG and BMPR2 in post-IVM ovine CC based on embryological outcomes. HAS2, $P G R$ and GJA1 were transformed (square root) and with VCAN, HSP90B1, FSHR and $B M P R 2$, were analysed by one-way ANOVA. EREG was analysed using a Kruskal-Wallis $\mathrm{H}$ test. The values for HAS2, PGR, GJA1 and EREG represent geometric mean and $95 \%$ confidence limits, the values for VCAN, HSP90B1, FSHR and BMPR2 represent mean \pm SEM of the linearised $\mathrm{C}_{\mathrm{T}}$ values. Data represents $7-12$ post-IVM CC samples. Where a statistical difference was identified, Tukey multiple comparison test was performed and statistical differences are denoted by asterisk $\left({ }^{*} P<0.05\right)$. 
Table 4-4: Summary of the Spearman's rank correlation coefficients $(\rho)$ between CC-derived gene expression and morphokinetic events. The values represent $\rho$ for each gene and morphokinetic event. Statistically significant correlations were denoted by asterisk $\left({ }^{*} \mathrm{P}<0.05,{ }^{* *} \mathrm{P}<0.01,{ }^{* * *} \mathrm{P}<0.001\right)$.

\begin{tabular}{|c|c|c|c|c|c|c|c|c|c|c|c|}
\hline & & & & & Mor & okinetic & Events & & & & \\
\hline & t2C & t3C & t4C & t5C & $t M$ & tMC & SB & B & cc2 & cc3 & s2 \\
\hline HAS2 & 0.040 & 0.151 & 0.104 & 0.089 & -0.079 & 0.389 & 0.086 & -0.127 & 0.248 & 0.054 & -0.108 \\
\hline VCAN & 0.280 & 0.106 & 0.067 & 0.001 & -0.167 & 0.002 & -0.286 & -0.491 & 0.151 & -0.097 & -0.073 \\
\hline HSP9OB1 & 0.147 & 0.184 & 0.111 & -0.042 & -0.121 & -0.156 & -0.437 & -0.345 & 0.212 & -0.218 & -0.048 \\
\hline FSHR & 0.088 & -0.159 & -0.129 & -0.225 & 0.285 & 0.235 & 0.272 & -0.200 & -0.144 & -0.235 & 0.121 \\
\hline$P G R$ & 0.096 & 0.039 & -0.150 & 0.043 & $-0.427^{*}$ & -0.384 & $-0.782^{\star * *}$ & -0.430 & 0.036 & -0.020 & -0.217 \\
\hline GJA1 & $0.511^{* * *}$ & -0.038 & -0.013 & 0.024 & 0.277 & 0.298 & 0.312 & -0.164 & -0.009 & 0.015 & -0.034 \\
\hline EREG & 0.078 & -0.089 & -0.195 & -0.203 & 0.163 & 0.302 & -0.067 & -0.006 & 0.051 & -0.221 & -0.289 \\
\hline BMPR2 & $0.356^{*}$ & 0.013 & 0.009 & 0.078 & -0.125 & -0.600 & -0.237 & -0.328 & 0.018 & 0.050 & 0.035 \\
\hline
\end{tabular}




\subsubsection{Predicting oocyte developmental competency using morphokinetic and molecular biomarkers}

The ability of individual morphokinetic and molecular biomarkers to predict developmental competency (i.e. blastocyst formation) was assessed using binomial logistic regression.

Each of the potential biomarkers was subjected to univariate binomial logistic regression and these results are summarised in Table 4-5. None of the morphokinetic or molecular markers investigated were shown to predict developmental competence, however some parameters, including the time taken to develop to the 5-cell stage (t5C; $\mathrm{P}=0.073$ ), the duration of the second cell cycle (cc2; $\mathrm{P}=0.064)$, GJA1 $(\mathrm{P}=0.082)$ and BMPR2 $(\mathrm{P}=0.068)$ expression trended towards statistical significance.

Table 4-5: Summary of univariate binomial logistic regression analyses. The odds ratio (OR) and $95 \%$ confidence intervals are listed for each variable. Parameters with significant associations to embryonic outcome are indicated by asterisk.

\begin{tabular}{cccc}
\hline Parameter & OR & $\mathbf{9 5} \% \mathbf{C l}$ & $\mathbf{P}$ - value \\
\hline$t 2 C$ & 1.136 & $(0.841,1.534)$ & 0.407 \\
$t 3 C$ & 1.200 & $(0.954,1.510)$ & 0.119 \\
$t 4 C$ & 1.008 & $(0.916,1.109)$ & 0.872 \\
$t 5 C$ & 1.125 & $(0.989,1.280)$ & 0.073 \\
$c c 2$ & 1.240 & $(0.988,1.558)$ & 0.064 \\
$c c 3$ & 1.107 & $(0.941,1.303)$ & 0.219 \\
$c c 3 a$ & 1.178 & $(0.969,1.432)$ & 0.082 \\
$s 2$ & 0.473 & $(0.649,1.222)$ & 0.473 \\
HAS2 & 0.002 & $(0.000,29.288)$ & 0.199 \\
VCAN & 1.075 & $(0.653,1.769)$ & 0.776 \\
HSP90B1 & 0.184 & $(0.004,8.791)$ & 0.184 \\
FSHR & 0.698 & $(0.063,7.691)$ & 0.769 \\
PGR & 96.764 & $(0.136,68648.412)$ & 0.172 \\
GJA1 & 5.599 & $(0.803,39.031)$ & 0.082 \\
EREG & 0.752 & $(0.460,1.232)$ & 0.258 \\
BMPR2 & 01.958 & $(0.952,4.031)$ & 0.068 \\
\hline
\end{tabular}

Although none of the parameters reached the predetermined level of significance $(P<0.05)$, a subsequent proof of principle analyses was performed to investigate whether a combination of morphokinetic and molecular markers could better predict developmental competency. For this multivariate analysis, parameters were included in the final multivariable model if $\mathrm{P}<0.07$. The final model consisting of $\mathrm{cc} 2$ and $B M P R 2$ was statistically significant $\left(P=0.013 ; X^{2}(2)=8.708\right)$ and explained $34.8 \%$ of the variance in blastocyst formation (data not shown). The expression of BMPR2 significantly predicted blastocyst formation ( $P=0.048$ ) while cc2 did not (Table 4-6). However, the combination of 
morphokinetic and molecular parameters in the multivariate model improved the predictive ability compared to either of these parameters alone (i.e. in the univariate models). The model suggests that a combination of a longer duration of cc2 and increased BMPR2 expression were associated with blastocyst formation.

Table 4-6: Multivariate logistic regression predicting the likelihood of blastocyst formation as a measure of developmental competency based on the duration of the second cell cycle (cc2) and BMPR2 mRNA expression levels.

\begin{tabular}{lcccccc}
\hline Predictor & $\boldsymbol{\beta}$ & SE & Wald $\mathbf{X}^{2}$ & $\mathbf{d f}$ & $\mathbf{P}$-value & $\begin{array}{c}\text { Odds ratio } \\
(\mathbf{9 5 \%} \mathbf{C l})\end{array}$ \\
\hline Constant & -5.156 & 1.855 & 7.728 & 1 & 0.005 & \\
cc2 & 0.268 & 0.140 & 3.694 & 1 & 0.055 & $\begin{array}{c}1.308 \\
(0.995,1.720)\end{array}$ \\
BMPR2 & 0.868 & 0.439 & 3.908 & 1 & 0.048 & $\begin{array}{c}2.382 \\
(1.007,5.634)\end{array}$ \\
\hline
\end{tabular}




\subsection{Discussion}

This study describes the development of an IVM/IVF system that enables morphokinetic events to be used in combination with molecular biomarkers for improved predictions of embryological outcomes in ovine embryos. To the best of my knowledge, this is the first study to report morphokinetic events in IVP ovine embryos using a time-lapse imaging system. The results reported herein also identified at least three biomarkers of developmental competency and indicated that utilising a combination of morphokinetic and molecular biomarkers improves the ability to predict developmental competency in IVP embryos.

Overall, the timings of the first four morphokinetic events, i.e. the times taken to develop into a 2-cell (t2C), 3-cell (t3C), 4-cell (t4C) and 5-cell (t5C) embryo, occurs over a short time interval. Whilst the time of fertilisation is unknown for each embryo, it is likely that the first three morphokinetic events occurred within 24 hours and exhibited less variation, compared to the other morphokinetic events tested. A similar pattern has also been observed in human embryos where variation in morphokinetic events increases following EGA ( 8 to 16 cells in sheep and $~ 8$ cells in humans; (Braude et al., 1988; Crosby et al., 1988; Wong et al., 2010; Herrero et al., 2013). These patterns imply that deficiencies in final maturation of the oocyte and early development of the embryo, thought to be characteristic of oocytes and embryos with decreased developmental competency, culminate in inadequate EGA and compromised development. This differential developmental competency becomes more apparent as the variation in the timings of postEGA morphokinetic events increase, for example, the time taken to develop to the morula stage (tM). As such morphokinetic parameters following EGA may be more suitable as biomarkers of developmental competency in embryos. Another possible explanation for the increased variation in time taken to develop to the morula (tM) and compacted morula (tMC) stage is the increased difficulty in precisely identifying the timing in which these events are initiated.

In human embryos, morphokinetic events are influenced by a variety of factors, including culture media used, IVC protocols utilising single or sequential cultures, controlled ovarian stimulation procedures, patient life-style factors (fertility and smoking status), method of fertilisation (IVF vs ICSI) and $\mathrm{O}_{2}$ concentrations during embryo culture (Ciray et al., 2012; Bellver et al., 2013; Cruz et al., 2013; Fréour et al., 2013; Muñoz et al., 2013). It is unclear whether selection models based on morphokinetic data are transferrable between clinics 
or research centres, with a number of recent external validation studies being unable to replicate the original results (Kirkegaard et al., 2014; Fréour et al., 2015). Nonetheless, similar morphokinetic timings were reported between in vivo produced and in vitro produced human embryos (Walls et al., 2015a; Dal Canto et al., 2016). The limited data from in vivo studies in sheep also indicate similar timings for morphokinetic events of in vivo produced (Rahman et al., 2008) and in vitro produced (this study) embryos and are summarised in Table 4-7. These comparisons provide evidence that the timings described herein can be utilised in other ovine time-lapse studies despite potential differences in embryo production methods and associated factors.

Table 4-7: Summary of morphokinetic events in ovine embryos (in vivo produced embryos; summarised by Rahman et al., 2008 and in in vitro produced embryos; this study). In vivo data was corrected to the estimated time of fertilisation from mating records while in vitro data was corrected to the time of sperm addition during IVF.

\begin{tabular}{lcc}
\hline Morphokinetic event & $\begin{array}{l}\text { In vivo derived embryo } \\
\text { (hours post-fertilisation) }\end{array}$ & $\begin{array}{l}\text { In vitro produced } \\
\text { embryo (hours post-IVF) }\end{array}$ \\
\hline 2-cell & $24-26$ & 23.70 \\
4-cell & $30-36$ & 31.69 \\
First appearance of & $95-120$ & 147.48 \\
blastocoel (SB) & & 189.27 \\
Blastocyst hatching (HB) & $168-192$ & \\
\hline
\end{tabular}

Of the morphokinetic parameters investigated in this study, the synchronicity of the second cell cycle ( $\mathrm{s} 2$; the time taken from first visualisation of cleavage furrow in 2-cell embryo (b3C) to the completion of division into four blastomeres (t4C)) differed between the different embryological outcomes measured. Similarly, the duration of the second cell cycle (i.e. cc2; b3C relative to the time taken to cleave to a 2-cell embryo) predicted blastocyst formation when combined with BMPR2 mRNA expression levels. The duration of s2 and to a lesser extent, cc2, have previously been shown to differ significantly between human embryos with different embryological outcomes (i.e. blastocyst formation; Wong et al., 2010; Cruz et al., 2012; Desai et al., 2014), and predict improved blastocyst morphology (Cruz et al., 2012; Dal Canto et al., 2012) and implantation potential (Meseguer et al., 2011). In these studies, a shorter s2 and cc2 duration (within the optimal range of timings) was associated with improved developmental competency. This current study also reports a shorter $\mathrm{s} 2$ duration in embryos that developed to the blastocyst stage, compared to those that arrested after the 8-cell stage. However, the current study indicated that a longer duration of $\mathrm{cc} 2$ in combination with increased BMPR2 expression 
was associated with blastocyst formation. In contrast, other studies have found no relationship between the duration of $s 2$ or cc2 and blastocyst formation, morphology (Hammond et al., 2015) or implantation (Dominguez et al., 2015). Rather than referring to absolute events, s2 refers to the interval between the beginning and end of two cleavage events (the 3-cell and 4-cell stage), while cc2 refers to the duration of a cell cycle. Thus, differences in the synchronicity of these early events may reflect differences in maternal transcripts or other factors that are known to regulate and facilitate development prior to EGA (Wong et al., 2010).

In the current study, CC-derived BMPR2 mRNA levels were shown to differ significantly between embryological outcomes and have the potential to predict blastocyst formation. The gene BMPR2 encodes the protein BMPR2, a serine-threonine type 2 receptor, expressed in the oocyte, granulosa and theca cells in ovine follicles (Feary et al., 2007) that binds both GDF9 and BMP15, as well as BMP6. As BMPR2 mRNA expression levels are higher in $\mathrm{CC}$ associated with oocytes that develop into blastocysts, compared to those that arrest after the 8-cell, but before the morula stage, it may be suggested that the developmental competency of $\mathrm{COC}$ is increased in coordination with their responsiveness to OSF. Interestingly, it has been reported that IVM protocols (i.e. co-culture of COC in the presence or absence of additional $\mathrm{CC}$ ) alters both oocyte maturation rate and BMPR2 expression levels in ovine COC (Kyasari et al., 2012). Additionally, the expression levels of BMPR2 mRNA in in vitro cultured ovine GC were dependent on the size of the follicle from which the GC were collected (i.e. the maturity of the follicle). The GC collected from larger ( $>5 \mathrm{~mm}$ ) follicles exhibited greater BMPR2 mRNA expression levels than that from smaller follicles (Chen et al., 2009). In the current experiment, COC were aspirated from follicles that were between $1-5 \mathrm{~mm}$ to avoid large antral follicles that may be undergoing atresia. If $B M P R 2 \mathrm{mRNA}$ expression levels in $\mathrm{CC}$ reflect differences in the maturity of the follicle from which they were extracted, then it is also possible that the potential embryological outcome of the oocyte is, at least in part, pre-determined depending on the follicle from which it was extracted. Together, this would indicate that despite being exposed to the same maturational signals present in IVM media, the hierarchical pattern of follicular development present in the ovary might not be altered, even following IVM. This phenomenon has also been reported in superovulation studies whereby the exogenous administration of gonadotrophins to ewes to stimulate maturation of multiple follicles was not able to overcome the hierarchical pattern of follicular development (McNatty et al., 2010). 
The relationship between morphokinetic and molecular biomarkers were explored in this study. Positive correlations were identified between the time taken from sperm addition to development of a 2-cell embryo (t2C) and CC-derived BMPR2 and GJA1 mRNA expression levels. Many morphokinetic studies reported that extended cleavage timings correlated with poor embryological outcome (Wong et al., 2010; Meseguer et al., 2011; Dal Canto et al., 2012) leading to the hypothesis that a shorter t2C interval is indicative of a better embryological outcome. Likewise, expression of BMPR2 and GJA1 mRNA increased with follicle size (Sommersberg et al., 2000; Calder et al., 2003; Feary et al., 2007; Chen et al., 2009; Paradis et al., 2009; Li et al., 2015b) and appeared to be influenced by gonadotropin signalling and oestradiol fluctuations during oestrus (Wiesen and Midgley, 1993; Granot and Dekel, 1997; Sommersberg et al., 2000; Chen et al., 2009). The preovulatory LH surge results in a marked decrease in GJA1 mRNA expression and consequently a reduction in CX43 protein levels and gap junction permeability, the latter of which contributes to the induction of meiotic resumption (Granot and Dekel, 1997; Norris et al., 2008). There is limited evidence that BMPR2 mRNA expression in GC is also downregulated in response to $\mathrm{LH} / \mathrm{hCG}$ and that morphokinetic events also appeared to be influenced by gonadotropin stimulation procedures and oestradiol concentrations (Muñoz et al., 2013; Nio-Kobayashi et al., 2015). In the in vivo situation, only the preovulatory follicle expresses the $\mathrm{LH}$ receptor and thus, is responsive to $\mathrm{LH}$ signalling, while in contrast, IVM procedures aim to induce LH-responsiveness in COC (Webb and England, 1982; Jeppesen et al., 2012). It is hypothesized that a shorter t2C together with lower expression levels of BMPR2 and GJA1 mRNA are associated with an improved embryological outcome, at least in part due to differential responsiveness of COC to specific components of the IVM media in which they are cultured, namely, oestradiol and gonadotropins. Additionally, as discussed previously with regards, to BMPR2, the shorter t2C interval and decreased expression of BMPR2 and GJA1 appear to mimic the situation in preovulatory follicles that contain a presumptive developmentally competent oocyte. These results suggest that in the majority of COC subjected to IVM in these experiments, the intrinsic competency of these oocytes was not overcome and is reflected in a suboptimal duration of $\mathrm{t} 2 \mathrm{C}$ and inadequate gene expression profiles of BMPR2 and GJA1.

In contrast, negative correlations were discovered between the total time taken to form a morula (tM) or blastocoel (SB) and CC-derived PGR mRNA expression levels. Again, it is assumed that a shorter duration to the morula stage and formation of a blastocoel together with higher $P G R$ mRNA are associated with an improved embryological outcome. The tM and SB events occur following EGA in ovine embryos (Crosby et al., 1988; Shirazi et al., 
2016). A shorter $\mathrm{tM}$ and SB have previously been associated with blastocyst formation in human embryos (Desai et al., 2014). An increased duration of these intervals in embryos is thought to reflect impaired EGA demonstrated through their inability to maintain the kinetics of development commonly observed in developmentally competent embryos. As discussed in relation to GJA1 and BMPR2, expression of PGR mRNA in CC in vivo, occurs in response to activation of the $\mathrm{LH}$ receptor which is selectively expressed in the ovulatory follicle (Webb and England, 1982; Hild-Petito et al., 1988; Park and Mayo, 1991). Activation of PGR in GC in response to the LH leads to a cascade of inflammatory signalling events that are imperative for matrix metalloproteinase induction and preparation of the rupture point for ovulation and the induction of EGF-like factors which are essential for CC expansion (Russell et al., 2003). Female $\mathrm{Pgr}^{-1}$ mice exhibit unaltered follicular development and luteinisation but impaired ovulation where the oocytes remain trapped within the luteinising follicle, while in pigs, the loss of progesterone signalling impairs CC function and the ability of the oocyte to complete meiosis (Lydon et al., 1995; Robker et al., 2000; Shimada and Terada, 2002). Accordingly, PGR expression in CC has been correlated to improved developmental competency in human oocytes (Hasegawa et al., 2005; Ekart et al., 2013). It is possible that the correlation between higher PGR expression and shorter $\mathrm{tM}$ and $\mathrm{SB}$ intervals may reflect an increased developmental competency of the oocyte/embryo.

It was hypothesised that the timing of post-EGA morphokinetic events may be better biomarkers of developmental competency. One major limitation to this in the sheep is that the cytoplasm of ovine embryos is markedly darker than that in human embryos. Subsequently, the exact timing of cleavage events in embryos with more than five or six blastomeres are difficult to assess. As a result, the current study only investigated cleavage timings to the 5-cell stage but when the intervals between later morphokinetic events (for example, the interval between time to form a morula, i.e. $\mathrm{tM}$, and the time taken to cleave to a 5-cell embryo, i.e. t5C, the interval between the time to form a blastocoel, i.e. $\mathrm{SB}$, to $\mathrm{t5C}$, and the interval between $\mathrm{SB}$ and $\mathrm{tM}$ ) were investigated, no significant associations with embryological outcomes were identified. Based on the data presented in this study and findings from other studies, it appears that morphokinetic events around the time of EGA would be worthy of further investigation (Herrero et al., 2013; Desai et al., 2014).

A major aim of the current study was to investigate whether using a combination of CCderived molecular markers and embryo-derived morphokinetic markers would further 
improve the ability to predict developmental competency of oocytes. The final binomial logistic regression analyses indicated that although none of the molecular or morphokinetic markers alone could predict blastocyst formation as a measure of development competency, a combination of the two markers, BMPR2 and the duration of the second cell cycle (cc2), significantly predicted blastocyst formation. The expression of BMPR2 was shown to differ based on embryonic outcome while cc2 has previously been associated with blastocyst formation and developmental competency (Meseguer et al., 2011; Desai et al., 2014). Furthermore, in combination, the predictive ability of each of these potential biomarkers was improved indicating that this approach is likely to identify better biomarkers of developmental competency. While a limitation of the current study was the relatively small sample size (a known limitation of regression analyses), these results illustrate the merit of this combined approach that has not been demonstrated previously (Hammond et al., 2015).

In conclusion, this is the first study to characterise the timing of cleavage events in early ovine embryos. These timings appear to be similar to those reported in human embryos and in in vivo matured ovine oocytes indicating that IVP ovine embryos are useful models for human embryos. Furthermore, this study identified three potential biomarkers of developmental competency in the oocyte (CC-derived BMPR2 expression) and embryo (cc2 and s2). Overall, the current study demonstrated that using combinations of molecular and morphokinetic markers can improve the ability to predict developmental competency and in particular, embryonic outcome. 
CHAPTER 5. THE EFFECTS OF SPECIFIC RATIOS OF GDF9

AND BMP15 ON BIOMARKERS OF DEVELOPMENTAL

COMPETENCY OF OVINE OOCYTES AND IVP EMBRYOS

\subsection{Introduction}

Supplementation of IVM media with native, or recombinant forms of OSF during IVM has been reported to improve oocyte developmental competency (Hussein et al., 2006, 2011; Yeo et al., 2008; Dey et al., 2012; Gomez et al., 2012; Mottershead et al., 2012; Sudiman et al., 2014a, 2014b). It appears that the CC are essential for this effect as the addition of OSF to denuded oocytes in culture has no effect on developmental competency (Hussein et al., 2011). The role of OSF in the attainment developmental competency during IVM are only beginning to be understood.

In recent years, new approaches to IVM systems have been developed which incorporate the increasing information available on the in vivo processes that occur at and around the time of the preovulatory LH surge (summarised in Figure 5-1). The preovulatory LH surge initiates a series of events that results in final maturation of the oocyte however, there is no evidence that either the CC or oocyte express LH receptors (Amsterdam et al., 1975; van Tol et al., 1996). Activation of the $L H$ receptors present on $G C$ leads to the production of EGF-like factors, including AREG, EREG and betacellulin (BTC). These EGF-like factors bind the EGF receptor on $G C$ and $C C$ and facilitate the downstream effects of $L H$, including CC expansion and prostaglandin E2 (PGE2) production (Park et al., 2004; Shimada et al., 2006; Chen et al., 2013). This initiates a paracrine and autocrine signalling loop as EGFR activation results in PGE2 production, which in turn induces EGF-like peptide production, although it has also been noted that EGF-like peptides exert negative feedback on EGFR function (Shimada et al., 2006; Richani et al., 2014a). There is extensive evidence that high intra-oocyte CAMP levels maintain the oocyte in a state of meiotic arrest and that a sharp rise in CAMP levels due to the action of the preovulatory $\mathrm{LH}$ surge on $\mathrm{LH}$ receptors induces meiotic resumption and expression of $\mathrm{LH}$-regulated genes including EGF-like factors (Mehlmann et al., 2002; Conti et al., 2012; Richani et al., 2014b). 


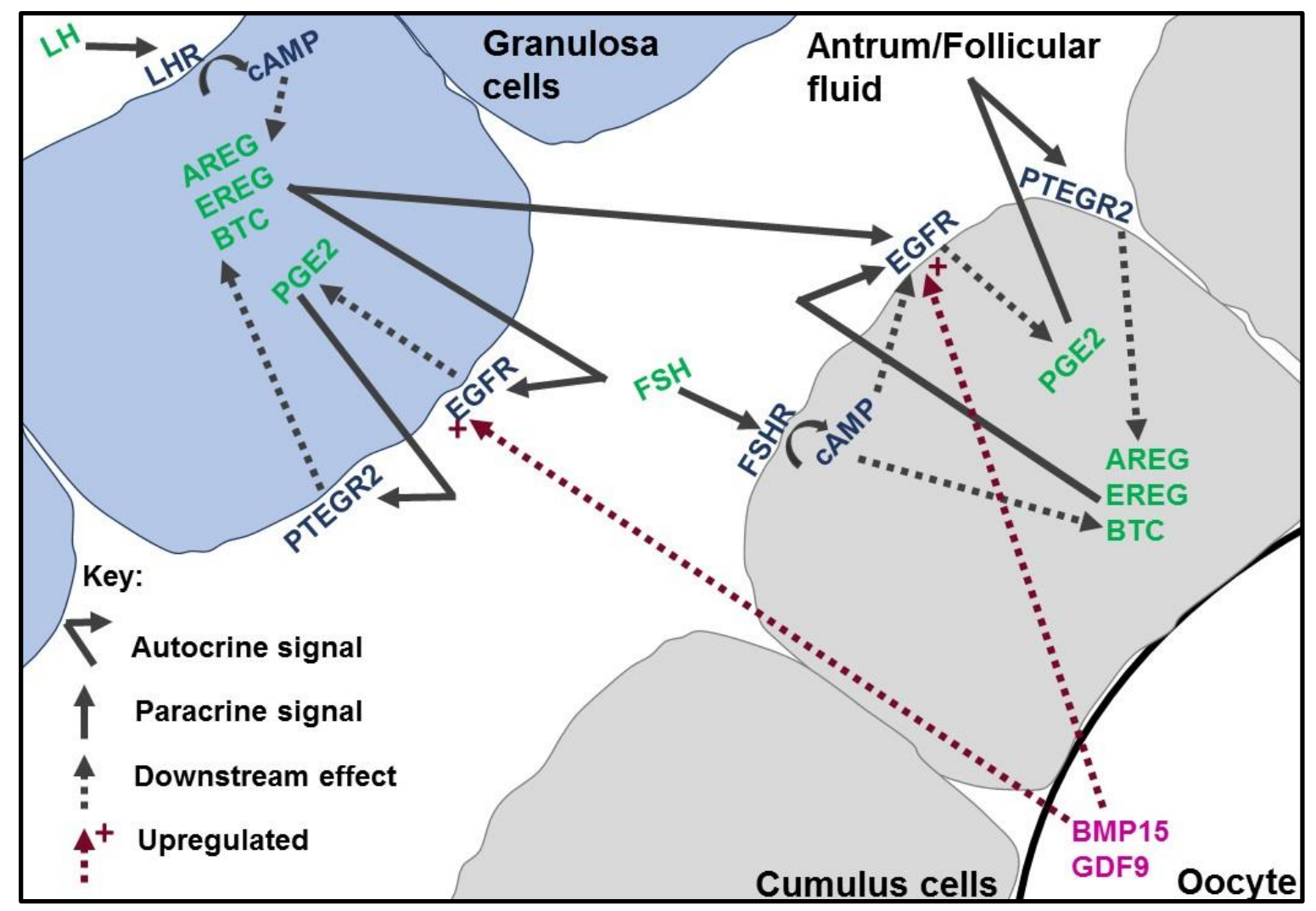

Figure 5-1: Key maturational processes influencing developmental competency in vivo and in vitro. This diagram summarises current understanding of the processes in response to activation of the $\mathrm{LH}$ receptor. Activation of the $\mathrm{LH}$ receptors on the granulosa cells (blue cells) results in increased cAMP production. The downstream effect of which induces expression of the EGF-like peptides (AREG, EREG and BTC). These EGF-like peptides function in an autocrine and paracrine manner through activation of EGFR on the granulosa and cumulus cells (grey cells). One of the associated downstream effects of which is PGE2 production. Activation of the PTEGR2 further increases AREG, EREG and BTC, perpetuating the autocrine/paracrine signalling loop. However, there is evidence that signalling through the EGFR results in downregulation of EGFR activity. There is also evidence that BMP15 and GDF9 produced by the oocyte (white cell), in the presence of adequate CAMP, upregulate and improve signalling through the EGFR on both the GC and CC. Abbreviations used: LHR - luteinising hormone receptor, cAMP - cyclic adenosine 3', 5' monophosphate, AREG - amphiregulin, EREG - epiregulin, BTC - betacellulin, PGE2 - prostaglandin E2, PTGER2 - prostaglandin E receptor 2, EGFR - epidermal growth factor receptor, FSHR - follicle stimulation hormone receptor, BMP15 - bone morphogenetic protein 15, GDF9 - growth differentiation factor 9

These studies have improved the current understanding of the mechanisms by which cAMP, EGF-like peptides and OSF improve developmental competency and how these factors may interact with each other. Modulating CAMP concentrations during IVM has been shown to improve developmental competency (Luciano et al., 1999; Albuz et al., 2010; Richani et al., 2014b; Zeng et al., 2014; Azari-Dolatabad et al., 2016). In addition, deficiencies in EGF-like peptide expression levels, as well as resultant EGF receptor activation have been identified under unmodified IVM conditions (Richani et al., 2013, 
2014b). Thus, the supplementation of EGF-like peptides, particularly EREG and AREG, to IVM media has been shown to improve developmental competency (Procházka et al., 2011; Yamashita et al., 2011; Richani et al., 2013, 2014b). Interestingly, pre-maturation in high cAMP also improved EGFR signalling and increased developmental competency (Richani et al., 2014b). Furthermore, OSF including GDF9 and BMP15 have been shown to increase EGFR gene expression as well as improve EGFR function, as measured by MAPK3/1 phosphorylation (Diaz et al., 2007; Su et al., 2010; Ritter et al., 2015). This is thought to be one of the mechanisms by which the addition of exogenous GDF9 and BMP15 to IVM culture media improves oocyte developmental competency.

The bioactivity of native OSF and recombinant BMP15 and GDF9, measured in terms of GC proliferation bioassays, appears to vary significantly depending on species of origin of both the proteins and GC (Reader et al., 2011, 2016; Lin et al., 2012; McIntosh et al., 2012; Christoforou, 2017). Furthermore, whilst homodimers of mature human BMP15, human GDF9 and mouse GDF9, as well as heterodimers of mature human BMP15 and GDF9 (i.e. cumulin) exhibited bioactivity with regards to GC proliferation, these dimers did not improve developmental competency (Sudiman et al., 2014b; Mottershead et al., 2015). In contrast, a human pro-mature heterodimeric form (i.e. cumulin), pro-mature BMP15 and conditioned media containing both pro-mature and mature forms of GDF9 or BMP15 improved developmental competency as measured by blastocyst rate. This suggests that different molecular forms or dimer combinations of BMP15 and GDF9 have differential effects on developmental competency (Hussein et al., 2006, 2011; Sudiman et al., 2014b; Mottershead et al., 2015).

In all mammalian species studied to date, the ratio GDF9 and BMP15 mRNA levels are conserved within species which led to the hypothesis that these ratios represent a mechanism by which OR was regulated (Crawford and McNatty, 2012). Apart from the pig, denuded oocytes from high OR species (rat and mouse), had higher levels of Gdf9, than Bmp15, mRNA. In low OR species such as sheep, cow and deer, GDF9 mRNA levels were lower than BMP15 mRNA. However, in the pig, a high OR species, intra-oocyte levels of GDF9 relative to BMP15 were lower. Whilst the equal addition of GDF9 and BMP15 mature proteins to IVM media have little effect on oocyte developmental competency (Sudiman et al., 2014a), the effects of differing the GDF9:BMP15 ratio on developmental competency of in vitro matured oocytes remains to be investigated. 
The overall aim of this experiment was to investigate the in vitro effects of low (similar to mRNA ratios in mono-ovulatory mammals) and high (similar to mRNA ratios in polyovulatory mammals) ratios of recombinant porcine mature GDF9 and BMP15 on developmental competency of cultured ovine oocytes. The specific aims were to investigate the effects the low (1:6) and high (6:1) ratios of mature GDF9:BMP15 on oocyte developmental competency by measuring: 1) CC expansion and the expression of key CC-derived maturation biomarkers and; 2) embryological outcomes following IVF including cleavage, timing of key morphokinetic events, and blastocyst rate. It was hypothesised that IVM conditions consisting of the higher GDF9:BMP15 ratio (i.e. 6:1) would improve developmental competence of oocytes. 


\subsection{Methodology}

\subsubsection{IVM conditions}

This study tested the effect supplementing IVM media with differing ratios of recombinant porcine mature GDF9 and BMP15 on cultured COC. The two GDF9:BMP15 ratios tested were representative of that in oocytes of low (1:6) and high (6:1) OR species. The caveat to these ratios is that the protein preparations were unpurified and concentrations were estimated against relevant E. coli-expressed GDF9 and BMP15 proteins using Western blotting (Alhussini, 2016; Swinerd, 2016). As such, it is possible that the ratios were not accurate however the fold difference within each protein between the two ratios tested were six-fold.

Recombinant porcine GDF9 and BMP15 (hereafter referred to as rec pGDF9 and rec pBMP15, respectively) used in this study were in the form of conditioned media that was produced in-house using methods previously described (Hobbs et al., 1998; McNatty et al., 2005). Briefly, full-length cDNA sequences were amplified by RT-PCR from pig ovarian RNA using primer sequences for pig GDF9 (NM_001001909; sense primer 5'cctcgagactatggcgcttcccaga3' and anti-sense primer 5'gaattcttaacgacacgtgcactttg3') and BMP15 (HQ45075, sense primer 5'gaattcgaacatgttgctgaacaagtctttc3' and anti-sense primer 5'tctagatcacctgcacgtacaggactgg 3 ') that were designed to incorporate restriction enzyme sites. The resultant PCR products were cloned into pGEMTeasy vector, which was then sub-cloned into the mammalian expression plasmid, pEFIRES (Hobbs et al., 1998) using Xho1/EcoR/ sites for GDF9 and EcoRI/Xbal sites for BMP15. The GDF9- and BMP15-pEFIRES ligation products were singly transfected into the human embryonic kidney cell line (HEK-293) as previously reported (McNatty et al., 2005) using the FuGENE $® H D$ transfection reagent and following the manufacturers protocol. Transfected cells were grown to confluency in growth medium (DMEM supplemented with $10 \%(\mathrm{v} / \mathrm{v})$ foetal calf serum, $100 \mathrm{IU} / \mathrm{mL}$ penicillin-streptomycin and $2 \mathrm{mM} \mathrm{L}$-glutamine) and selected through their resistance to increasing concentrations of puromycin up to $100 \mu \mathrm{g} / \mathrm{mL}$. Thereafter, cells were incubated in expression medium (DMEM/Ham's F-12 (1:1) supplemented with $0.01 \%(\mathrm{w} / \mathrm{v})$ bovine serum albumin (BSA), $100 \mathrm{IU} / \mathrm{mL}$ penicillinstreptomycin, $2 \mathrm{mM} \mathrm{L}$-glutamine and $100 \mu \mathrm{g} / \mathrm{mL}$ heparin. The expression media (conditioned media) containing a mix of pro-mature and mature porcine GDF9 and BMP15 (Alhussini, 2016; Swinerd, 2016) was collected and stored at $-80^{\circ} \mathrm{C}$ until required.

In this experiment, four different IVM conditions were assessed and are as follows; 
i. 'Group control' group: The COC in this group received the standard IVM conditions as described in Section 2.6 (Figure 2-2). To normalise against any effects due to secretions from the HEK-293 cells, other than that of the transfected proteins, IVM media was supplemented with an equivalent volume of conditioned media from HEK-293 cells that were transfected with an empty vector. Eight to ten COC were cultured in each $50 \mu \mathrm{L}$ IVM media drop. This IVM condition group was included to test effects of native OSF secretions from accompanying COC.

ii. 'Single control' group: The COC in this group were exposed to IVM media and conditions that were identical to that of the 'group control' group, with the exception that only one COC was cultured per $50 \mu \mathrm{L}$ IVM media drop. This IVM condition was included as a direct control for the 'low ratio' and 'high ratio' groups.

iii. 'Low ratio' group: The COC in this group were exposed to IVM media and conditions that were identical to that for the 'single control' group, with the exception that IVM media was supplemented with secreted media containing a $1: 6$ ratio of rec pGDF9 $(16.7 \mathrm{ng} / \mathrm{mL})$ and $r e c$ pBMP15 $(100.0 \mathrm{ng} / \mathrm{mL})$. A single COC was added to each IVM drop which had a final volume of $50 \mu \mathrm{L}$. This IVM condition mimics the GDF9:BMP15 ratio of oocytes of low OR species (extrapolated from mRNA data; Crawford and McNatty, 2012).

iv. 'High ratio' group: The COC in this group were exposed to IVM media and conditions that were identical to that for the 'single control' group, with the exception that IVM media was supplemented with secreted media containing a $6: 1$ of ratio rec pGDF9 (100.0 ng/mL) and rec pBMP15 (16.7 ng/mL). A single COC was added to each IVM drop which had a final volume of $50 \mu \mathrm{L}$. This IVM condition mimics the GDF9:BMP15 ratio of oocytes of high OR species (extrapolated from mRNA data; Crawford and McNatty, 2012).

The concentration of all other IVM media components were constant for all IVM conditions tested.

\subsubsection{IVP}

In these experiments, IVP was performed as described previously in Section 2.6. Briefly, conditioned and IVM media for each experiment was thawed on the morning of IVM (Figure 2-2) and the media for the different IVM conditions was prepared as described in Section 
5.2.1. Following extraction from the ovaries, COC with multiple intact and compact CC layers were washed twice in $\mathrm{H} 199+10 \% \mathrm{FBS}$ and transferred into equilibrated B199 + $10 \%$ FBS and then into the IVM drops. The COC were incubated in $50 \mu \mathrm{L}$ of IVM media for 25 hours. The next morning, the modified IVF plates were prepared and placed in the embryo box to equilibrate. At the end of IVM, COC were removed from the IVM drops and transferred through two washes of HSOF and then into $10 \mu \mathrm{L}$ of HSOF. The degree of expansion was assessed using a CC expansion index (CEI) that has been described previously (Fagbohun and Downs, 1990; Vanderhyden et al., 1990; Dragovic et al., 2005). The CEI consists of a scale of 0 - 4 and each COC was scored according to the criteria in Table 5-1.

Table 5-1: Definition of CC expansion index (CEI) scores. Adapted from Vanderhyden et al. (1990). Abbreviations used: CC - cumulus cells, CR - corona radiata.

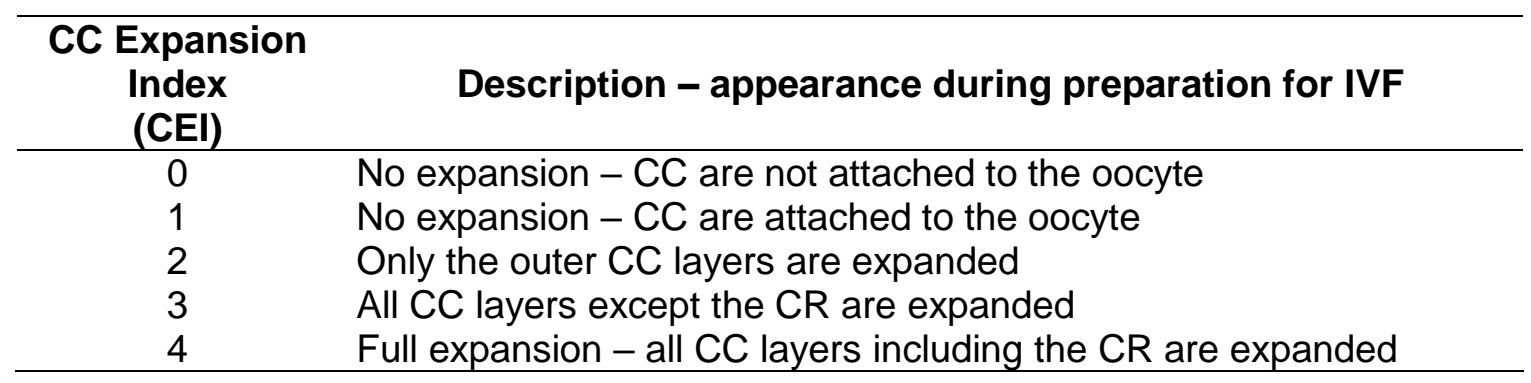

The CC were loosened by repeated manual pipetting and the partially denuded COC was transferred into a HSOF wash and then into equilibrated IVF media. The COC was transferred in $2 \mu \mathrm{L}$ of IVF media into the well of the prepared IVF plate and the well number was recorded. The plates containing the oocytes were returned to the embryo box and the box was resealed. The stripped CC were transferred into a $0.65 \mathrm{~mL}$ tube, snap-frozen and stored at $-80^{\circ} \mathrm{C}$.

The sperm was prepared and added to the oocytes at a concentration of 75,000 sperm/drop and returned to the embryo box. The IVF plates were incubated for 18 hours after which the presumptive zygote was removed and washed in HSOF. The remaining $\mathrm{CC}$ were removed and the presumptive zygote was transferred into a well in a 16-well PrimoVision ${ }^{\mathrm{TM}}$ embryo culture plate and the well number recorded. The final volume of the IVC drop was equivalent to $2 \mu \mathrm{L}$ per embryo and once all the embryos had been placed in a well, the plate was positioned on the camera and the time-lapse program initiated. The camera was set to acquire images every five minutes for nine days. This extended culture period was selected to ensure that if development in embryos was 
delayed due to any of the conditions, there would still be associated morphokinetic data. The media in the drops was replaced on Day five with fresh equilibrated SOF.

Ten replicate experiments were performed. Due to the availability of only one embryo box at the time of these experiments, each replicate experiment included a 'group control', 'single control' and either a 'low ratio' or 'high ratio' group. The CC samples were collected from COC from all replicate experiments. Due to a malfunction in PrimoVision ${ }^{\mathrm{TM}}$ cameras for two experiments and seasonal differences in ovary, and thus oocyte, quality in a further two experiments, morphokinetic data was only included from embryos of six replicate experiments. However embryological outcome data used results from eight replicate experiments (excluded experiments that used poor quality oocytes due to season).

\subsubsection{Embryological outcomes}

At the end of IVC period, the embryological outcome for each embryo was determined as stage to which the embryo developed during the nine-day incubation period as described previously. Embryos were identified as having arrested at or before the 8-cell stage ( $\leq 8$ cells), arrested after the 8-cell stage but before morula formation (>8-cells), developed to the compact morula stage or until the blastocoel could be visualised (CMEB), or to the blastocyst stage for which the criteria was that the blastocoel filled greater than half of the embryo (Blastocyst).

\subsubsection{Morphokinetic parameters}

After the IVC experiments were completed, the time-lapse videos were viewed and annotated to identify the exact timings of the morphokinetic events. The cleavage events were corrected to the time to develop to a 2-cell embryo (as described previously; Table 2-2). All timing data were reported in decimal time.

\subsubsection{Gene expression analysis}

The CC samples were randomly selected such that appropriate numbers from each representative embryological outcome group for each of the treatments were compared, with the exception of the blastocyst group in which all of the embryos were included. Total RNA, cDNA synthesis and mRNA expression level measurements were performed and analysed as described in Section 2.7. 


\subsubsection{Statistical procedures}

The cleavage rate was calculated as the percentage of presumptive zygotes that cleaved to a two-cell embryo, while the blastocyst rate was calculated as the percentage of cleaved embryos that developed to the blastocyst stage (i.e. a blastocoel was visualised). Differences between experiments in the proportions of embryos that cleaved, arrested at a specific developmental stage or formed a blastocyst were analysed using Chi-square tests. Where significant differences between groups were noted, pairwise Fisher's exact tests were implemented. The effects of IVM conditions, CEI and embryological outcome on CC gene expression, and the timing of morphokinetic events was analysed using a Kruskal-Wallis $\mathrm{H}$ test with Dunn's test of multiple comparisons using rank sums where data were non-normally distributed and a one-way ANOVA with Tukey multiple comparisons test where data were normally distributed. Statistical analyses in this chapter were performed using the $R$ software program (version 3.3.1) while the figures in this chapter were created using GraphPad Prism (version 5.0). The alpha level for these analyses was 0.05 . 


\subsection{Results}

\subsubsection{Overall embryological outcomes}

The overall embryological outcomes, regardless of IVM condition, for the eight replicate experiments performed are listed in Table 5-2.

Table 5-2: Summary of the total numbers of embryos assessed in the IVP experiments. Data shows the proportion (\%) of embryos in each of the categories and the ratios of the number of embryos to the total number of embryos are listed in brackets.

\begin{tabular}{ll}
\hline Summary of experiments & Rate (\#) \\
& \\
\hline Cleavage & \\
Cleaved & $78.3 \%(288 / 368)$ \\
Uncleaved & $9.8 \% \quad(36 / 368)$ \\
Abnormal & $12.0 \%(44 / 368)$ \\
Embryonic Development & \\
s8-cell & $28.5 \%(82 / 288)$ \\
$>8$-cell & $32.3 \%(93 / 288)$ \\
CMEB & $31.6 \%(91 / 288)$ \\
Blastocysts & $7.6 \%(22 / 288)$ \\
Overall blastocyst rate & $29.2 \%(84 / 288)$ \\
\hline
\end{tabular}

\subsection{Effects of IVM conditions on $\mathrm{CC}$ function}

The effects of modulating IVM conditions on CC expansion and expression of associated key genes were investigated.

\subsubsection{Effects of IVM conditions on CC expansion}

The degree of CC expansion in COCs matured under different IVM conditions are shown in Figure 5-2A. There was a main effect $(P<0.0001)$ of IVM conditions on the degree of expansion. The CEI scores were highest in $\mathrm{COC}$ cultured in the 'high ratio' IVM condition (6:1 GDF9:BMP15) compared to 'group control', 'single control' and 'low ratio' IVM conditions (1:6 GDF9:BMP15; $\mathrm{P}=0.0001, \mathrm{P}<0.0001$ and $\mathrm{P}=0.0001$, respectively). The CEI scores were lowest in $\mathrm{COC}$ cultured in the 'single control' IVM condition compared to the 'group control' and 'low ratio' IVM conditions ( $P=0.0020$ and $P=0.0127$, respectively), 
whilst the CEI scores for the 'group control' and 'low ratio' IVM conditions were equivalent. These results reveal that GDF9 and BMP15, regardless of whether it is a recombinant or native source, improved $\mathrm{CC}$ expansion. The $\mathrm{CC}$ of the $\mathrm{COC}$ in the 'single culture' group did not receive recombinant GDF9 or BMP15, nor native OSF secreted from surrounding $\mathrm{COC}$ as in the 'group control' group and thus had the lowest CEI.

Likewise, there was a trend of CC expansion levels being different when associated with oocytes with different embryological outcomes (Figure 5-2B; $P=0.0513$ ). Whilst post-hoc analyses did not identify differences between pairs of embryological outcomes, it appeared that the CC associated with oocytes that failed to reach an 8-cell embryo had a lower degree of expansion.
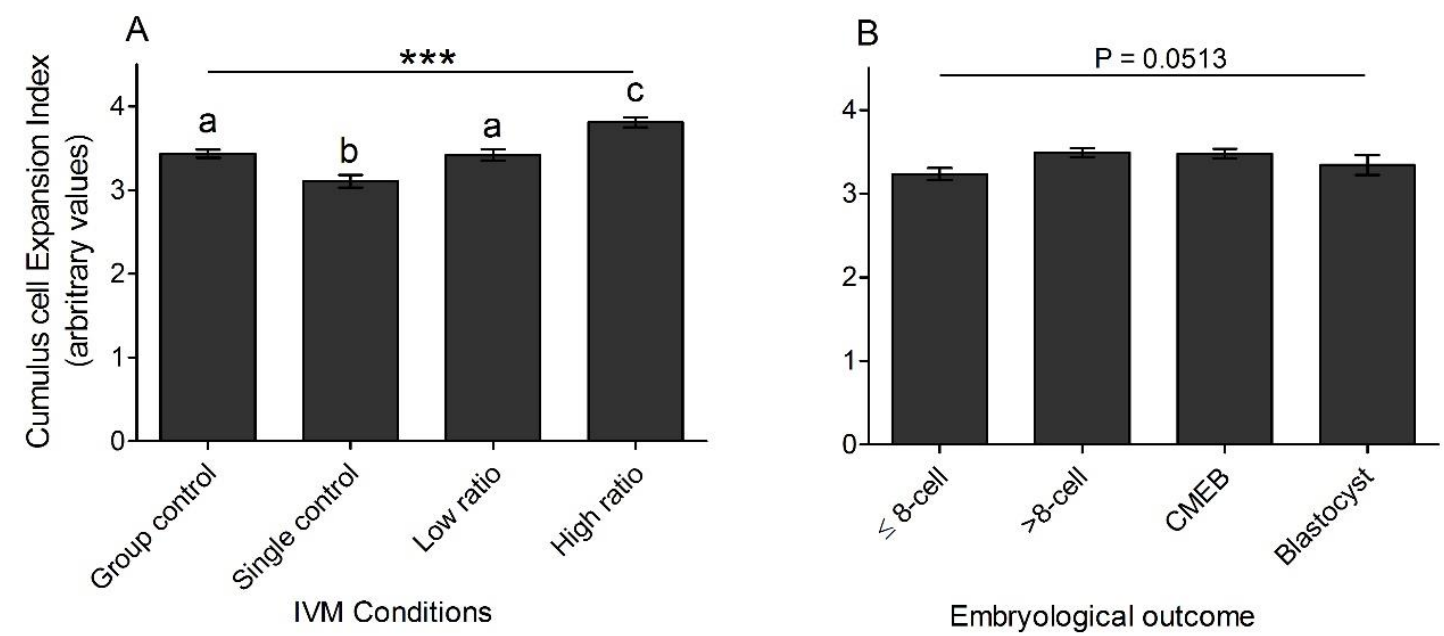

Figure 5-2: $C C$ expansion index (CEI) score between $C O C$ that were incubated in different IVM conditions (A) and between different embryological outcomes (B). Data represents 22 - 155 individual COC and are presented as the geometric mean and $95 \%$ $\mathrm{Cl}$. Data was analysed using Kruskal-Wallis $\mathrm{H}$ tests. Where statistical differences were identified, (denoted by ${ }^{*} \mathrm{P}<0.05$, ${ }^{* *} \mathrm{P}<0.01$, ${ }^{* * *} \mathrm{P}<0.001$ ), Dunn's multiple comparison test was performed. Groups not sharing a common letter are significantly different $(P<0.05)$.

\subsubsection{Association between CC expansion and morphokinetic timings}

The timings of key morphokinetic markers in embryos that exhibited differing degrees of CC expansion following IVM were compared. There were no effects of CC expansion on the total time taken to develop into 3-cell (t3C), 4-cell (t4C), 5-cell (t5C) stage, morula (tM), compact morula (tMC), development of a blastocoel (SB) or the duration of the second (cc2) or third (cc3) cell cycle, the interval between the cleavage to 3- and 4-cell stage 
(cc3a), or the synchronicity of the second cell cycle (s2; data not shown). In contrast, the total time taken from sperm addition to development of a 2-cell stage (t2C) embryo was different between $C O C$ with differing degrees of $C C$ expansion ( $P=0.0404$; Figure 5-3). Specifically, the duration of $\mathrm{t} 2 \mathrm{C}$ was shorter in COC that were fully expanded, compared to those in which only the outer layers, or all layers excluding the CR were expanded $(P=0.0146$ and $P=0.0339$, respectively).

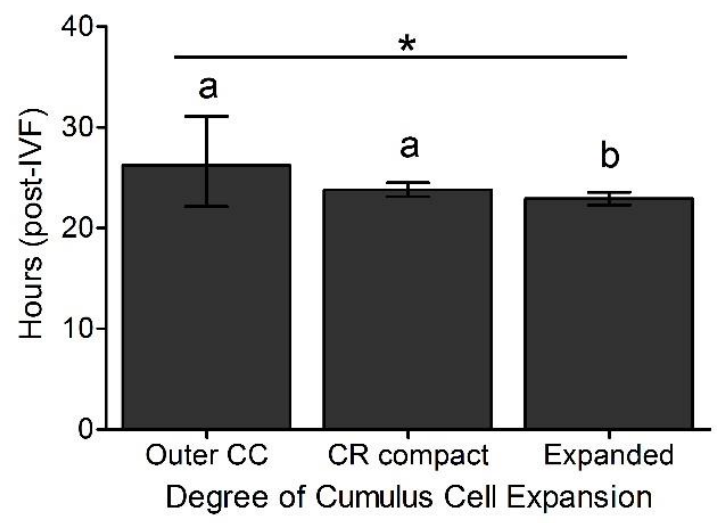

Figure 5-3: Total time taken to reach the 2-cell stage (t2C) in ovine embryos associated with different CC expansion index (CEI) scores following IVM. The values represent the total time in decimal hours post-IVF and are presented as the geometric mean and $95 \% \mathrm{Cl}$ of $14-199$ individual CC masses. Where a statistical difference was identified (denoted by asterisk; ${ }^{*} \mathrm{P}<0.05$ ), Dunn's test was performed and groups not sharing a common letter are statistically different $(P<0.05)$.

\subsubsection{Effects of IVM conditions on CC gene expression}

The mean relative expression levels of key CC-derived genes from COC cultured under different IVM conditions are shown in Figure 5-4. There were main effects of IVM condition on all genes tested, namely HAS2 ( $\mathrm{P}<0.0001), \operatorname{VCAN}(\mathrm{P}<0.0001), H S P 90 B 1(\mathrm{P}<0.0001)$, FSHR $(\mathrm{P}=0.0235), P G R(\mathrm{P}<0.0001)$, GJA1 $(\mathrm{P}=0.0087)$, EREG $(\mathrm{P}<0.0001)$ and BMPR2 $(P=0.0008)$.

Mean HAS2 mRNA levels were lower in the 'single control' group compared to all other conditions tested $(\mathrm{P}<0.0001$ for all). Whilst HAS2 expression levels were similar between the 'high ratio' and 'group control' groups, they were higher $(P=0.0024)$ in the 'low ratio', compared to the 'group control', group.

Mean VCAN mRNA levels were higher in the 'low ratio' ( $P<0.0001$ for both) and 'high ratio' ( $P=0.0122$ and $P=0.0003$, respectively) groups compared to the 'group control' and 'single control' groups. 
Mean HSP90B1 mRNA levels were lowest in the 'group control' group, compared to the 'single control', 'low ratio' and 'high ratio' groups $(P=0.0011, P<0.0001$ and $P<0.0001$, respectively). Additionally, mean $H S P 90 B 1$ expression was significantly higher in the 'low ratio', compared to the 'group control', group $(P=0.0389)$, but neither of these differed from that in the 'high ratio' group.

Mean FSHR mRNA was higher in the 'single control' group, compared to 'group control', 'low ratio' and 'high ratio' groups $(\mathrm{P}=0.0015, \mathrm{P}=0.0502$ and $\mathrm{P}=0.0232$, respectively).

The expression levels of PGR mRNA were lowest in the 'group control' group, compared to the 'single control', 'low ratio' and 'high ratio' groups $(\mathrm{P}=0.0043, \mathrm{P}<0.0001$ and $\mathrm{P}<0.0001$, respectively). Moreover, mean $P G R$ mRNA levels were lower in the 'single control' compared to the 'low ratio' and 'high ratio' groups $(P=0.0003$ and $P<0.0001$, respectively).

The expression of GJA1 was lowest in the 'group control' group, compared to the 'single control', 'low ratio' and 'high ratio' groups $(P=0.0086, P=0.0006$ and $P=0.0304$, respectively), which were not different to each other.

Unlike all other genes tested, EREG mRNA levels were highest in the 'group control', compared to the 'single control', 'low ratio' and 'high ratio' $(P=0.0003, P<0.0001$ and $\mathrm{P}<0.0001$, respectively), groups. Likewise, it was lowest in the 'low ratio' and 'high ratio' groups, compared to the 'single control' group ( $\mathrm{P}=0.0218$ and $\mathrm{P}=0.0002$, respectively).

Mean BMPR2 expression levels were lowest in the 'group control', compared to the 'low ratio' and 'high ratio' ( $\mathrm{P}=0.0006$ and $\mathrm{P}=0.0353$, respectively) groups. Mean $B M P R 2$ mRNA levels in the 'single control' IVM condition were not different to any other group. 

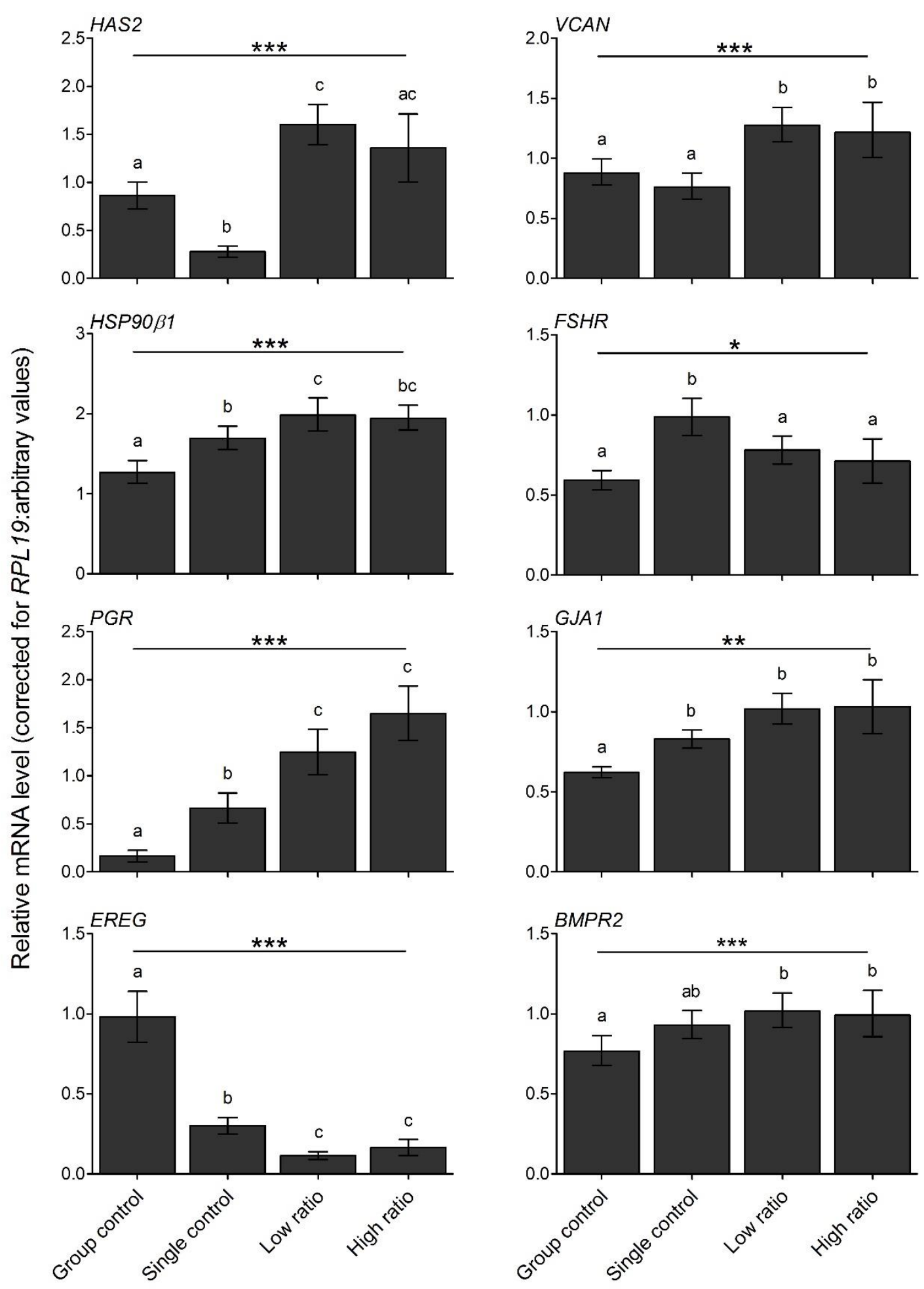

IVM conditions 
Figure 5-4: Relative mRNA levels of HAS2, VCAN, HSP90B1, FSHR, PGR, GJA1, EREG and BMPR2 in ovine CC masses matured under different IVM conditions. HAS2, FSHR, PGR, GJA1 and EREG were analysed using Kruskal-Wallis $\mathrm{H}$ tests, while VCAN, HSP90B1 and BMPR2 were transformed (square root) and analysed by one-way ANOVA. The values for HAS2, FSHR, PGR, GJA1 and EREG represent mean \pm SEM while the values for VCAN, HSP90B1 and BMPR2 represent the geometric mean and 95 $\%$ confidence limits of the linearised $C_{T}$ values. Data represents $23-55$ post-IVM CC samples, where a statistical difference was identified (denoted by asterisk, ${ }^{*} P<0.05$, ** $P<0.01,{ }^{* * *} P<0.001$ ), Tukey multiple comparisons test (one-way ANOVA) or Dunn's test (Kruskal-Wallis) were performed and groups not sharing a common letter are statistically different $(\mathrm{P}<0.05)$.

\subsubsection{Association between CC expansion and gene expression}

The relationship between CC expansion and mRNA expression levels of HAS2, VCAN, HSP9OB1, FSHR, PGR, GJA1, EREG and BMPR2 were investigated, and those with differences are depicted in Figure 5-5. The degree of CC expansion had no effect on the expression levels of HSP90B1, FSHR, PGR, GJA1, EREG and BMPR2 mRNA (data not shown). In contrast, there were main effects of CC expansion on mean HAS2 and VCAN mRNA levels ( $P=0.0055$ and $P=0.0206$, respectively).
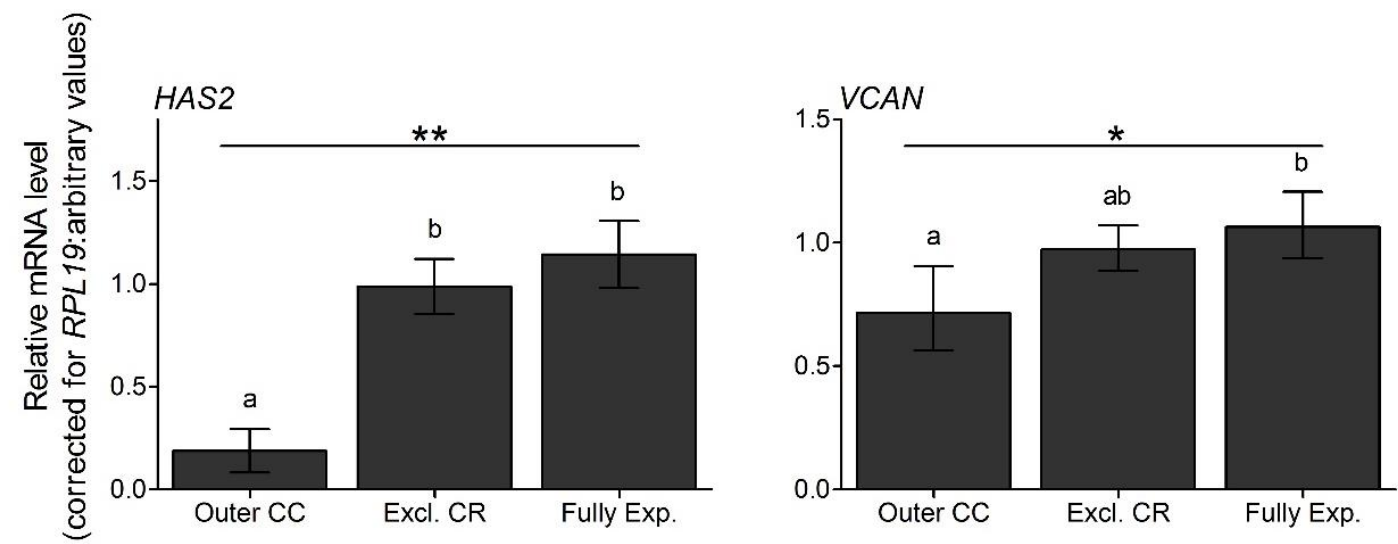

IVM conditions

Figure 5-5: Relative mRNA levels of HAS2 and VCAN in post-IVM ovine CC masses with different degrees of $\mathrm{CC}$ expansion. The data for $H A S 2$ was analysed using a Kruskal-Wallis $\mathrm{H}$ test and values are represented as mean \pm SEM of the linearised $\mathrm{C}_{T}$ values. Data for VCAN was transformed (square root) and analysed by one-way ANOVA, values represent the geometric mean and $95 \% \mathrm{Cl}$. Data represents $11-97 \mathrm{CC}$ samples. Differences were denoted by asterisk * $\left(P<0.05,{ }^{* *} P<0.01\right)$, following a Dunn's (KruskalWallis) or Tukey multiple comparisons (one-way ANOVA) test. Groups not sharing a common letter are statistically different $(P<0.05)$. 
Mean HAS2 mRNA was higher in fully-expanded (i.e. $C E I=4 ; P=0.0006$ ) and expanded $\mathrm{CC}$ associated with a compact $\mathrm{CR}$ layer (i.e. $\mathrm{CEI}=3, \mathrm{P}=0.0022$ ), compared to those in which only the outer layers were expanded (i.e. $C E I=2$ ). Likewise, the expression of VCAN mRNA was highest $(P=0.0192)$ in fully expanded $C C$ compared to those in which only the outer layers were expanded.

\subsubsection{Effects of IVM conditions on early embryonic development}

The effects of modulating IVM conditions on cleavage rates, embryological outcomes, and timings of key morphokinetic events in the early embryo were investigated.

\subsubsection{Effects of IVM conditions on oocyte developmental competency}

Preliminary analyses showed no effect of IVM conditions on the proportion of embryos attributed to the blastocyst group (i.e. blastocysts where the blastocoel filled greater than half of the embryo; data not shown). Subsequently, the effects of IVM conditions on developmental competency of oocytes was measured by comparing the proportions of embryos that formed any grade blastocyst (i.e. early and late stage blastocyst; termed blastocyst rate) and these results are depicted in Figure 5-6. There was a main effect of IVM condition on blastocyst rate ( $\mathrm{P}=0.0316)$, with those COC matured under 'high ratio' IVM conditions having a higher blastocyst rate compared to those matured under the 'group control', 'single control' and 'low ratio' IVM conditions ( $P=0.0056, P=0.0496$ and $P$ $=0.0349$, respectively). 


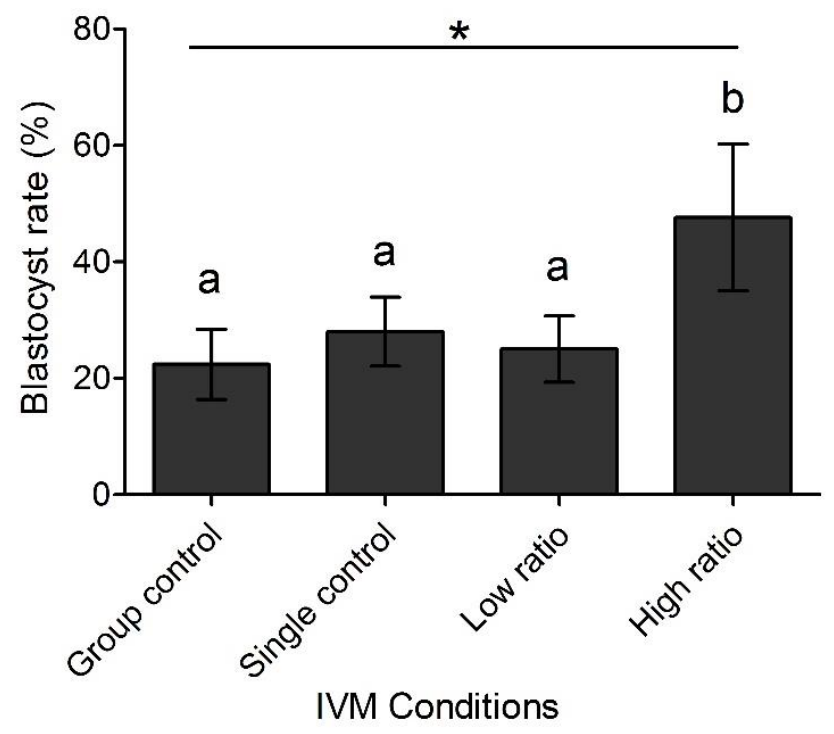

Figure 5-6: Proportion of blastocysts (\%) following IVM under different conditions. Data represents the mean \pm SEM blastocyst rate from three to eight replicate experiments and was analysed by Chi-square tests. Significant differences are denoted by asterisk (* $P<0.05)$. Pairwise comparisons were made using Fisher's exact test and groups that do not share a common letter are significantly different $(P<0.05)$.

\subsubsection{Effects of IVM conditions on cleavage rate and embryological outcomes}

There were no main effects of IVM conditions on the proportion of presumptive zygotes that successfully cleaved to 2-cells (i.e. cleavage rate; Figure 5-7A). When embryological outcomes were compared, different IVM conditions had no effect on the proportions of cleaving embryos that arrested at $\leq 8$-cells, between 8-cells and morula, between morula and early blastocyst stage, or that successfully developed into a late blastocyst (Figure 5-7B). However, it appeared that fewer embryos arrested at $\leq 8$-cell stage and a greater proportion developed into compact morulae or early blastocysts following maturation in 'high ratio' IVM conditions, compared to all other IVM conditions. 


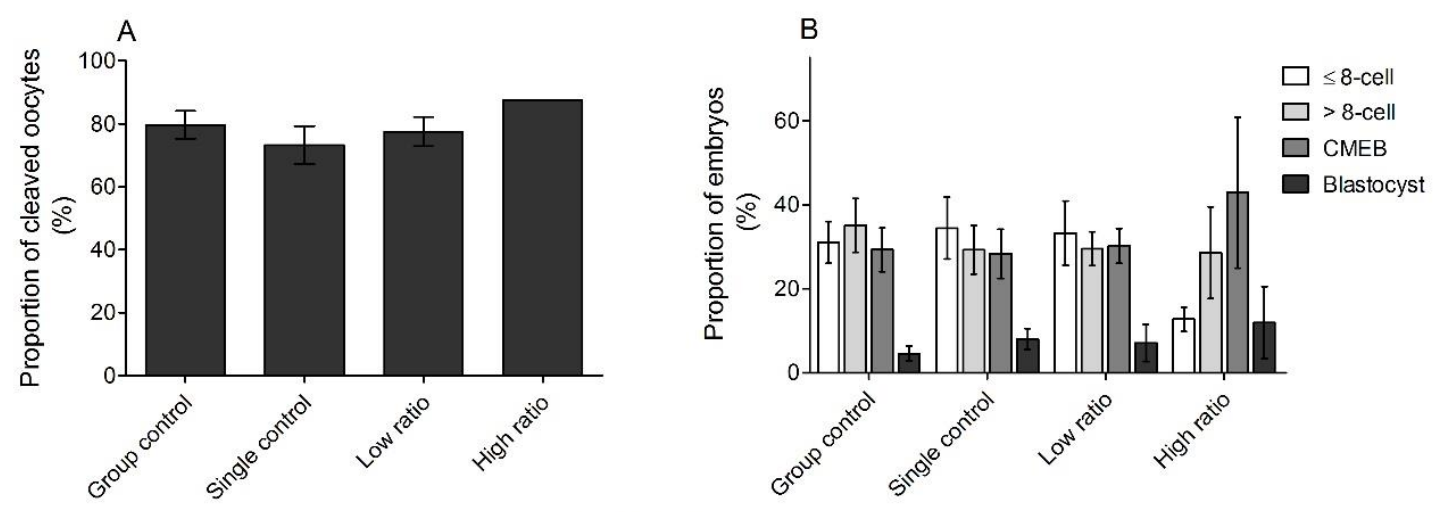

IVM Conditions

Figure 5-7: The proportion of presumptive zygotes that underwent cleavage to 2-cells (A) and of cleaving embryos with different embryological outcomes (B) (\%) following maturation under different IVM conditions. Data represents the mean \pm SEM from three to eight replicate experiments and was analysed by Chi-square tests.

\subsubsection{Associations between morphokinetic markers and embryological outcomes}

The effects of different embryological outcomes on the timings of key embryonic cleavage events (i.e. morphokinetic markers) are depicted in Table 5-3. There were no differences between embryological outcome and the total time taken to develop to the 3-cell ( $\mathrm{t} 3 \mathrm{C})$ or compact morula stage (tMC;), visualise a blastocoel (SB) or the duration of the second cycle (cc2). In contrast, there were differences in the total time taken to develop to the 2cell (t2C; $\mathrm{P}<0.0001$ ), 4-cell (t4C; $\mathrm{P}=0.0066$ ), 5-cell stage (t5C; $\mathrm{P}=0.0011$ ), morula ( $\mathrm{tM}$; $P=0.0041)$, the duration of the third cell cycle (cc3; $P=0.0004)$, the interval between the cleavage to 3 - and 4-cell stage (cc3a; $\mathrm{P}=0.0075$ ) and the synchronicity of the second cell cycle (s2; $\mathrm{P}=0.0360)$ and embryological outcomes.

The time taken to develop to the 2-cell stage was significantly longer for embryos that arrested at or before the 8-cell stage ( $\leq 8$-cell) than for embryos that arrested after the 8-cell stage (>8-cell), developed into compact morula and early blastocysts (CMEB) or developed to the blastocyst stage (Blastocyst; $P<0.0001, P<0.0001$ and $P=0.0190$, respectively).

In contrast, the time taken to develop to the 4-cell ( $\mathrm{t} 4 \mathrm{C})$ and 5-cell ( $\mathrm{t} 5 \mathrm{C})$ stage, the duration of the third cell cycle and the interval between the cleavage to 3- and 4-cell stage was significantly shorter for embryos that arrested at $\leq 8$-cell stage compared to embryos that 
arrested $>8$-cell stage $(P=0.0017, P<0.0001, P=0.0001$ and $P=0.0008$, respectively $)$, at compact morula or early blastocysts $(P=0.0011, P=0.0002, P=0.0003$ and $P=0.0117$, respectively) or developed into blastocysts $(P=0.0315, P=0.0118, P=0.0074$ and $\mathrm{P}=0.0173$, respectively). Likewise, the total time taken to develop into a morula (tM) was significantly shorter in embryos that arrested $>8$-cell stage than for embryos that developed into compact morula and early blastocysts or blastocysts $(P=0.0022$ and $P=0.0038$, respectively).

The duration of the second cell cycle (s2) was significantly shorter for embryos that arrested after the 8-cell stage than for those that arrested at $\leq 8$-cell stage or those developed into compact morula and early blastocysts $(P=0.0204$ and $P=0.0026$, respectively). 
Table 5-3: Timings of morphokinetic events in ovine embryos with different embryological outcomes following maturation under different IVM conditions. The t2C values are represented in decimal hours post-IVF while the remaining morphokinetic parameters are normalised to t2C (hours). Values represent the geometric mean (95\% $\mathrm{Cl}$ ) with the number of observations noted in []. The values representing $\mathrm{IMC}$ and SB were analysed by $\mathrm{t}$-test and $\mathrm{t} 2 \mathrm{C}, \mathrm{t} 3 \mathrm{C}, \mathrm{t} 4 \mathrm{C}, \mathrm{t} 5 \mathrm{C}, \mathrm{tM}, \mathrm{cc} 2, \mathrm{cc} 3, \mathrm{cc} 3 \mathrm{a}$ and $\mathrm{s} 2$ values were analysed using Kruskal-Wallis $\mathrm{H}$ tests. Where statistical differences were identified, (denoted by * $\mathrm{P}<0.05$, ${ }^{* *} \mathrm{P}<0.01,{ }^{* * *} \mathrm{P}<0.001$ ), Dunn's test was performed. Groups not sharing a common letter are significantly different $(P<0.05)$, NS denotes the within row values are not significantly different to each other.

\begin{tabular}{|c|c|c|c|c|c|}
\hline \multicolumn{6}{|c|}{ Embryological Outcome } \\
\hline & $\begin{array}{c}\text { Arrest } \leq 8 \text {-cell } \\
\text { stage }\end{array}$ & $\begin{array}{c}\text { Arrest }>8 \text {-cell } \\
\text { stage }\end{array}$ & CMEB & Blastocyst & $\begin{array}{c}P \text { - } \\
\text { value }\end{array}$ \\
\hline t2C & $\begin{array}{c}25.69^{\mathrm{a}} \\
(24.50,26.94) \\
{[\mathrm{n}=65]}\end{array}$ & $\begin{array}{c}22.62^{\mathrm{b}} \\
(22.62,23.39) \\
{[\mathrm{n}=64]}\end{array}$ & $\begin{array}{c}22.71^{\mathrm{b}} \\
(22.07,23.37) \\
{[\mathrm{n}=80]}\end{array}$ & $\begin{array}{c}23.53^{\mathrm{b}} \\
(21.43,25.83) \\
{[\mathrm{n}=18]}\end{array}$ & $\star \star \star *$ \\
\hline t3c & $\begin{array}{c}4.31 \\
(3.19,5.82) \\
{[n=57]}\end{array}$ & $\begin{array}{c}3.43 \\
(2.75,4.275) \\
{[n=64]}\end{array}$ & $\begin{array}{c}4.34 \\
(3.57,5.29) \\
{[n=80]}\end{array}$ & $\begin{array}{c}4.69 \\
(3.31,6.64) \\
{[n=18]}\end{array}$ & NS \\
\hline $\mathrm{t} 4 \mathrm{C}$ & $\begin{array}{c}7.35^{\mathrm{a}} \\
(5.81,9.29) \\
{[\mathrm{n}=54]}\end{array}$ & $\begin{array}{c}5.32^{\mathrm{b}} \\
(4.44,6.38) \\
{[\mathrm{n}=64]}\end{array}$ & $\begin{array}{c}7.69^{\mathrm{a}} \\
(6.55,9.02) \\
{[\mathrm{n}=80]}\end{array}$ & $\begin{array}{c}7.28^{a} \\
(5.17,10.23) \\
{[n=18]}\end{array}$ & $\star \star$ \\
\hline t5C & $\begin{array}{c}15.89^{\mathrm{a}} \\
(12.84,19.66) \\
{[\mathrm{n}=40]}\end{array}$ & $\begin{array}{c}8.86^{\mathrm{b}} \\
(7.56,10.38) \\
{[\mathrm{n}=64]}\end{array}$ & $\begin{array}{c}13.00^{\mathrm{a}} \\
(11.31,14.96) \\
{[\mathrm{n}=80]}\end{array}$ & $\begin{array}{c}13.03^{\mathrm{a}} \\
(9.49,17.89 \\
{[\mathrm{n}=18]}\end{array}$ & $\star \star$ \\
\hline tM & - & $\begin{array}{c}31.42^{\mathrm{a}} \\
(27.72,35.61) \\
{[\mathrm{n}=53]}\end{array}$ & $\begin{array}{c}40.19^{b} \\
(36.10,44.73) \\
{[n=80]}\end{array}$ & $\begin{array}{c}42.67^{b} \\
(34.57,52.66) \\
{[n=15]}\end{array}$ & $\star \star$ \\
\hline tMC & - & - & $\begin{array}{c}82.65 \\
(77.08,88.63) \\
{[n=80]}\end{array}$ & $\begin{array}{c}79.93 \\
(70.74,90.31) \\
{[n=18]}\end{array}$ & NS \\
\hline SB & - & - & $\begin{array}{c}112.70 \\
(105.30,120.60) \\
{[n=55]}\end{array}$ & $\begin{array}{c}109.70 \\
(98.49,122.20) \\
{[n=18]}\end{array}$ & NS \\
\hline cc2 & $\begin{array}{c}2.41 \\
(1.59,3.65) \\
{[n=58]}\end{array}$ & $\begin{array}{c}1.89 \\
(1.32,2.72) \\
{[n=64]}\end{array}$ & $\begin{array}{c}2.49 \\
(1.84,3.36) \\
{[n=80]}\end{array}$ & $\begin{array}{c}3.35 \\
(2.17,5.17) \\
{[n=18]}\end{array}$ & NS \\
\hline $\operatorname{cc3}$ & $\begin{array}{c}6.19^{\mathrm{a}} \\
(4.02,15.38) \\
{[\mathrm{n}=41]}\end{array}$ & $\begin{array}{c}2.53^{\mathrm{b}} \\
(1.86,3.44) \\
{[\mathrm{n}=64]}\end{array}$ & $\begin{array}{c}4.93^{\mathrm{a}} \\
(3.76,6.48) \\
{[\mathrm{n}=80]}\end{array}$ & $\begin{array}{c}5.47^{\mathrm{a}} \\
(3.20,9.34) \\
{[\mathrm{n}=18]}\end{array}$ & $\star \star \star$ \\
\hline cc3a & $\begin{array}{c}5.11^{\mathrm{a}} \\
(3.36,7.76) \\
{[40]}\end{array}$ & $\begin{array}{c}2.39^{b} \\
(1.85,3.09) \\
{[64]}\end{array}$ & $\begin{array}{c}3.56^{\mathrm{a}} \\
(2.78,4.55) \\
{[80]}\end{array}$ & $\begin{array}{c}4.57^{\mathrm{a}} \\
(2.84,7.35) \\
{[18]}\end{array}$ & $\star \star$ \\
\hline s2 & $\begin{array}{c}2.75^{\mathrm{a}} \\
(2.09,3.62) \\
{[\mathrm{n}=54]}\end{array}$ & $\begin{array}{c}1.97^{\mathrm{b}} \\
(1.57,2.46) \\
{[\mathrm{n}=64]}\end{array}$ & $\begin{array}{c}3.09^{\mathrm{a}} \\
(2.48,3.84) \\
{[\mathrm{n}=80]}\end{array}$ & $\begin{array}{c}2.88^{\mathrm{ab}} \\
(1.83,4.56) \\
{[\mathrm{n}=18]}\end{array}$ & * \\
\hline
\end{tabular}




\subsection{Discussion}

The experiments described herein investigated the effects of different IVM conditions, specifically the addition of low and high ratios of rec pGDF9:BMP15, on oocyte developmental competency, CC expansion and gene expression as well as embryological outcomes. This study utilised the molecular and morphokinetic markers characterised in CHAPTER 4 aboveto elucidate the effects of the different IVM conditions on CC maturation, and the relationship between early embryonic cleavage timings and embryonic outcomes. The key finding of this study was that a 'high ratio', (i.e. 6:1) of GDF9:BMP15 supplemented to IVM media improved blastocyst rate and thus developmental competency of ovine oocytes. This effect may, at least in part, be due to modulation of maturational processes in the CC. The results also indicated that the while GDF9 and BMP15 altered the degree of expansion and gene expression in CC, they did not affect the timing of morphokinetic events. This suggests that IVM conditions do not change the timing of morphokinetic events in embryos that are grouped on embryonic outcomes (i.e. arrest at specific stages or successfully develop to the blastocyst stage following IVM and IVF).

In order to differentiate between the positive effects of group culture and the addition of low and high ratios of GDF9:BMP15, single IVM culture methodologies were employed. Culturing single COC during the IVM period has been shown previously to produce embryos with decreased developmental competency, compared to group culture systems (Blondin and Sirard, 1995; Feng et al., 2007). The current study attempted to minimise differences due to reasons other than media supplementation. For example, IVM media volume was kept constant regardless of the number of oocytes per drop in order to standardise the concentration of media components, particularly, lipid soluble components such as oestradiol, which are known to be lost from media when overlaid with mineral oil (Reinsberg et al., 2004). Moreover, two controls were included, a standard group culture control, and a single culture control, differing only by the number of $\mathrm{COC}$ cultured per drop and the presence of the microwells. Contrary to previous evidence, the current experiments showed no difference in blastocyst rate between the group and single control groups. This is supported by evidence from Carolan et al. (1996), who reported that differences in blastocyst rate between group and single culture methodologies are eliminated when IVM conditions, such as media components, were adequately optimised. 
In the 'high ratio' IVM condition group, blastocyst rate was approximately 1.8-fold higher than any other experimental group. The blastocyst rates were similar between COC matured under 'group control', 'single control', and 'low ratio' IVM conditions. The commonality between these IVM conditions was that despite differences in the concentration and species of origin of GDF9 and BMP15 in the IVM media, the ratio of these proteins reflected that of mono-ovulatory species (i.e. low ratio of GDF9:BMP15 and native GDF9:BMP15 ratio secreted from sheep oocytes). Hence, increasing GDF9 and BMP15 concentrations during IVM does not necessarily improve developmental competency as if this were the case, blastocyst rates in the 'group control' and 'low ratio' groups would be higher than that of the 'single control' group. In the context of the current study, the two treatment groups (i.e. low and high ratio) reflect the generalisation that the ratio of GDF9:BMP15 mRNA in oocytes is low and high in the mono-ovulatory and polyovulatory mammalian species, respectively, with the exception of the pig (Crawford and McNatty, 2012). It is thought that this, at least in part, contributes to the regulation of OR in mammals. The specific ratios utilised in this study reflect the ratios determined for the mouse (high ratio $=6.00$ c.f. 5.26 ) and the cow (low ratio $=0.17$ c.f. 0.11 ). In women undergoing ART, there is also evidence that differences in the ratio of GDF9:BMP15 to which maturating $\mathrm{COC}$ are exposed are associated with differences in developmental competency. Specifically, higher follicular fluid concentrations of mature GDF9 were associated with improved embryo quality, however no differences in BMP15 concentrations were identified (Gode et al., 2011).

Naturally occurring mutations in BMP15 and GDF9 in ewes have shown that these proteins have indispensable roles in folliculogenesis and modulation of OR in sheep (Galloway et al., 2000; Hanrahan et al., 2004). However, to the best of my knowledge, this has been the first study to test the effects of exogenous GDF9 and BMP15 on developmental competency (as measured by blastocyst rate) in sheep. Studies in other species however, have shown that the addition of recombinant GDF9 and BMP15, alone and in combination improved developmental competency. These studies used commercially available or inhouse produced mouse GDF9 (Hussein et al., 2006, 2011; Yeo et al., 2008; Sudiman et al., 2014a, 2014b), human GDF9 (Li et al., 2015a; Mottershead et al., 2015), human BMP15 (Sudiman et al., 2014a, 2014b; Machado et al., 2015; Mottershead et al., 2015) and ovine BMP15 (Hussein et al., 2006, 2011). Since producing rec pGDF9 and BMP15, the Pitman lab has characterised the forms and bioactivity of these proteins that are present in the conditioned media. This data has indicated that the predominant forms in the conditioned media are the mature protein, followed by the pro-mature forms (Alhussini, 
2016; Swinerd, 2016). The conditioned media containing either rec pGDF9 or BMP15 were able to stimulate proliferation in ovine GC, indicating that the proteins were biologically active (Alhussini, 2016). In light of this data, it would be interesting to determine the effects of purified components of the conditioned media (pro-mature compared to mature proteins) and indeed whether porcine GDF9 and BMP15 differentially influences oocyte developmental competency (i.e. blastocyst rate) compared to GDF9 and BMP15 from other species. This is particularly relevant, given that investigations of cumulin (heterodimer of mature human BMP15 and GDF9), have shown that the only the pro-mature (pro-cumulin), and not the mature, form increased blastocyst rate when added during IVM (Mottershead et al., 2015). Based on the data discussed herein, it is plausible that the ratio of GDF9 relative to BMP15, rather than the absolute concentrations of these proteins, modulates developmental competency in ovine COC matured in vitro.

Different IVM conditions had a significant impact on the degree of expansion and gene expression of CC. In the in vivo situation, CC expansion occurs as a result of the preovulatory LH-surge and thus is restricted to preovulatory follicles (Eppig, 1980; Webb and England, 1982). In contrast, superovulation and IVM procedures override or eliminate the inhibitory hormones produced by the preovulatory follicle, thus allowing more antral follicles to mature. However, these procedures do not remove the inherent hierarchy of developing follicles within an ovary (McNatty et al., 2010). As a result, the majority of these COC undergo CC expansion, regardless of the developmental competency of the associated oocyte, as evidenced by the low success rates associated with ART. Thus, it was unsurprising that an association between IVM conditions and CC maturation in this study were observed. As mention above, both BMP15 and GDF9 are known to modulate CC function. In particular, GDF9 has been shown to be essential for CC expansion in vitro, while BMP15 has been shown to induce expansion in bovine CC (Vanderhyden et al., 2003; Dragovic et al., 2005; Gilchrist et al., 2006; Yeo et al., 2008; Machado et al., 2015). Indeed, in the IVM conditions where GDF9 and BMP15 concentrations were high, that is, in the 'group control', 'low ratio' and 'high ratio' groups, CEI scores were higher. Furthermore, COC from the 'high ratio' group had the highest CEI, which is in agreement with previous studies that showed that increased levels of GDF9 resulted in a greater degree of CC expansion (Vanderhyden et al., 2003; Dragovic et al., 2005; Yeo et al., 2008).

Of the CC genes investigated, only HAS2 and VCAN expression were related to degree of $C C$ expansion. Unsurprisingly, these genes encode proteins that are involved in CC 
expansion. The HAS2 gene encodes for hyaluronan synthase 2 and regulates the synthesis of hyaluronic acid, while the VCAN gene encodes for versican which binds hyaluronic acid contributing to changes in the extracellular matrix associated with expansion (LeBaron et al., 1992; Fülöp et al., 1997). Previous reports have shown that there are differences in HAS2 and VCAN expression levels in in vitro and in vivo matured CC (Dunning et al., 2007). Hence, it is likely that some key molecular processes may be altered or impaired in in vitro matured COC despite morphologically similarities to in vivo matured COC. Both ratios of GDF9 and BMP15 tested herein resulted in increased HAS2 and VCAN expression levels compared to the 'single control' IVM condition and in the case of $V C A N$, in comparison to the 'group control' group as well. This supports data from previous studies where GDF9 upregulated HAS2 expression in CC. While VCAN expression in CC and GC is known to be regulated by LH and EGF-like peptides, GDF9 in combination with $\mathrm{FSH}$ also increased VCAN expression in whole follicles (Park and Mayo, 1991; Elvin et al., 2000; Russell et al., 2003; Pangas et al., 2004; Cotterill et al., 2012; Vasconcelos et al., 2013).

Although in vivo, the preovulatory LH surge initiates meiotic resumption and results in maturation of preovulatory follicles and CC expansion, CC expansion during IVM is thought to occur due to the effects of $\mathrm{FSH}$, particularly as initial studies indicated that the LHR was not expressed in CC (Amsterdam et al., 1975; van Tol et al., 1996). However, subsequent studies have identified LHR expression on CC during IVM and provide evidence of functional responses to LH from COC in culture (Peng et al., 1991; Kawashima et al., 2008; Jeppesen et al., 2012). In a porcine IVM model, a 20-hour incubation with FSH upregulated LHR expression (Kawashima et al., 2008). By incorporating this prematuration step aimed at inducing $L H R$ expression in CC, blastocyst rate was improved following the exposure of COC to $\mathrm{LH}$. In the absence of conclusive evidence of functional $\mathrm{LH}$ signalling in CC following IVM, FSH signalling is known to recapitulate some of the downstream effects of $\mathrm{LH}$ signalling, including the induction of $\mathrm{CC}$ expansion and expression of EGF-like factors (Eppig, 1980; Yamashita et al., 2011). Regardless of the reason, it is possible that $\mathrm{COC}$ associated with an up-regulation of genes downstream of $\mathrm{LH}$ have an inherent advantage or that these COC are of higher developmental competency at the time of collection indicating that IVM did not alter developmental competency.

This discussion is also relevant when considering that $F S H R$ expression was only upregulated in the 'single control' group. In the in vivo situation, FSHR expression is 
downregulated preovulatory follicles around the time of oestrus but highly expressed in small (<3 mm) and medium (3-5 mm) sized follicles (Liu et al., 1998). Furthermore, FSHR expression in GC decreases with increasing follicle size and peaks during the first six hours of IVM (Calder et al., 2005; Jeppesen et al., 2012). In this context, it could be inferred that maturational processes in $\mathrm{COC}$ from the 'single control' group may be delayed or impaired compared to COC in all other groups. Indeed, BMP15 has been shown to decrease FSHR expression in cultured rat GC (Otsuka et al., 2001). This is relevant to the current study too, as all groups with higher concentrations of BMP15 (i.e., 'group control', 'low ratio' and 'high ratio') exhibited decreased FSHR expression. Despite the requirement for FSH signalling during IVM, it seems likely that FSHR expression is down-regulated in response to BMP15 and perhaps reflects the in vivo situation where FSHR is downregulated in preovulatory follicles in favour of $L H R$ expression.

In addition to the HAS2 and VCAN genes, expression of genes like GJA1, PGR and $B M P R 2$ were also up-regulated in CC exposed to rec pGDF9 and BMP15, regardless of ratio. The expression of these genes in $\mathrm{GC}$ is reported to increase with follicular diameter, fluctuate at oestrus and in response to LH/hCG (Park and Mayo, 1991; Wiesen and Midgley, 1993; Granot and Dekel, 1997; Sommersberg et al., 2000; Calder et al., 2003; Russell et al., 2003; Feary et al., 2007; Norris et al., 2008; Chen et al., 2009; Paradis et al., 2009; Li et al., 2015b).

The GJA1 gene encodes connexin 43, a component of gap junctions in the GC and CC in ovarian follicles (Juneja et al., 1999; Ackert et al., 2001). Within the follicle, gap junctions couple the oocyte and CC and GC to each other physically and metabolically. Maintaining gap junction communication, particularly during the early stages of IVM, improves developmental competency in bovine oocytes (Luciano et al., 1999; Atef et al., 2005; Albuz et al., 2010; Gilchrist, 2011; Sugimura et al., 2014; Li et al., 2016). A number of the components of IVM media used in the current study, including $\mathrm{FSH}, \mathrm{LH}$ and oestradiol, as well as GDF9 have been shown to modulate gap junction communication. Whilst FSH and oestradiol increased GJA1 expression and gap junction communication, LH and GDF9 decreased GJA1 expression in in vitro cultured GC and COC (Wiesen and Midgley, 1993; Chang et al., 2014; El-Hayek and Clarke, 2015). In the current experiment, GJA1 expression was higher in CC from the 'single control', 'low ratio' and 'high ratio' IVM conditions. Alternatively, it is also possible that during IVM, certain paracrine factors produced by the COC down-regulate GJA1 expression as was seen in the 'group control' in these experiments. It would also be worthwhile investigating whether the observed 
changes in GJA1 expression are associated with alterations in CX43 protein levels and gap junction permeability as this may be another mechanism through which GDF9 and BMP15 modulate developmental competency during IVM.

The expression of $P G R$, which encodes the progesterone receptor, was highest in CC which were incubated with rec pGDF9 and BMP15 during IVM and was progressively lower in the 'single control' and 'group control', respectively. In the in vivo situation, PGR expression is induced as a result of LH signalling and increased expression in CC from women undergoing IVF has been correlated with improved developmental competency (Park and Mayo, 1991; Natraj and Richards, 1993; Hasegawa et al., 2005; Ekart et al., 2013). The progesterone receptor has been shown to modulate EGF-like peptide expression and loss of progesterone signalling results in impaired CC function and ovulation (Lydon et al., 1995; Robker et al., 2000; Shimada et al., 2006). These results further indicate that supplementation with exogenous GDF9 and BMP15 improved CC maturation.

In contrast, EREG expression was lower in COC incubated in IVM conditions containing rec pGDF9 and BMP15, compared to 'single control' and 'group control' COC. The expression of EGF-like factors in in vivo matured follicles is rapidly and transiently induced in response to $\mathrm{LH} / \mathrm{hCG}$ stimulation and EREG expression is elevated for up to 12 hours in GC in mice (Park et al., 2004). Likewise, during IVM, expression of EREG in bovine CC peaks at 12 hours of culture in the presence of FSH (Caixeta et al., 2013). In the context of these studies, the results presented herein indicate that the induction of EREG and perhaps other EGF-like peptides is delayed under the single and group control IVM conditions. The CC samples were collected after 25 hours of IVM and based on previous studies, it would be expected that EREG expression would be low. It is possible that the altered expression of EREG in the 'group control' and 'single control' culture group indicate that maturation is delayed or incomplete in $\mathrm{COC}$ from these groups.

The BMPR2 gene encodes the BMPR2 protein, a type II receptor which is known to bind both GDF9 and BMP15 (Vitt et al., 2002; Moore et al., 2003). A positive relationship between follicle diameter and BMPR2 has been reported and thus it is likely expression levels may be related to the maturity of the associated follicle (Feary et al., 2007; Chen et al., 2009; Paradis et al., 2009). The results reported herein show that BMPR2 expression was the highest in CC that were exposed to exogenous GDF9 and BMP15 ('low ratio' and 'high ratio' groups). However, when COC were cultured in higher levels of native GDF9 
and BMP15 ('group control'), BMPR2 expression was low. The expression of BMPR2 is influenced by other components of the media too, namely, oestradiol and FSH (Jayawardana et al., 2006; Miyoshi et al., 2006; Chen et al., 2009). Under group culture condition, it is possible that these components may be less available to each individual $\mathrm{COC}$ or that $\mathrm{COC}$ are influenced by other paracrine factors which may inhibit BMPR2 expression.

The levels of RNA and protein synthesis in oocytes varies during different stages of folliculogenesis and this may also be reflected in the levels of chaperone proteins (Fair et al., 1995). The HSP90B1 gene encodes a chaperone protein localised to the endoplasmic reticulum that is involved in the regulation of protein folding and processing (Marzec et al., 2012). There is evidence that $H S P 90 B 1$ expression in $C C$ is upregulated in response to culture with FSH and thus would be expected to be upregulated in the current study (Assidi et al., 2008). However, expression was lowest in the 'group control', possibly indicating that there is decreased protein synthesis or that regulation of protein processing was impaired (Takeo et al., 2013). It could be suggested that COC in the 'single control', 'low ratio' and 'high ratio', in which HSP9OB1 expression was higher, would have increased transcriptional activity or improved regulation of protein synthesis.

Thus far, the effects of the different IVM conditions have been discussed in the context of the effects of native and recombinant GDF9 and BMP15, however it is important consider the potential effects of other paracrine factors both in the conditioned media or produced by the COC in the 'group control'. A positive group culture effect on developmental competency, mediated by the production of paracrine factors, during IVM and embryo culture has been observed (Paria and Dey, 1990). Whilst this was not found in the current study, it appears that paracrine factors may influence CC gene expression. The conditioned media, containing rec pGDF9 and BMP15, used during IVM is likely to contain other paracrine factors, some of which may influence developmental competency. To account for this, equivalent amounts of conditioned media, varying only in the presence of rec pGDF9 and BMP15, were added to all IVM conditions. As such, any effects due to paracrine factors other than rec pGDF9 and BMP15 in the conditioned media would not be expected to differ between the different IVM conditions. For some genes, expression levels in the 'group control' were noticeably different from expression in the other IVM conditions indicating that other paracrine factors produced by COC during IVM modulated gene expression levels in the CC. This was observed for HSP90B1, PGR, GJA1 and EREG. With the exception of EREG where the highest expression levels were found in the 
'group control', expression was lowest in the 'group control' compared to the other IVM conditions. Other OSF, for example, fibroblast growth factor 10 (FGF-10), have also been shown to alter CC gene expression profiles and improve developmental competency (Zhang et al., 2010a; Caixeta et al., 2013). Furthermore, there are likely to be other, as yet uncharacterised, paracrine factors produced by $\mathrm{COC}$ that influence developmental competency.

Of the morphokinetic parameters investigated, only the total time taken to develop to the 2-cell stage (t2C) differed between $\mathrm{COC}$ with the degrees of $\mathrm{CC}$ expansion. It is plausible that $\mathrm{COC}$ with $\mathrm{CC}$ exhibiting a greater the degree of expansion are more mature and the time taken between addition of sperm and fertilisation is shorter. In other words, COC that had undergone full CC expansion and would be expected to have completed maturation, were able to begin embryonic development sooner. In general, a shorter $\mathrm{t} 2 \mathrm{C}$ is associated with improved embryonic outcomes. Furthermore, embryos that took longer to complete cytokinesis at $\mathrm{t} 2 \mathrm{C}$ are known to have decreased developmental competency (Wong et al., 2010; Dal Canto et al., 2012; Meseguer et al., 2012; Burruel et al., 2014).

While morphokinetic parameters did not differ between different IVM conditions, almost all of the morphokinetic parameters investigated differed between embryos with different embryological outcomes. The total time taken to reach the 4-cell, 5-cell and morula stage, duration of the third cell cycle, interval between the 3- and 4-cell stage and synchronicity of the second cell cycle were all shorter in embryos that arrested after the 8-cell stage compared to embryos that arrested at or before the 8-cell stage, embryos that developed into compact morula and early blastocysts or developed to the blastocyst stage. This would suggest that these embryos represent a distinct cohort of embryos, with compromised developmental competency, that can be identified due to this distinct morphokinetic profile. These embryos arrested at or around the time of EGA suggesting impaired EGA. Within this group some embryos developed to the morula stage, these embryos are likely to, comparatively, have better stores of maternal factors (Toralová et al., 2009). These results also support evidence that optimal timings for morphokinetic events exist within a range, bounded by upper and lower values and that although some variation in morphokinetics appears to be tolerated, embryos that consistently fall outside of these accepted timings generally lack developmental competency. The majority of the prediction models for developmental competency in the embryo have shared this commonality, despite using slightly different parameters (Meseguer et al., 2012; Conaghan et al., 2013). 
It is worthwhile discussing that a limitation of the current study was the relatively small sample size. Despite the significant differences in blastocyst rate, none of the parameters relating to early embryonic development (cleavage rate, proportion of embryos that developed to each embryological outcome or morphokinetic events) differed between any of the IVM conditions tested. Moreover, CC gene expression did not differ between embryological outcome. Compared to CHAPTER 4, the current chapter had a much larger sample, particularly when investigating the difference between the morphokinetic outcomes. In the previous study, only s2 was different in embryos with different embryonic outcomes. However, in the current study despite similar overall timings, the total time taken to reach the 4-cell, 5-cell and morula stage, duration of the third cell cycle, interval between the 3- and 4-cell stage and synchronicity of the second cell cycle was different between embryos with different embryological outcomes. This was likely due to the larger sample size in the current study. However, it is also important to note that other studies found no differences in any morphokinetic parameters between embryos that underwent in vivo and IVM despite better rates of blastocyst formation in the former (Walls et al., 2015b; Dal Canto et al., 2016). In particular, the study by Walls et al. (2015b), reported results similar to that presented herein, although IVM was associated with an increased proportion of embryos that arrested during early embryonic development, those embryos that developed to the blastocyst stage did not display altered morphokinetics.

In summary, the results of these experiments indicate that the ratio at which GDF9 and BMP15 were supplemented to IVM media influenced developmental competency. Furthermore, the presence of native and exogenous GDF9 and BMP15 and perhaps other paracrine factors, altered $\mathrm{CC}$ function as measured by $\mathrm{CC}$ expansion and gene expression. Based on the data presented herein, it is possible that $\mathrm{COC}$ matured in media supplemented with GDF9 and BMP15 display gene expression profiles characteristic of CC that were responsive to $\mathrm{LH}$ signalling and that this is associated with improved developmental competency. In contrast, the timing of the majority of morphokinetic events differed depending on embryological outcome but not IVM conditions. This suggests the improvement in developmental competency associated with the high ratio of recombinant porcine GDF9 and BMP15 was due to modulation of CC function, possibly resulting in improved maturation. This requires further investigation to elucidate the precise mechanisms by which this occurs. 


\section{CHAPTER 6. GENERAL DISCUSSION}

Perhaps the most significant factor impeding the improvement of assisted reproductive technologies (ART) is an incomplete understanding of the factors that regulate the attainment of developmental competency in oocytes. The experiments described in this thesis utilised an ovine model to investigate maturational processes both in vivo and in vitro. Overall, the in vivo and in vitro maturation studies yielded key insights into the intrafollicular factors that regulate oocyte developmental competency and how these may be impaired during IVM. Despite significant alterations in CC gene expression due to follicular stage and genotype (in vivo), and modifications to IVM conditions (in vitro), the expression of key genes in the oocyte and morphokinetic parameters in embryos, were not altered. Secondly, mimicking the ratio of GDF9:BMP15 present in high OR, compared to low OR, species in IVM media improved developmental competency of oocytes in vitro. Moreover, the ability of the follicular somatic cells $\mathrm{GC}$ and $\mathrm{CC}$ ) to respond to $\mathrm{LH}$-signalling was related to improved developmental competency both in vivo and in vitro. This study also provided preliminary data indicating that a combination of CC-derived molecular markers (gene expression) and morphokinetic markers of embryos, which have been characterised for the first time in an ovine model, improved the ability to predict developmental competency in oocytes, compared to either of these biomarkers alone.

In spite of changes in the follicular microenvironment and subsequent gene expression in the somatic cells during oocyte maturation, gene expression in oocytes matured in vivo was not altered. These changes included genotypic differences in gonadotrophinresponsiveness of GC and follicular fluid composition in presumptive preovulatory (PPOV) follicles, as well as CC gene expression levels in ++ and I+B+ ewes. Similarly, the timing of morphokinetic events of embryos matured in vitro, were not altered by differences in IVM conditions. These differences in IVM conditions included group and single culture methodologies as well as low and high ratios of exogenous rec pGDF9 and BMP15. Together, these results suggest that regardless of the differing environments in which developmentally-competent oocytes (i.e. from preovulatory follicles in vivo) and highquality embryos (i.e. blastocysts in vitro) develop, they share similarities regarding genetic signatures and timings of early embryonic cleavage events. In support, other studies have also shown that under in vitro conditions, the $\mathrm{CC}$ reduce the negative effects of reactive oxygen species (ROS), lifestyle factors and environmental contaminants (Tatemoto et al., 2000; Fatehi et al., 2005; Dunning et al., 2007; Campen et al., 2017). Furthermore, all the IVM conditions included in the current study resulted in high degrees of CC expansion but 
diverse CC gene expression profiles. Together this data supports the results presented by McNatty et al., (2010), which demonstrated that superovulation procedures do not overcome the hierarchical nature of follicular development, despite inducing more follicles to develop to a large size. Likewise, IVM resulted in the morphological changes indicative of COC maturation (i.e. CC expansion) but overall developmental competency remained low. It is also worth considering that whole follicle culture techniques or extended IVM procedures may be necessary to allow for adequate maturation in a wider range of follicles (Xu et al., 2006; Albuz et al., 2010).

In sheep, naturally-occurring mutations in either the GDF9 or BMP15 genes result in sterility in homozygous carriers and an increased OR in heterozygous carriers (Davis et al., 1991; Galloway et al., 2000; Hanrahan et al., 2004). There is also evidence that in the mammalian species studied to date, the ratio of GDF9:BMP15 mRNA in oocytes may be characteristic of the OR of the species (Crawford and McNatty, 2012). The experiments documented herein have focused on the period during which the oocyte completes the final maturational processes and the effects of modulating the microenvironment during this period, on developmental competency. A key finding of the current study was that supplementing IVM media with exogenous GDF9 and BMP15 proteins at a ratio indicative of a high OR species (i.e. GDF9:BMP15 ratio of 6:1), improved developmental competency. In the in vivo study, the high OR genotype $(\mathrm{I}+\mathrm{B}+)$, are known to have mutations in the BMP15 gene (Inverdale; $\mathrm{I}+$ ) and the type I receptor BMPRIB (Booroola; $\mathrm{B}+$ ) gene (Galloway et al., 2000; Wilson et al., 2001). The increased OR associated with these mutations are thought to be due to decreased BMP15 signalling as this effect on OR could be replicated through partial immunoneutralization against BMP15 (Juengel et al., 2004). Evidence from the current and previous studies indicates that in $\mathrm{I}+\mathrm{B}+$ and $\mathrm{BB}$ ewes, $B M P 15$ expression in oocytes is decreased while GDF9 expression remains unchanged (Crawford et al., 2011). This suggests that in these high OR genotypes, the GDF9:BMP15 protein ratio to which the maturing $\mathrm{COC}$ is exposed, may be altered compared to wild-type ewes. However, the levels of GDF9 and BMP15 protein produced by oocytes from I+B+ ewes has yet to be determined. It is also important to note that this increase in OR is concomitant with a higher lambing rate $\left(\mathrm{I}_{+}\right)$and high rates of recovery of good quality embryos following embryo transfer $\left(\mathrm{I}_{+} \mathrm{B}+\right)$, indicating that despite the increased OR, developmental competency is not compromised (Davis et al., 1991; McNatty et al., 2016). Together, this provides strong evidence that the ratio of GDF9:BMP15 protein which COC are exposed to during maturation is important for developmental competency as well as OR. 
A recurring point of interest in the current study was that the expression of LH-responsive genes, or lack thereof, in the CC, was associated with developmental competency. Indeed, premature responsiveness to LH was a characteristic of the $\mathrm{I}+\mathrm{B}+$ ewes , and is thought to underpin the mechanism by which OR is increased (Davis et al., 1991; McNatty et al., 2016). Moreover, perturbations in the expression of CC genes regulated by $\mathrm{LH}$-signalling were noted in $\mathrm{I}+\mathrm{B}+$ compared to ++ ewes and following IVM. Of the genes that were investigated in the CC, the expression of VCAN, PGR, GJA1, EREG and BMPR2 have been reported to be regulated by LH/hCG (Park and Mayo, 1991; Granot and Dekel, 1997; Russell et al., 2003; Park et al., 2004; Nio-Kobayashi et al., 2015). Herein, during IVM, upregulation of LH-responsive genes (including VCAN, PGR, GJA1 and BMPR2) occurred in $\mathrm{CC}$ exposed to IVM conditions that contained higher concentrations of native or exogenous GDF9 and BMP15. Nevertheless, only a high ratio of GDF9:BMP15 protein improved developmental competency in terms of blastocyst rate. These LH-responsive genes have also been identified as potential biomarkers of developmental competency for ART (Hasegawa et al., 2005; Adriaenssens et al., 2010; Ekart et al., 2013; Richani et al., 2013; Li et al., 2015a). Furthermore, the use of EGF-like factors, including AREG and EREG, to induce LH-signalling during IVM improved developmental competency (Richani et al., 2013; Sugimura et al., 2014; Richani and Gilchrist, 2017). This would suggest that the ability to respond to $\mathrm{LH}$ signalling maybe indicative of the inherent developmental competency of the COC.

Generally, where genotype influenced gene expression levels, the differences were only detectable in growing, and not PPOV, follicles. In combination with the altered follicular microenvironment, it appears that the follicular somatic (granulosa and cumulus) cells in $\mathrm{I}+\mathrm{B}+$ ewes are functionally different from those in ++ ewes. This may represent a compensatory mechanism by which a developmentally-competent oocyte is produced, despite differences in preovulatory follicle size and GC number. It is unknown whether development of preovulatory follicles in $\mathrm{I}+\mathrm{B}+$ ewes occurs over a shorter period, or that the rate of growth is slower than in ++ ewes. Given the role of OSF in proliferation rate of GC, it is speculated that the rate of follicular growth would be slower in antral follicles of $\mathrm{I}+\mathrm{B}+$ ewes. These results indicate that there are other key periods prior to final maturation that are initiated by $\mathrm{LH}$. In $\mathrm{I}+\mathrm{B}+$ ewes, smaller follicles were able to respond to low circulating LH concentrations and perhaps this allowed for premature initiation of these processes and developmental competency of oocytes in smaller-sized follicles. This idea is supported by studies showing that modified IVM procedures which incorporate prematuration steps result in improved developmental competency in oocytes, suggesting 
that the duration of exposure to current IVM conditions is not sufficient for the attainment of developmental competency (Albuz et al., 2010; Richani et al., 2014b; Zeng et al., 2014).

During IVM, the majority of COC underwent CC expansion. However, only a small proportion of these in vitro-matured $\mathrm{COC}$ will develop to the blastocyst stage indicative of developmental competency. In the current study, CC gene expression was significantly altered in in vivo compared to in vitro matured COC (Figure 6-1). There was noticeably less variation and lower expression of CC genes following IVM, providing further evidence that maturational processes are perturbed, or at least delayed during IVM (Dunning et al., 2007; Kind et al., 2013; Richani et al., 2013). It is widely accepted that in vivo matured oocytes have increased developmental competency and improved outcomes such as live birth rate compared to in vitro-matured oocytes. This is likely to be due, at least in part, to alterations in maturational processes in the CC (Rizos et al., 2002; Liu et al., 2008).

Another notable difference between in vivo and in vitro maturation is the microenvironment, particularly as the follicular fluid is known to contain factors that influence developmental competency. This is the first study to extensively investigate the composition of follicular fluid in sheep. The results presented herein indicated that the amino acid concentrations in ovine follicular fluid differs significantly from those reported in mice, cows and humans, as well as in IVM media (Harris et al., 2005; Orsi et al., 2005; Hudson et al., 2014; Jóźwik et al., 2017). When compared to the formulation of M199 that was used in the IVM media in the current study (Table 6-1), only the concentrations of histidine and proline were within the range measured in PPOV. Moreover, glutamic acid, isoleucine, phenylalanine and valine were within the range measured in ++ ewes, while arginine, aspartic acid, hydroxyproline, leucine, lysine and methionine were within the range measured in $\mathrm{I}+\mathrm{B}+$ ewes. The reasons for and implications of these discrepancies are unclear but warrant further investigation as modulation of amino acid concentrations in IVM media is known to alter developmental competency (Lee and Fukui, 1996; Hong and Lee, 2007).

These findings illustrate a conflict in current approaches to ART. Often discussed in terms of embryo culture but also relevant to IVM. The "back to nature" approach aims to recapitulate the in vivo microenvironment and usually involves two-step culture protocols with different media at each step. In contrast, the "single step" approach utilises culture media that contains all the components that could be required at any stage during IVM or embryo culture, the oocyte or embryo utilises whichever components are required. These 
approaches are known alter morphokinetic profiles however, overall there is no consensus as to which results in improved developmental competency (Ciray et al., 2012). In conjunction with evidence that metabolism is impaired under current IVM and embryo culture conditions, it would be worthwhile investigating physiologically-relevant maturation and embryo culture systems (Dunning et al., 2007; Richani et al., 2014a). In terms of IVM systems, the use of physiologically-relevant concentrations of ovine $\mathrm{LH}$ and FSH have been shown to improve the developmental competency of ovine oocytes in serum-free conditions (Cotterill et al., 2012).

Another key consideration is that group culture techniques, commonly used during IVM, do not reflect the situation in vivo, where each $\mathrm{COC}$ is encapsulated within a follicle and physically separated from other COC in the ovary. However, single culture techniques are rarely used during IVM due to evidence that developmental competency is decreased due to the absence of OSF in IVM media (Blondin and Sirard, 1995; Feng et al., 2007). The current study has presented evidence that other paracrine factors, produced by the COC, may also modulate $\mathrm{CC}$ function in vitro. This would suggest that single culture procedures may be preferential during IVM, especially when characterising the effects of novel in vitro culture systems, provided that the appropriate OSF are included in the media. 


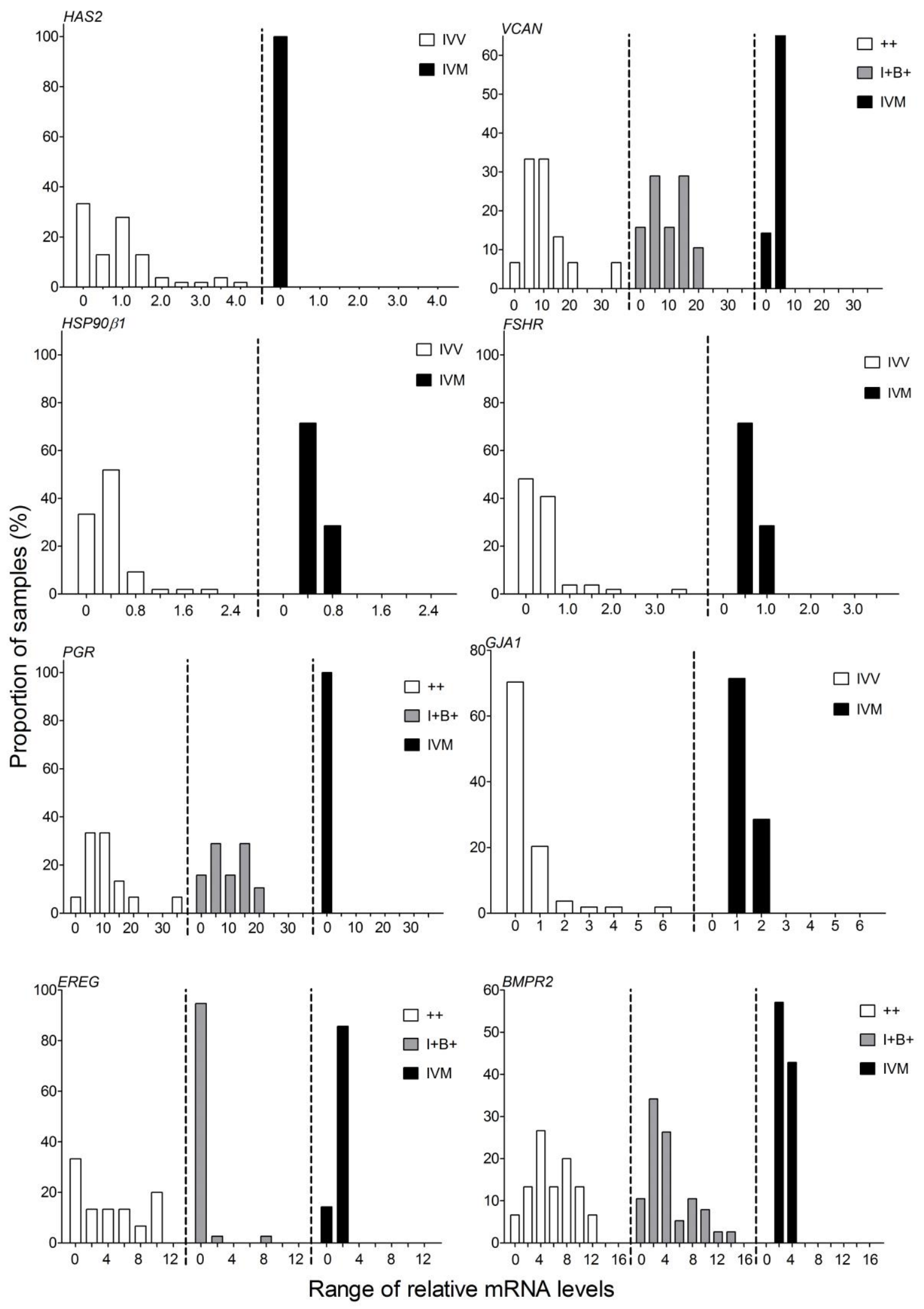


Figure 6-1: Distribution of HAS2, VCAN, HSP90B1, FSHR, PGR, GJA1, EREG and $B M P R 2$ in $\mathrm{CC}$ from in vivo (IVV; white bars or ++; white bars, and I+B+; grey bars) and in vitro (IVM; black bars) matured COC. Data represents the distribution of linearised $\mathrm{C}_{\mathrm{T}}$ values for each gene. For in vivo matured COC (CHAPTER 3), only data from PPOV were included. Where genotype differences were identified, the distribution for ++ and $\mathrm{I}+\mathrm{B}+$ ewes are presented separately. For in vitro matured COC (CHAPTER 4), only data from embryos in the blastocyst group are presented. Data were corrected to the same calibrator sample allowing for these comparisons.

Table 6-1: Comparison of concentrations of IVM media components and the concentrations in ovine follicular fluid. Concentrations of amino acids in M199 are sourced from the Sigma-Aldrich website ${ }^{1}$. PPOV follicular fluid concentrations are reported as the median (range), where there was no genotype difference, the overall value is reported.

\begin{tabular}{|c|c|c|c|}
\hline \multirow{2}{*}{ Amino acid } & \multirow{2}{*}{$\begin{array}{c}\text { IVM media } \\
\text { components }(\mathrm{mM})\end{array}$} & \multicolumn{2}{|c|}{ PPOV follicular fluid (mM) } \\
\hline & & $\mathrm{I}+\mathrm{B}+$ & ++ \\
\hline L-alanine & 0.281 & \multicolumn{2}{|c|}{$\begin{array}{c}0.774 \\
(0.659,0.883)\end{array}$} \\
\hline L-arginine & 0.402 & $\begin{array}{c}0.357 \\
(0.278,0.443)\end{array}$ & $\begin{array}{c}0.124 \\
(0.105,0.197)\end{array}$ \\
\hline L-aspartic acid & 0.225 & $0.170(0.107,0.263)$ & $\begin{array}{c}0.035 \\
(0.026,0.053)\end{array}$ \\
\hline L-glutamic acid & 0.454 & $\begin{array}{c}0.967 \\
(0.759,1.142)\end{array}$ & $0.491(0.406,0.631)$ \\
\hline L-glutamine & 0.684 & $\begin{array}{c}1.133 \\
(0.869,1.481)\end{array}$ & $\begin{array}{c}0.268 \\
(0.127,0.408)\end{array}$ \\
\hline L-glycine & 0.666 & $\begin{array}{c}1.543 \\
(1.299,1.993)\end{array}$ & $\begin{array}{c}0.900 \\
(0.717,0.917)\end{array}$ \\
\hline L-histidine $\mathrm{HCl}-\mathrm{H}_{2} \mathrm{O}$ & 0.104 & \multicolumn{2}{|c|}{$\begin{array}{c}0.188 \\
(0.105,0.390)\end{array}$} \\
\hline L-hydroxyproline & 0.076 & $\begin{array}{c}0.061 \\
(0.043,0.081)\end{array}$ & $\begin{array}{c}0.016 \\
(0.014,0.025)\end{array}$ \\
\hline L-isoleucine & 0.152 & $\begin{array}{c}0.458 \\
(0.331,0.507)\end{array}$ & $\begin{array}{c}0.163 \\
(0.099,0.261)\end{array}$ \\
\hline L-leucine & 0.457 & $\begin{array}{c}0.419 \\
(0.357,0.554)\end{array}$ & $\begin{array}{c}0.209 \\
(0.141,0.355)\end{array}$ \\
\hline L-lysine & 0.479 & $\begin{array}{c}0.568 \\
(0.396,0.657)\end{array}$ & $\begin{array}{c}0.245 \\
(0.188,0.331)\end{array}$ \\
\hline L-methionine & 0.101 & $\begin{array}{c}0.112 \\
(0.077,0.127)\end{array}$ & $\begin{array}{c}0.045 \\
(0.026,0.065)\end{array}$ \\
\hline L-phenylalanine & 0.151 & $\begin{array}{c}0.362 \\
(0.261,0.404)\end{array}$ & $\begin{array}{c}0.134 \\
(0.083,0.168)\end{array}$ \\
\hline L-proline & 0.347 & \multicolumn{2}{|c|}{$\begin{array}{c}0.482 \\
(0.335,0.883)\end{array}$} \\
\hline L-serine & 0.238 & $\begin{array}{c}0.374 \\
(0.301,0.446)\end{array}$ & $\begin{array}{c}0.171 \\
(0.112,0.218)\end{array}$ \\
\hline L-threonine & 0.252 & \multicolumn{2}{|c|}{$\begin{array}{c}0.102 \\
(0.075,0.141)\end{array}$} \\
\hline $\begin{array}{l}\text { L-tyrosine-2Na- } \\
2 \mathrm{H} 2 \mathrm{O}\end{array}$ & 0.256 & $\begin{array}{c}0.164 \\
(0.124,0.224)\end{array}$ & $\begin{array}{c}0.105 \\
(0.092,0.163)\end{array}$ \\
\hline L-valine & 0.213 & $\begin{array}{c}0.449 \\
(0.349,0.543)\end{array}$ & $\begin{array}{c}0.277 \\
(0.216,0.386)\end{array}$ \\
\hline
\end{tabular}

${ }^{1}$ http://www.sigmaaldrich.com/life-science/cell-culture/learning-center/media-formulations/medium-199.html 
There is also evidence that recapitulating fundamental aspects of in vivo maturation result in improved developmental competency. For example, COC that are removed from antral follicles undergo spontaneous meiotic resumption due to significant decreases in intraoocyte cAMP levels (Pincus and Enzmann, 1935). Whereas IVM systems that maintain high intraoocyte CAMP concentrations and prevent spontaneous meiotic resumption, improved developmental competency (Albuz et al., 2010; Zeng et al., 2014). This has also been demonstrated with regards to inducing EGF network and OSF signalling. Neither the CC nor the oocyte express the $\mathrm{LH}$ receptor. (Amsterdam et al., 1975; van Tol et al., 1996). Thus, LHR activation in the GC induces EGF-like peptide production and these activate EGFR on the CC, propagating the initial LH signal (Figure 6-1; Park et al., 2004). During IVM, FSH induces the downstream effects of $\mathrm{LH}$, including CC expansion and indeed some LHR expression (Peng et al., 1991; Kawashima et al., 2008; Jeppesen et al., 2012). The expression of $A R E G$ and $E R E G$, in response to hCG in $\mathrm{CC}$ from patients undergoing IVF was correlated to increased developmental competency and embryo quality (Huang et al., 2015). Moreover, using EGF-like factors instead of LH during IVM results in improved developmental competency (Procházka et al., 2011; Richani et al., 2014a; Sugimura et al., 2014). Likewise, when OSF and EGF-like factors are added to IVM media or EGFR signalling is enhanced, developmental competency was improved (Hussein et al., 2006, 2011; Sugimura et al., 2014; Machado et al., 2015).

An alternative but complementary approach to improving the success rates of ART would be to develop tools for identifying developmentally competent oocytes and embryos. While a number of studies have investigated the efficacy of using either CC-derived gene expression profiles or morphokinetic markers in embryos, to my knowledge, there has only been one other study that investigated the efficacy of utilising this combination of biomarkers (Hammond et al., 2015). These types of multifaceted approaches are particularly important in light of evidence that there is limited potential for the improvement of predictive models based on morphokinetics alone (Milewski et al., 2017). Furthermore, the current study has demonstrated that during IVM, CC gene expression profiles are significantly altered by different IVM conditions and that these changes were not associated with embryological outcome. This proof of concept study demonstrated, for the first time that the combination of CC-derived molecular markers and morphokinetic markers could better predict developmental competency of embryos compared to either of these alone. 
The results presented herein have shown that developmental competency is influenced by the intrafollicular microenvironment during maturation both in vivo and in vitro. In particular, when the ratio of GDF9:BMP15 was increased, oocytes exhibited increased developmental competency. Despite this increased developmental competency, processes in the oocyte and embryo were not significantly affected as evidenced by unaltered gene expression profiles in the oocyte, and timings of morphokinetic events in embryos. Furthermore, the expression of LH-responsive genes in the CC appeared to reflect the inherent developmental competency of the associated oocyte providing novel insights into the development of biomarkers that can improve the prediction developmental competency. This thesis has provided novel data regarding the intrafollicular factors that influence developmental competency.

\subsection{Future work arising from this study}

Several areas that require further investigation have also been identified based on the findings of the current study. The high OR ewes included in this study were heterozygous carriers of two mutations, the Inverdale and Booroola mutations $(\mathrm{I}+\mathrm{B}+)$. The high $\mathrm{OR}$ phenotype is associated with premature responsiveness to $\mathrm{LH}$. However, there is conflicting evidence that GC from I+ ewes may also have increased responsiveness to $\mathrm{FSH}$ as well. The initial reports of increased responsiveness to FSH were attributed to the use of high concentrations of an LH-contaminated FSH preparation (Shackell et al., 1993; McNatty et al., 2009; Crawford et al., 2011). However, the current study classified follicles based on gonadotropin-responsiveness rather than size and a highly-purified FSH preparation (OVA2) was used. It was clear that $\mathrm{FSH}$-responsive follicles from I+B+ewes exhibited an increased basal responsiveness to FSH that was also reflected in the whole follicle cAMP concentrations. Furthermore, basal cAMP concentrations were higher in $\mathrm{I}+\mathrm{B}+$ ewes indicating that there may be uncharacterised mechanisms of cAMP production in $\mathrm{I}+\mathrm{B}+$ ewes. A recent study of Booroola (BB) ewes indicated that there was increased FSHR and LHR expressed on the surface of GC (Regan et al., 2015). Moreover, the expression of $\mathrm{FSH}$-responsive genes in $\mathrm{CC}$ of growing follicles (i.e. non- and $\mathrm{FSH}$ responsive follicles) was altered but CC-derived FSHR expression itself was not. Therefore, $\mathrm{FSH}$-responsiveness in $\mathrm{I}+\mathrm{B}+$ ewes requires further investigation as it could alter current understanding of the effects of mutations in BMP15 and BMPR1B on OR.

Moreover, it would be important to investigate the effects of a range of different ratios of GDF9:BMP15, in light of the evidence that the ratio, and not simply increasing the 
concentrations of GDF9 and BMP15, influenced developmental competency. Although the mRNA levels of BMP15 and GDF9 have been investigated in $\mathrm{I}+\mathrm{B}+$ ewes in the current and previous studies, it is also necessary to determine the effects of these mutations on the protein levels of GDF9 and BMP15. The GDF9:BMP15 ratio is a proposed component of the mechanism by which OR is regulated in mammals, however the current study has also provided evidence that this ratio modulates developmental competency. The species of origin of the recombinant GDF9 and BMP15 included in the current study was the pig and consisted predominantly of the mature forms, although the pro-mature form was also present. There is growing evidence that although the mature forms are biologically active, in terms of stimulating GC proliferation, they do not alter developmental competency (Sudiman et al., 2014a; Mottershead et al., 2015). Therefore, it is unclear whether the effects observed in the current study were due to modulation of the ratio of mature proteins or the pro-mature forms. It would be interesting to purify the pro-mature and mature forms to identify the form responsible for the effects observed. Regardless, the results of this study indicate that modulating the ratio of GDF9:BMP15 influences developmental competency. It would also be interesting to investigate the effects of different ratios of GDF9 and BMP15 from other species, but in particular the ovine proteins, on developmental competency.

Growing evidence indicates that the "back to nature" approach yields more favourable outcomes and developing an understanding of the processes in vivo to inform the development of these technologies would be worthwhile. Modified IVM procedures are widespread in the literature and generally involve the addition of pre-maturation steps. These enable the oocyte to develop the appropriate machinery to respond to this stimulation as depicted in Figure 5-1. This study also provides evidence that it is likely that there are other key periods during maturation that are not supported during conventional IVM. Therefore it would be worthwhile incorporating a pre-maturation step and employing EGF-like factors, for example, AREG, to current IVM procedures (Richani et al., 2014b; Sugimura et al., 2014). Furthermore, it would be interesting to determine whether IVM media formulations that are based on the composition of follicular fluid from PPOV follicles would improve developmental competency. The concentrations tended to differ between genotypes in the PPOV follicles with concentrations in $\mathrm{I}+\mathrm{B}+$ ewes generally being higher. Thus, it would be interesting to determine whether these genotypic differences affect developmental competency. Although the current study has provided preliminary evidence that these genotypic differences were largely due to genotypic differences in the size of PPOV follicles, this is yet to be confirmed. Significant species differences also exist and it 
would be interesting to determine the implications of these differences. The data presented regarding amino acid concentrations in sheep strongly suggests that transport of amino acids into the follicle occurs via active transport but these systems have not been fully characterised.

Finally, although none of the morphokinetic or molecular markers were predictive of embryological outcome, this study has shown for the first time that a combination of these improved the ability to predict embryological outcome. The duration of the second cell cycle (cc2) and CC-derived BMPR2 expression only trended towards significance, however in combination the predictive potential of both biomarkers was improved. It is likely that there are other CC-derived molecular markers that would improve prediction. Although unfeasible in the current study, it is hypothesised that the morphokinetic markers at or around the time of EGA (approximately the $8-16$ cell stage) would provide useful insights into the developmental competency of the embryo. As illustrated herein, the morphokinetic parameters in this study significantly identified a population of embryos that lacked developmental competency (embryos that arrested after the 8-cell stage (>8-cell).

This study has provided a number of new insights into the intrafollicular factors that influence developmental competency and identified areas in which further research is required. 


\subsection{Concluding remarks}

Overall, this study has provided several significant insights into the key processes and factors that influence developmental competency in ovine oocytes. This knowledge can be used to improve prediction of developmentally competent oocytes used for ART. One of the key findings from the current study was that despite significant differences in the microenvironment during maturation both in vitro and in vivo, gene expression in oocytes and morphokinetic events in embryos were unaltered. However, when high ratios of exogenous GDF9:BMP15 were supplemented to IVM media, blastocyst rates were improved signifying that developmental competency was improved. This appeared to be due, in part, to modulation of CC function which appeared to favour maturation and the majority of the differentially expressed genes were LH-responsive genes. Meanwhile, the high OR ewes utilised in this study have known mutations in BMP15 and BMPR1B and this results in the development of smaller-sized PPOV follicles and the premature expression of LH-responsive genes in the CC Together, this suggests that the maturational processes begin in smaller follicles, allowing for sufficient time for maturation. Furthermore, this study has provided preliminary evidence that using a combination of molecular (CC-derived gene expression) and morphokinetic markers enhanced the ability to identify embryos with improved developmental competency. 


\section{APPENDICES}

\section{APPENDIX 1: Summary of Information From Each Animal in the In Vivo Maturation Study (CHAPTER 3)}

Table A1-2: Summary of data collected from each animal for the in vivo maturation study.

\begin{tabular}{|c|c|c|c|c|c|c|c|c|c|c|c|c|}
\hline \multirow{2}{*}{$\begin{array}{c}\text { Animal ID } \\
\text { number } \\
\text { (Sheep } \\
\text { number) }\end{array}$} & \multirow{2}{*}{$\begin{array}{l}\text { Total number } \\
\text { of follicles } \\
\text { collected } \\
(>1 \mathrm{~mm})\end{array}$} & \multicolumn{2}{|c|}{ COC Morphology } & \multicolumn{3}{|c|}{$\begin{array}{l}\text { Follicles containing gonadotropin- } \\
\text { responsive GC }\end{array}$} & \multicolumn{2}{|c|}{$\begin{array}{l}\text { Follicular fluid } \\
\text { analysis }\end{array}$} & \multicolumn{2}{|c|}{$\begin{array}{c}\text { Gene expression } \\
\text { analysis (Cumulus } \\
\text { cell) }\end{array}$} & \multicolumn{2}{|c|}{$\begin{array}{l}\text { Gene expression } \\
\text { analysis (Oocyte) }\end{array}$} \\
\hline & & Compact & Expanded & $\begin{array}{c}\text { Non- } \\
\text { responsive }\end{array}$ & $\begin{array}{c}\text { FSH- } \\
\text { responsive }\end{array}$ & $\begin{array}{c}\text { LH- } \\
\text { responsive }\end{array}$ & Growing & PPOV & Growing $^{c}$ & PPOV & Growing & PPOV \\
\hline $\begin{array}{l}\mathbf{+ +} \\
\text { B0006 (29) } \\
\text { B1001 (30) } \\
\text { B1046 (33) } \\
\text { B0024 (36) } \\
\text { B1050 (37) } \\
\text { B0021 (38) } \\
\text { B0011 (41) } \\
\text { B0036 (43) } \\
\text { B0092 (44) } \\
\text { B0176 (47) } \\
\text { B0180 (48) }\end{array}$ & $\begin{array}{l}19 \\
38 \\
30 \\
38 \\
18 \\
21 \\
22 \\
16 \\
28 \\
59 \\
27\end{array}$ & $\begin{array}{l}12 \\
30 \\
25 \\
27 \\
12 \\
13 \\
18 \\
12 \\
22 \\
49 \\
23 \\
\end{array}$ & $\begin{array}{l}0 \\
0 \\
2 \\
1 \\
2 \\
1 \\
2 \\
1 \\
2 \\
2 \\
2\end{array}$ & $\begin{array}{l}6 \\
23 \\
7 \\
11 \\
9 \\
5 \\
0 \\
1 \\
\text { Exclude } \\
46 \\
13 \\
\end{array}$ & $\begin{array}{c}0 \\
4 \\
8 \\
7 \\
1 \\
8 \\
2 \\
7 \\
\text { - experimen } \\
0 \\
5 \\
\end{array}$ & \begin{tabular}{|c}
1 \\
0 \\
$1^{\mathrm{a}}$ \\
$0^{\mathrm{a}}$ \\
2 \\
2 \\
2 \\
3 \\
2 \\
I error $^{\mathrm{a}}$ \\
2 \\
4 \\
\end{tabular} & $\begin{array}{l}\text { Excluc } \\
\text { Excluc } \\
2 \\
2 \\
2 \\
0^{c} \\
1 \\
2 \\
0^{c} \\
2 \\
2\end{array}$ & $\begin{array}{l}\text { ed }{ }^{b} \\
\text { b } \\
2 \\
1 \\
1 \\
1 \\
1 \\
0^{c} \\
2 \\
2 \\
1 \\
\end{array}$ & $\begin{array}{c}4 \\
18 \\
11 \\
17 \\
10 \\
11 \\
9 \\
9 \\
17 \\
36 \\
11\end{array}$ & $\begin{array}{l}0 \\
0 \\
2 \\
1 \\
2 \\
1 \\
2 \\
1 \\
2 \\
2 \\
2 \\
\end{array}$ & $\begin{array}{c}4 \\
21 \\
13 \\
17 \\
10 \\
11 \\
9 \\
12 \\
19 \\
42 \\
18 \\
\end{array}$ & $\begin{array}{l}0 \\
0 \\
2 \\
1 \\
1 \\
1 \\
1 \\
0 \\
2 \\
2 \\
2 \\
\end{array}$ \\
\hline 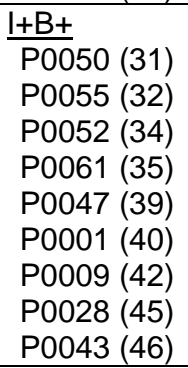 & $\begin{array}{l}48 \\
23 \\
33 \\
42 \\
36 \\
49 \\
37 \\
53 \\
31 \\
\end{array}$ & $\begin{array}{l}22 \\
10 \\
20 \\
29 \\
24 \\
36 \\
24 \\
43 \\
18 \\
\end{array}$ & $\begin{array}{l}3 \\
7 \\
7 \\
1 \\
5 \\
3 \\
8 \\
5 \\
3 \\
\end{array}$ & $\begin{array}{c}1 \\
2 \\
10 \\
4 \\
2 \\
10 \\
0 \\
5 \\
12 \\
\end{array}$ & $\begin{array}{c}6 \\
2 \\
7 \\
5 \\
8 \\
3 \\
0 \\
10 \\
0 \\
\end{array}$ & $\begin{array}{l}4 \\
7 \\
2 \\
6 \\
6 \\
3 \\
7 \\
7 \\
3\end{array}$ & $\begin{array}{l}0^{\mathrm{c}} \\
2 \\
1 \\
1 \\
0^{\mathrm{c}} \\
1 \\
1 \\
1 \\
0^{\mathrm{c}}\end{array}$ & $\begin{array}{l}1 \\
4 \\
3 \\
0^{c} \\
4 \\
1 \\
6 \\
4 \\
3 \\
\end{array}$ & $\begin{array}{c}1 \\
2 \\
12 \\
12 \\
10 \\
29 \\
9 \\
21 \\
7 \\
\end{array}$ & $\begin{array}{l}2 \\
6 \\
5 \\
1 \\
5 \\
2 \\
8 \\
6 \\
3\end{array}$ & $\begin{array}{c}2 \\
4 \\
12 \\
12 \\
9 \\
28 \\
10 \\
24 \\
10 \\
\end{array}$ & $\begin{array}{l}2 \\
5 \\
4 \\
1 \\
4 \\
1 \\
6 \\
6 \\
3 \\
\end{array}$ \\
\hline
\end{tabular}

a - Experimental error - treatments (gonadotropins) were not added to the appropriate sample(s)

b - No morphologically expanded follicles were collected from these sheep, so data from these sheep were excluded in follicular fluid analysis

$c$ - Excluded due to $<2 \mu \mathrm{L}$ of follicular fluid or contamination with blood 


\section{APPENDIX 2: Reagents and Equipment}

\section{A2.1: Reagents}

\begin{tabular}{|c|c|c|}
\hline Reagent & Catalogue number & Manufacturer \\
\hline $\begin{array}{l}\text { 3-isobutyl-1-methylxanthine } \\
\text { (IBMX) }\end{array}$ & 15879 & Sigma-Aldrich, MI, USA \\
\hline $\begin{array}{l}\text { Adenosine 3', 5'-cyclic } \\
\text { monophosphate (free acid } \\
\text { form) }\end{array}$ & A9501 & Sigma-Aldrich \\
\hline $\begin{array}{l}\text { Adenosine 3', 5'-cyclic } \\
\text { phosphoric acid, } 2 \text {-O- } \\
\text { succinyl [125I]-iodotyrosine } \\
\text { methyl ester (cAMP tracer) }\end{array}$ & NEX130010UC & PerkinEImer, MA, USA \\
\hline Acetic acid & AC03522500 & $\begin{array}{l}\text { Scharlau Chemie, Adelaide, } \\
\text { Australia }\end{array}$ \\
\hline Acetic anhydride & 242845 & BDH ProLabo \\
\hline Cysteamine hydrochloride & M6500 & Sigma-Aldrich. \\
\hline Bovine serum albumin (BSA) & Low Endotoxin ABRE & $\begin{array}{l}\text { ICPbio Reproduction, New } \\
\text { Zealand }\end{array}$ \\
\hline $\begin{array}{l}\text { Brilliant II SYBR® Green } \\
\text { QPCR Master Mix kit }\end{array}$ & 600828 & $\begin{array}{l}\text { Agilent Technologies, CA, } \\
\text { USA }\end{array}$ \\
\hline Brilliant QPCR Master Mix kit & 600553 & Agilent Technologies \\
\hline $\begin{array}{l}\text { Dulbecco's Modified Eagle's } \\
\text { Medium (DMEM) }\end{array}$ & $12320-032$ & Sigma-Aldrich. \\
\hline Ethanol & ET0016 & Scharlau Chemie \\
\hline Ethanol (RNase-free) & APPA39281000PE & $\begin{array}{l}\text { Global Science, New } \\
\text { Zealand }\end{array}$ \\
\hline Foetal bovine serum (FBS) & $12003 C$ & Sigma-Aldrich \\
\hline hCG (CR121; 13,450 IU/mg;) & & $\mathrm{NICHD}, \mathrm{MD}, \mathrm{USA}$ \\
\hline $\begin{array}{l}\text { Heat inactivated day } 1.5 \\
\text { Post-oestrus sheep serum }\end{array}$ & & $\begin{array}{l}\text { Produced and gifted by } \\
\text { Dr Jenny Juengel, } \\
\text { AgResearch Invermay. }\end{array}$ \\
\hline Heparin & H3149 & Sigma-Aldrich \\
\hline HEPES Free Acid & $\mathrm{H} 6147$ & Sigma-Aldrich \\
\hline HEPES Sodium Salt & H3784 & Sigma-Aldrich \\
\hline $\begin{array}{l}\text { HSOF media } \\
\text { (HEPES-buffered SOF) }\end{array}$ & & $\begin{array}{l}\text { Supplied by Jan Oliver, } \\
\text { AgResearch Ruakura }\end{array}$ \\
\hline $\begin{array}{l}\text { Hypophysectomised sheep } \\
\text { serum }\end{array}$ & & $\begin{array}{l}\text { Produced and gifted by } \\
\text { Dr Jenny Juengel, } \\
\text { AgResearch Invermay. }\end{array}$ \\
\hline $\begin{array}{l}\text { Hypotaurine } \\
\text { (2-Aminoethanesulfinic acid) }\end{array}$ & H1384 & Sigma-Aldrich \\
\hline
\end{tabular}




\begin{tabular}{|c|c|c|}
\hline Isopropanol (RNase-free) & APPA39281000PE & $\begin{array}{l}\text { Global Science, New } \\
\text { Zealand }\end{array}$ \\
\hline $\begin{array}{l}\text { IVM media } \\
(\mathrm{M} 199+10 \% \mathrm{FCS}+ \\
10 \mu \mathrm{g} / \mathrm{mL} \text { ovine FSH + } \\
1 \mu \mathrm{g} / \mathrm{mL} \beta \text {-oestradiol }+0.2 \\
\text { mM sodium pyruvate) }\end{array}$ & & $\begin{array}{l}\text { Produced and supplied by } \\
\text { Jan Oliver, AgResearch } \\
\text { Ruakura }\end{array}$ \\
\hline $\begin{array}{l}\text { IVF media } \\
\text { (Bicarbonate- buffered SOF) }\end{array}$ & & $\begin{array}{l}\text { Produced and supplied by } \\
\text { Jan Oliver, AgResearch } \\
\text { Ruakura }\end{array}$ \\
\hline Kanamycin & K1377 & Sigma-Aldrich \\
\hline $\begin{array}{l}\text { MasterPure }^{\mathrm{TM}} \text { RNA } \\
\text { Purification Kit (formerly, } \\
\text { ArrayPure }^{\mathrm{TM}} \text { Nano-scale RNA } \\
\text { Purification Kit) }\end{array}$ & $\begin{array}{c}\text { MCR85102 } \\
\text { (MSPS04050) }\end{array}$ & Epicentre, WI, USA \\
\hline Medium 199 (M199) & M5017 & Sigma-Aldrich \\
\hline Mineral oil & M5310 & Sigma-Aldrich \\
\hline Ova2 (Moore et al., 1997) & & $\begin{array}{l}\text { Gifted by Dr Jenny Juengel, } \\
\text { AgResearch Invermay. }\end{array}$ \\
\hline PDF2 $\alpha$ (Cloprostenol) & & $\begin{array}{l}\text { Bayer Animal Health, } \\
\text { Auckland, New Zealand. }\end{array}$ \\
\hline D-penicillamine & P4875 & Sigma-Aldrich \\
\hline $\begin{array}{l}90 \% \text { and } 45 \% \text { Percoll Plus } \\
\text { diultions }\end{array}$ & & $\begin{array}{l}\text { Produced and supplied by } \\
\text { Jan Oliver, AgResearch } \\
\text { Ruakura }\end{array}$ \\
\hline $\begin{array}{l}\text { Phosphate-buffered saline } \\
\text { (PBS;) }\end{array}$ & P4417-100TAB & Sigma-Aldrich. \\
\hline $\begin{array}{l}\text { Polyethlene glycol (PEG- } \\
8000)\end{array}$ & 889510 & Sigma-Aldrich \\
\hline Pyruvic acid sodium salt & P4562 & Sigma-Aldrich. \\
\hline Semen straws (Ovine) & Ram - Waihora 40 & $\begin{array}{l}\text { Genetic Gain Ltd, New } \\
\text { Zealand. }\end{array}$ \\
\hline $\begin{array}{l}\text { Sodium acetate } \\
\left(\mathrm{CH}_{3} \mathrm{COONa}\right)\end{array}$ & S2889 & Sigma-Aldrich \\
\hline Sodium chloride $(\mathrm{NaCl})$ & P4562 & Sigma-Aldrich. \\
\hline $\begin{array}{l}\text { Sodium bicarbonate } \\
\text { (NaHCO3) }\end{array}$ & S5761 & Sigma-Aldrich. \\
\hline $\begin{array}{l}\text { SOF media } \\
\text { (Synthetic oviductal fluid) }\end{array}$ & & $\begin{array}{l}\text { Produced and supplied by } \\
\text { Jan Oliver, AgResearch } \\
\text { Ruakura }\end{array}$ \\
\hline $\begin{array}{l}\text { SuperScript }{ }^{\circledR} \text { VILO } \\
\text { Synthesis } \text { cDit }\end{array}$ & 11754250 & $\begin{array}{l}\text { ThermoFisher Scientific, CA, } \\
\text { USA }\end{array}$ \\
\hline Triethylamine & T0886 & Sigma-Aldrich \\
\hline $\begin{array}{l}\text { UltraPure }{ }^{\mathrm{TM}} \text { distilled water } \\
\left(\mathrm{U} / \mathrm{P} \mathrm{dH}_{2} \mathrm{O}\right)\end{array}$ & 10977 & ThermoFisher Scientific \\
\hline
\end{tabular}




\begin{tabular}{|c|c|}
\hline & \\
\hline Antibodies (RIA) & \\
\hline $\begin{array}{l}\text { Primary antibody: } \\
\text { Rabbit-raised anti-0, 2- } \\
\text { monosuccinyl-adenosine- } \\
\text { 3',5'- cAMP IgG }\end{array}$ & $\begin{array}{l}\text { Produced and gifted by } \\
\text { Dr Jenny Juengel, } \\
\text { AgResearch Invermay. }\end{array}$ \\
\hline $\begin{array}{l}\text { Secondary antibody: } \\
\text { Sheep-raised anti-rabbit lgG }\end{array}$ & \\
\hline
\end{tabular}




\section{A2.2: Consumables}

\begin{tabular}{|c|c|c|}
\hline Consumable & Catalogue number & Manufacturer \\
\hline $\begin{array}{l}\text { Centrifuge tubes: } \\
15 \mathrm{~mL} \text {, } \\
50 \mathrm{~mL}\end{array}$ & $\begin{array}{l}430791 \\
430829\end{array}$ & $\begin{array}{l}\text { Corning Incorporated, NY, } \\
\text { USA }\end{array}$ \\
\hline $\begin{array}{l}\text { Culture plates: } \\
\text { 48-well } \\
\text { 96-well }\end{array}$ & $\begin{array}{l}\text { TCP-000-048 } \\
\text { TCP-000-096 } \\
\end{array}$ & Jet Biofil, China \\
\hline $\begin{array}{l}\text { Double ended drill bit } \\
(1.5 \mathrm{~mm})\end{array}$ & & Mitre 10, New Zealand \\
\hline $\begin{array}{l}\text { Microcentrifuge tubes: } \\
0.5 \mathrm{~mL} \text { (clear) } \\
1.5 \mathrm{~mL} \text { (clear) } \\
1.5 \mathrm{~mL} \text { (amber) } \\
2.0 \mathrm{~mL}\end{array}$ & $\begin{array}{l}1110-00 \\
1210-00 \\
1210-07 \\
1310-00\end{array}$ & $\begin{array}{l}\text { Scientific Specialities } \\
\text { Incorporated, CA, USA. }\end{array}$ \\
\hline Nichrome loops (5 mm) & T066/50 & $\begin{array}{l}\text { ProSciTech, QLD, } \\
\text { Australia }\end{array}$ \\
\hline $\begin{array}{l}\text { Petri dish: } \\
35 \mathrm{~mm} \\
60 \mathrm{~mm} \\
100 \mathrm{~mm}\end{array}$ & $\begin{array}{l}\text { TCD000035 } \\
2303-1060 \\
150350\end{array}$ & $\begin{array}{l}\text { Jet Biofil } \\
\text { Citotest, China } \\
\text { ThermoFisher }\end{array}$ \\
\hline $\begin{array}{l}\text { PCR tubes } \\
0.2 \mathrm{~mL}\end{array}$ & 981005 & Qiagen, Germany \\
\hline $\begin{array}{l}\text { PrecisionGlide }{ }^{\mathrm{TM}} 20 \text {-gauge } \\
\text { needle }\end{array}$ & 302025 & $\begin{array}{l}\text { Becton, Dickinson and } \\
\text { company (BD), Singapore. }\end{array}$ \\
\hline $\begin{array}{l}\text { Primo Vision }{ }^{\mathrm{TM}} \text { culture } \\
\text { dish: } \\
9 \text { - well } \\
16 \text { - well }\end{array}$ & $\begin{array}{l}16604 \\
16606\end{array}$ & Vitrolife, Sweden. \\
\hline Strip tubes $-0.1 \mathrm{~mL}$ & 981103 & Qiagen. \\
\hline $\begin{array}{l}\text { Syringe: } \\
1 \mathrm{~mL} \\
5 \mathrm{~mL} \\
60 \mathrm{~mL}\end{array}$ & $\begin{array}{l}309628 \\
301235 \\
\text { SG-503P-LL }\end{array}$ & $\begin{array}{l}\text { BD } \\
\text { BD } \\
\text { Interlab, New Zealand }\end{array}$ \\
\hline $\begin{array}{l}\text { Minisart } \AA \text { syringe filter } \\
(0.2 \mu \mathrm{m})\end{array}$ & 16534 & $\begin{array}{l}\text { Sartorius Stedim Biotech, } \\
\text { Germany }\end{array}$ \\
\hline
\end{tabular}




\section{A2.3: Equipment and Software Programs}

\begin{tabular}{|c|c|}
\hline Equipment & Manufacturer \\
\hline $\begin{array}{l}\text { Low } \mathrm{O}_{2} \text { gas mixture: } 5 \% \mathrm{CO}_{2}, 7 \% \mathrm{O}_{2} \text { in } \\
\mathrm{N}_{2} \text { (Recipe: MU82559, Gas code: } 163 \text { ) }\end{array}$ & BOC Ltd, Auckland, New Zealand \\
\hline Beacon Designer software package & Premier Biosoft International, CA, USA \\
\hline $\begin{array}{l}\text { Microscopes: } \\
\text { Dissection (Model: MZ95) } \\
\text { Inverted (Model DM1000) }\end{array}$ & Leica Microsystems, Germany \\
\hline $\begin{array}{l}\text { Primo Vision }{ }^{\mathrm{TM}} \text { Capture software (Cat } \\
\text { No.: 16608) }\end{array}$ & Vitrolife \\
\hline $\begin{array}{l}\text { Primo Vision }{ }^{\mathrm{TM}} \text { microscope (Cat. No. } \\
\text { 16600) }\end{array}$ & Vitrolife \\
\hline $\begin{array}{l}\text { Rotor-Gene }{ }^{\mathrm{TM}} 6000 \text { Rotary Analyzer } \\
\text { (Model No. 11754-050) }\end{array}$ & Qiagen \\
\hline $\begin{array}{l}\text { Wallac Wizard }{ }^{2} \text { Automatic Gamma } \\
\text { Counter }\end{array}$ & PerkinElmer \\
\hline
\end{tabular}




\section{APPENDIX 3: Media Composition and Stock Solutions}

\section{A3.1: General solutions and reagents}

\section{$0.9 \%(w / v)$ saline}

$\begin{array}{ll}\mathrm{NaCl} & 9 \mathrm{~g} \\ \mathrm{dH}_{2} \mathrm{O} & 1 \mathrm{~L}\end{array}$

The $\mathrm{NaCl}$ is dissolved in $1 \mathrm{~L}$ of $\mathrm{dH}_{2} \mathrm{O}$ and autoclaved prior to use.

$70 \%(v / v)$ aqueous ethanol

$\begin{array}{ll}\text { Ethanol } & 700 \mathrm{~mL} \\ \mathrm{dH}_{2} \mathrm{O} & 300 \mathrm{~mL}\end{array}$

The ethanol was added to a $1 \mathrm{~L}$ bottle and the $\mathrm{dH}_{2} \mathrm{O}$ added.

$1 \times$ phosphate buffered saline (PBS)

$\begin{array}{ll}\text { PBS } & 1 \text { tablet } \\ \mathrm{dH}_{2} \mathrm{O} & 200 \mathrm{~mL}\end{array}$

The PBS tablet was dissolved in the $\mathrm{dH}_{2} \mathrm{O}$ and autoclaved prior to use.

\section{GC culture media}

DMEM (with 25mM HEPES) 1 bottle $(500 \mathrm{~mL})$

BSA $500 \mathrm{mg}$

The BSA weighed out and added to the DMEM and mixed using a stirring bar on a magnetic plate. It was stored at $4{ }^{\circ} \mathrm{C}$ for up to a week.

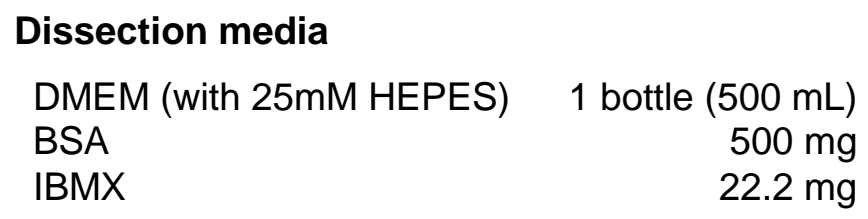

The BSA and IBMX were added to the DMEM and mixed using a stirring bar on a magnetic plate. It was stored at $4{ }^{\circ} \mathrm{C}$ for up to a week. IBMX was added to dissection media inhibit the activity of phosphodiesterase enzymes, particularly in the GC. This was done to ensure that assessment of GC gonadotropin-responsiveness was not influenced by phosphodiesterase activity. 


\section{A3.2: IVP media and stock solutions}

\section{$2 \times$ M199 stock solution}

$\begin{array}{lr}\mathrm{M} 199 \text { (powder) } & 1 \text { sachet } \\ \mathrm{Kanamycin} & 63.35 \mathrm{mg} \\ \mathrm{dH}_{2} \mathrm{O} & 500 \mathrm{~mL}\end{array}$

M199 powder and, kanamycin and $\mathrm{dH}_{2} \mathrm{O}$ were added to a beaker and mixed using a stirring bar on a magnetic plate until. The media was filtered using a $0.2 \mu \mathrm{m}$ filter and vacuum pump and stored at $4{ }^{\circ} \mathrm{C}$ for up to 6 months. (Osmolality: 490 - 500 mOsm).

\section{Stock B - $250 \mathrm{Mm} \mathrm{NaHCO}$ (Sodium Bicarbonate) \\ $\mathrm{NaHCO}_{3} \quad 1.05 \mathrm{~g}$ \\ $\mathrm{dH}_{2} \mathrm{O}$ (final volume) $\quad 50 \mathrm{~mL}$}

$\mathrm{NaHCO}_{3}$ was added to a beaker and made up to a volume of $50 \mathrm{~mL}$ using $\mathrm{dH}_{2} \mathrm{O}$. Once dissolved it was filtered using a syringe filter attached to a $60 \mathrm{~mL}$ syringe and stored at $4{ }^{\circ} \mathrm{C}$ for up to 3 months. (Osmolality: $430-440 \mathrm{mOsm}$ ).

\section{Stock C - 33 mM pyruvic acid (Pyruvate)}

Pyruvic Acid $\mathrm{dH}_{2} \mathrm{O}$ (final volume)

Pyruvic acid was made up to a total volume of $5 \mathrm{~mL}$ in $\mathrm{dH}_{2} \mathrm{O}$ and filtered. It was aliquoted in $100 \mu \mathrm{L}$ aliquots and stored a $-80^{\circ} \mathrm{C}$ for up to a year. (Osmolality: 55 - $60 \mathrm{mOSM}$ )

\section{Stock H - 250 mM 4-(2-hydroxyethyl)-1-piperazineethanesulfonic acid (HEPES) \\ HEPES Free Acid \\ HEPES Sodium Salt \\ $\mathrm{dH}_{2} \mathrm{O}$ (final volume) \\ $50 \mathrm{~mL}$}

The HEPES free acid and sodium salt were weighed out and made up to a total volume of $50 \mathrm{~mL}$ with $\mathrm{dH}_{2} \mathrm{O}$ and filtered. It was stored at $4{ }^{\circ} \mathrm{C}$ for up to three months.

\section{$20 \%$ BSA}

\section{BSA}

$0.9 \%$ Saline

$20 \mathrm{~mL}$

The BSA was weighed out and added to $100 \mathrm{~mL}$ bottle and the saline added. It was left in the fridge overnight and mixed gently. It was filtered and $1 \mathrm{~mL}$ aliquots were stored at $20^{\circ} \mathrm{C}$. 


\section{2 mM Penicillamine}

Penicillamine $\quad 5 \mathrm{mg}$

$0.9 \%$ Saline $\quad 8.38 \mathrm{~mL}$

Penicillamine was weighed out and made up to a total volume of $8.38 \mathrm{~mL}$ with saline and mixed until completely dissolved.

\section{1 mM Hypotaurine}

Hypotaurine

Hypotaurine was weighed out and made up to a total volume of $9.17 \mathrm{~mL}$ with saline and mixed until completely dissolved.

\section{Penicillamine/Hypotaurine}

$2 \mathrm{mM}$ penicillamine

$1 \mathrm{mM}$ hypotaurine

Both stock solutions were added together, mixed thoroughly, filtered and stored at $-20{ }^{\circ} \mathrm{C}$ in $100 \mu \mathrm{L}$ aliquots.

\section{$10 \mathrm{mM}$ Cysteamine hydrochloride}

$\begin{array}{lr}\text { Cysteamine hydrochloride } & 10 \mathrm{mg} \\ \text { B199 + } 10 \% \text { FBS } & 8.80 \mathrm{~mL}\end{array}$

Cysteamine hydrochloride was weighed out and then made up to a total volume of $8.80 \mathrm{~mL}$ with B199 + 10\% FBS and mixed until completely dissolved. It was filtered and stored at $-20^{\circ} \mathrm{C}$ in $40 \mu \mathrm{L}$ aliquots.

\section{B199}

$2 \times$ M199

Stock B

Stock C

$\mathrm{dH}_{2} \mathrm{O}$

$$
\begin{array}{r}
50 \mathrm{~mL} \\
10 \mathrm{~mL} \\
0.6 \mathrm{~mL} \\
39.4 \mathrm{~mL}
\end{array}
$$

The $2 \times$ M199 stock solution, Stock $\mathrm{B}$, Stock $\mathrm{C}$ and $\mathrm{dH}_{2} \mathrm{O}$ were added to a beaker and mixed using a stirring bar on a magnetic plate. The media was transferred into falcon tubes and stored at $4{ }^{\circ} \mathrm{C}$ for a up to a week due to the instability of Stock C (Osmolality: 288 $298 \mathrm{mOsm})$. 
B199 + $10 \%$ FCS

H199 $9 \mathrm{~mL}$

FCS $1 \mathrm{~mL}$

The B199 and FCS were added to a sterile $15 \mathrm{~mL}$ tube and inverted several times to mix. This media was made fresh for each experiment.

\section{H199}

$2 \times \mathrm{M} 199$

Stock H

$100 \mathrm{~mL}$

Stock B

$12 \mathrm{~mL}$

$\mathrm{dH}_{2} \mathrm{O}$

$4 \mathrm{~mL}$

$84 \mathrm{~mL}$

The $2 \times$ M199 stock solution, Stock $\mathrm{H}$, Stock $\mathrm{B}$ and $\mathrm{dH}_{2} \mathrm{O}$ were added to a beaker and mixed using a stirring bar on a magnetic plate. The media was transferred into falcon tubes and stored at $4{ }^{\circ} \mathrm{C}$ for up to a month. (Osmolality: 275 - $284 \mathrm{mOsm}$ )

\section{H199 + $10 \%$ FCS}

H199

$18 \mathrm{~mL}$

FCS

$2 \mathrm{~mL}$

The H199 and FCS were added to a sterile $50 \mathrm{~mL}$ tube and inverted several times to mix.

This media was made up fresh for each experiment.

\section{Aspiration Media}

$\begin{array}{lr}\text { H199 } & 100 \mathrm{~mL} \\ \text { Heparin }(5000 \mathrm{IU} / \mathrm{mL}) & 93 \mu \mathrm{L} \\ 20 \% \text { BSA } & 1 \mathrm{~mL}\end{array}$

The $\mathrm{H} 199$, heparin and $20 \% \mathrm{BSA}$ added to a beaker and mixed gently using a stirring bar on a magnetic plate. This media was made up fresh for each experiment.

\section{IVM Media}

Ovine IVM media

$10 \mathrm{mM}$ cysteamine

$500 \mu \mathrm{L}$

$5 \mu \mathrm{L}$

The ovine maturation media was thawed and the cysteamine was added before vortexing. This media was made up fresh for each experiment. 


\section{Complete IVF Media}

IVF media

Penicillamine/hypotaurine stock

solution

Day 1.5 post-oestrus sheep serum
$5 \mathrm{~mL}$

$50 \mu \mathrm{L}$

$1 \mathrm{~mL}$

IVF media, penicillamine/hypotaurine stock solution and Day 1.5 post-oestrus sheep serum were added to a $15 \mathrm{~mL}$ centrifuge tube and inverted several times to mix. This media was made fresh for each experiment.

\section{A3.3: RIA stock solutions and buffers}

\section{Assay buffer (50 $\mathrm{mM} \mathrm{CH}_{3} \mathrm{COONa}$; sodium acetate)}

Sodium acetate $\mathrm{dH}_{2} \mathrm{O}$
$4.10 \mathrm{~g}$

$1 \mathrm{~L}$

The sodium acetate stock solution was weighed out, added to a beaker. The $\mathrm{dH}_{2} \mathrm{O}$ was added and it was mixed using a stirring bar on a magnetic plate. The $\mathrm{pH}$ of the stock solution was adjusted to 6.5 with glacial acetic acid if necessary and then transferred to a $1 \mathrm{~L}$ bottle and stored at room temperature.

\section{Primary antibody buffer}

$\begin{array}{ll}\text { Assay buffer } & 200 \mathrm{~mL} \\ \text { BSA } & 200 \mathrm{mg}\end{array}$

The BSA was weighed out and added to the assay buffer and mixed gently using a stirring bar on a magnetic plate and then stored at $4{ }^{\circ} \mathrm{C}$ for up to a week. The primary antibody was diluted 1:15,000 in this buffer prior to use.

\section{Secondary antibody buffer}
Assay buffer
$15 \mathrm{~mL}$
Hypophysectomised sheep serum
$4.5 \mathrm{~mL}$

The hypophysectomised sheep serum was added to the assay buffer and mixed gently using a stirring bar on a magnetic plate and the secondary antibody was diluted 1:30 in this buffer prior to use. 


\section{Tracer buffer}
Assay buffer
$200 \mathrm{~mL}$
BSA
$4 \mathrm{~g}$
Normal rabbit serum (NRS)
$0.5 \mathrm{~mL}$

The BSA was weighed out and added to the assay buffer. Likewise, the NRS was thawed and then added and mixed gently using a stirring bar on a magnetic plate and then stored at $4{ }^{\circ} \mathrm{C}$ for up to a week.

\section{Acetylating reagent}

Acetic anhydride

Triethylamine

$500 \mu \mathrm{L}$

$1 \mathrm{~mL}$

The acetic anhydride and triethylamine were added to a $2.0 \mathrm{~mL}$ microcentrifuge tube and vortexed thoroughly. The acetylating reagent was made fresh prior to the acetylating step each experiment.

\section{Separation buffer}

Polyethylene glycol (PEG-8000)

PBS

The PEG was weighed out and the PBS was added and mixed using a stirring bar on a magnetic plate before being stored at $4{ }^{\circ} \mathrm{C}$ 


\section{APPENDIX 4: Summary of Generalised Linear Mixed Models (GLMM)}

\section{A4.1: Amino Acids:}

These tables are summaries of the fixed effects in the GLMM model of the factors influencing amino acid concentrations (Section 3.3.3.2.1) in ovine follicular fluid. The fixed effects were follicular stage (i.e. growing or PPOV) and genotype (i.e. ++ or I+B+). The interaction between follicular stage and genotype was also included. Sheep number was included as a random factor and the proportion of variation that could be attributed to between sheep variation for each model was determined.

Table A4-1: Summary of fixed effects included in the GLMM model (fitted to a Gaussian distribution) influencing alanine concentration in ovine follicular fluid. Sheep-to-sheep variation accounted for $20.1 \%$ of the variation.

\begin{tabular}{lcccc}
\hline & F & df1 & df2 & P-Value \\
\hline Follicular stage & 7.162 & 1 & 49 & 0.010 \\
Genotype & 0.130 & 1 & 23 & 0.722 \\
Follicular stage $\times$ Genotype & 1.974 & 1 & 49 & 0.166 \\
\hline
\end{tabular}

Table A4-2: Summary of fixed effects included in the GLMM model (fitted to a Gaussian distribution) influencing arginine concentration in ovine follicular fluid. Sheep-to-sheep variation accounted for $22.9 \%$ of the variation.

\begin{tabular}{lcccc}
\hline & F & df1 & df2 & P-Value \\
\hline Follicular stage & 8.885 & 1 & 49 & 0.004 \\
Genotype & 5.867 & 1 & 23 & 0.026 \\
Follicular stage $\times$ Genotype & 1.551 & 1 & 49 & 0.219 \\
\hline
\end{tabular}

Table A4-3: Summary of fixed effects included in the GLMM model (fitted to a Gaussian distribution) influencing asparagine concentration in ovine follicular fluid. Sheep sheep-to-sheep variation accounted for $19.9 \%$ of the variation.

\begin{tabular}{lcccc}
\hline & F & df1 & df2 & P-Value \\
\hline Follicular stage & 9.751 & 1 & 49 & 0.003 \\
Genotype & 0.795 & 1 & 24 & 0.382 \\
Follicular stage $\times$ Genotype & 5.656 & 1 & 49 & 0.021 \\
\hline
\end{tabular}


Table A4-4: Summary of fixed effects included in the GLMM model (fitted to a Gaussian distribution) influencing aspartic acid concentration in ovine follicular fluid. Sheep-to-sheep variation accounted for $19.2 \%$ of the variation.

\begin{tabular}{lcccc}
\hline & F & df1 & df2 & P-Value \\
\hline Follicular stage & 1.218 & 1 & 6 & 0.310 \\
Genotype & 2.920 & 1 & 4 & 0.162 \\
Follicular stage $\times$ Genotype & 8.464 & 1 & 6 & 0.026 \\
\hline
\end{tabular}

Table A4-5: Summary of fixed effects included in the GLMM model (fitted to a Gaussian distribution) influencing citrulline concentration in ovine follicular fluid. Sheep-to-sheep variation accounted for $21.4 \%$ of the variation.

\begin{tabular}{lcccc}
\hline & F & df1 & df2 & P-Value \\
\hline Follicular stage & 26.269 & 1 & 49 & $<0.0005$ \\
Genotype & 10.038 & 1 & 22 & 0.004 \\
Follicular stage $\times$ Genotype & 1.358 & 1 & 49 & 0.250 \\
\hline
\end{tabular}

Table A4-6: Summary of fixed effects included in the GLMM model (fitted to a Gaussian distribution with a log link function) influencing glutamic acid concentration in ovine follicular fluid. Sheep-to-sheep variation accounted for $<0.1 \%$ of the variation.

\begin{tabular}{lcccc}
\hline & F & df1 & df2 & P-Value \\
\hline Follicular stage & 0.030 & 1 & 49 & 0.864 \\
Genotype & 0.465 & 1 & 40 & 0.499 \\
Follicular stage $\times$ Genotype & 4.315 & 1 & 49 & 0.043 \\
\hline
\end{tabular}

Table A4-7: Summary of fixed effects included in the GLMM model (fitted to a Gaussian distribution) influencing glutamine concentration in ovine follicular fluid. Sheep -to-sheep variation accounted for $11.0 \%$ of the variation.

\begin{tabular}{lcccc}
\hline & F & df1 & df2 & P-Value \\
\hline Follicular stage & 80.068 & 1 & 47 & $<0.0005$ \\
Genotype & 17.054 & 1 & 15 & 0.001 \\
Follicular stage $\times$ Genotype & 1.333 & 1 & 47 & 0.254 \\
\hline
\end{tabular}


Table A4-8: Summary of fixed effects included in the GLMM model (fitted to a Gaussian distribution) influencing glycine concentration in ovine follicular fluid. Sheep-to-sheep variation accounted for $12.7 \%$ of the variation.

\begin{tabular}{lcccc}
\hline & F & df1 & df2 & P-Value \\
\hline Follicular stage & 27.252 & 1 & 52 & $<0.0005$ \\
Genotype & 0.003 & 1 & 53 & 0.958 \\
Follicular stage $\times$ Genotype & 0.142 & 1 & 52 & 0.708 \\
\hline
\end{tabular}

Table A4-9: Summary of fixed effects included in the GLMM model (fitted to a Gaussian distribution with a log link function) influencing histidine concentration in ovine follicular fluid. Sheep-to-sheep variation accounted for $0.1 \%$ of the variation.

\begin{tabular}{lcccc}
\hline & F & df1 & df2 & P-Value \\
\hline Follicular stage & 14.270 & 1 & 41 & $<0.0005$ \\
Genotype & 2.605 & 1 & 52 & 0.113 \\
Follicular stage $\times$ Genotype & 2.724 & 1 & 41 & 0.106 \\
\hline
\end{tabular}

Table A4-10: Summary of fixed effects included in the GLMM model (fitted to a Gaussian distribution with a log link function) influencing hydroxyproline concentration in ovine follicular fluid. Sheep -to-sheep variation accounted for $<0.1 \%$ of the variation.

\begin{tabular}{lcccc}
\hline & F & df1 & df2 & P-Value \\
\hline Follicular stage & 15.079 & 1 & 42 & $<0.0005$ \\
Genotype & 3.220 & 1 & 52 & 0.079 \\
Follicular stage $\times$ Genotype & 5.914 & 1 & 42 & 0.019 \\
\hline
\end{tabular}

Table A4-11: Summary of fixed effects included in the GLMM model (fitted to a Gaussian distribution) influencing isoleucine concentration in ovine follicular fluid. Sheep -to-sheep variation accounted for $7.6 \%$ of the variation.

\begin{tabular}{lcccc}
\hline & F & df1 & df2 & P-Value \\
\hline Follicular stage & 49.176 & 1 & 49 & $<0.0005$ \\
Genotype & 23.263 & 1 & 19 & $<0.0005$ \\
Follicular stage $\times$ Genotype & 0.021 & 1 & 49 & 0.885 \\
\hline
\end{tabular}


Table A4-12: Summary of fixed effects included in the GLMM model (fitted to a Gaussian distribution) influencing leucine concentration in ovine follicular fluid. Sheep -to-sheep variation accounted for $24.2 \%$ of the variation.

\begin{tabular}{lcccc}
\hline & F & df1 & df2 & P-Value \\
\hline Follicular stage & 15.286 & 1 & 48 & $<0.0005$ \\
Genotype & 10.412 & 1 & 22 & 0.004 \\
Follicular stage $\times$ Genotype & 0.889 & 1 & 48 & 0.351 \\
\hline
\end{tabular}

Table A4-13: Summary of fixed effects included in the GLMM model (fitted to a Gaussian distribution) influencing lysine concentration in ovine follicular fluid. Sheep-to-sheep variation accounted for $2.5 \%$ of the variation.

\begin{tabular}{lcccc}
\hline & F & df1 & df2 & P-Value \\
\hline Follicular stage & 19.509 & 1 & 50 & $<0.0005$ \\
Genotype & 24.871 & 1 & 22 & $<0.0005$ \\
Follicular stage $\times$ Genotype & 0.046 & 1 & 50 & 0.830 \\
\hline
\end{tabular}

Table A4-14: Summary of fixed effects included in the GLMM model (fitted to a Gaussian distribution) influencing methionine concentration in ovine follicular fluid. Sheep-to-sheep variation accounted for $<0.1 \%$ of the variation.

\begin{tabular}{lcccc}
\hline & F & df1 & df2 & P-Value \\
\hline Follicular stage & 54.064 & 1 & 53 & $<0.0005$ \\
Genotype & 17.449 & 1 & 53 & $<0.0005$ \\
Follicular stage $\times$ Genotype & 1.336 & 1 & 53 & 0.253 \\
\hline
\end{tabular}

Table A4-15: Summary of fixed effects included in the GLMM model (fitted to a Gaussian distribution with a log link function) influencing phenylalanine concentration in ovine follicular fluid. Sheep-to-sheep variation accounted for $<0.1 \%$ of the variation.

\begin{tabular}{lcccc}
\hline & F & df1 & df2 & P-Value \\
\hline Follicular stage & 24.134 & 1 & 42 & $<0.0005$ \\
Genotype & 6.761 & 1 & 49 & 0.012 \\
Follicular stage $\times$ Genotype & 5.586 & 1 & 42 & 0.023 \\
\hline
\end{tabular}


Table A4-16: Summary of fixed effects included in the GLMM model (fitted to a Gaussian distribution with a log link function) influencing proline concentration in ovine follicular fluid. Sheep-to-sheep variation accounted for $10.1 \%$ of the variation.

\begin{tabular}{lcccc}
\hline & F & df1 & df2 & P-Value \\
\hline Follicular stage & 41.153 & 1 & 49 & $<0.0005$ \\
Genotype & 2.125 & 1 & 20 & 0.160 \\
Follicular stage $\times$ Genotype & 1.450 & 1 & 49 & 0.2340 \\
\hline
\end{tabular}

Table A4-17: Summary of fixed effects included in the GLMM model (fitted to a Gaussian distribution) influencing serine concentration in ovine follicular fluid. Sheep-to-sheep variation accounted for $8.7 \%$ of the variation.

\begin{tabular}{lcccc}
\hline & F & df1 & df2 & P-Value \\
\hline Follicular stage & 29.758 & 1 & 53 & $<0.0005$ \\
Genotype & 3.312 & 1 & 7 & 0.112 \\
Follicular stage $\times$ Genotype & 5.525 & 1 & 53 & 0.022
\end{tabular}

Table A4-18: Summary of fixed effects included in the GLMM model (fitted to a Gaussian distribution) influencing taurine concentration in ovine follicular fluid. Sheep-to-sheep variation accounted for $3.5 \%$ of the variation.

\begin{tabular}{lcccc}
\hline & F & df1 & df2 & P-Value \\
\hline Follicular stage & 33.643 & 1 & 15 & $<0.0005$ \\
Genotype & 5.557 & 1 & 15 & 0.032 \\
Follicular stage $\times$ Genotype & 0.228 & 1 & 15 & 0.640 \\
\hline
\end{tabular}

Table A4-19: Summary of fixed effects included in the GLMM model (fitted to a Gaussian distribution) influencing threonine concentration in ovine follicular fluid. Sheep-to-sheep variation accounted for $24.3 \%$ of the variation.

\begin{tabular}{lcccc}
\hline & F & df1 & df2 & P-Value \\
\hline Follicular stage & 0.753 & 1 & 43 & 0.390 \\
Genotype & 2.005 & 1 & 12 & 0.183 \\
Follicular stage $\times$ Genotype & 0.190 & 1 & 43 & 0.665
\end{tabular}


Table A4-20: Summary of fixed effects included in the GLMM model (fitted to a Gaussian distribution) influencing tyrosine concentration in ovine follicular fluid. Sheep-to-sheep variation accounted for $<0.1 \%$ of the variation.

\begin{tabular}{lcccc}
\hline & F & df1 & df2 & P-Value \\
\hline Follicular stage & 3.121 & 1 & 9 & 0.110 \\
Genotype & 8.191 & 1 & 4 & 0.042 \\
Follicular stage $\times$ Genotype & 0.195 & 1 & 9 & 0.669 \\
\hline
\end{tabular}

Table A4-21: Summary of fixed effects included in the GLMM model (fitted to a Gaussian distribution with a log link function) influencing valine concentration in ovine follicular fluid. Sheep -to-sheep variation accounted for $<0.1 \%$ of the variation.

\begin{tabular}{lcccc}
\hline & F & df1 & df2 & P-Value \\
\hline Follicular stage & 3.431 & 1 & 48 & 0.070 \\
Genotype & 12.704 & 1 & 22 & 0.002 \\
Follicular stage $\times$ Genotype & 0.067 & 1 & 48 & 0.797 \\
\hline
\end{tabular}

\section{A4.2: Energy substrates}

These tables are summaries of the fixed effects in the GLMM model of the factors influencing energy substrate concentrations (Section 3.3.3.2.2) in ovine follicular fluid. The fixed effects were follicular stage (i.e. growing or PPOV) and genotype (i.e. ++ or I+B+). The interaction between follicular stage and genotype was also included. Sheep number was included as a random factor and the proportion of variation that could be attributed to between sheep variation for each model was determined.

Table A4-22: Summary of fixed effects included in the GLMM model (fitted to a Gaussian distribution) influencing glucose concentration in ovine follicular fluid. Sheep -to-sheep variation accounted for $19.0 \%$ of the variation.

\begin{tabular}{lcccc}
\hline & F & df1 & df2 & P-Value \\
\hline Follicular stage & 45.734 & 1 & 16 & $<0.0005$ \\
Genotype & 2.229 & 1 & 13 & 0.159 \\
Follicular stage $\times$ Genotype & 4.935 & 1 & 16 & $<0.0005$ \\
\hline
\end{tabular}


Table A4-23: Summary of fixed effects included in the GLMM model (fitted to a Gaussian distribution with a log link function) influencing cholesterol concentration in ovine follicular fluid. Sheep -to-sheep variation accounted for $1.9 \%$ of the variation.

\begin{tabular}{lcccc}
\hline & F & df1 & df2 & P-Value \\
\hline Follicular stage & 18.446 & 1 & 41 & $<0.0005$ \\
Genotype & 3.419 & 1 & 52 & 0.070 \\
Follicular stage $\times$ Genotype & 5.334 & 1 & 41 & 0.026 \\
\hline
\end{tabular}

\section{A4.3: Steroid hormones:}

These tables are summaries of the fixed effects in the GLMM model of the factors influencing steroid hormone concentrations (Section 3.3.3.2.3) in ovine follicular fluid. The fixed effects were follicular stage (i.e. growing or PPOV) and genotype (i.e. ++ or I+B+). The interaction between follicular stage and genotype was also included. Sheep number was included as a random factor and the proportion of variation that could be attributed to between sheep variation for each model was determined.

Table A4-24: Summary of fixed effects included in the GLMM model (fitted to a Gaussian distribution) influencing cortisone concentration in ovine follicular fluid. Sheep-to-sheep variation accounted for $33.0 \%$ of the variation.

\begin{tabular}{lcccc}
\hline & F & df1 & df2 & P-Value \\
\hline Follicular stage & 0.153 & 1 & 42 & 0.698 \\
Genotype & 0.129 & 1 & 15 & 0.725 \\
Follicular stage $\times$ Genotype & 1.743 & 1 & 42 & 0.194 \\
\hline
\end{tabular}

Table A4-25: Summary of fixed effects included in the GLMM model (fitted to a Gaussian distribution with a log link function) influencing androstenedione concentration in ovine follicular fluid. Sheep -to-sheep variation accounted for $0.8 \%$ of the variation.

\begin{tabular}{lcccc}
\hline & F & df1 & df2 & P-Value \\
\hline Follicular stage & 10.7423 & 1 & 43 & 0.002 \\
Genotype & 0.013 & 1 & 43 & 0.910 \\
Follicular stage $\times$ Genotype & 9.539 & 1 & 46 & 0.003 \\
\hline
\end{tabular}


Table A4-26: Summary of fixed effects included in the GLMM model (fitted to a Gaussian distribution with a log link function) influencing testosterone concentration in ovine follicular fluid. Sheep-to-sheep variation accounted for $1.4 \%$ of the variation.

\begin{tabular}{lcccc}
\hline & F & df1 & df2 & P-Value \\
\hline Follicular stage & 15.484 & 1 & 43 & $<0.0005$ \\
Genotype & 0.193 & 1 & 53 & 0.662 \\
Follicular stage $\times$ Genotype & 2.071 & 1 & 43 & 0.157 \\
\hline
\end{tabular}

Table A4-27: Summary of fixed effects included in the GLMM model (fitted to a Gaussian distribution) influencing $17 \beta$-oestradiol concentration in ovine follicular fluid. Sheep to-sheep variation accounted for $<0.1 \%$ of the variation.

\begin{tabular}{lcccc}
\hline & F & df1 & df2 & P-Value \\
\hline Follicular stage & 4.869 & 1 & 53 & 0.032 \\
Genotype & 0.980 & 1 & 53 & 0.327 \\
Follicular stage $\times$ Genotype & 1.159 & 1 & 53 & 0.287 \\
\hline
\end{tabular}

Table A4-28: Summary of fixed effects included in the GLMM model (fitted to a Gaussian distribution with a log link function) influencing progesterone concentration in ovine follicular fluid. Sheep number was included as a random factor and sheep-to-sheep variation accounted for $0.1 \%$ of the variation.

\begin{tabular}{lcccc}
\hline & F & df1 & df2 & P-Value \\
\hline Follicular stage & 6.157 & 1 & 42 & 0.017 \\
Genotype & 0.000 & 1 & 49 & 0.997 \\
Follicular stage $\times$ Genotype & 1.021 & 1 & 42 & 0.318 \\
\hline
\end{tabular}

\section{A4.4: Oocyte-derived gene expression}

These tables are summaries of the fixed effects in the GLMM model of the factors influencing oocyte derived gene expression (Section 3.3.4.2). The fixed effects were follicular stage (i.e. growing or PPOV) and genotype (i.e. ++ or $\mathrm{I}+\mathrm{B}+$ ). The interaction between follicular stage and genotype was also included. Sheep number was included as a random factor and the proportion of variation that could be attributed to between sheep variation for each model was determined. 
Table A4-29: Summary of fixed effects included in the GLMM model (fitted to a Gaussian distribution with a log link function) influencing PTTG1 expression in oocytes. Sheep-to-sheep variation accounted for $67.2 \%$ of the variation.

\begin{tabular}{lcccc}
\hline & F & df1 & df2 & P-Value \\
\hline Follicular stage & 0.463 & 1 & 307 & 0.497 \\
Genotype & 1.493 & 1 & 37 & 0.229 \\
Follicular stage $\times$ Genotype & 0.228 & 1 & 307 & 0.633 \\
\hline
\end{tabular}

Table A4-30: Summary of fixed effects included in the GLMM model (fitted to a Gaussian distribution with a log link function) influencing HSF1 expression in oocytes. Sheep-to-sheep variation accounted for $83.1 \%$ of the variation.

\begin{tabular}{lcccc}
\hline & F & df1 & df2 & P-Value \\
\hline Follicular stage & 0.131 & 1 & 4 & 0.735 \\
Genotype & 1.362 & 1 & 8 & 0.277 \\
Follicular stage $\times$ Genotype & 0.606 & 1 & 4 & 0.478
\end{tabular}

Table A4-31: Summary of fixed effects included in the GLMM model (fitted to a Gaussian distribution with a log link function) influencing ZP3 expression in oocytes. Sheep-to-sheep variation accounted for $81.6 \%$ of the variation.

\begin{tabular}{lcccc}
\hline & F & df1 & df2 & P-Value \\
\hline Follicular stage & 0.286 & 1 & 306 & 0.593 \\
Genotype & 1.887 & 1 & 116 & 0.172 \\
Follicular stage $\times$ Genotype & 0.880 & 1 & 306 & 0.349 \\
\hline
\end{tabular}

Table A4-32: Summary of fixed effects included in the GLMM model (fitted to a Gaussian distribution) influencing PDE3A expression in oocytes. Sheep-to-sheep variation accounted for $98.7 \%$ of the variation.

\begin{tabular}{lcccc}
\hline & F & df1 & df2 & P-Value \\
\hline Follicular stage & 0.003 & 1 & 15 & 0.960 \\
Genotype & 1.053 & 1 & 17 & 0.320 \\
Follicular stage $\times$ Genotype & 0.162 & 1 & 15 & 0.693
\end{tabular}


Table A4-33: Summary of fixed effects included in the GLMM model (fitted to a Gaussian distribution with a log link function) influencing PAPOLA expression in oocytes. Sheep-to-sheep variation accounted for $65.5 \%$ of the variation.

\begin{tabular}{lcccc}
\hline & F & df1 & df2 & P-Value \\
\hline Follicular stage & 0.415 & 1 & 303 & 0.520 \\
Genotype & 1.365 & 1 & 39 & 0.250 \\
Follicular stage $\times$ Genotype & 0.195 & 1 & 303 & 0.659 \\
\hline
\end{tabular}

Table A4-34: Summary of fixed effects included in the GLMM model (fitted to a Gaussian distribution with a log link function) influencing ATR expression in oocytes. Sheep-to-sheep variation accounted for $82.7 \%$ of the variation.

\begin{tabular}{lcccc}
\hline & F & df1 & df2 & P-Value \\
\hline Follicular stage & 2.166 & 1 & 2 & 0.267 \\
Genotype & 2.282 & 1 & 11 & 0.160 \\
Follicular stage $\times$ Genotype & 6.131 & 1 & 2 & 0.119
\end{tabular}

Table A4-35: Summary of fixed effects included in the GLMM model (fitted to a Gaussian distribution with a log link function), of the factors influencing BMP15 expression in oocytes. Sheep-to-sheep variation accounted for $75.7 \%$ of the variation.

\begin{tabular}{lcccc}
\hline & F & df1 & df2 & P-Value \\
\hline Follicular stage & 0.155 & 1 & 32 & 0.696 \\
Genotype & 4.715 & 1 & 12 & 0.051 \\
Follicular stage $\times$ Genotype & 0.569 & 1 & 32 & 0.456 \\
\hline
\end{tabular}

Table A4-36: Summary of fixed effects included in the GLMM model (fitted to a Gaussian distribution with a log link) influencing GDF9 expression in oocytes. Sheep -to-sheep variation accounted for $98.7 \%$ of the variation.

\begin{tabular}{lcccc}
\hline & F & df1 & df2 & P-Value \\
\hline Follicular stage & 0.472 & 1 & 321 & 0.492 \\
Genotype & 0.555 & 1 & 110 & 0.458 \\
Follicular stage $\times$ Genotype & 1.611 & 1 & 321 & 0.205 \\
\hline
\end{tabular}




\section{BIBLIOGRAPHY}

Aardema, H., Lolicato, F., van de Lest, C.H., Brouwers, J.F., Vaandrager, A.B., van Tol, H.T., Roelen, B.A.J., Vos, P.L.A.M., Helms, J.B., Gadella, B.M., 2013a. Bovine cumulus cells protect maturing oocytes from increased fatty acid levels by massive intracellular lipid storage. Biol. Reprod. 88.

Aardema, H., Roelen, B.A.J., van Tol, H.T.A., Oei, C.H.Y., Gadella, B.M., Vos, P.L.A.M., 2013b. Follicular 17 $\beta$-estradiol and progesterone concentrations and degree of cumulus cell expansion as predictors of in vivo-matured oocyte developmental competence in superstimulated heifers. Theriogenology $80,576-583$.

Ackert, C.L., Gittens, J.E.I., O’Brien, M.J., Eppig, J.J., Kidder, G.M., 2001. Intercellular communication via connexin43 gap junctions is required for ovarian folliculogenesis in the mouse. Dev. Biol. 233, 258-270.

Adriaenssens, T., Wathlet, S., Segers, I., Verheyen, G., De Vos, A., Van der Elst, J., Coucke, W., Devroey, P., Smitz, J., 2010. Cumulus cell gene expression is associated with oocyte developmental quality and influenced by patient and treatment characteristics. Hum. Reprod. 25, 1259-1270.

Albuz, F.K., Sasseville, M., Lane, M., Armstrong, D.T., Thompson, J.G., Gilchrist, R.B., 2010. Simulated physiological oocyte maturation (SPOM): A novel in vitro maturation system that substantially improves embryo yield and pregnancy outcomes. Hum. Reprod. 25, 2999-3011.

Alhussini, A., 2016. The molecular forms of GDF9 in a range of mammalian species (Master's thesis). Victoria University of Wellington, Wellington.

Amsterdam, A., Koch, Y., Lieberman, M.E., Lindner, H.R., 1975. Distribution of binding sites for human chorionic gonadotropin in the preovulatory follicle of the rat. J. Cell Biol. 67, 894-900.

Anderson, E., Albertini, D.F., 1976. Gap junctions between the oocyte and companion follicle cells in the mammalian ovary. J. Cell Biol. 71, 680-686.

Anderson, R.A., Sciorio, R., Kinnell, H., Bayne, R. a. L., Thong, K.J., Sousa, P.A. de, Pickering, S., 2009. Cumulus gene expression as a predictor of human oocyte fertilisation, embryo development and competence to establish a pregnancy. Reproduction 138, 629-637.

Arce, J.-C., Ziebe, S., Lundin, K., Janssens, R., Helmgaard, L., Sørensen, P., 2006. Interobserver agreement and intraobserver reproducibility of embryo quality assessments. Hum. Reprod. 21, 2141-2148.

Armstrong, D.T., Xia, P., Gannes, G. de, Tekpetey, F.R., Khamsi, F., 1996. Differential effects of insulin-like growth factor-I and follicle-stimulating hormone on proliferation and differentiation of bovine cumulus cells and granulosa cells. Biol. Reprod. 54, 331-338. 
Assey, R.J., Hyttel, P., Greve, T., Purwantara, B., 1994. Oocyte morphology in dominant and subordinate follicles. Mol. Reprod. Dev. 37, 335-344.

Assidi, M., Dufort, I., Ali, A., Hamel, M., Algriany, O., Dielemann, S., Sirard, M.-A., 2008. Identification of potential markers of oocyte competence expressed in bovine cumulus cells matured with follicle-stimulating hormone and/or phorbol myristate acetate in vitro. Biol. Reprod. 79, 209-222.

Assidi, M., Montag, M., Van Der Ven, K., Sirard, M.-A., 2011. Biomarkers of human oocyte developmental competence expressed in cumulus cells before ICSI: a preliminary study. J. Assist. Reprod. Genet. 28, 173-188.

Assidi, M., Richard, F.J., Sirard, M.-A., 2013. FSH in vitro versus LH in vivo: similar genomic effects on the cumulus. J. Ovarian Res. 6, 68.

Assin, R.R. de, Clavero, A., Gonzalvo, M.C., Rosales, A., Zamora, S., Martinez, L., Mozas, J., Castilla, J.A., 2011. Reducing inter-observer variability in embryo evaluation by means of training courses. J. Assist. Reprod. Genet. 28, 1129-1133.

Assou, S., Haouzi, D., Dechaud, H., Gala, A., Ferrières, A., Hamamah, S., 2013. Comparative gene expression profiling in human cumulus cells according to ovarian gonadotropin treatments. BioMed Res. Int.

Atef, A., François, P., Christian, V., Marc-André, S., 2005. The potential role of gap junction communication between cumulus cells and bovine oocytes during in vitro maturation. Mol. Reprod. Dev. 71, 358-367.

Azari-Dolatabad, N., Rahmani, H.R., Hajian, M., Ostadhosseini, S., Hosseini, S.M., NasrEsfahani, M.H., 2016. Effects of cilostamide and/or forskolin on the meiotic resumption and development competence of growing ovine oocytes selected by brilliant cresyl blue staining. Theriogenology 85, 1483-1490.

Baby, T.E., Bartlewski, P.M., 2011. Circulating concentrations of ovarian steroids and follicle-stimulating hormone (FSH) in ewes with 3 or 4 waves of antral follicle emergence per estrous cycle. Reprod. Biol. 11, 19-36.

Baird, D.T., Campbell, B.K., Mann, G.E., McNeilly, A.S., 1991. Inhibin and oestradiol in the control of FSH secretion in the sheep. J. Reprod. Fertil. Suppl. 43, 125-138.

Bao, S., Obata, Y., Carroll, J., Domeki, I., Kono, T., 2000. Epigenetic modifications necessary for normal development are established during oocyte growth in mice. Biol. Reprod. 62, 616-621.

Bellver, J., Mifsud, A., Grau, N., Privitera, L., Meseguer, M., 2013. Similar morphokinetic patterns in embryos derived from obese and normoweight infertile women: a timelapse study. Hum. Reprod. 28, 794-800.

Bierkamp, C., Luxey, M., Metchat, A., Audouard, C., Dumollard, R., Christians, E., 2010. Lack of maternal Heat Shock Factor 1 results in multiple cellular and developmental defects, including mitochondrial damage and altered redox homeostasis, and leads to reduced survival of mammalian oocytes and embryos. Dev. Biol., Special Section: Gene Expression and Development 339, 338-353. 
Bigelow, K.L., Fortune, J.E., 1998. Characteristics of prolonged dominant versus control follicles: follicle cell numbers, steroidogenic capabilities, and messenger ribonucleic acid for steroidogenic enzymes. Biol. Reprod. 58, 1241-1249.

Biggers, J.D., Whittingham, D.G., Donahue, R.P., 1967. The pattern of energy metabolism in the mouse oocyte and zygote. Proc. Natl. Acad. Sci. U. S. A. 58, 560-567.

Blondin, P., Sirard, M.-A., 1995. Oocyte and follicular morphology as determining characteristics for developmental competence in bovine oocytes. Mol. Reprod. Dev. 41, 54-62.

Bloomfield, F.H., van Zijl, P.L., Bauer, M.K., Harding, J.E., 2002. Effects of intrauterine growth restriction and intraamniotic insulin-like growth factor-I treatment on blood and amniotic fluid concentrations and on fetal gut uptake of amino acids in lategestation ovine fetuses. J. Pediatr. Gastroenterol. Nutr. 35, 287-297.

Boland, N.I., Humpherson, P.G., Leese, H.J., Gosden, R.G., 1994. Characterization of follicular energy metabolism. Hum. Reprod. 9, 604-609.

Botero-Ruiz, W., Laufer, N., DeCherney, A.H., Polan, M.L., Haseltine, F.P., Behrman, H.R., 1984. The relationship between follicular fluid steroid concentration and successful fertilization of human oocytes in vitro. Fertil. Steril. 41, 820-826.

Bottiglieri, T., 2002. S-Adenosyl-I-methionine (SAMe): from the bench to the bedsidemolecular basis of a pleiotropic molecule. Am. J. Clin. Nutr. 76, 1151S-1157S.

Bracken, C.J., Radcliff, R.P., McCormack, B.L., Keisler, D.H., Lucy, M.C., 2007. Two days of pulsatile $\mathrm{GnRH}$ infusion beginning 4 days before weaning in sows initiates a wave of follicular growth that is not sustained after weaning. Anim. Reprod. Sci. $102,158-164$.

Brannian, J., Eyster, K., Mueller, B.A., Bietz, M.G., Hansen, K., 2010. Differential gene expression in human granulosa cells from recombinant $\mathrm{FSH}$ versus human menopausal gonadotropin ovarian stimulation protocols. Reprod. Biol. Endocrinol. $8,25$.

Braude, P., Bolton, V., Moore, S., 1988. Human gene expression first occurs between the four- and eight-cell stages of preimplantation development. Nature 332, 459-461.

Brevini-Gandolfi, T.A.L., Gandolfi, F., 2001. The maternal legacy to the embryo: cytoplasmic components and their effects on early development. Theriogenology 55, 1255-1276.

Brower, P.T., Schultz, R.M., 1982. Intercellular communication between granulosa cells and mouse oocytes: Existence and possible nutritional role during oocyte growth. Dev. Biol. 90, 144-153.

Brown, A.D., Sager, B.W., Gorthi, A., Tonapi, S.S., Brown, E.J., Bishop, A.J.R., 2014. ATR suppresses endogenous DNA damage and allows completion of homologous recombination repair. PLOS ONE 9, e91222. 
Bruzzone, R., White, T.W., Goodenough, D.A., 1996. The cellular internet: On-line with connexins. BioEssays 18, 709-718.

Burruel, V., Klooster, K., Barker, C.M., Pera, R.R., Meyers, S., 2014. Abnormal early cleavage events predict early embryo demise: sperm oxidative stress and early abnormal cleavage. Sci. Rep. 4, 6598.

Caixeta, E.S., Sutton-McDowall, M.L., Gilchrist, R.B., Thompson, J.G., Price, C.A., Machado, M.F., Lima, P.F., Buratini, J., 2013. Bone morphogenetic protein 15 and fibroblast growth factor 10 enhance cumulus expansion, glucose uptake, and expression of genes in the ovulatory cascade during in vitro maturation of bovine cumulus-oocyte complexes. Reproduction 146, 27-35.

Calder, M.D., Caveney, A.N., Sirard, M.-A., Watson, A.J., 2005. Effect of serum and cumulus cell expansion on marker gene transcripts in bovine cumulus-oocyte complexes during maturation in vitro. Fertil. Steril. 83, 1077-1085.

Calder, M.D., Caveney, A.N., Smith, L.C., Watson, A.J., 2003. Responsiveness of bovine cumulus-0ocyte-complexes (COC) to porcine and recombinant human $\mathrm{FSH}$, and the effect of $\mathrm{COC}$ quality on gonadotropin receptor and $\mathrm{C} \times 43$ marker gene mRNAs during maturation in vitro. Reprod. Biol. Endocrinol. 1, 14.

Camous, S., Heyman, Y., Méziou, W., Ménézo, Y., 1984. Cleavage beyond the block stage and survival after transfer of early bovine embryos cultured with trophoblastic vesicles. J. Reprod. Fertil. 72, 479-485.

Campbell, A., Fishel, S., Bowman, N., Duffy, S., Sedler, M., Hickman, C.F.L., 2013. Modelling a risk classification of aneuploidy in human embryos using non-invasive morphokinetics. Reprod. Biomed. Online 26, 477-485.

Campbell, B.K., Souza, C.J.H., Skinner, A.J., Webb, R., Baird, D.T., 2006. Enhanced response of granulosa and theca cells from sheep carriers of the FecB mutation in vitro to gonadotropins and bone morphogenic protein-2, -4, and -6. Endocrinology 147, 1608-1620.

Campen, K.A., 2013. Investigation of exposure to lifestyle and environmental factors on cumulus-oocyte complex function (Ph.D. thesis). Victoria University of Wellington.

Campen, K.A., Clark, Z.L., Olds, M.A., McNatty, K.P., Pitman, J.L., 2016. The in-vitro effects of cAMP and cGMP modulators on inter-cellular dye transfer and gene expression levels in rat cumulus cell - oocyte complexes. Mol. Cell. Endocrinol. 420, 46-56.

Campen, K.A., McNatty, K.P., Pitman, J.L., 2017. A protective role of cumulus cells after short-term exposure of rat cumulus cell-oocyte complexes to lifestyle or environmental contaminants. Reprod. Toxicol. 69, 19-33.

Carabatsos, M.J., Sellitto, C., Goodenough, D.A., Albertini, D.F., 2000. Oocyte-granulosa cell heterologous gap junctions are required for the coordination of nuclear and cytoplasmic meiotic competence. Dev. Biol. 226, 167-179. 
Carolan, C., Lonergan, P., Khatir, H., Mermillod, P., 1996. In vitro production of bovine embryos using individual oocytes. Mol. Reprod. Dev. 45, 145-150.

Carroll, J., Marangos, P., 2013. The DNA damage response in mammalian oocytes. Front. Genet. 4.

Chand, A.L., Legge, M., 2011. Amino acid transport system L activity in developing mouse ovarian follicles. Hum. Reprod. 26, 3102-3108.

Chang, H.-M., Cheng, J.-C., Taylor, E., Leung, P.C.K., 2014. Oocyte-derived BMP15 but not GDF9 down-regulates connexin43 expression and decreases gap junction intercellular communication activity in immortalized human granulosa cells. MHR Basic Sci. Reprod. Med. 20, 373-383.

Chavez, S.L., Loewke, K.E., Han, J., Moussavi, F., Colls, P., Munne, S., Behr, B., Reijo Pera, R.A., 2012. Dynamic blastomere behaviour reflects human embryo ploidy by the four-cell stage. Nat. Commun. 3, 1251.

Chen, A.Q., Yu, S.D., Wang, Z.G., Xu, Z.R., Yang, Z.G., 2009. Stage-specific expression of bone morphogenetic protein type I and type II receptor genes: Effects of folliclestimulating hormone on ovine antral follicles. Anim. Reprod. Sci. 111, 391-399.

Chen, J., Torcia, S., Xie, F., Lin, C.-J., Cakmak, H., Franciosi, F., Horner, K., Onodera, C., Song, J.S., Cedars, M.I., Ramalho-Santos, M., Conti, M., 2013. Somatic cells regulate maternal mRNA translation and developmental competence of mouse oocytes. Nat. Cell Biol. 15, 1415-1423.

Chiquoine, A.D., 1954. The identification, origin, and migration of the primordial germ cells in the mouse embryo. Anat. Rec. 118, 135-146.

Cho, W.K., Stern, S., Biggers, J.D., 1974. Inhibitory effect of dibutyryl cAMP on mouse oocyte maturation in vitro. J. Exp. Zool. 187, 383-386.

Christians, E., Davis, A.A., Thomas, S.D., Benjamin, I.J., 2000. Embryonic development: Maternal effect of Hsf1 on reproductive success. Nature 407, 693-694.

Christoforou, E., 2017. The effects of oocytes on Smad signalling pathways in granulosa cells (Master's thesis). Victoria University of Wellington, Wellington, New Zealand.

Chu, T., Dufort, I., Sirard, M.-A., 2012. Effect of ovarian stimulation on oocyte gene expression in cattle. Theriogenology 77, 1928-1938.

Cillo, F., Brevini, T.A.L., Antonini, S., Paffoni, A., Ragni, G., Gandolfi, F., 2007. Association between human oocyte developmental competence and expression levels of some cumulus genes. Reproduction 134, 645-650.

Ciray, H.N., Aksoy, T., Goktas, C., Ozturk, B., Bahceci, M., 2012. Time-lapse evaluation of human embryo development in single versus sequential culture media-a sibling oocyte study. J. Assist. Reprod. Genet. 29, 891-900.

Colonna, R., Mangia, F., 1983. Mechanisms of amino acid uptake in cumulus-enclosed mouse oocytes. Biol. Reprod. 28, 797-803. 
Conaghan, J., Chen, A.A., Willman, S.P., Ivani, K., Chenette, P.E., Boostanfar, R., Baker, V.L., Adamson, G.D., Abusief, M.E., Gvakharia, M., Loewke, K.E., Shen, S., 2013. Improving embryo selection using a computer-automated time-lapse image analysis test plus day 3 morphology: results from a prospective multicenter trial. Fertil. Steril. 100, 412-419.e5.

Conti, M., Hsieh, M., Musa Zamah, A., Oh, J.S., 2012. Novel signaling mechanisms in the ovary during oocyte maturation and ovulation. Mol. Cell. Endocrinol. 356, 65-73.

Conti, M., Hsieh, M., Park, J.-Y., Su, Y.-Q., 2006. Role of the epidermal growth factor network in ovarian follicles. Mol. Endocrinol. 20, 715-723.

Cotterill, M., Catt, S.L., Picton, H.M., 2012. Characterisation of the cellular and molecular responses of ovine oocytes and their supporting somatic cells to pre-ovulatory levels of LH and FSH during in vitro maturation. Reproduction 144, 195-207.

Crawford, J.L., Heath, D.A., Reader, K.L., Quirke, L.D., Hudson, N.L., Juengel, J.L., McNatty, K.P., 2011. Oocytes in sheep homozygous for a mutation in bone morphogenetic protein receptor 1B express lower mRNA levels of bone morphogenetic protein 15 but not growth differentiation factor 9 . Reproduction 142, 53-61.

Crawford, J.L., McNatty, K.P., 2012. The ratio of growth differentiation factor 9: Bone morphogenetic protein 15 mRNA expression is tightly co-regulated and differs between species over a wide range of ovulation rates. Mol. Cell. Endocrinol. 348, 339-343.

Crosby, I.M., Gandolfi, F., Moor, R.M., 1988. Control of protein synthesis during early cleavage of sheep embryos. J. Reprod. Fertil. 82, 769-775.

Cruz, M., Gadea, B., Garrido, N., Pedersen, K.S., Martinez, M., Perez-Cano, I., Munoz, M., Meseguer, M., 2011. Embryo quality, blastocyst and ongoing pregnancy rates in oocyte donation patients whose embryos were monitored by time-lapse imaging. J. Assist. Reprod. Genet. 28, 569-573.

Cruz, M., Garrido, N., Gadea, B., Muñoz, M., Pérez-Cano, I., Meseguer, M., 2013. Oocyte insemination techniques are related to alterations of embryo developmental timing in an oocyte donation model. Reprod. Biomed. Online 27, 367-375.

Cruz, M., Garrido, N., Herrero, J., Pérez-Cano, I., Muñoz, M., Meseguer, M., 2012. Timing of cell division in human cleavage-stage embryos is linked with blastocyst formation and quality. Reprod. Biomed. Online 25, 371-381.

Dal Canto, M., Coticchio, G., Mignini Renzini, M., De Ponti, E., Novara, P.V., Brambillasca, F., Comi, R., Fadini, R., 2012. Cleavage kinetics analysis of human embryos predicts development to blastocyst and implantation. Reprod. Biomed. Online 25, 474-480.

Dal Canto, M., Novara, P.V., Coticchio, G., Mignini Renzini, M., Brambillasca, F., Brigante, C., De Ponti, E., Fadini, R., 2016. Morphokinetics of embryos developed from oocytes matured in vitro. J. Assist. Reprod. Genet. N. Y. 33, 247-253. 
Davis, G.H., Dodds, K.G., Bruce, G.D., 1999. Combined effect of the Inverdale and Booroola prolificacy genes on ovulation rate in sheep. Proc Assoc Adv Anim Breed Genet 13, 74-77.

Davis, G.H., McEwan, J.C., Fennessy, P.F., Dodds, K.G., Farquhar, P.A., 1991. Evidence for the presence of a major gene influencing ovulation rate on the $X$ chromosome of sheep. Biol. Reprod. 44, 620-624.

Davis, G.H., Montgomery, G.W., Allison, A.J., Kelly, R.W., Bray, A.R., 1982. Segregation of a major gene influencing fecundity in progeny of Booroola sheep. N. Z. J. Agric. Res. 25, 525-529.

De La Fuente, R., Eppig, J.J., 2001. Transcriptional activity of the mouse oocyte genome: companion granulosa cells modulate transcription and chromatin remodelling. Dev. Biol. 229, 224-236.

De Vos, M., Smitz, J., Thompson, J.G., Gilchrist, R.B., 2016. The definition of IVM is clear-variations need defining. Hum. Reprod. 31, 2411-2415.

Demmers, K.J., Smaill, B., Davis, G.H., Dodds, K.G., Juengel, J.L., 2011. Heterozygous Inverdale ewes show increased ovulation rate sensitivity to pre-mating nutrition. Reprod. Fertil. Dev. 23, 866-875.

Desai, N., Ploskonka, S., Goodman, L.R., Austin, C., Goldberg, J., Falcone, T., 2014. Analysis of embryo morphokinetics, multinucleation and cleavage anomalies using continuous time-lapse monitoring in blastocyst transfer cycles. Reprod. Biol. Endocrinol. 12, 54.

Dey, S.R., Deb, G.K., Ha, A.N., Lee, J.I., Bang, J.I., Lee, K.L., Kong, I.K., 2012. Coculturing denuded oocytes during the in vitro maturation of bovine cumulus oocyte complexes exerts a synergistic effect on embryo development. Theriogenology 77 , 1064-1077.

Dhali, A., Javvaji, P.K., Kolte, A.P., Francis, J.R., Roy, S.C., Sejian, V., 2017. Temporal expression of cumulus cell marker genes during in vitro maturation and oocyte developmental competence. J. Assist. Reprod. Genet. 1-8.

Diaz, F.J., Wigglesworth, K., Eppig, J.J., 2007. Oocytes are required for the preantral granulosa cell to cumulus cell transition in mice. Dev. Biol. 305, 300-311.

Dieleman, S.J., Hendriksen, P.J.M., Viuff, D., Thomsen, P.D., Hyttel, P., Knijn, H.M., Wrenzycki, C., Kruip, T.A.M., Niemann, H., Gadella, B.M., Bevers, M.M., Vos, P.L.A.M., 2002. Effects of in vivo prematuration and in vivo final maturation on developmental capacity and quality of pre-implantation embryos. Theriogenology $57,5-20$.

DiLuigi, A., Weitzman, V.N., Pace, M.C., Siano, L.J., Maier, D., Mehlmann, L.M., 2008. Meiotic arrest in human oocytes is maintained by a Gs signaling pathway. Biol. Reprod. 78, 667-672. 
Domínguez, F., Gadea, B., Esteban, F.J., Horcajadas, J.A., Pellicer, A., Simón, C., 2008. Comparative protein-profile analysis of implanted versus non-implanted human blastocysts. Hum. Reprod. 23, 1993-2000.

Dominguez, F., Meseguer, M., Aparicio-Ruiz, B., Piqueras, P., Quiñonero, A., Simón, C., 2015. New strategy for diagnosing embryo implantation potential by combining proteomics and time-lapse technologies. Fertil. Steril. 104, 908-914.

Dong, J., Albertini, D.F., Nishimori, K., Kumar, T.R., Lu, N., Matzuk, M.M., 1996. Growth differentiation factor-9 is required during early ovarian folliculogenesis. Nature 383, $531-535$.

Dragovic, R.A., Ritter, L.J., Schulz, S.J., Amato, F., Armstrong, D.T., Gilchrist, R.B., 2005. Role of oocyte-secreted growth differentiation factor 9 in the regulation of mouse cumulus expansion. Endocrinology 146, 2798-2806.

Dufour, J., Cahill, L.P., Mauléon, P., 1979. Short- and long-term effects of hypophysectomy and unilateral ovariectomy on ovarian follicular populations in sheep. J. Reprod. Fertil. 57, 301-309.

Dunning, K.R., Lane, M., Brown, H.M., Yeo, C., Robker, R.L., Russell, D.L., 2007. Altered composition of the cumulus-oocyte complex matrix during in vitro maturation of oocytes. Hum. Reprod. 22, 2842-2850.

Dutta, D.J., Raj, H., Dev, H., 2016. Polyadenylated tail length variation pattern in ultrarapid vitrified bovine oocytes. Vet. World 9, 1070-1074.

Dyer, S., Chambers, G.M., de Mouzon, J., Nygren, K.G., Zegers-Hochschild, F., Mansour, R., Ishihara, O., Banker, M., Adamson, G.D., 2016. International committee for monitoring assisted reproductive technologies world report: Assisted reproductive technology 2008, 2009 and 2010. Hum. Reprod. 31, 1588-1609.

Edwards, R.G., 1965. Maturation in vitro of mouse, sheep, cow, pig, rhesus monkey and human ovarian oocytes. Nature 208, 349-351.

Edwards, R.G., 1974. Follicular fluid. J. Reprod. Fertil. 37, 189-219.

Edwards, R.G., Tarkowski, A.K., McLaren, A., Peters, H., 1970. Are oocytes formed and used sequentially in the mammalian ovary? [and discussion]. Philos. Trans. R. Soc. Lond. B. Biol. Sci. 259, 103-106.

Ekart, J., McNatty, K., Hutton, J., Pitman, J., 2013. Ranking and selection of MII oocytes in human ICSI cycles using gene expression levels from associated cumulus cells. Hum. Reprod. 28, 2930-2942.

El-Fouly, M.A., Cook, B., Nekola, M., Nalbandov, A.V., 1970. Role of the ovum in follicular luteinization. Endocrinology 87, 288-293.

El-Hayek, S., Clarke, H.J., 2015. Follicle-stimulating hormone increases gap junctional communication between somatic and germ-line follicular compartments during murine oogenesis. Biol. Reprod. 93. 
Elvin, J.A., Yan, C., Matzuk, M.M., 2000. Growth differentiation factor-9 stimulates progesterone synthesis in granulosa cells via a prostaglandin E2/EP2 receptor pathway. Proc. Natl. Acad. Sci. 97, 10288-10293.

Eppig, J.J., 1980. Regulation of cumulus oophorus expansion by gonadotropins in vivo and in vitro. Biol. Reprod. 23, 545-552.

Eppig, J.J., O'Brien, M.J., 1996. Development in vitro of mouse oocytes from primordial follicles. Biol. Reprod. 54, 197-207.

Eppig, J.J., Pendola, F.L., Wigglesworth, K., Pendola, J.K., 2005. Mouse oocytes regulate metabolic cooperativity between granulosa cells and oocytes: Amino acid transport. Biol. Reprod. 73, 351-357.

Eppig, J.J., Wigglesworth, K., Pendola, F.L., 2002. The mammalian oocyte orchestrates the rate of ovarian follicular development. Proc. Natl. Acad. Sci. 99, 2890-2894.

Fagbohun, C.F., Downs, S.M., 1990. Maturation of the mouse oocyte-cumulus cell complex: stimulation by lectins. Biol. Reprod. 42, 413-423.

Fair, T., Carter, F., Park, S., Evans, A.C.O., Lonergan, P., 2007. Global gene expression analysis during bovine oocyte in vitro maturation. Theriogenology, Proceedings of the International Conference on Farm Animal Reproduction "From Egg to Embryo" International Conference on Farm Animal Reproduction 68, Supplement 1, S91S97.

Fair, T., Hyttel, P., Greve, T., 1995. Bovine oocyte diameter in relation to maturational competence and transcriptional activity. Mol. Reprod. Dev. 42, 437-442.

Fatehi, A.N., Roelen, B.A.J., Colenbrander, B., Schoevers, E.J., Gadella, B.M., Bevers, M.M., Hurk, R. van den, 2005. Presence of cumulus cells during in vitro fertilization protects the bovine oocyte against oxidative stress and improves first cleavage but does not affect further development. Zygote 13, 177-185.

Feary, E.S., Juengel, J.L., Smith, P., French, M.C., O'Connell, A.R., Lawrence, S.B., Galloway, S.M., Davis, G.H., McNatty, K.P., 2007. Patterns of Expression of messenger RNAs encoding GDF9, BMP15, TGFBR1, BMPR1B, and BMPR2 during follicular development and characterization of ovarian follicular populations in ewes carrying the Woodlands FecX2W mutation. Biol. Reprod. 77, 990-998.

Felig, P., Marliss, E., Cahill, G.F.J., 1969. Plasma amino acid levels and insulin secretion in obesity. N. Engl. J. Med. 281, 811-816.

Feng, W.-G., Sui, H.-S., Han, Z.-B., Chang, Z.-L., Zhou, P., Liu, D.-J., Bao, S., Tan, J.-H., 2007. Effects of follicular atresia and size on the developmental competence of bovine oocytes: A study using the well-in-drop culture system. Theriogenology 67, 1339-1350.

Fitzgerald, O., Harris, K., Paul, R.C., Georgina M. Chambers, 2017. Assisted reproductive technology in Australia and New Zealand 2015 (Annual Report), ANZARD Reports. National Perinatal Epidemiology and Statistics Unit, The University of New South Wales, Sydney. 
Flagg-Newton, J., Simpson, I., Loewenstein, W.R., 1979. Permeability of the cell-to-cell membrane channels in mammalian cell junction. Science 205, 404-407.

Forde, N., O'Gorman, A., Whelan, H., Duffy, P., O'Hara, L., Kelly, A.K., Havlicek, V., Besenfelder, U., Brennan, L., Lonergan, P., 2016. Lactation-induced changes in metabolic status and follicular-fluid metabolomic profile in postpartum dairy cows. Reprod. Fertil. Dev. 28, 1882-1892.

Fréour, T., Dessolle, L., Lammers, J., Lattes, S., Barrière, P., 2013. Comparison of embryo morphokinetics after in vitro fertilization-intracytoplasmic sperm injection in smoking and nonsmoking women. Fertil. Steril. 99, 1944-1950.

Fréour, T., Fleuter, N.L., Lammers, J., Splingart, C., Reignier, A., Barrière, P., 2015. External validation of a time-lapse prediction model. Fertil. Steril. 103, 917-922.

Fülöp, C., Salustri, A., Hascall, V.C., 1997. Coding sequence of a hyaluronan synthase homologue expressed during expansion of the mouse cumulus-oocyte complex. Arch. Biochem. Biophys. 337, 261-266.

Galloway, S.M., McNatty, K.P., Cambridge, L.M., Laitinen, M.P.E., Juengel, J.L., Jokiranta, T.S., McLaren, R.J., Luiro, K., Dodds, K.G., Montgomery, G.W., Beattie, A.E., Davis, G.H., Ritvos, O., 2000. Mutations in an oocyte-derived growth factor gene (BMP15) cause increased ovulation rate and infertility in a dosage-sensitive manner. Nat. Genet. 25, 279-283.

Gandolfi, F., Moor, R.M., 1987. Stimulation of early embryonic development in the sheep by co-culture with oviduct epithelial cells. J. Reprod. Fertil. 81, 23-28.

Gao, L.-L., Zhou, C.-X., Zhang, X.-L., Liu, P., Jin, Z., Zhu, G.-Y., Ma, Y., Li, J., Yang, Z.X., Zhang, D., 2017. ZP3 is required for germinal vesicle breakdown in mouse oocyte meiosis. Sci. Rep. 7, srep41272.

Gardner, D.K., Schoolcraft, W.B., 1999. Culture and transfer of human blastocysts. Curr. Opin. Obstet. Gynecol. 11, 307-311.

Gebhardt, K.M., Feil, D.K., Dunning, K.R., Lane, M., Russell, D.L., 2011. Human cumulus cell gene expression as a biomarker of pregnancy outcome after single embryo transfer. Fertil. Steril. 96, 47-52. e2.

Gerard, N., Loiseau, S., Duchamp, G., Seguin, F., 2002. Analysis of the variations of follicular fluid composition during follicular growth and maturation in the mare using proton nuclear magnetic resonance (1H NMR). Reproduction 124, 241-248.

Gilchrist, R.B., 2011. Recent insights into oocyte - follicle cell interactions provide opportunities for the development of new approaches to in vitro maturation. Reprod. Fertil. Dev. 23, 23.

Gilchrist, R.B., Lane, M., Thompson, J.G., 2008. Oocyte-secreted factors: regulators of cumulus cell function and oocyte quality. Hum. Reprod. Update 14, 159-177. 
Gilchrist, R.B., Ritter, L.J., Myllymaa, S., Kaivo-Oja, N., Dragovic, R.A., Hickey, T.E., Ritvos, O., Mottershead, D.G., 2006. Molecular basis of oocyte-paracrine signalling that promotes granulosa cell proliferation. J. Cell Sci. 119, 3811-3821.

Gilula, N.B., Epstein, M.L., Beers, W.H., 1978. Cell-to-cell communication and ovulation. A study of the cumulus-oocyte complex. J. Cell Biol. 78, 58-75.

Ginsburg, M., Snow, M.H., McLaren, A., 1990. Primordial germ cells in the mouse embryo during gastrulation. Development 110, 521-528.

Ginther, O.J., Beg, M.A., Donadeu, F.X., Bergfelt, D.R., 2003. Mechanism of follicle deviation in monovular farm species. Anim. Reprod. Sci., Ovarian Follicle Development 78, 239-257.

Gode, F., Gulekli, B., Dogan, E., Korhan, P., Dogan, S., Bige, O., Cimrin, D., Atabey, N., 2011. Influence of follicular fluid GDF9 and BMP15 on embryo quality. Fertil. Steril. 95, 2274-2278.

Gomez, M.N.L., Kang, J.T., Koo, O.J., Kim, S.J., Kwon, D.K., Park, S.J., Atikuzzaman, M., Hong, S.G., Jang, G., Lee, B.C., 2012. Effect of oocyte-secreted factors on porcine in vitro maturation, cumulus expansion and developmental competence of parthenotes. Zygote 20, 135-145.

Gosden, R.G., Sadler, I.H., Reed, D., Hunter, R.H.F., 1990. Characterization of ovarian follicular fluids of sheep, pigs and cows using proton nuclear magnetic resonance spectroscopy. Experientia 46, 1012-1015.

Granot, I., Dekel, N., 1997. Developmental expression and regulation of the gap junction protein and transcript in rat ovaries. Mol. Reprod. Dev. 47, 231-239.

Grazul-Bilska, A.T., Reynolds, L.P., Redmer, D.A., 1997. Gap junctions in the ovaries. Biol. Reprod. 57, 947-957.

Green, M.P., Ledgard, A.M., Beaumont, S.E., Berg, M.C., McNatty, K.P., Peterson, A.J., Back, P.J., 2011. Long-term alteration of follicular steroid concentrations in relation to subclinical endometritis in postpartum dairy cows. J. Anim. Sci. 89, 3551-3560.

Grindler, N.M., Moley, K.H., 2013. Maternal obesity, infertility and mitochondrial dysfunction: potential mechanisms emerging from mouse model systems. MHR Basic Sci. Reprod. Med. 19, 486-494.

Hammond, E.R., Stewart, B., Peek, J.C., Shelling, A.N., Cree, L.M., 2015. Assessing embryo quality by combining non-invasive markers: early time-lapse parameters reflect gene expression in associated cumulus cells. Hum. Reprod. 30, 1850-1860.

Hanrahan, J.P., Gregan, S.M., Mulsant, P., Mullen, M., Davis, G.H., Powell, R., Galloway, S.M., 2004. Mutations in the genes for oocyte-derived growth factors GDF9 and BMP15 are associated with both increased ovulation rate and sterility in Cambridge and Belclare sheep (Ovis aries). Biol. Reprod. 70, 900-909.

Harris, K., Fitzgerald, O., Paul, R.C., Macaldowie, A., Lee, E., Chambers, G.M., 2016. Assisted reproductive technology in Australia and New Zealand 2014 (Annual 
Report), ANZARD Reports. National Perinatal Epidemiology and Statistics Unit, The University of New South Wales, Sydney.

Harris, S.E., Adriaens, I., Leese, H.J., Gosden, R.G., Picton, H.M., 2007. Carbohydrate metabolism by murine ovarian follicles and oocytes grown in vitro. Reproduction $134,415-424$.

Harris, S.E., Gopichandran, N., Picton, H.M., Leese, H.J., Orsi, N.M., 2005. Nutrient concentrations in murine follicular fluid and the female reproductive tract. Theriogenology 64, 992-1006.

Hasegawa, J., Yanaihara, A., Iwasaki, S., Otsuka, Y., Negishi, M., Akahane, T., Okai, T., 2005. Reduction of progesterone receptor expression in human cumulus cells at the time of oocyte collection during IVF is associated with good embryo quality. Hum. Reprod. 20, 2194-2200.

Hashimoto, S., Kato, N., Saeki, K., Morimoto, Y., 2012. Selection of high-potential embryos by culture in poly(dimethylsiloxane) microwells and time-lapse imaging. Fertil. Steril. 97, 332-337.

Hayashi, M., McGee, E.A., Min, G., Klein, C., Rose, U.M., Van Duin, M., Hsueh, A.J., 1999. Recombinant growth differentiation factor-9 (GDF-9) enhances growth and differentiation of cultured early ovarian follicles. Endocrinology 140, 1236-1244.

Hemmings, K.E., Leese, H.J., Picton, H.M., 2012. Amino acid turnover by bovine oocytes provides an index of oocyte developmental competence in vitro. Biol. Reprod. 86.

Henderson, K.M., McNatty, K.P., O'Keeffe, L.E., Lun, S., Heath, D.A., Prisk, M.D., 1987. Differences in gonadotrophin-stimulated cyclic AMP production by granulosa cells from Booroola $\times$ Merino ewes which were homozygous, heterozygous or noncarriers of a fecundity gene influencing their ovulation rate. J. Reprod. Fertil. 81, 395-402.

Henderson, S.A., Edwards, R.G., 1968. Chiasma frequency and maternal age in mammals. Nature 218, 22-28.

Herrero, J., Tejera, A., Albert, C., Vidal, C., de los Santos, M.J., Meseguer, M., 2013. A time to look back: analysis of morphokinetic characteristics of human embryo development. Fertil. Steril. 100, 1602-1609.e4.

Hild-Petito, S., Stouffer, R.L., Brenner, R.M., 1988. Immunocytochemical localization of estradiol and progesterone receptors in the monkey ovary throughout the menstrual cycle. Endocrinology 123, 2896-2905.

Hirshfield, A.N., 1991. Development of follicles in the mammalian ovary. Int. Rev. Cytol. 124, 43-101.

Hobbs, S., Jitrapakdee, S., Wallace, J.C., 1998. Development of a bicistronic vector driven by the human polypeptide chain elongation factor $1 \alpha$ promoter for creation of stable mammalian cell lines that express very high levels of recombinant proteins. Biochem. Biophys. Res. Commun. 252, 368-372. 
Homa, S.T., 1988. Effects of cyclic AMP on the spontaneous meiotic maturation of cumulus-free bovine oocytes cultured in chemically defined medium. J. Exp. Zool. 248, 222-231.

Hong, J., Lee, E., 2007. Intrafollicular amino acid concentration and the effect of amino acids in a defined maturation medium on porcine oocyte maturation, fertilization, and preimplantation development. Theriogenology 68, 728-735.

Huang, Y., Zhao, Y., Yu, Y., Li, R., Lin, S., Zhang, C., Liu, P., Qiao, J., 2015. Altered amphiregulin expression induced by diverse luteinizing hormone receptor reactivity in granulosa cells affects IVF outcomes. Reprod. Biomed. Online 30, 593-601.

Hudson, N.L., Berg, M.C., Green, M.P., Back, P.J., Thorstensen, E.B., Peterson, A.J., Pitman, J.L., McNatty, K.P., 2014. The microenvironment of the ovarian follicle in the postpartum dairy cow: Effects on reagent transfer from cumulus cells to oocytes in vitro. Theriogenology 82, 563-573.

Hussein, T.S., Froiland, D.A., Amato, F., Thompson, J.G., Gilchrist, R.B., 2005. Oocytes prevent cumulus cell apoptosis by maintaining a morphogenic paracrine gradient of bone morphogenetic proteins. J. Cell Sci. 118, 5257-5268.

Hussein, T.S., Sutton-McDowall, M.L., Gilchrist, R.B., Thompson, J.G., 2011. Temporal effects of exogenous oocyte-secreted factors on bovine oocyte developmental competence during IVM. Reprod. Fertil. Dev. 23, 576-584.

Hussein, T.S., Thompson, J.G., Gilchrist, R.B., 2006. Oocyte-secreted factors enhance oocyte developmental competence. Dev. Biol. 296, 514-521.

Hyttel, P., Callesen, H., Greve, T., 1989. A comparative ultrastructural study of in vivo versus in vitro fertilization of bovine oocytes. Anat. Embryol. (Berl.) 179, 435-442.

lager, A.E., Kocabas, A.M., Otu, H.H., Ruppel, P., Langerveld, A., Schnarr, P., Suarez, M., Jarrett, J.C., Conaghan, J., Rosa, G.J.M., Fernández, E., Rawlins, R.G., Cibelli, J.B., Crosby, J.A., 2013. Identification of a novel gene set in human cumulus cells predictive of an oocyte's pregnancy potential. Fertil. Steril. 99, 745-752.e6.

Jayawardana, B.C., Shimizu, T., Nishimoto, H., Kaneko, E., Tetsuka, M., Miyamoto, A., 2006. Hormonal regulation of expression of growth differentiation factor- 9 receptor type I and II genes in the bovine ovarian follicle. Reproduction 131, 545-553.

Jeppesen, J.V., Kristensen, S.G., Nielsen, M.E., Humaidan, P., Dal Canto, M., Fadini, R., Schmidt, K.T., Ernst, E., Yding Andersen, C., 2012. LH-receptor gene expression in human granulosa and cumulus cells from antral and preovulatory follicles. J. Clin. Endocrinol. Metab. 97, E1524-E1531.

Jiao, Z.-X., Woodruff, T.K., 2013. Follicle microenvironment-associated alterations in gene expression in the mouse oocyte and its polar body. Fertil. Steril. 99, 1453-1459.e1.

Jiao, Z.-X., Xu, M., Woodruff, T.K., 2012. Age-associated alteration of oocyte-specific gene expression in polar bodies: potential markers of oocyte competence. Fertil. Steril. $98,480-486$. 
Jolly, P.D., Tisdall, D.J., De'ath, G., Heath, D.A., Lun, S., Hudson, N.L., McNatty, K.P., 1997. Granulosa cell apoptosis, aromatase activity, cyclic adenosine 3',5'monophosphate response to gonadotropins, and follicular fluid steroid levels during spontaneous and induced follicular atresia in ewes. Biol. Reprod. 56, 830-836.

Jóźwik, M., Jóźwik, M., Milewska, A.J., Battaglia, F.C., Jóźwik, M., 2017. Competitive inhibition of amino acid transport in human preovulatory ovarian follicles. Syst. Biol. Reprod. Med. 63, 311-317.

Juengel, J.L., French, M.C., Quirke, L.D., Kauff, A., Smith, G.W., Johnstone, P.D., 2017. Differential expression of CART in ewes with differing ovulation rates. Reproduction 153, 471-479.

Juengel, J.L., Hudson, N.L., Whiting, L., McNatty, K.P., 2004. Effects of immunization against bone morphogenetic protein 15 and growth differentiation factor 9 on ovulation rate, fertilization, and pregnancy in ewes. Biol. Reprod. 70, 557-561.

Juengel, J.L., Sawyer, H.R., Smith, P.R., Quirke, L.D., Heath, D.A., Lun, S., Wakefield, S.J., McNatty, K.P., 2002. Origins of follicular cells and ontogeny of steroidogenesis in ovine fetal ovaries. Mol. Cell. Endocrinol. 191, 1-10.

Juneja, S.C., Barr, K.J., Enders, G.C., Kidder, G.M., 1999. Defects in the germ line and gonads of mice lacking connexin43. Biol. Reprod. 60, 1263-1270.

Katz-Jaffe, M.G., Gardner, D.K., Schoolcraft, W.B., 2006. Proteomic analysis of individual human embryos to identify novel biomarkers of development and viability. Fertil. Steril. 85, 101-107.

Katz-Jaffe, M.G., Linck, D.W., Schoolcraft, W.B., Gardner, D.K., 2005. A proteomic analysis of mammalian preimplantation embryonic development. Reproduction 130, 899-905.

Kawashima, I., Okazaki, T., Noma, N., Nishibori, M., Yamashita, Y., Shimada, M., 2008. Sequential exposure of porcine cumulus cells to $\mathrm{FSH}$ and/or $\mathrm{LH}$ is critical for appropriate expression of steroidogenic and ovulation-related genes that impact oocyte maturation in vivo and in vitro. Reproduction 136, 9-21.

Khurana, N.K., Niemann, H., 2000. Energy metabolism in preimplantation bovine embryos derived in vitro or in vivo. Biol. Reprod. 62, 847-856.

Kieslinger, D.C., De Gheselle, S., De Sutter, P., Kostelijk, E.H., van Rijswijk, J., Lambalk, C.B., van den Abbeel, E., Vergouw, C.G., 2015. Embryo selection using the Eeva Test, an automated time-lapse quantitative analysis, in conjunction with standard morphology: a prospective multi-center pilot study. Fertil. Steril., Scientific Program Supplement: Oral and Poster Session Abstracts71st Annual Meeting of the American Society for Reproductive Medicine 104, e22.

Kind, K.L., Banwell, K.M., Gebhardt, K.M., Macpherson, A., Gauld, A., Russell, D.L., Thompson, J.G., 2013. Microarray analysis of mRNA from cumulus cells following in vivo or in vitro maturation of mouse cumulus-oocyte complexes. Reprod. Fertil. Dev. 25, 426-438. 
Kirkegaard, K., Campbell, A., Agerholm, I., Bentin-Ley, U., Gabrielsen, A., Kirk, J., Sayed, S., Ingerslev, H.J., 2014. Limitations of a time-lapse blastocyst prediction model: a large multicentre outcome analysis. Reprod. Biomed. Online 29, 156-158.

Kirkegaard, K., Hindkjaer, J.J., Grøndahl, M.L., Kesmodel, U.S., Ingerslev, H.J., 2012. A randomized clinical trial comparing embryo culture in a conventional incubator with a time-lapse incubator. J. Assist. Reprod. Genet. 29, 565-572.

Klatsky, P.C., Wessel, G.M., Carson, S.A., 2010. Detection and quantification of mRNA in single human polar bodies: a minimally invasive test of gene expression during oogenesis. Mol. Hum. Reprod. 16, 938-943.

Kyasari, O.R., Valojerdi, M.R., Farrokhi, A., Ebrahimi, B., 2012. Expression of maturation genes and their receptors during in vitro maturation of sheep COCs in the presence and absence of somatic cells of cumulus origin. Theriogenology 77, 12-20.

Lawson, K.A., Hage, W.J., 1994. Clonal analysis of the origin of primordial germ cells in the mouse. Ciba Found. Symp. 182, 68-84; discussion 84-91.

LeBaron, R.G., Zimmermann, D.R., Ruoslahti, E., 1992. Hyaluronate binding properties of versican. J. Biol. Chem. 267, 10003-10010.

Lee, E.S., Fukui, Y., 1996. Synergistic effect of alanine and glycine on bovine embryos cultured in a chemically defined medium and amino acid uptake by vitro-produced bovine morulae and blastocysts. Biol. Reprod. 55, 1383-1389.

Leroy, J.L.M.R., Vanholder, T., Delanghe, J.R., Opsomer, G., Van Soom, A., Bols, P.E.J., de Kruif, A., 2004. Metabolite and ionic composition of follicular fluid from differentsized follicles and their relationship to serum concentrations in dairy cows. Anim. Reprod. Sci. 80, 201-211.

Li, H.J., Sutton-McDowall, M.L., Wang, X., Sugimura, S., Thompson, J.G., Gilchrist, R.B., 2016. Extending prematuration with CAMP modulators enhances the cumulus contribution to oocyte antioxidant defence and oocyte quality via gap junctions. Hum. Reprod. 31, 810-821.

Li, J.-J., Sugimura, S., Mueller, T.D., White, M.A., Martin, G.A., Ritter, L.J., Liang, X.-Y., Gilchrist, R.B., Mottershead, D.G., 2015a. Modifications of human growth differentiation factor 9 to improve the generation of embryos from low competence oocytes. Mol. Endocrinol. 29, 40-52.

Li, Q., McKenzie, L.J., Matzuk, M.M., 2008. Revisiting oocyte-somatic cell interactions: in search of novel intrafollicular predictors and regulators of oocyte developmental competence. Mol. Hum. Reprod. 14, 673-678.

Li, S.-H., Lin, M.-H., Hwu, Y.-M., Lu, C.-H., Yeh, L.-Y., Chen, Y.-J., Lee, R.K.-K., 2015b. Correlation of cumulus gene expression of GJA1, PRSS35, PTX3, and SERPINE2 with oocyte maturation, fertilization, and embryo development. Reprod. Biol. Endocrinol. 13. 
Lin, J.Y., Pitman-Crawford, J.L., Bibby, A.H., Hudson, N.L., McIntosh, C.J., Juengel, J.L., McNatty, K.P., 2012. Effects of species differences on oocyte regulation of granulosa cell function. Reproduction 144, 557-567.

Lintern-Moore, S., Moore, G.P., 1979. The initiation of follicle and oocyte growth in the mouse ovary. Biol. Reprod. 20, 773-778.

Liu, J., Aronow, B.J., Witte, D.P., Pope, W.F., Barbera, L., R, A., 1998. Cyclic and maturation-dependent regulation of follicle-stimulating hormone receptor and luteinizing hormone receptor messenger ribonucleic acid expression in the porcine ovary. Biol. Reprod. 58, 648-658.

Liu, L., Aoki, V.W., Carrell, D.T., 2008. Evaluation of the developmental competence and chromosomal compliment of mouse oocytes derived from in-vitro growth and maturation of preantral follicles. J. Assist. Reprod. Genet. 25, 107-113.

Livak, K.J., Schmittgen, T.D., 2001. Analysis of relative gene expression data using realtime quantitative PCR and the 2- $\Delta \Delta C T$ method. Methods 25, 402-408.

Logan, K.A., Juengel, J.L., McNatty, K.P., 2002. Onset of steroidogenic enzyme gene expression during ovarian follicular development in sheep. Biol. Reprod. 66, 906916.

Lonergan, P., Gutiérrez-Adán, A., Rizos, D., Pintado, B., De La Fuente, J., Boland, M.P., 2003. Relative messenger RNA abundance in bovine oocytes collected in vitro or in vivo before and $20 \mathrm{hr}$ after the preovulatory luteinizing hormone surge. Mol. Reprod. Dev. 66, 297-305.

Luciano, A. m., Pocar, P., Milanesi, E., Modina, S., Rieger, D., Lauria, A., Gandolfi, F., 1999. Effect of different levels of intracellular cAMP on the in vitro maturation of cattle oocytes and their subsequent development following in vitro fertilization. Mol. Reprod. Dev. 54, 86-91.

Luciano, A.M., Lodde, V., Beretta, M.S., Colleoni, S., Lauria, A., Modina, S., 2005. Developmental capability of denuded bovine oocyte in a co-culture system with intact cumulus-oocyte complexes: Role of cumulus cells, cyclic adenosine 3',5'monophosphate, and glutathione. Mol. Reprod. Dev. 71, 389-397.

Lucidi, P., Bernabò, N., Turriani, M., Barboni, B., Mattioli, M., 2003. Cumulus cells steroidogenesis is influenced by the degree of oocyte maturation. Reprod. Biol. Endocrinol. RBE 1, 45.

Lydon, J.P., DeMayo, F.J., Funk, C.R., Mani, S.K., Hughes, A.R., Montgomery, C.A., Shyamala, G., Conneely, O.M., O'Malley, B.W., 1995. Mice lacking progesterone receptor exhibit pleiotropic reproductive abnormalities. Genes Dev. 9, 2266-2278.

Macabelli, C.H., Ferreira, R.M., Gimenes, L.U., Carvalho, N.A.T. de, Soares, J.G., Ayres, H., Ferraz, M.L., Watanabe, Y.F., Watanabe, O.Y., Sangalli, J.R., Smith, L.C., Baruselli, P.S., Meirelles, F.V., Chiaratti, M.R., 2014. Reference gene selection for gene expression analysis of oocytes collected from dairy cattle and buffaloes during winter and summer. PLOS ONE 9, e93287. 
Machado, M.F., Caixeta, E.S., Sudiman, J., Gilchrist, R.B., Thompson, J.G., Lima, P.F., Price, C.A., Buratini, J., 2015. Fibroblast growth factor 17 and bone morphogenetic protein 15 enhance cumulus expansion and improve quality of in vitro-produced embryos in cattle. Theriogenology 84, 390-398.

Manikandan, S., 2011. Measures of central tendency: The mean. J. Pharmacol. Pharmacother. 2, 140-142.

Mann, G.E., Campbell, B.K., McNeilly, A.S., Baird, D.T., 1992. The role of inhibin and oestradiol in the control of FSH secretion in the sheep. J. Endocrinol. 133, 381391.

Marzec, M., Eletto, D., Argon, Y., 2012. GRP94: An HSP90-like protein specialized for protein folding and quality control in the endoplasmic reticulum. Biochem. Biophys. Acta 1823, 774-787.

Mattson, M.P., Shea, T.B., 2003. Folate and homocysteine metabolism in neural plasticity and neurodegenerative disorders. Trends Neurosci. 26, 137-146.

McIntosh, C.J., Lawrence, S., Smith, P., Juengel, J.L., McNatty, K.P., 2012. Active immunization against the proregions of GDF9 or BMP15 alters ovulation rate and litter size in mice. Reproduction 143, 195-201.

McKenzie, L.J., Pangas, S.A., Carson, S.A., Kovanci, E., Cisneros, P., Buster, J.E., Amato, P., Matzuk, M.M., 2004. Human cumulus granulosa cell gene expression: a predictor of fertilization and embryo selection in women undergoing IVF. Hum. Reprod. 19, 2869-2874.

McNatty, K.P., Heath, D.A., Clark, Z., Reader, K.L., Juengel, J.L., Pitman, J., 2016. Ovarian follicular characteristics in sheep with multiple fecundity genes. Reproduction REP-16-0587.

McNatty, K.P., Heath, D.A., Henderson, K.M., Lun, S., Hurst, P.R., Ellis, L.M., Montgomery, G.W., Morrison, L., Thurley, D.C., 1984. Some aspects of thecal and granulosa cell function during follicular development in the bovine ovary. J. Reprod. Fertil. 72, 39-53.

McNatty, K.P., Heath, D.A., Hudson, N.L., Lun, S., Juengel, J.L., Moore, L.G., 2009. Gonadotrophin-responsiveness of granulosa cells from bone morphogenetic protein 15 heterozygous mutant sheep. Reproduction 138, 545-551.

McNatty, K.P., Heath, D.A., Hudson, N.L., Reader, K.L., Quirke, L., Lun, S., Juengel, J.L., 2010. The conflict between hierarchical ovarian follicular development and superovulation treatment. Reproduction 140, 287-294.

McNatty, K.P., Juengel, J.L., Reader, K.L., Lun, S., Myllymaa, S., Lawrence, S.B., Western, A., Meerasahib, M.F., Mottershead, D.G., Groome, N.P., Ritvos, O., Laitinen, M.P.E., 2005. Bone morphogenetic protein 15 and growth differentiation factor 9 co-operate to regulate granulosa cell function. Reproduction 129, 473480. 
McNatty, K.P., Lun, S., Heath, D.A., Ball, K., Smith, P., Hudson, N.L., McDiarmid, J., Gibb, M., Henderson, K.M., 1986. Differences in ovarian activity between Booroola $\times$ Merino ewes which were homozygous, heterozygous and non-carriers of a major gene influencing their ovulation rate. J. Reprod. Fertil. 77, 193-205.

McNatty, K.P., Smith, D.M., Makris, A., Osathanondh, R., Ryan, K.J., 1979. The microenvironment of the human antral follicle: Interrelationships among the steroid levels in antral fluid, the population of granulosa cells, and the status of the oocyte in vivo and in vitro. J. Clin. Endocrinol. Metab. 49, 851-860.

McNatty, K.P., Smith, P., Hudson, N.L., Heath, D.A., Tisdall, D.J., O, W.S., Braw-Tal, R., 1995. Development of the sheep ovary during fetal and early neonatal life and the effect of fecundity genes. J. Reprod. Fertil. Suppl. 49, 123-135.

McNatty, Pitman, J., Juengel, J., 2014. Oocyte-somatic cell interactions and ovulation rate: Effects on oocyte quality and embryo yield. Reprod. Biol. Insights 1.

McNeil, C.J., Hoskin, S.O., Bremner, D.M., Holtrop, G., Lobley, G.E., 2016. Whole-body and splanchnic amino acid metabolism in sheep during an acute endotoxin challenge. Br. J. Nutr. 116, 211-222.

Mehlmann, L.M., 2005. Stops and starts in mammalian oocytes: Recent advances in understanding the regulation of meiotic arrest and oocyte maturation. Reproduction 130, 791-799.

Mehlmann, L.M., Jones, T.L.Z., Jaffe, L.A., 2002. Meiotic arrest in the mouse follicle maintained by a $\mathrm{G}(\mathrm{s})$ protein in the oocyte. Science $297,1343-5$.

Meseguer, M., Herrero, J., Tejera, A., Hilligsøe, K.M., Ramsing, N.B., Remohí, J., 2011. The use of morphokinetics as a predictor of embryo implantation. Hum. Reprod. 26, 2658-2671.

Meseguer, M., Rubio, I., Cruz, M., Basile, N., Marcos, J., Requena, A., 2012. Embryo incubation and selection in a time-lapse monitoring system improves pregnancy outcome compared with a standard incubator: a retrospective cohort study. Fertil. Steril. 98, 1481-1489.e10.

Milewski, R., Kuczyńska, A., Stankiewicz, B., Kuczyński, W., 2017. How much information about embryo implantation potential is included in morphokinetic data? A prediction model based on artificial neural networks and principal component analysis. Adv. Med. Sci. 62, 202-206.

Mills, T.M., Feit, E.I., 1976. Amino acid transport in follicles isolated from the rabbit ovary. Endocrinology 99, 1597-1604.

Miyoshi, T., Otsuka, F., Suzuki, J., Takeda, M., Inagaki, K., Kano, Y., Otani, H., Mimura, Y., Ogura, T., Makino, H., 2006. Mutual regulation of follicle-stimulating hormone signaling and bone morphogenetic protein system in human granulosa cells. Biol. Reprod. 74, 1073-1082. 
Moor, R.M., Hay, M.F., Seamark, R.F., 1975. The sheep ovary: Regulation of steroidogenic, haemodynamic and structural changes in the largest follicle and adjacent tissue before ovulation. J. Reprod. Fertil. 45, 595-604.

Moore, L.G., Ng-Chie, W., Lun, S., Lawrence, S.B., Young, W., McNatty, K.P., 1997. Follicle-stimulating hormone in the brushtail possum (Trichosurus vulpecula): purification, characterization, and radioimmunoassay. Gen. Comp. Endocrinol. 106, 30-38.

Moore, R.K., Otsuka, F., Shimasaki, S., 2003. Molecular basis of bone morphogenetic protein-15 signaling in granulosa cells. J. Biol. Chem. 278, 304-310.

Moore, S.G., O'Gorman, A., Brennan, L., Fair, T., Butler, S.T., 2017. Follicular fluid and serum metabolites in Holstein cows are predictive of genetic merit for fertility. Reprod. Fertil. Dev. 29, 658-669.

Mottershead, D.G., Ritter, L.J., Gilchrist, R.B., 2012. Signalling pathways mediating specific synergistic interactions between GDF9 and BMP15. Mol. Hum. Reprod. $18,121-128$.

Mottershead, D.G., Sugimura, S., Al-Musawi, S.L., Li, J.-J., Richani, D., White, M.A., Martin, G.A., Trotta, A.P., Ritter, L.J., Shi, J., Mueller, T.D., Harrison, C.A., Gilchrist, R.B., 2015. Cumulin, an oocyte-secreted heterodimer of the transforming growth factor- $\beta$ family, is a potent activator of granulosa cells and improves oocyte quality. J. Biol. Chem. 290, 24007-24020.

Mourot, M., Dufort, I., Gravel, C., Algriany, O., Dieleman, S., Sirard, M.-A., 2006. The influence of follicle size, FSH-enriched maturation medium, and early cleavage on bovine oocyte maternal mRNA levels. Mol. Reprod. Dev. 73, 1367-1379.

Mulsant, P., Lecerf, F., Fabre, S., Schibler, L., Monget, P., Lanneluc, I., Pisselet, C., Riquet, J., Monniaux, D., Callebaut, I., Cribiu, E., Thimonier, J., Teyssier, J., Bodin, L., Cognié, Y., Chitour, N., Elsen, J.-M., 2001. Mutation in bone morphogenetic protein receptor-IB is associated with increased ovulation rate in Booroola merino ewes. Proc. Natl. Acad. Sci. U. S. A. 98, 5104-5109.

Muñoz, M., Cruz, M., Humaidan, P., Garrido, N., Pérez-Cano, I., Meseguer, M., 2013. The type of $\mathrm{GnRH}$ analogue used during controlled ovarian stimulation influences early embryo developmental kinetics: a time-lapse study. Eur. J. Obstet. Gynecol. Reprod. Biol. 168, 167-172.

Nandi, S., Kumar, V.G., Manjunatha, B.M., Gupta, P.S.P., 2007. Biochemical composition of ovine follicular fluid in relation to follicle size. Dev. Growth Differ. 49, 61-66.

Natraj, U., Richards, J.S., 1993. Hormonal regulation, localization, and functional activity of the progesterone receptor in granulosa cells of rat preovulatory follicles. Endocrinology 133, 761-769.

Nio-Kobayashi, J., Trendell, J., Giakoumelou, S., Boswell, L., Nicol, L., Kudo, M., Sakuragi, N., Iwanaga, T., Duncan, W.C., 2015. Bone morphogenetic proteins are mediators of luteolysis in the human corpus luteum. Endocrinology 156, 1494-1503. 
Niswender, G.D., McNatty, K.P., Smith, P., Niswender, K.D., Farin, C.E., Sawyer, H.R., 1990. Numbers of steroidogenic luteal cells in Booroola Merino ewes. J. Reprod. Fertil. 90, 185-190.

Norris, R.P., Freudzon, M., Mehlmann, L.M., Cowan, A.E., Simon, A.M., Paul, D.L., Lampe, P.D., Jaffe, L.A., 2008. Luteinizing hormone causes MAP kinasedependent phosphorylation and closure of connexin 43 gap junctions in mouse ovarian follicles: one of two paths to meiotic resumption. Development 135, 32293238.

Norris, R.P., Ratzan, W.J., Freudzon, M., Mehlmann, L.M., Krall, J., Movsesian, M.A., Wang, H., Ke, H., Nikolaev, V.O., Jaffe, L.A., 2009. Cyclic GMP from the surrounding somatic cells regulates cyclic AMP and meiosis in the mouse oocyte. Development 136, 1869-1878.

O'Brien, J.K., Catt, S.L., Ireland, K.A., Maxwell, W.M.C., Evans, G., 1997. In vitro and in vivo developmental capacity of oocytes from prepubertal and adult sheep. Theriogenology 47, 1433-1443.

Offer, N.W., Tas, M.V., Axford, R.F.E., Evans, R.A., 1975. The effect of glucose infusion on the plasma free amino acids in sheep. Br. J. Nutr. 34, 375-382.

Orozco-Lucero, E., Dufort, I., Robert, C., Sirard, M.-A., 2014. Rapidly cleaving bovine twocell embryos have better developmental potential and a distinctive mRNA pattern. Mol. Reprod. Dev. 81, 31-41.

Orsi, N.M., Gopichandran, N., Leese, H.J., Picton, H.M., Harris, S.E., 2005. Fluctuations in bovine ovarian follicular fluid composition throughout the oestrous cycle. Reproduction 129, 219-228.

Otsuka, F., Yamamoto, S., Erickson, G.F., Shimasaki, S., 2001. Bone morphogenetic protein-15 inhibits follicle-stimulating hormone ( $\mathrm{FSH})$ action by suppressing FSH receptor expression. J. Biol. Chem. 276, 11387-11392.

Paczkowski, M., Schoolcraft, W.B., Krisher, R.L., 2014. Fatty acid metabolism during maturation affects glucose uptake and is essential to oocyte competence. Reproduction 148, 429-439.

Pangas, S.A., Jorgez, C.J., Matzuk, M.M., 2004. Growth differentiation factor 9 regulates expression of the bone morphogenetic protein antagonist gremlin. J. Biol. Chem. 279, 32281-32286.

Paradis, F., Novak, S., Murdoch, G.K., Dyck, M.K., Dixon, W.T., Foxcroft, G.R., 2009. Temporal regulation of BMP2, BMP6, BMP15, GDF9, BMPR1A, BMPR1B, BMPR2 and TGFBR1 mRNA expression in the oocyte, granulosa and theca cells of developing preovulatory follicles in the pig. Reproduction 138, 115-129.

Paria, B.C., Dey, S.K., 1990. Preimplantation embryo development in vitro: cooperative interactions among embryos and role of growth factors. Proc. Natl. Acad. Sci. 87, 4756-4760. 
Park, J.-Y., You-Qiang, S., Ariga, M., Law, E., Jin, S.-L.C., Conti, M., 2004. EGF-like growth factors as mediators of LH action in the ovulatory follicle. Sci. Wash. 303, $682-4$.

Park, O.-K., Mayo, K.E., 1991. Transient expression of progesterone receptor messenger RNA in ovarian granulosa cells after the preovulatory luteinizing hormone surge. Mol. Endocrinol. 5, 967-978.

Paternot, G., Wetzels, A.M., Thonon, F., Vansteenbrugge, A., Willemen, D., Devroe, J., Debrock, S., D'Hooghe, T.M., Spiessens, C., 2011. Intra- and interobserver analysis in the morphological assessment of early stage embryos during an IVF procedure: a multicentre study. Reprod. Biol. Endocrinol. 9, 127.

Payne, D., Flaherty, S.P., Barry, M.F., Matthews, C.D., 1997. Preliminary observations on polar body extrusion and pronuclear formation in human oocytes using time-lapse video cinematography. Hum. Reprod. 12, 532-541.

Peng, X.-R., Hsueh, A.J.W., Lapolt, P.S., Bjersing, L., Ny, T., 1991. Localization of luteinizing hormone receptor messenger ribonucleic acid expression in ovarian cell types during follicle development and ovulation. Endocrinology 129, 3200-3207.

Perry, G.A., 2016. 2015 statistics of embryo collection and transfer in domestic farm animals, Embryo Transfer Newsletter.

Peters, H., Byskov, A.G., Himelstein-Braw, R., Faber, M., 1975. Follicular growth: The basic event in the mouse and human ovary. J. Reprod. Fertil. 45, 559-566.

Pincus, G., Enzmann, E.V., 1935. The comparative behavior of mammalian eggs in vivo and in vitro I. The activation of ovarian eggs. J. Exp. Med. 62, 665-675.

Plonowski, A., K. Kaplinski, A., Radzikowska, M., Borowiec, M., Baranowska, B., 1999. Correlation between 21 amino acid endothelin, intrafollicular steroids and follicle size in stimulated cycles. Hum. Reprod. 14, 2323-2327.

Polani, P.E., Crolla, J.A., 1991. A test of the production line hypothesis of mammalian oogenesis. Hum. Genet. 88, 64-70.

Procházka, R., Petlach, M., Nagyová, E., Němcová, L., 2011. Effect of epidermal growth factor-like peptides on pig cumulus cell expansion, oocyte maturation, and acquisition of developmental competence in vitro: comparison with gonadotropins. Reproduction 141, 425-435.

Ptak, G., Matsukawa, K., Palmieri, C., Salda, L.D., Scapolo, P.A., Loi, P., 2006. Developmental and functional evidence of nuclear immaturity in prepubertal oocytes. Hum. Reprod. 21, 2228-2237.

Racowsky, C., Stern, J.E., Gibbons, W.E., Barry, B., Pomeroy, K.O., Biggers, J.D., 2009. National collection of embryo morphology data in SARTCORS: associations among cell number, fragmentation and blastomere asymmetry on day 3 (d3) with live birth rate. Fertil. Steril., Scientific Abstracts from the 2009 Annual Meeting of the American Society for Reproductive Medicine 92, S82. 
Rahman, A.N.M.A., Abdullah, R.B., Wan-Khadijah, W.E., 2008. Gametogenesis, Fertilization and Early Embryogenesis in Mammals with Special Reference to Goat: A Review. J. Biol. Sci. 8, 1115-1128.

Reader, K.L., Cox, N.R., Stanton, J.-A.L., Juengel, J.L., 2015a. Mitochondria and vesicles differ between adult and prepubertal sheep oocytes during IVM. Reprod. Fertil. Dev. 27, 513-522.

Reader, K.L., Cox, N.R., Stanton, J.-A.L., Juengel, J.L., 2015b. Effects of acetyl-L-carnitine on lamb oocyte blastocyst rate, ultrastructure, and mitochondrial DNA copy number. Theriogenology 83, 1484-1492.

Reader, K.L., Heath, D.A., Lun, S., Mclntosh, C.J., Western, A.H., Littlejohn, R.P., McNatty, K.P., Juengel, J.L., 2011. Signalling pathways involved in the cooperative effects of ovine and murine GDF9+BMP15-stimulated thymidine uptake by rat granulosa cells. Reproduction 142, 123-131.

Reader, K.L., Mottershead, D.G., Martin, G.A., Gilchrist, R.B., Heath, D.A., McNatty, K.P., Juengel, J.L., 2016. Signalling pathways involved in the synergistic effects of human growth differentiation factor 9 and bone morphogenetic protein 15. Reprod. Fertil. Dev. 28, 491-498.

Redding, G.P., Bronlund, J.E., Hart, A.L., 2007. Mathematical modelling of oxygen transport-limited follicle growth. Reproduction 133, 1095-1106.

Regan, S.L.P., McFarlane, J.R., O'Shea, T., Andronicos, N., Arfuso, F., Dharmarajan, A., Almahbobi, G., 2015. Flow cytometric analysis of FSHR, BMRR1B, LHR and apoptosis in granulosa cells and ovulation rate in merino sheep. Reproduction 150, 151-163.

Reich, A., Klatsky, P., Carson, S., Wessel, G., 2011. The transcriptome of a human polar body accurately reflects its sibling oocyte. J. Biol. Chem. 286, 40743-40749.

Reichman, D.E., Politch, J., Ginsburg, E.S., Racowsky, C., 2010. Extended in vitro maturation of immature oocytes from stimulated cycles: an analysis of fertilization potential, embryo development, and reproductive outcomes. J. Assist. Reprod. Genet. 27, 347-356.

Reinsberg, J., Ackermann, D., Ven, H. van der, 2004. Pitfalls in assessment of progesterone production by granulosa cells cultured in contact with silicone rubber or paraffin oil. Arch. Gynecol. Obstet. 270, 174-178.

Resende, L.O.T. de, Vireque, A.A., Santana, L.F., Moreno, D.A., Silva, A.C.J. de S.R. e, Ferriani, R.A., Scrideli, C.A., Reis, R.M., 2012. Single-cell expression analysis of $B M P 15$ and GDF9 in mature oocytes and BMPR2 in cumulus cells of women with polycystic ovary syndrome undergoing controlled ovarian hyperstimulation. J. Assist. Reprod. Genet. 29, 1057-1065.

Richani, D., Gilchrist, R.B., 2017. The epidermal growth factor network: role in oocyte growth, maturation and developmental competence. Hum. Reprod. Update 1-14. 
Richani, D., Ritter, L.J., Thompson, J.G., Gilchrist, R.B., 2013. Mode of oocyte maturation affects EGF-like peptide function and oocyte competence. MHR Basic Sci. Reprod. Med. 19, 500-509.

Richani, D., Sutton-McDowall, M.L., Frank, L.A., Gilchrist, R.B., Thompson, J.G., 2014a. Effect of epidermal growth factor-like peptides on the metabolism of in vitromatured mouse oocytes and cumulus cells. Biol. Reprod. 90.

Richani, D., Wang, X., Zeng, H. t., Smitz, J., Thompson, J. g., Gilchrist, R. b., 2014b. Prematuration with cAMP modulators in conjunction with EGF-like peptides during in vitro maturation enhances mouse oocyte developmental competence. Mol. Reprod. Dev. 81, 422-435.

Richard, F.J., Tsafriri, A., Conti, M., 2001. Role of phosphodiesterase type 3A in rat oocyte maturation. Biol. Reprod. 65, 1444-1451.

Richardson, C.R., Hatfield, E.E., 1978. The limiting amino acids in growing cattle. J. Anim. Sci. 46, 740-745.

Richardson, S.J., Senikas, V., Nelson, J.F., 1987. Follicular depletion during the menopausal transition: Evidence for accelerated loss and ultimate exhaustion. J. Clin. Endocrinol. Metab. 65, 1231-1237.

Rieger, D., Loskutoff, N.M., 1994. Changes in the metabolism of glucose, pyruvate, glutamine and glycine during maturation of cattle oocytes in vitro. J. Reprod. Fertil. 100, 257-262.

Ritter, L.J., Sugimura, S., Gilchrist, R.B., 2015. Oocyte induction of EGF responsiveness in somatic cells is associated with the acquisition of porcine oocyte developmental competence. Endocrinology 156, 2299-2312.

Rizos, D., Ward, F., Duffy, P., Boland, M.P., Lonergan, P., 2002. Consequences of bovine oocyte maturation, fertilization or early embryo development in vitro versus in vivo: Implications for blastocyst yield and blastocyst quality. Mol. Reprod. Dev. 61, 234248.

Robker, R.L., Russell, D.L., Espey, L.L., Lydon, J.P., O’Malley, B.W., Richards, J.S., 2000. Progesterone-regulated genes in the ovulation process: ADAMTS-1 and cathepsin L proteases. Proc. Natl. Acad. Sci. U. S. A. 97, 4689-4694.

Rodgers, R.J., Irving-Rodgers, H.F., 2010. Formation of the ovarian follicular antrum and follicular fluid. Biol. Reprod. 82, 1021-1029.

Rubio, I., Galán, A., Larreategui, Z., Ayerdi, F., Bellver, J., Herrero, J., Meseguer, M., 2014. Clinical validation of embryo culture and selection by morphokinetic analysis: a randomized, controlled trial of the EmbryoScope. Fertil. Steril. 102, 1287-1294.e5.

Russell, D.L., Doyle, K.M.H., Ochsner, S.A., Sandy, J.D., Richards, J.S., 2003. Processing and localization of ADAMTS-1 and proteolytic cleavage of versican during cumulus matrix expansion and ovulation. J. Biol. Chem. 278, 42330-42339. 
Salhab, M., Dhorne-Pollet, S., Auclair, S., Guyader-Joly, C., Brisard, D., Dalbies-Tran, R., Dupont, J., Ponsart, C., Mermillod, P., Uzbekova, S., 2013. In vitro maturation of oocytes alters gene expression and signaling pathways in bovine cumulus cells. Mol. Reprod. Dev. 80, 166-182.

Satterfield, M.C., Dunlap, K.A., Keisler, D.H., Bazer, F.W., Wu, G., 2012. Arginine nutrition and fetal brown adipose tissue development in diet-induced obese sheep. Amino Acids 43, 1593-1603.

Savage, T., Peek, J.C., Robinson, E.M., Green, M.P., Miles, H.L., Mouat, F., Hofman, P.L., Cutfield, W.S., 2012. Ovarian stimulation leads to shorter stature in childhood. Hum. Reprod. 27, 3092-3099.

Sawyer, H.R., Smith, P., Heath, D.A., Juengel, J.L., Wakefield, S.J., McNatty, K.P., 2002. Formation of ovarian follicles during fetal development in sheep. Biol. Reprod. 66, 1134-1150.

Schier, A.F., 2007. The maternal-zygotic transition: Death and birth of RNAs. Science 316, 406-407.

Schwab, C.G., Bozak, C.K., Whitehouse, N.L., Mesbah, M.M., 1992. Amino acid limitation and flow to duodenum at four stages of lactation. 1. Sequence of lysine and methionine limitation. J. Dairy Sci. 75, 3486-3502.

Shackell, G.H., Hudson, N.L., Heath, D.A., Lun, S., Shaw, L., Condell, L., Blay, L.R., McNatty, K.P., 1993. Plasma gonadotropin concentrations and ovarian characteristics in Inverdale ewes that are heterozygous for a major gene (FecX1) on the X chromosome that influences ovulation rate. Biol. Reprod. 48, 1150-1156.

Shen, W., Ahmad, F., Hockman, S., Ma, J., Omi, H., Raghavachari, N., Manganiello, V., 2010. Female infertility in PDE3A -/- mice: Polo-like kinase 1 (Plk1) may be a target of Protein Kinase A (PKA) and involved in meiotic arrest of oocytes from PDE3A /- mice. Cell Cycle 9, 4720-4734.

Shimada, M., Hernandez-Gonzalez, I., Gonzalez-Robayna, I., Richards, J.S., 2006. Paracrine and autocrine regulation of epidermal growth factor-like factors in cumulus oocyte complexes and granulosa cells: Key roles for prostaglandin synthase 2 and progesterone receptor. Mol. Endocrinol. 20, 1352-1365.

Shimada, M., Terada, T., 2002. FSH and LH induce progesterone production and progesterone receptor synthesis in cumulus cells: a requirement for meiotic resumption in porcine oocytes. MHR Basic Sci. Reprod. Med. 8, 612-618.

Shirazi, A., Naderi, M.M., Hassanpour, H., Heidari, M., Borjian, S., Sarvari, A., Akhondi, M.M., 2016. The effect of ovine oocyte vitrification on expression of subset of genes involved in epigenetic modifications during oocyte maturation and early embryo development. Theriogenology 86, 2136-2146.

Silva, J.M., Hamel, M., Sahmi, M., Price, C.A., 2006. Control of oestradiol secretion and of cytochrome P450 aromatase messenger ribonucleic acid accumulation by $\mathrm{FSH}$ involves different intracellular pathways in oestrogenic bovine granulosa cells in vitro. Reproduction 132, 909-917. 
Simon, A.M., Goodenough, D.A., Li, E., Paul, D.L., 1997. Female infertility in mice lacking connexin 37. Nature 385, 525-529.

Simoni, M., Gromoll, J., Nieschlag, E., 1997. The follicle-stimulating hormone receptor: biochemistry, molecular biology, physiology, and pathophysiology. Endocr. Rev. 18, 739-773.

Sinclair, K., Lunn, L., Kwong, W., Wonnacott, K., Linforth, R., Craigon, J., 2008. Amino acid and fatty acid composition of follicular fluid as predictors of in-vitro embryo development. Reprod. Biomed. Online 16, 859-868.

Sirois, J., Fortune, J.E., 1988. Ovarian follicular dynamics during the estrous cycle in heifers monitored by real-time ultrasonography. Biol. Reprod. 39, 308-317.

Smith, P., O, W.-S., Hudson, N.L., Shaw, L., Heath, D.A., Condell, L., Phillips, D.J., McNatty, K.P., 1993. Effects of the Booroola gene (FecB) on body weight, ovarian development and hormone concentrations during fetal life. J. Reprod. Fertil. 98, 41-54.

Sommersberg, B., Bulling, A., Salzer, U., Fröhlich, U., Garfield, R.E., Amsterdam, A., Mayerhofer, A., 2000. Gap junction communication and connexin 43 gene expression in a rat granulosa cell line: regulation by follicle-stimulating hormone. Biol. Reprod. 63, 1661-1668.

Souza, C.J., Campbell, B.K., Baird, D.T., 1997. Follicular dynamics and ovarian steroid secretion in sheep during the follicular and early luteal phases of the estrous cycle. Biol. Reprod. 56, 483-488.

Spits, C., Guzman, L., Mertzanidou, A., Jacobs, K., Ortega-Hrepich, C., Gilchrist, R.B., Thompson, J.G., De Vos, M., Smitz, J., Sermon, K., 2015. Chromosome constitution of human embryos generated after in vitro maturation including 3isobutyl-1-methylxanthine in the oocyte collection medium. Hum. Reprod. 30, 653663.

Su, Y.-Q., Sugiura, K., Li, Q., Wigglesworth, K., Matzuk, M.M., Eppig, J.J., 2010. Mouse oocytes enable LH-induced maturation of the cumulus-oocyte complex via promoting EGF receptor-dependent signaling. Mol. Endocrinol. 24, 1230-1239.

Su, Y.-Q., Sugiura, K., Wigglesworth, K., O'Brien, M.J., Affourtit, J.P., Pangas, S.A., Matzuk, M.M., Eppig, J.J., 2008. Oocyte regulation of metabolic cooperativity between mouse cumulus cells and oocytes: BMP15 and GDF9 control cholesterol biosynthesis in cumulus cells. Development 135, 111-121.

Sudiman, J., Ritter, L.J., Feil, D.K., Wang, X., Chan, K., Mottershead, D.G., Robertson, D.M., Thompson, J.G., Gilchrist, R.B., 2014a. Effects of differing oocyte-secreted factors during mouse in vitro maturation on subsequent embryo and fetal development. J. Assist. Reprod. Genet. 31, 295-306.

Sudiman, J., Sutton-McDowall, M.L., Ritter, L.J., White, M.A., Mottershead, D.G., Thompson, J.G., Gilchrist, R.B., 2014b. Bone morphogenetic protein 15 in the promature complex form enhances bovine oocyte developmental competence. PLOS ONE 9, e103563. 
Sugimura, S., Ritter, L.J., Sutton-McDowall, M.L., Mottershead, D.G., Thompson, J.G., Gilchrist, R.B., 2014. Amphiregulin co-operates with bone morphogenetic protein 15 to increase bovine oocyte developmental competence: effects on gap junctionmediated metabolite supply. Mol. Hum. Reprod. 20, 499-513.

Sugiura, K., Pendola, F.L., Eppig, J.J., 2005. Oocyte control of metabolic cooperativity between oocytes and companion granulosa cells: energy metabolism. Dev. Biol. $279,20-30$

Sugiura, K., Su, Y.-Q., Diaz, F.J., Pangas, S.A., Sharma, S., Wigglesworth, K., O'Brien, M.J., Matzuk, M.M., Shimasaki, S., Eppig, J.J., 2007. Oocyte-derived BMP15 and FGFs cooperate to promote glycolysis in cumulus cells. Development 134, 25932603.

Sugiura, K., Su, Y.-Q., Eppig, J.J., 2009. Targeted suppression of Has2 mRNA in mouse cumulus cell-oocyte complexes by adenovirus-mediated short-hairpin RNA expression. Mol. Reprod. Dev. 76, 537-547.

Sunderland, S.J., Knight, P.G., Boland, M.P., Roche, J.F., Ireland, J.J., 1996. Alterations in intrafollicular levels of different molecular mass forms of inhibin during development of follicular- and luteal-phase dominant follicles in heifers. Biol. Reprod. 54, 453-462.

Sutton, M.L., Cetica, P.D., Beconi, M.T., Kind, K.L., Gilchrist, R.B., Thompson, J.G., 2003. Influence of oocyte-secreted factors and culture duration on the metabolic activity of bovine cumulus cell complexes. Reproduction 126, 27-34.

Sutton-McDowall, M.L., Gilchrist, R.B., Thompson, J.G., 2004. Cumulus expansion and glucose utilisation by bovine cumulus-oocyte complexes during in vitro maturation: the influence of glucosamine and follicle-stimulating hormone. Reproduction 128, 313-319.

Sutton-McDowall, M.L., Gilchrist, R.B., Thompson, J.G., 2010. The pivotal role of glucose metabolism in determining oocyte developmental competence. Reproduction 139, 685-695.

Swinerd, G., 2016. The molecular forms of BMP15 in a range of mammalian species (Master's thesis). Victoria University of Wellington, Wellington, New Zealand.

Takeo, S., Kawahara-Miki, R., Goto, H., Cao, F., Kimura, K., Monji, Y., Kuwayama, T., Iwata, H., 2013. Age-associated changes in gene expression and developmental competence of bovine oocytes, and a possible countermeasure against ageassociated events. Mol. Reprod. Dev. 80, 508-521.

Tatemoto, H., Sakurai, N., Muto, N., 2000. Protection of porcine oocytes against apoptotic cell death caused by oxidative stress during in vitro maturation: Role of cumulus cells. Biol. Reprod. 63, 805-810.

Telford, N.A., Watson, A.J., Schultz, G.A., 1990. Transition from maternal to embryonic control in early mammalian development: A comparison of several species. Mol. Reprod. Dev. 26, 90-100. 
Tesfaye, D., Ghanem, N., Carter, F., Fair, T., Sirard, M., Hoelker, M., Schellander, K., Lonergan, P., 2009. Gene expression profile of cumulus cells derived from cumulus-oocyte complexes matured either in vivo or in vitro. Reprod. Fertil. Dev. 21, 451-461.

Thelen, T.M., Löest, C.A., Taylor, J.B., Wang, S., Lewis, G.S., 2007. Intrauterine bacterial inoculation and level of dietary methionine alter amino acid metabolism in nulliparous yearling ewes. J. Anim. Sci. Champaign 85, 3371-82.

Thomas, R.E., Armstrong, D.T., Gilchrist, R.B., 2002. Differential effects of specific phosphodiesterase isoenzyme inhibitors on bovine oocyte meiotic maturation. Dev. Biol. 244, 215-225.

Thompson, J.G., Gilchrist, R.B., 2013. Pioneering contributions by Robert Edwards to oocyte in vitro maturation (IVM). MHR Basic Sci. Reprod. Med. 19, 794-798.

Thorstensen, E.B., Derraik, J.G.B., Oliver, M.H., Jaquiery, A.L., Bloomfield, F.H., Harding, J.E., 2012. Effects of periconceptional undernutrition on maternal taurine concentrations in sheep. Br. J. Nutr. 107, 466-472.

Toralová, T., Šušor, A., Němcová, L., Kepková, K., Kaňka, J., 2009. Silencing CENPF in bovine preimplantation embryo induces arrest at 8-cell stage. Reproduction 138, 783-791.

Trounson, A., Wood, C., Kausche, A., 1994. In vitro maturation and the fertilization and developmental competence of oocytes recovered from untreated polycystic ovarian patients. Fertil. Steril. 62, 353-362.

Tsafriri, A., Channing, C.P., 1975. An inhibitory influence of granulosa cells and follicular fluid upon porcine oocyte meiosis in vitro. Endocrinology 96, 922-927.

Tsafriri, A., Chun, S.-Y., Zhang, R., Hsueh, A.J.W., Conti, M., 1996. Oocyte maturation involves compartmentalization and opposing changes of cAMP levels in follicular somatic and germ cells: Studies using selective phosphodiesterase inhibitors. Dev. Biol. 178, 393-402.

Tsafriri, A., Lindner, H.R., Zor, U., Lamprecht, S.A., 1972. In-vitro induction of meiotic division in follicle-enclosed rat oocytes by LH, cyclic AMP and prostaglandin E2. J. Reprod. Fertil. 31, 39-50.

van Tol, H. t. a., van Eijk, M. j. t., Mummery, C. I., van Den Hurk, R., Bevers, M. m., 1996. Influence of FSH and hCG on the resumption of meiosis of bovine oocytes surrounded by cumulus cells connected to membrana granulosa. Mol. Reprod. Dev. 45, 218-224.

Vanderhyden, B.C., Caron, P.J., Buccione, R., Eppig, J.J., 1990. Developmental pattern of the secretion of cumulus expansion-enabling factor by mouse oocytes and the role of oocytes in promoting granulosa cell differentiation. Dev. Biol. 140, 307-317.

Vanderhyden, B.C., Cohen, J.N., Morley, P., 1993. Mouse oocytes regulate granulosa cell steroidogenesis. Endocrinology 133, 423-426. 
Vanderhyden, B.C., Macdonald, E.A., Nagyova, E., Dhawan, A., 2003. Evaluation of members of the TGFbeta superfamily as candidates for the oocyte factors that control mouse cumulus expansion and steroidogenesis. Reprod. Camb. Engl. Suppl. 61, 55-70.

Vasconcelos, G.L., Saraiva, M.V.A., Costa, J.J.N., Passos, M.J., Silva, A.W.B., Rossi, R.O.D.S., Portela, A.M.L.R., Duarte, A.B.G., Magalhães-Padilha, D.M., Campelo, C.C., Figueiredo, J.R., Hurk, R. van den, Silva, J.R.V., 2013. Effects of growth differentiation factor-9 and FSH on in vitro development, viability and mRNA expression in bovine preantral follicles. Reprod. Fertil. Dev. 25, 1194-1203.

VerMilyea, M.D., Tan, L., Anthony, J.T., Conaghan, J., Ivani, K., Gvakharia, M., Boostanfar, R., Baker, V.L., Suraj, V., Chen, A.A., Mainigi, M., Coutifaris, C., Shen, S., 2014. Computer-automated time-lapse analysis results correlate with embryo implantation and clinical pregnancy: A blinded, multi-centre study. Reprod. Biomed. Online 29, 729-736.

Vernon, M.W., Stern, J.E., Ball, G.D., Wininger, J.D., Mayer, J.F., Racowsky, C., 2009. Utility of the national embryo morphology data collected by SART: correlation between morphologic grade and live birth rate. Fertil. Steril., Scientific Abstracts from the 2009 Annual Meeting of the American Society for Reproductive Medicine 92, S164.

Virant-Klun, I., Knez, K., Tomazevic, T., Skutella, T., 2013. Gene expression profiling of human oocytes developed and matured in vivo or in vitro. BioMed Res. Int. 2013, e879489.

Vitt, U.A., Hayashi, M., Klein, C., Hsueh, A.J.W., 2000. Growth differentiation factor-9 stimulates proliferation but suppresses the follicle-stimulating hormone-induced differentiation of cultured granulosa cells from small antral and preovulatory rat follicles. Biol. Reprod. 62, 370-377.

Vitt, U.A., Mazerbourg, S., Klein, C., Hsueh, A.J.W., 2002. Bone morphogenetic protein receptor type II is a receptor for growth differentiation factor-9. Biol. Reprod. 67, 473-480.

Walls, M.L., Hunter, T., Ryan, J.P., Keelan, J.A., Nathan, E., Hart, R.J., 2015a. In vitro maturation as an alternative to standard in vitro fertilization for patients diagnosed with polycystic ovaries: a comparative analysis of fresh, frozen and cumulative cycle outcomes. Hum. Reprod. 30, 88-96.

Walls, M.L., Ryan, J.P., Keelan, J.A., Hart, R., 2015b. In vitro maturation is associated with increased early embryo arrest without impairing morphokinetic development of useable embryos progressing to blastocysts. Hum. Reprod. 30, 1842-1849.

Wang, W., Wu, Z., Dai, Z., Yang, Y., Wang, J., Wu, G., 2013. Glycine metabolism in animals and humans: implications for nutrition and health. Amino Acids 45, 463477.

Webb, R., England, B.G., 1982. Identification of the ovulatory follicle in the ewe: associated changes in follicular size, thecal and granulosa cell luteinizing hormone receptors, 
antral fluid steroids, and circulating hormones during the preovulatory period. Endocrinology 110, 873-881.

Wiesen, J.F., Midgley, A.R., 1993. Changes in expression of connexin 43 gap junction messenger ribonucleic acid and protein during ovarian follicular growth. Endocrinology 133, 741-746.

Wilson, T., Wu, X.-Y., Juengel, J.L., Ross, I.K., Lumsden, J.M., Lord, E.A., Dodds, K.G., Walling, G.A., McEwan, J.C., O'Connell, A.R., McNatty, K.P., Montgomery, G.W., 2001. Highly prolific Booroola sheep have a mutation in the intracellular kinase domain of bone morphogenetic protein $1 \mathrm{~B}$ receptor $(A L K-6)$ that is expressed in both oocytes and granulosa cells. Biol. Reprod. 64, 1225-1235.

Wong, C.C., Loewke, K.E., Bossert, N.L., Behr, B., De Jonge, C.J., Baer, T.M., Pera, R.A.R., 2010. Non-invasive imaging of human embryos before embryonic genome activation predicts development to the blastocyst stage. Nat. Biotechnol. 28, 11151121.

Xu, M., Kreeger, P.K., Shea, L.D., Woodruff, T.K., 2006. Tissue-engineered follicles produce live, fertile offspring. Tissue Eng. 12, 2739-2746.

Yamashita, Y., Okamoto, M., Kawashima, I., Okazaki, T., Nishimura, R., Gunji, Y., Hishinuma, M., Shimada, M., 2011. Positive feedback loop between prostaglandin E2 and EGF-like factors is essential for sustainable activation of MAPK3/1 in cumulus cells during in vitro maturation of porcine cumulus oocyte complexes. Biol. Reprod. 85, 1073-1082.

Yang, Y., Li, Z., 2005. Roles of Heat Shock Protein gp96 in the ER Quality control: redundant or unique function? Mol. Cells Springer Sci. Bus. Media BV 20, 173182.

Yeo, C.X., Gilchrist, R.B., Thompson, J.G., Lane, M., 2008. Exogenous growth differentiation factor 9 in oocyte maturation media enhances subsequent embryo development and fetal viability in mice. Hum. Reprod. 23, 67-73.

Yool, A.J., Stamer, W.D., Regan, J.W., 1996. Forskolin stimulation of water and cation permeability in aquaporin 1 water channels. Science 273, 1216-1218.

Yoshino, O., McMahon, H.E., Sharma, S., Shimasaki, S., 2006. A unique preovulatory expression pattern plays a key role in the physiological functions of BMP-15 in the mouse. Proc. Natl. Acad. Sci. 103, 10678-10683.

You, J., Lee, E., Bonilla, L., Francis, J., Koh, J., Block, J., Chen, S., Hansen, P.J., 2012. Treatment with the proteasome inhibitor MG132 during the end of oocyte maturation improves oocyte competence for development after fertilization in cattle. PLOS ONE 7, e48613.

Zamboni, L., 1974. Fine Morphology of the follicle wall and follicle cell-oocyte association. Biol. Reprod. 10, 125-149. 
Zamboni, L., Bézard, J., Mauléon, P., 1979. The role of the mesonephros in the development of the sheep fetal ovary. Ann. Biol. Anim. Biochim. Biophys. 19, 1153-1178.

Zeng, H.-T., Richani, D., Sutton-McDowall, M.L., Ren, Z., Smitz, J.E.J., Stokes, Y., Gilchrist, R.B., Thompson, J.G., 2014. Prematuration with cyclic adenosine monophosphate modulators alters cumulus cell and oocyte metabolism and enhances developmental competence of in vitro-matured mouse oocytes. Biol. Reprod. 91.

Zhang, K., Hansen, P.J., Ealy, A.D., 2010a. Fibroblast growth factor 10 enhances bovine oocyte maturation and developmental competence in vitro. Reproduction 140, 815-826.

Zhang, M., Su, Y.-Q., Sugiura, K., Xia, G., Eppig, J.J., 2010b. Granulosa cell ligand NPPC and its receptor NPR2 maintain meiotic arrest in mouse oocytes. Science 330, 366-369. 